Pacific Northwest

National Laboratory

Operated by Battelle for the

U.S. Department of Energy

\title{
Validation of Hanford Personnel and Extremity Dosimeters in Plutonium Environments
}

\author{
RI Scherpelz \\ JJ Fix \\ BA Rathbone
}

January 2000

Prepared for the U.S. Department of Energy under Contract DE-AC06-76RL01830 


\title{
DISCLAIMER
}

This report was prepared as an account of work sponsored by an agency of the United States Government. Neither the United States Government nor any agency thereof, nor Battelle Memorial Institute, nor any of their employees, makes any warranty, express or implied, or assumes any legal liability or responsibility for the accuracy, completeness, or usefulness of any information, apparatus, product, or process disclosed, or represents that its use would not infringe privately owned rights. Reference herein to any specific commercial product, process, or service by trade name, trademark, manufacturer, or otherwise does not necessarily constitute or imply its endorsement, recommendation, or favoring by the United States Government or any agency thereof, or Battelle Memorial Institute. The views and opinions of authors expressed herein do not necessarily state or reflect those of the United States Government or any agency thereof.

\author{
PACIFIC NORTHWEST NATIONAL LABORATORY \\ operated by \\ BATTELLE \\ for the \\ UNITED STATES DEPARTMENT OF ENERGY
}

under Contract DE-AC06-76RL01830

Printed in the United States of America

Available to DOE and DOE contractors from the

Office of Scientific and Technical Information,

P.O. Box 62, Oak Ridge, TN 37831-0062;

ph: (865) 576-8401

fax: (865) 576-5728

email: reports@adonis.osti.gov

\begin{abstract}
Available to the public from the National Technical Information Service, U.S. Department of Commerce, 5285 Port Royal Rd., Springfield, VA 22161 ph: (800) 553-6847 fax: (703) 605-6900

email: orders@ntis.fedworld.gov

online ordering: http://www.ntis.gov/ordering.htm
\end{abstract}

This document was printed on recycled paper.

$(8 / 00)$ 
PNNL-13136

\section{VALIDATION OF HANFORD PERSONNEL AND EXTREMITY DOSIMETERS IN PLUTONIUM ENVIRONMENTS}

R. I. Scherpelz

J. J. Fix

B. A. Rathbone

January 31, 2000

Prepared for

The U.S. Department of Energy

Under Contract DE-AC06-76RLO 1830

Pacific Northwest National Laboratory

Richland, Washington 99352 


\begin{abstract}
A study was performed to assess the performance of Hanford personnel neutron dosimetry. Measurements were performed in the Plutonium Finishing Plant (PFP), which is the facility with the most significant worker exposures to neutrons on the Hanford site. The study was conducted in two parts: one assessing whole body dosimetry and one assessing extremity dosimetry. For both parts of the study, the Tissue-Equivalent Proportional Counter (TEPC) was used as the principle instrument for characterizing workplace neutron fields.

In the whole body study, 12.7-cm-diameter TEPCs were used in ten different locations in the facility. At each location, TLD and TED personnel dosimeters were exposed on a water-filled phantom at the same location to enable a comparison of neutron dose equivalents as measured by the TEPC and as determined from the personnel dosimeters.

In the extremity study, 1.27-cm-diameter TEPCs were exposed inside the fingers of gloves worn in gloveboxes. Hanford extremity dosimeters (gamma sensitive ring TLDs) were wrapped around the TEPCs. The glove, loaded with TEPCs and dosimeters, was exposed to six different cans of plutonium, simulating the exposure that a worker's fingers would receive in a glovebox. The comparison of TEPC-measured neutron dose equivalent to TLD-measured gamma dose equivalent provided neutron-to-gamma ratios that can be used to estimate the neutron dose equivalent received by a worker's finger based on the gamma readings of an extremity dosimeter.
\end{abstract}

The study also utilized other neutron instruments including a Snoopy and detectors based on bubble technology for assessing neutron exposures, providing a comparison of the effectiveness of these instruments for workplace monitoring.

The study concludes that the TLD component of the Hanford Combination Neutron Dosimeter (HCND) performs adequately overall, with a positive bias of $30 \%$, but exhibits excessive variability in individual results due to instabilities in the algorithm. The electrochemically etched TED response was less variable but only $20 \%$ of the TEPC reference dose on average because of the low neutron energies involved. The neutron response of the Hanford Standard Dosimeter (TLD) was more variable than the TLD component of the HCND and biased high by a factor of 8 overall due to its calibration to unmoderated ${ }^{252} \mathrm{Cf}$. The study recommends further work to correct instabilities in the HCND algorithm and to explore the potential shown by the bubble-based dosimeters. 


\section{EXECUTIVE SUMMARY}

This report describes measurements performed in the Plutonium Finishing Plant (PFP) work environment to validate the recorded neutron dose for Hanford workers. The responses of Hanford dosimeter components, including the Hanford standard dosimeter (HSD), and both the thermoluminescent dosimeter (TLD) and track-etch dosimeter (TED) components of the Hanford combination neutron dosimeter (HCND) have been well characterized under the low-scatter conditions of the Hanford 318 Radiation Standards Laboratory. Hanford whole body personnel dosimeter response has also been measured previously under the relatively high-scatter conditions in the workplace at the PFP, because the majority of personnel neutron dose at Hanford (currently and historically) occurs at the PFP.

To validate the accuracy of recorded neutron doses in work locations at PFP, neutron doses were measured with several methods and compared with doses measured with a tissue equivalent proportional counter (TEPC). Measurements of neutron dose were also made using a Bubble Technology Industries (BTI) bubble detector, an Apfel REMBrandt survey meter, a Snoopy survey meter, and Hanford dosimeters. Measurement locations were selected with the assistance of PFP operational staff to be representative of work areas that currently contribute the majority of personnel neutron dose and represent the type of work planned in the future.

The study also investigated the assessment of extremity neutron dose at PFP. Small TEPC detectors and BTI bubble detectors with extremity dosimeters wrapped around them were exposed inside lead-lined gloves to collect data for determining neutron-to-gamma ratios. Extremity measurements were performed for six different types of plutonium sources.

Conclusions based on these measurements are:

- Measurements indicated that neutron energies in the workplace locations selected for evaluation were significantly moderated, indicative of the scattering that occurs in the extensive shielding used throughout PFP work areas. These neutron energies are important to the dosimeter and instrument response characteristics. Notably, these radiation fields have a substantial number of neutrons with energies below the response threshold for the TED. The TLD responds easily to these neutron energies but accurate calibration and dose interpretation can be difficult.

- Bubble detector performance, based on laboratory exposures in the 318 Calibration LowScatter Room (LSR), showed that the bubble detectors could typically give results within $30 \%$ of the accepted value when at least 35 bubbles were collected. Reading the detectors by eye gave more accurate results than automated reading of the detector.

Bubble detector performance in the work environment was not as good. The bubble detectors sometimes read higher, sometimes lower, than the TEPCs. In general, there was not good agreement among the three bubble detectors exposed on each phantom. When the bubble detectors were exposed inside the leaded glove in the extremity study, there was usually good agreement between the two bubble detectors, but the bubble detectors consistently gave lower dose equivalent rates than the TEPCs. 
- REMBrandt performance shows an over-response of about 53\% in the LSR when exposed to neutrons from an unmoderated ${ }^{252} \mathrm{Cf}$ source. This over-response is partly attributed to a previous calibration appropriate for an AmBe source. However, even with updated calibration factors from the vendor for neutron energies characteristic of moderated fission spectra, there was an over-response. For the analysis of these measurements a calibration factor was derived using LSR exposures. Both calibration factors were used in the field measurements.

Using the original calibration factor, the REMBrandt had responses similar to the Snoopy. Using the derived calibration factor, the REMBrandt under-responded for high dose rates (greater than $10 \mathrm{mrem} / \mathrm{h}$ ), and was very close to the TEPC measurements for low dose rates (less than $5 \mathrm{mrem} / \mathrm{h}$ ).

- Hanford standard dosimeter (HSD) neutron doses were always high, in some cases by as much as a factor of 18, compared with the TEPC for measuring neutron dose equivalent. Because this is a single element dosimeter there is no option but to use a single calibration factor. It may be possible to choose a single factor on the basis of these measurements which would reduce the bias overall, but the variability in individual dose results would be substantially larger than that seen for Hanford combination neutron dosimeters.

- The Hanford combination neutron dosimeter - thermoluminescent dosimeter (HCND-TLD) performed well for evaluating neutron dose equivalent. For the HCNDs exposed onphantom, there was usually good agreement among the three dosimeters exposed on each face of a phantom, but there were instances where a small difference in chip responses could produce a large difference in evaluated doses because of branching options in the plutonium algorithm. In several cases, there was poor agreement between the HCNDs exposed on one face of a phantom compared with those exposed on another face of the phantom in the same location. This face-to-face disagreement was expected and is an indication of the directionality of the neutron radiation field. Overall, the HCND-TLD results showed a combined positive bias of 1.3, based on a comparison of the HCND-TLD and TEPC dose equivalent rate. However, for individual HCND-TLD results, some dose results were underreported by a factor of 5 .

- The Hanford combination neutron dosimeter - track-etch dosimeter (HCND-TED) performed better than the HCND-TLD in terms of precision for neutrons in the fields measured but showed an under-response bias compared with the TEPC dose measurements. The bias is expected to be a result of the highly scattered neutron fields, resulting in substantially degraded neutron energy spectra, and the angular response characteristics associated with the TED thin rectangular foil. The TED bias would be expected to be relatively small for higherenergy neutrons greater than the response threshold of about $100 \mathrm{keV}$, because of its relatively flat energy response, and for exposure conditions that are predominantly anteriorposterior.

- The Hanford extremity dosimeter response was generally good in terms of precision among similarly exposed dosimeters. Twelve of the 29 sets of dosimeters had a set of dose 
equivalent rates with standard deviations less than $10 \%$ of the mean; another 15 had standard deviations between 10 and $20 \%$.

- Extremity neutron-to-gamma ratios ranged from 0.09 up to 0.65 .

Recommendations based on the study conclusions include:

- Further investigation of the suitability of the BTI bubble detector for use as a supporting real-time personnel neutron monitor and the Apfel REMBrandt for use as a neutron survey instrument in Hanford neutron environments would be valuable. These instruments possess technical attributes of a direct-responding, tissue-like response that are expected to provide superior performance, compared with albedo or track-etch dosimeters, once the technology is fully developed.

- The plutonium algorithm of the HCND needs to be studied and if possible improved to prevent occurrences where similar chip responses can produce different evaluated neutron dose equivalents.

- The following neutron-to-gamma ratios would be suitable for extremity dose assessment:

- 0.36 for sources similar to the " $6 \%$ oxide" can

- 0.14 for sources similar to the " $12 \%$ oxide" can

- 0.090 for sources similar to the " $20 \%$ oxide" can

- 0.47 for sources similar to the "metal" can

- 0.25 for sources similar to the " $17 \%$ oxide" can with 0.02 -in. lead foil shielding

- 0.55 for sources similar to the " $17 \%$ oxide" can with heavy lead shielding.

The proper application of these ratios to specific workplace conditions must consider factors such as the type of material in a can, the internal shielding of the can, and the thickness of shielding in the glovebox glove. These ratios are appropriate only for Hanford ring dosimeters worn inside the same type of lead-lined glove used in this study.

- These measurements showed that highly scattered neutron fields exist in PFP work locations. The significant dependence of albedo-type thermoluminescent dosimeters (e.g., HCND and HSD) on neutron energy is well documented. As noted in the DOE Standard Guide of Good Practices for Occupational Radiological Protection in Plutonium Facilities, validation studies of dosimeter performance should be performed periodically and whenever there are major operational changes. A schedule should be adopted to repeat this study every two to three years at a minimum, so that up-to-date validation data are available. 


\section{ACKNOWLEDGEMENTS}

The authors are grateful to Lester Aldrich and David Ottley for technical direction, and to Joel Cooper, Rich Szempruch, Rick Wilbanks, and Rob Gregory for assistance with the measurements at PFP. Paul Tomeraasen provided invaluable assistance with

instrumentation. Susan Ennor did the technical editing; and Deborah Brown, Toni Stacy and Jamie Eder assisted with document production. 


\section{ACRONYMS}

\begin{tabular}{|c|c|c|}
\hline ABS $\mathrm{ADC}$ & $\begin{array}{l}\text { acrylonitrile } \\
\text { analog-to-digital }\end{array}$ & $\begin{array}{c}\text {-butadiene-styrene } \\
\text { converter }\end{array}$ \\
\hline ANSI & Am & erican National Standards Institute \\
\hline BTI & Bubble & Technology Industries \\
\hline CFR & Code & of Federal Regulations \\
\hline DOE & U.S. & Department of Energy \\
\hline DOELAP & U.S. & Department of Energy Laboratory Accreditation Program \\
\hline $\mathrm{ECC}$ & elem & ent correction coefficient \\
\hline $\begin{array}{l}\text { FCF } \\
\text { FN }\end{array}$ & $\begin{array}{l}\mathrm{f} \\
\text { fast }\end{array}$ & $\begin{array}{l}\text { lity calibration factor } \\
\text { neutron }\end{array}$ \\
\hline $\begin{array}{l}\text { HCND } \\
\text { HED } \\
\text { HSD }\end{array}$ & $\begin{array}{l}\text { Hanford } \\
\text { Hanford } \\
\text { Hanford }\end{array}$ & $\begin{array}{l}\text { combination neutron dosimeter } \\
\text { External Dosimetry } \\
\text { standard dosimeter }\end{array}$ \\
\hline $\begin{array}{l}\text { ICRP } \\
\text { ICRU }\end{array}$ & $\begin{array}{l}\text { Intern } \\
\text { International }\end{array}$ & $\begin{array}{l}\text { ational Commission on Radiological Protection } \\
\text { Commission on Radiation Units and Measurements }\end{array}$ \\
\hline $\begin{array}{l}\text { LET } \\
\text { LSR }\end{array}$ & $\begin{array}{l}\text { linear } \\
\text { Low-Scatter }\end{array}$ & $\begin{array}{c}\text { energy transfer } \\
\text { Room }\end{array}$ \\
\hline MCA & multichanne & 1 analyzer \\
\hline NCRP & National & Council on Radiation Protection and Measurements \\
\hline NIM & Nuclear & Instrument Module \\
\hline NIST & National & Institute of Standards and Technology \\
\hline NVLAP & National & Voluntary Laboratory Accreditation Program \\
\hline $\begin{array}{l}\text { PFP } \\
\text { PMT } \\
\text { PNAD } \\
\text { PNNL } \\
\text { PTFE }\end{array}$ & $\begin{array}{l}\text { Plutonium } \\
\text { Photom } \\
\text { personnel } \\
\text { Pacific } \\
\text { polytetrafluroethy }\end{array}$ & $\begin{array}{l}\text { Finishing Plant } \\
\text { ultiplier Tube } \\
\text { nuclear accident dosimeter } \\
\text { Northwest National Laboratory } \\
\text { ylene }\end{array}$ \\
\hline $\begin{array}{l}\text { REX } \\
\text { RCF } \\
\text { RRF } \\
\text { SN }\end{array}$ & $\begin{array}{l}\text { Radiological } \\
\text { reader } \\
\text { relative } \\
\text { slow }\end{array}$ & $\begin{array}{l}\text { EXposure system } \\
\text { calibration factor } \\
\text { response factor } \\
\text { neutron }\end{array}$ \\
\hline
\end{tabular}




$\begin{array}{llc}\text { TE } & \text { tissue } & \text { equivalent } \\ \text { TED } & \text { track } & \text {-etch dosimeter } \\ \text { TEPC } & \text { tissue-equivalent } & \text { proportional counter } \\ \text { TLD } & \text { therm } & \text { oluminescent dosimeter }\end{array}$




\section{CONTENTS}

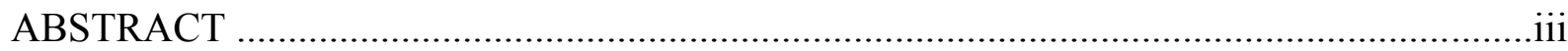

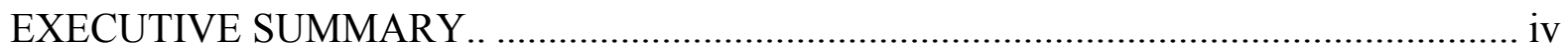

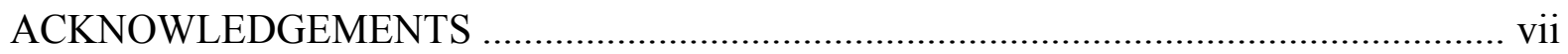

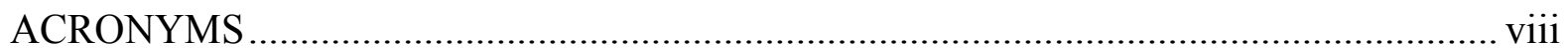

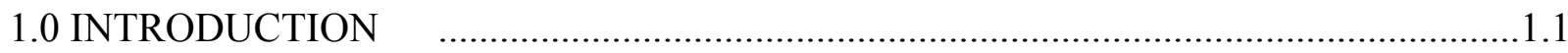

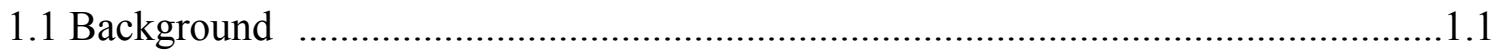

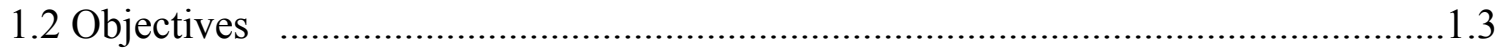

1.3 Dosimeter Calibration Sources and Calibration Factors.........................................1.3

1.4 Neutron Dose Measurements ..............................................................................

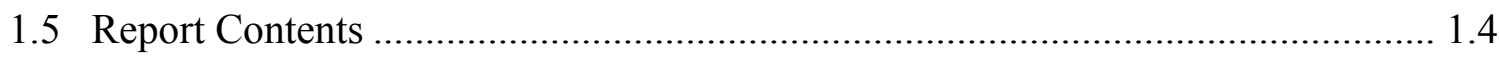

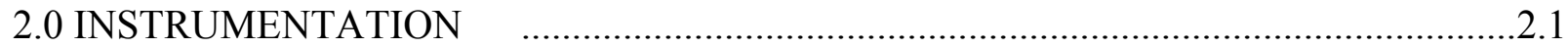

2.1 Tissue Equivalent Proportional Counter ……….................................................

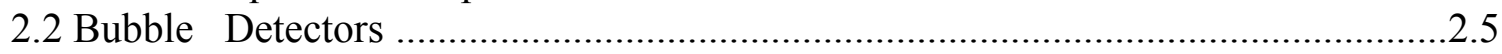

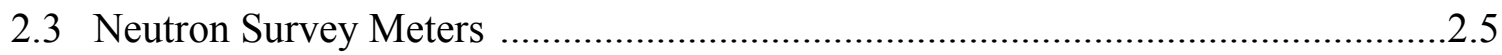

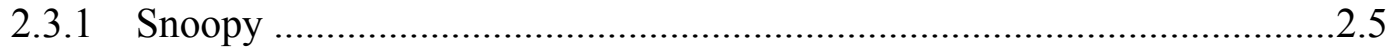

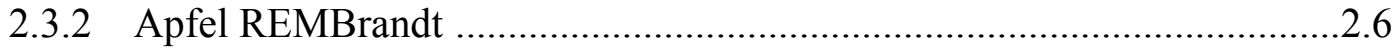

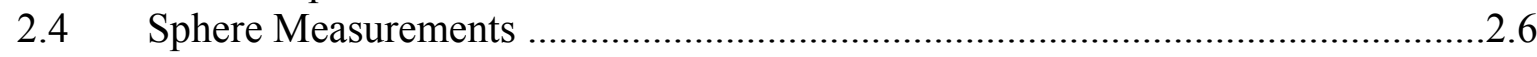

3.0 HANFORD PERSONNEL NEUTRON DOSIMETERS …….................................... 3.1

3.1 Hanford TLD Dosimeters …………...................................................................

3.2 Hanford TLD Processing Data..........................................................................

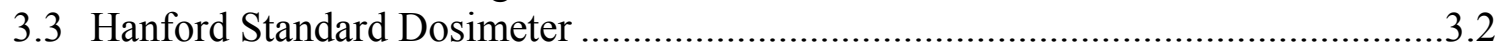

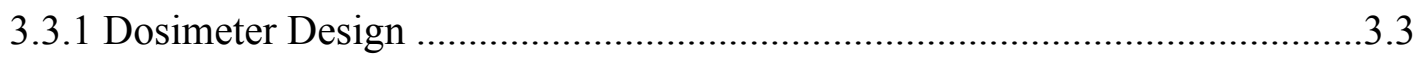

3.3.2 Neutron Dose Algorithm ..............................................................................3.3

3.3.3 HSD Neutron Dose Calibration ....................................................................

3.4 Hanford Combination Neutron Dosimeter ………..................................................6

3.4.1 Dosimeter Design ..................................................................................

3.4.2 HCND Neutron Dose Algorithm ...........................................................

3.4.2.1 Californium Algorithm (Case 0).................................................12

3.4.2.2 Plutonium Algorithm (Case 1) ......................................................12

3.4.2.3 $\mathrm{D}_{2} \mathrm{O}$ Moderated ${ }^{252} \mathrm{Cf}$ Algorithm (Case 2) ................................... 3.14

3.4.2.4 Bare ${ }^{252} \mathrm{Cf}$ Algorithm (Case 3) ....................................................14

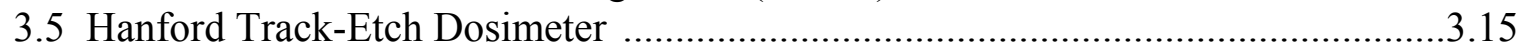

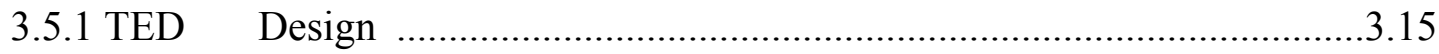

3.5.2 TED Neutron Dose Algorithm ……………………………………... 3.15

4.0 LOW SCATTER ROOM MEASUREMENTS _................................................. 4.1

4.1 TEPC Measurements in the LSR .............................................................. 4.1 
4.2 Sphere Measurements in the LSR ................................................................. 4.3

4.3 BTI Bubble Detector Measurements in the LSR .......................................... 4.4

4.4 Apfel REMBrandt Measurements in the LSR ............................................... 4.5

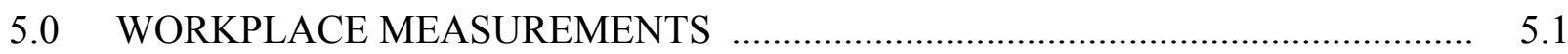

5.1 Whole Body Measurements ........................................................................... 5.1

5.1.1 Measurement Locations ............................................................... 5.1

5.1.2 Equipment Setup and Data Collection............................................ 5.6

5.1.3 Measurement Results and Data Analysis ...................................... $\quad 5.7$

5.1.3.1 Dose Equivalent Rates ..................................................... 5.7

5.1.3.2 Sphere Ratios ............................................................ 5.8

5.1.3.3 Dosimeter Results ......................................................... 5.9

5.2 Extremity Measurements ....................................................................... 5.17

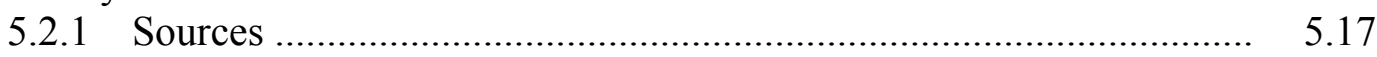

5.2.2 Equipment Setup and Data Collection ............................................ 5.18

5.2.3 Measurement Results and Data Analysis ........................................ 5.19

5.2.3.1 Neutron Dose Equivalent Rates ......................................... 5.20

5.2.3.2 Extremity Dosimeter Results .............................................. 5.22

5.2.3.3 Neutron-to-Gamma Ratios for Extremity Doses ................. 5.22

6.0 CONCLUSIONS AND RECOMMENDATIONS ...................................... 6.1

$6.1 \quad$ Neutron Dose Equivalent Rates ........................................................ 6.1

6.2 Neutron Energies ............................................................................. 6.2

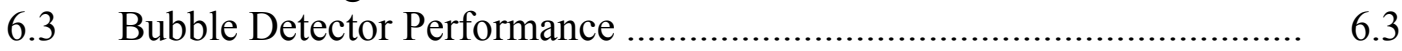

6.4 REMBrandt Performance ..................................................................... 6.4

6.5 Dosimeter Performance ..................................................................... 6.5

6.5.1 Whole Body Dosimeter Performance ……………………………... 6.5

6.5.2 Extremity Dosimeter Performance ………………………………....... 6.6

6.6 Extremity Neutron-to-Gamma Ratios .................................................... 6.6

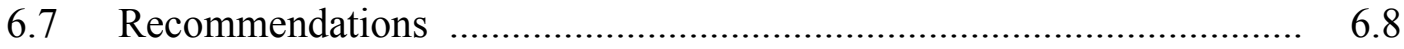

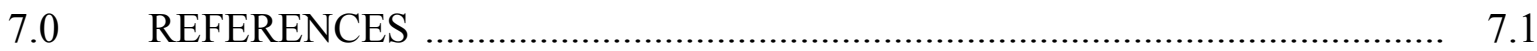

APPENDIX A: TEPC Results in Low Scatter Room ………...................................... A.1

APPENDIX B: TEPC Results for the Whole Body Measurements ………………...... B. B.1

APPENDIX C: Results for BTI Bubble Dosimeters .................................................. C.1

APPENDIX D: Results for HCND and HSD Dosimeters ……..................................... D. D.

APPENDIX E: TEPC Extremity Measurement Results ................................................... E. E.1

APPENDIX F: Extremity Dosimeter Results ........................................................... F. F.1 


\subsection{INTRODUCTION}

This report documents performance of Hanford personnel neutron dosimeters in the complex neutron fields of the Hanford Plutonium Finishing Plant (PFP).

\subsection{Background}

The existing Hanford personnel dosimetry system was implemented on January 1, 1995. This dosimetry system was first accredited under the U.S. Department of Energy (DOE) Laboratory Accreditation Program (DOELAP) during 1994; and has since been re-accredited during 1996 and 1998. The National Voluntary Laboratory Accreditation Program (NVLAP) also accredited the system during 1997. Pacific Northwest National Laboratory (PNNL) ${ }^{(1)}$ administers the Hanford External Dosimetry (HED) program, which provides dosimeter processing and technical support to Hanford contractor organizations. This report documents a study of the accuracy of Hanford personnel dosimeters under actual work environments. Hanford currently uses several dosimeter systems to measure and record personnel neutron dose, as follows:

- Hanford combination neutron dosimeter (HCND) is the whole body dosimeter worn by Hanford workers who have the potential for receiving neutron dose at or above the monitoring level. This dosimeter has three neutron radiation dose capabilities: 1) a Harshaw $^{(2)} 8816$ thermoluminescent dosimeter (TLD) holder with 7666 TLD card, 2) a Harshaw 8825 TLD holder with 7777 TLD card, and 3) a Hanford track-etch dosimeter (TED) consisting of two CR-39 track-etch foils.

- The Hanford standard dosimeter (HSD) is the whole body dosimeter worn by Hanford workers who have the potential for dose from beta/photon radiation at or above the monitoring level. The HSD consists of the Harshaw 8825 dosimeter holder with a 7776 TLD card. In addition to being NVLAP- and DOELAP-accredited for a variety of beta and photon radiations, the HSD is a DOELAP- and NVLAP-accredited neutron dosimeter that can be used to measure neutron dose in cases where the spectra are well characterized, consistent, and the potential neutron dose is less than the DOE administrative guideline for neutron personnel monitoring.

- The Hanford track-etch Dosimeter (TED) is composed of two CR-39 foils. The TED is a component of the HCND. The HCND is DOELAP- and NVLAP-accredited either with or without the TED component.

- The Hanford extremity dosimeter consists of the Harshaw XD740 chipstrate TLD sealed in a hard plastic ring. The XD740 (TLD-700) is sensitive to beta-gamma radiation only. Extremity neutron dose is calculated using the measured gamma dose and an assumed neutron-to-gamma ratio for the workplace in which the dosimeter is used.

1) Managed for the U.S. Department of Energy by Battelle Memorial Institute under contract DE-AC06-76RLO1830.

2) Manufactured by Bicron, Saint-Govain/Norton Industrial Ceramic Corporation, Solon, Ohio. 
The scientific basis for neutron dose is complicated. The International Commission on Radiological Protection (ICRP) publication 51, Data for Use in Protection Against External Radiation (ICRP 1987), provides some guidance and dose conversion factors that can be used to determine effective dose equivalent for external radiation. The DOE has traditionally followed the recommendations of the ICRP and the National Council on Radiation Protection and Measurements (NCRP) (1971) to calculate personnel dose equivalent. Currently, neutron dosimetry practices must comply with the requirements of Occupational Radiation Protection, Title 10 of the Code of Federal Regulations (CFR) Part 835 (1993) that regulates DOE and its contractors. The quality factors and conversion coefficients contained in Part 835, paragraph 835.2 of Subpart A, are identical to those found in Table 2 in NCRP report 38 (1971) and are fluence-to-dose equivalent conversion factors, not the conversion coefficients for effective dose equivalence found in ICRP publication 26 (1977) or ICRP publication 51 (1987).

Validation of dosimeter performance in the complex Hanford neutron radiation work environments is necessary to comply with guidelines in the DOE Standard Guide of Good Practices for Occupational Radiological Protection in Plutonium Facilities. This is necessary to ensure satisfactory performance, even though Hanford dosimeters are DOELAP- and NVLAPaccredited. NVLAP performance testing is based on laboratory irradiations using the American National Standards Institute (ANSI) consensus standard: ANSI/N13.11-1989 and 1993, American National Standard - Personnel Dosimeter Performance: Criteria for Testing. DOELAP performance testing is based on a similar standard for DOE contractors, DOE/EH0027 Department of Energy Standard for the Performance Testing of Personnel Dosimetry Systems (DOE 1986). Both standards use the same NCRP 38/10CFR835 neutron quality factors and fluence-to-dose equivalent conversion factors to determine the delivered dose equivalent from bare and moderated californium sources. The application of these quality factors to the neutron energy spectra from bare and moderated californium to determine fluence-to-dose equivalent conversion factors for these spectra is based on work conducted at the National Institute of Standards and Technology (NIST) (Schwartz and Eisenhauer 1982). Hanford routinely uses several dosimeter systems to measure and record personnel neutron dose.

Responses of Hanford dosimeter components have been well characterized under the low-scatter conditions of the Hanford 318 Radiation Standards Laboratory. These irradiation fields are essentially identical to those used in DOELAP and NVLAP performance testing. Hanford whole body personnel dosimeter response has also been measured previously under the high-scatter conditions in the workplace at the PFP. The majority of personnel neutron dose at Hanford (currently and historically) occurs at the PFP.

Field neutron spectra and dose measurements are critically important to the technical basis for personnel neutron dose because of the following:

- Increased accuracy is achieved using field calibration factors based on dose measurements.

- Dose and spectral measurements provide a basis for recalculation of dosimetric quantities for future changes in radiation protection standards.

Neutron dosimeters are typically calibrated in the laboratory under carefully controlled conditions. Neutron energy spectra and irradiation geometries in the workplace are usually quite 
different from those in the calibration laboratory. Correction factors are often applied to compensate for any differences in laboratory and workplace dosimeter dose response.

Measurements described in this report provide a technical basis for the use of correction factors specific to actual work locations.

\subsection{Objectives}

The objectives of the measurements described in this report include the following:

- Evaluate and document the response characteristics of Hanford personnel dosimeters in Hanford PFP work environments.

- Evaluate the neutron-to-gamma ratio used to assess neutron dose to the extremities for Hanford PFP workers.

- Evaluate the response characteristics of the Bubble Technology Industries (BTI) bubble detector $^{(1)}$ and the Apfel REMBrandt ${ }^{(2)}$ survey meter in Hanford neutron environments.

- Evaluate the relative performance of the HSD and the HCND compared with the TEPC measured neutron dose equivalent.

- Evaluate the performance of the HCND with and without the TED component.

\subsection{Dosimeter Calibration Sources and Calibration Factors}

Radiation sources used for calibrating Hanford personnel dosimeters are traceable to NIST. Primary Hanford dosimeter calibration is routinely based on:

- on-phantom ${ }^{137} \mathrm{Cs}$ irradiations for the deep-dose equivalent photon component, - on-phantom ${ }^{252} \mathrm{Cf}$ irradiations for the fast-neutron component.

Extensive dosimeter response data are available for many NIST-traceable beta, photon, and neutron radiation sources, including the NIST-traceable bare and moderated ${ }^{252} \mathrm{Cf}$ source.

In general, dose algorithms determined from the respective NIST-traceable calibration sources are used directly to determine dose in Hanford work environments, without any modification for field conditions. For neutron dose, two primary dose algorithms are used for Hanford worker dose. The default algorithm is based on dosimeter response data determined from a NISTtraceable ${ }^{252} \mathrm{Cf}$ source. These irradiations were performed in the Hanford Calibration Laboratory. A plutonium algorithm was developed from dosimeter irradiations at the PFP using plutonium sources (Endres et al. 1996).

\subsection{Neutron Dose Measurements}

The most significant source of personnel neutron dose at Hanford involves activities associated with the handling and storage of plutonium. The majority of personnel neutron dose at Hanford (currently and historically) occurs at the PFP. Workers receive doses as they work in the vicinity

1) Manufactured by Bubble Technology Industries, Inc.

2) M anufactured by Apfel Enterprises, Inc. 
of process lines and as they work in the $2736 \mathrm{ZB}$ storage vaults, which contain several tons of plutonium. Therefore, PFP was chosen as the location for the validation measurements.

Validation measurements were performed for whole body dose assessment, using HCNDs and HSDs, and for extremity dose assessment, using extremity dosimeters. Several locations within the PFP were selected for evaluation.

For the whole body measurements, dosimeters were mounted on water-filled phantoms to simulate the effect of a person wearing the dosimeter. Tissue-equivalent proportional counters (TEPCs) were used to measure the neutron dose equivalent rate at the phantom locations. Dose equivalent rates from plutonium oxide and plutonium metal sources were measured under various shielding configurations. Results from the TEPC were compared with the dose measured using the HSD, HCND (TLD), and HCND (TED) personnel neutron dosimeters and the bubble dosimeter. The Snoopy, a portable neutron survey meter used by Hanford radiation protection staff to monitor and control worker exposure between personnel dosimeter processings, was also exposed at phantom locations. The performance of BTI bubble detectors and the REMBrandt survey meter were also evaluated in this study for their suitability for future use on the Hanford Site.

For the extremity study, neutron and gamma measurements were made inside a lead-lined glove exposed to several different plutonium oxide and metal sources. These measurements were performed to validate the neutron-to-gamma ratios used for assessing the extremity doses received by workers handling these sources.

\section{5 $\quad$ Report Contents}

Chapter 2.0 describes characteristics of the instrumentation used to measure neutron dose. Chapter 3.0 describes Hanford personnel neutron dosimeters and the algorithms used to calculate dose. Chapter 4.0 describes measurements made in the 318 Building's Low-Scatter Room to calibrate the detectors and characterize their responses. Chapter 5.0 describes the workplace measurements, both for whole body measurements and for extremity measurements, that compare instrument and dosimeter measured dose. Chapter 6.0 provides conclusions and recommendations based on the measurement results. The ensuing chapters describe instrumentation, dosimeters, algorithms and measurements made to document the performance of Hanford personnel neutron dosimeters. Chapter 7.0 lists references cited in the text and the Appendices contain detailed measurement results. 


\subsection{INSTRUMENTATION}

This chapter describes characteristics of the instrumentation used to measure the neutron dose in PFP work environments.

\section{$2.1 \quad$ Tissue Equivalent Proportional Counter}

Tissue-equivalent proportional counters provide an absolute measurement of absorbed dose in a tissue-like material. With appropriate algorithms, TEPCs also provide an estimate of lineal energy distributions and quality factors. From this information, a single TEPC measurement can provide an estimate of dose equivalent. For fission energies, existing algorithms for determining quality factors from absorbed dose distributions measured by the TEPC are reasonably accurate. For example, when a TEPC is exposed to a NIST-calibrated neutron source, the dose equivalent determined from the TEPC is usually within about $10 \%$ of the dose equivalent value calculated from the neutron flux and neutron fluence-to- dose-equivalent conversion factors recommended by NIST (Schwartz and Eisenhauer 1982).

The TEPC consists of a hollow sphere of tissue-equivalent (TE) plastic filled with TE gas. Exact compositions of the TE plastic walls and fill gas can be found in Appendix C of International Commission on Radiation Units and Measurements publication 36 (ICRU 1983). The pressure of the TE gas is adjusted so that the sphere of TE gas has the same mass stopping power as a sphere of solid tissue a few micrometers in diameter. For example, the spherical TEPC used in the PFP whole body measurements has an internal diameter of $127 \mathrm{~mm}$ (5 in.), a wall thickness of $2.1 \mathrm{~mm}(0.084 \mathrm{in}$.), and was filled with a methane-based TE gas at a pressure of 11.3 torr (a near vacuum). The TE gas has the same stopping power as a $2-\mu \mathrm{m}$ sphere of solid tissue. The smaller TEPC used in the PFP extremity measurements has an internal diameter of $12.7 \mathrm{~mm}(0.5$ in.), a wall thickness of $1.3 \mathrm{~mm}$ (0.05 in.), and was filled with a propane-based TE gas at a pressure of 33.5 torr. The TE gas in this smaller chamber has the same stopping power as a 1$\mu \mathrm{m}$ sphere of solid tissue.

Neutrons and other radiations interact with the TE plastic walls to produce secondary charged particles, which deposit energy in the sphere of TE gas and create ions. The TE gas is the active volume of a proportional counter, which produces a pulse proportional to the number of ions or the energy deposition. For neutrons with energies below about $20 \mathrm{MeV}$, electronic equilibrium exists, and the ionization in the gas cavity provides an absolute measurement of absorbed dose. Because the composition of the walls and gas are tissue-equivalent, the energy deposition measured in a known mass of TE gas provides an absolute measurement of absorbed dose in tissue.

Unlike most neutron dosimeters, it is not necessary to calibrate the TEPC to a NIST-standard neutron source, but it is necessary to relate the pulse height from the TEPC to energy deposition. This can be accomplished by at least two methods. The first is to use an internal alpha source of known energy (and known linear energy transfer [LET]) to calculate the energy deposited in the counter. The second is to use the characteristic "proton edge" or "proton drop point," which is produced when the TEPC is exposed to neutron sources. From a simplistic point of view, the 
energy deposited in the TE counter is the product of the LET of the proton recoil times the path length. The maximum energy deposition possible in the gas cavity is the product of the maximum LET (the Bragg peak of the proton) times the diameter of the sphere. This maximum energy deposition for a proton recoil corresponds to an "edge" or discontinuity in the energy deposition spectrum at a lineal energy of $147 \mathrm{keV} / \mu \mathrm{m}$ for methane-based TE gas.

Figure 2.1 shows a typical energy deposition spectrum measured by a TEPC exposed to gamma rays from a ${ }^{60} \mathrm{Co}$ source and $1.3 \mathrm{-MeV}$ neutrons produced by an accelerator. It is easy to differentiate gamma rays from neutrons because gamma rays can deposit only a limited amount of energy (event sizes of $10 \mathrm{keV} / \mu \mathrm{m}$ or lineal energies of $15 \mathrm{keV} / \mu \mathrm{m}$ ). The dose distribution is easily calculated from the pulse-height data recorded from the TEPC. For a given event size or lineal energy, the absorbed dose contribution is the number of pulses or events multiplied by the size of the event. The total absorbed dose can be found by summing each contribution over the appropriate event sizes or lineal energies.

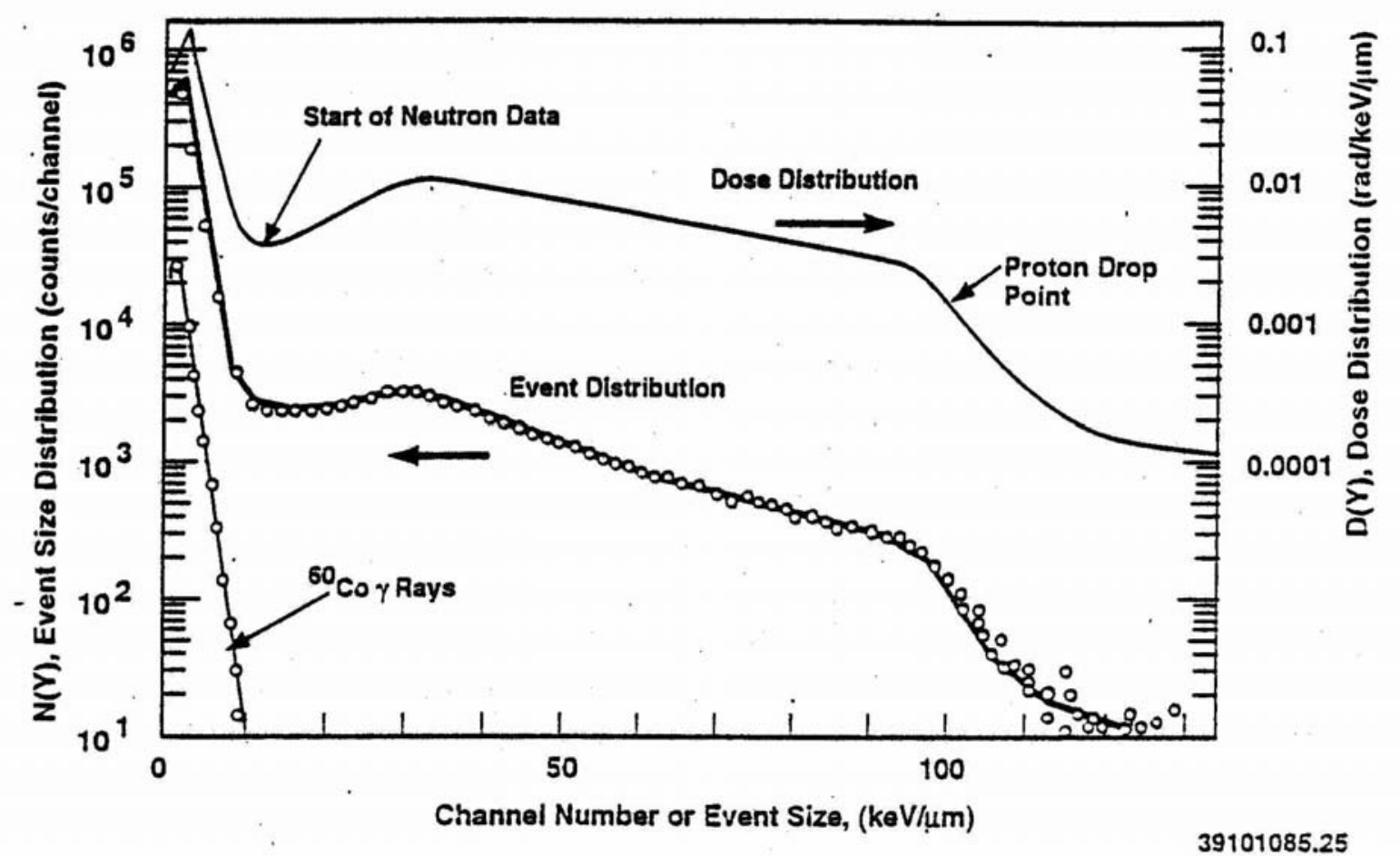

Figure 2.1 Typical Spectrum Recorded from a TEPC Operated with a 2- $\mu \mathrm{m}$ Equivalent Diameter Exposed to Neutrons and Gamma Rays

The absorbed neutron dose (D) can be found from Equation (2.1):

$$
\mathrm{D}=\left(\frac{\mathrm{c}}{\mathrm{m}}\right) \sum \mathrm{N}(\mathrm{E}) \mathrm{E}
$$


where

$\mathrm{m}=$ mass of gas in the cavity (the product of the volume times the gas density)

$\mathrm{c}=$ constant of proportionality relating the energy deposition to the event size or channel number

$\mathrm{N}(\mathrm{E})=$ number of events of energy E measured by the TEPC

$\mathrm{E}=$ energy deposited in terms of the channel number in a multichannel analyzer.

The most difficult problem in analyzing the data from a TEPC measurement is converting absorbed dose distributions to LET distributions, so that quality factors can be determined. At the present time in the United States, quality factors are defined as a function of LET (NCRP 1971; DOE 1994). The definition of this relationship is given in Table 2.1.

Table 2.1 Relationship Between Quality Factor and Linear Energy Transfer

\begin{tabular}{|c|c|}
\hline Quality Factor & $\begin{array}{c}\text { Linear Energy } \\
\text { Transfer } \\
\text { (keV/ } \mathbf{\mu m} \text { ) }\end{array}$ \\
\hline 1 & $<3.5$ \\
\hline 2 & 7 \\
\hline 5 & 23 \\
\hline 10 & 53 \\
\hline 20 & $\geq 175$ \\
\hline
\end{tabular}

Tissue-equivalent proportional counters measure lineal energy, y, defined as the energy deposited in the site (gas cavity) divided by the mean chord length of the site. For spherical proportional counters, the mean chord length is two-thirds of the diameter. For these counters, the theoretical basis for algorithms relating lineal energy (measured by the TEPC) to LET (required for quality factors) was developed by Albrecht Kellerer (1969), as follows:

$$
\overline{\mathrm{L}_{\mathrm{D}}}=\left(\frac{8}{9}\right) \overline{\mathrm{y}_{\mathrm{D}}}
$$


where

$\begin{aligned} \overline{L_{D}}= & \text { the dose-mean LET, } \\ \overline{y_{D}}= & \text { the dose mean of the event spectrum measured by the TEPC (i.e., the } \\ & \text { average lineal energy, or first moment of the dose distribution), so that: }\end{aligned}$

$$
\overline{y_{D}}=\frac{\int y D(y) d y}{\int D(y) d y}
$$

where

$$
\mathrm{y}=\text { lineal energy }
$$

$\mathrm{D}(\mathrm{y})=$ differential absorbed dose distribution as a function of lineal energy.

Because of the linear and additive relationship, this relationship is true for all values of $L$ to determine a quality factor value for each channel number or event size.

The quality factor for each channel number is found by using the above equation to convert from lineal energy to LET, then linearly interpreting the quality-factor/LET relationship given in Table 2.1. The dose equivalent is then found by summing over all channels or LETs of interest, as follows:

$$
\mathrm{H}=\Sigma \mathrm{Q}(\mathrm{L}) \mathrm{D}(\mathrm{L})
$$

where

$$
\begin{aligned}
& \mathrm{H}=\text { the dose equivalent } \\
& \mathrm{Q}(\mathrm{L})=\text { the quality factor interpolated for this channel } \\
& \mathrm{D}(\mathrm{L})=\text { the differential absorbed dose distribution as a function of LET. }
\end{aligned}
$$

This dose equivalent is determined at a depth corresponding to the wall thickness of the TEPC ( $2.1 \mathrm{~mm}$ for a 5 -in. detector and $1.3 \mathrm{~mm}$ for a $1 / 2$-in. detector) and is more closely related to the operational quantity ambient dose equivalent than to the protection quantity effective dose equivalent currently required by 10CFR 835 for dosimetry at DOE sites. For fission neutrons, however, the dose equivalent measured by the TEPC is a good estimate of dose equivalent.

In practice, data collected by a TEPC is stored on a computer disk and analyzed using a computer code called TEPC_NG. This code performs the calculations described in this section using computer algorithms documented in (Cummings, 1984). TEPC_NG will provide values for measured neutron dose rate, quality factor, and dose equivalent rate. 


\subsection{Bubble Detectors}

Neutron bubble detectors are reusable, integrating, passive dosimeters that allow for instant, visible detection of neutron radiation. A detector consists of an elastic polymer throughout which droplets of superheated liquid have been dispersed. When neutrons strike these drops of liquid they form small but visible gas bubbles that remain fixed in the polymer to provide a realtime, immediately visible record of the dose. The number of bubbles formed is directly proportional to the dose. The detector response is independent of dose rate and is tissueequivalent. Bubble detectors have a nearly isotropic angular response.

The bubble detectors used in this study were provided by Bubble Technology Industries (BTI), product number BD-PND. They were all chosen with sensitivities of approximately 0.7 bubbles per mrem. They were included in this study to evaluate their effectiveness for use at Hanford as real-time personnel dosimeters.

After a bubble detector has been exposed to radiation, the bubbles must be counted to evaluate the neutron dose. The bubbles can be counted by eye if not more than 40 or 50 bubbles are present in the detector. It is possible, on the other hand, to use an automated reader to count the bubbles in an exposed detector. Both counting-by-eye and automated counting were used in this study. For automated counting, the study used a reader provided by BTI that included a chargecoupled device (CCD) camera and image-recognition software integrated into an attached computer system. After an exposed bubble detector was counted, it could be prepared for reuse by screwing a small piston into the cap. This action recompressed the fluid in the detector and collapsed the bubbles.

\section{$2.3 \quad$ Neutron Survey Meters}

Two types of neutron survey meters were used in the field measurements as described in the following sections.

\subsubsection{Snoopy}

Neutron dose equivalent rates were routinely measured in this study using the Snoopy, which is the instrument used routinely for surveying neutron environments at Hanford. The Snoopy is a version of the Andersson-Braun remmeter, which uses a cylindrical polyethylene moderator surrounding a $\mathrm{BF}_{3}$ proportional counter. The count rate of the detector is displayed on an analog meter, with the meter calibrated by exposure to neutrons from a ${ }^{252} \mathrm{Cf}$ source. The instrument shows some energy dependence in its response, and performs best when used in a neutron field with very little moderation. 


\subsubsection{Apfel REMBrandt}

This study also used a new type of survey meter, the REMBrandt, Model AP2001. This instrument is manufactured by Apfel Industries, and offers a promising alternative to traditional neutron survey instruments. The REMBrandt uses a superheated drop technology, similar to the BTI bubble detectors. The liquid in the REMBrandt's active cartridge contains microscopic liquid drops that are superheated in typical room temperature ranges. The drops remain in suspension indefinitely, and when a neutron impinges on a drop, the drop rapidly boils and changes into a bubble. There is an audible pop when this occurs, and the detector employs an acoustic sensor that records this event in the detector's microelectronics.

The instrument is designed to serve as a survey meter. It is insensitive to photons. It has a visual display that will give a real-time readout of dose rate, and the internal microelectronics will store many hours of data for later transfer to a computer. It provides a possible lightweight alternative to traditional moderator-based instruments, so it was included in this study for an initial evaluation of its performance in typical Hanford work environments.

\section{$2.4 \quad$ Sphere Measurements}

This study did not use any true neutron spectrometer, but parts of a multisphere spectrometer were used to provide a general indication of neutron energy distribution. A LiI(Eu) detector was used inside two polyethylene spheres to determine count rates at selected locations. The $\mathrm{LiI}(\mathrm{Eu})$ detector is sensitive to neutrons with thermal energies. Signals from the detector are routed into a MCA, and a pulse-height spectrum is collected. The spectrum will exhibit a peak resulting from the ${ }^{6} \mathrm{Li}(\mathrm{n}, \alpha)^{3} \mathrm{H}$ reaction. The area under this peak can be integrated to determine the neutron counts deposited in the detector.

Since the $\operatorname{LiI}(\mathrm{Eu})$ detector is sensitive to thermal neutrons, it can be placed in the center of a moderating sphere, and the detector's count rate will be determined by the amount of moderation surrounding the detector. In this study the detector was used inside two different polyethylene spheres, one with a diameter of 3 in. $(7.6 \mathrm{~cm})$ and one with a diameter of 8 in. $(20.3 \mathrm{~cm})$. The ratio of the count rates in the two different spheres is an indication of the energy of the neutrons being measured. The count rate inside the 8 -in. sphere, when used with a calibration factor that is a function of the 8 -in.-to-3-in. ratio, is a reasonable indication of dose equivalent rate.

In the 1995 study of Hanford dosimeter responses in the workplace (Endres et al. 1996), Section 6.1 describes the use of this type of sphere measurement in neutron fields. This study found that 8 in.-to-3 in. ("8-3") sphere ratios ranged from 0.5 for a low-energy neutron spectrum up to 3.0 for a high-energy spectrum. It also determined a calibration factor, as a function of 8-3 sphere ratio, for converting the count rate inside the 8 -in. sphere. Using the data presented in this report, the equation for the calibration factor can be stated as:

where

$$
\mathrm{CF}=0.0338+0.114 \mathrm{R}
$$

$$
\mathrm{CF}=\text { calibration factor }(\mathrm{mrem} / \mathrm{h} \text { per } \mathrm{c} / \mathrm{s})
$$


$\mathrm{R}=$ ratio of count rate in 8 -in sphere to count rate in 3-in sphere. 


\subsection{HANFORD PERSONNEL NEUTRON DOSIMETERS}

This chapter describes the Hanford standard dosimeter (HSD), Hanford combination neutron dosimeter (HCND), track-etch dosimeter (TED), and extremity dosimeter used to determine the personnel neutron dose. Substantial technical documentation for these dosimeters is provided in the Hanford External Dosimetry Technical Basis Manual. ${ }^{(1)}$

\subsection{Hanford TLD Dosimeters}

The Hanford HSD and HCND represent TLD-albedo-type personnel neutron dosimeters. This type of dosimeter is the most common type in use throughout DOE facilities. Hanford TLDalbedo dosimeter designs employ a slow neutron detector (TLD-600) worn on the surface of the body. Fast neutrons strike the body and are moderated and reflected, and then return to the surface, where they are detected by the TLDs. Because the neutrons are reflected back from the body, these dosimeter designs are called "albedo." The TLD-600 isotope ${ }^{6} \mathrm{Li}$ absorbs a neutron and creates an alpha particle and a triton, which deposit energy in the TLD chip or phosphor. When the TLD chip is heated, it emits light in proportion to the radiation dose deposited by the neutron-induced events. The cross section for the ${ }^{6} \mathrm{Li}(\mathrm{n}, \alpha)^{3} \mathrm{H}$ reaction is inversely proportional to the velocity or the square root of the energy of the neutron absorbed in the reaction. Thus, the TLD-600 chip is very sensitive to thermal neutrons, where the cross section is about 941 barns. However, the bare TLD is relatively insensitive to fast neutrons, where the cross section is less than 1 barn. A simplified explanation of the energy dependence is that low-energy neutrons enter the body and are easily thermal zed and reflected back to the surface, where they are detected by the TLD crystal. High-energy neutrons, however, must penetrate deep into the body before becoming thermalized, and relatively few are able to diffuse back to the TLD crystal to be detected. Most of these neutrons are absorbed in the body before reaching the surface and the TLD chip. This is the reason for the pronounced energy dependence of the TLD-albedo dosimeter.

\subsection{Hanford TLD Processing Data}

The Harshaw reader system used to process the TLD cards provides calibrated chip readings. The calibrated chip readings are calculated by the reader using element correction coefficients (ECCs) and reader calibration factors (RCFs) to convert the raw light output (expressed as nanocoulombs of PMT charge collected) to chip readings $\left(\mathrm{X}_{\mathrm{i}}\right)$ expressed in units of $\mathrm{mR}$. For the TLD reader systems at Hanford, the $\mathrm{mR}$ chip reading is a ${ }^{60} \mathrm{Co}$ in air equivalent reading because the reader is calibrated with bare cards exposed in free air to a known exposure with a NISTtraceable ${ }^{60} \mathrm{Co}$ source. The method used by the reader to obtain calibrated chip readings, $\mathrm{X}_{\mathrm{i}}$, is as follows:

$$
\mathrm{X}_{\mathrm{i}}(\mathrm{mR})=\text { raw chip reading }(\mathrm{nC}) \times \mathrm{ECC}_{\mathrm{i}} / \mathrm{RCF}_{\mathrm{i}}(\mathrm{nC} / \mathrm{mR})
$$

1) PNL-MA-842, Hanford External Dosimetry Technical Basis Manual, Pacific Northwest National Laboratory, Richland, WA (internal manual). 
The calibrated chip readings obtained from the reader are then adjusted by subtracting background, correcting for fade, correcting for supralinearity, and correcting for the difference in response between bare chips exposed in free air to ${ }^{60} \mathrm{Co}$ and chips exposed in the holder on a phantom to ${ }^{137} \mathrm{Cs}$. The relationship between chip response to exposure in air and response in holder, on phantom, is referred to as the ${ }^{137} \mathrm{Cs}$ relative response factor (RRF) for the dosimeter and has units of $\mathrm{mR} / \mathrm{rem}$. The resulting "adjusted" chip readings thus have units of rem $\left({ }^{137} \mathrm{Cs}\right.$ rem equivalent). Each adjusted chip reading will accurately reflect the delivered deep dose equivalent when the card is exposed in a holder, on a phantom to ${ }^{137} \mathrm{Cs}$, and read using a reader calibrated as described above. The following equation describes the method used to obtain "adjusted" chip readings from the "calibrated" chip readings provided by the TLD reader:

$$
\mathrm{D}_{\mathrm{i}}=\left(\mathrm{X}_{\mathrm{i}}-\mathrm{B}_{\mathrm{i}}\right) /\left(\mathrm{RRF}_{\mathrm{i}} * \mathrm{~F}_{\mathrm{i}} * \mathrm{~S}_{\mathrm{i}}\right)
$$

where

$\mathrm{D}_{\mathrm{i}} \quad=$ adjusted chip reading for chip $\mathrm{i}\left({ }^{137} \mathrm{Cs}\right.$ rem equivalent $)$

$\mathrm{X}_{\mathrm{i}} \quad=$ calibrated chip reading for chip $\mathrm{i}(\mathrm{mR})$

$\mathrm{B}_{\mathrm{I}} \quad=$ background for chip $\mathrm{i}(\mathrm{mR})$

RRF $\quad i={ }^{137} \mathrm{Cs}$ relative response factor for chip $\mathrm{i}(\mathrm{mR} / \mathrm{rem})$

$\mathrm{F}_{\mathrm{i}} \quad=$ fade factor for chip $\mathrm{i}$.

$\mathrm{S}_{\mathrm{i}} \quad=$ supralinearity correction factor for chip $\mathrm{i}$ (dimensionless)

A detailed description of the formulae and methods used for determining the values of $B_{i}, R_{R} F_{i}$, $\mathrm{F}_{\mathrm{i}}$ and $\mathrm{S}_{\mathrm{i}}$ is given in PNL-MA-842.

Adjusted chip readings are used in the 8825 and 8816 algorithms described in following sections. Before use by the 8825 algorithms proper, the adjusted readings given by chip position are transformed into adjusted readings by element type, where L1 = adjusted reading from deep dose element (bubble), L2 = adjusted reading from eye dose element (copper filter), L3 = adjusted reading from shallow dose element (beta window), and L4 = adjusted reading from photon energy discrimination/neutron detection element. The transformation is performed as follows: $\mathrm{L} 1=\mathrm{D} 2, \mathrm{~L} 2=\mathrm{D} 1, \mathrm{~L} 3=\mathrm{D} 3$, and L4=D4. The conversion is done to make the algorithm understandable in terms of element type regardless of physical position on a dosimeter, and it makes the algorithm universally applicable to a variety of holder designs using the same combination of element filtrations.

\subsection{Hanford Standard Dosimeter}

The 8825 HSD is issued to all Hanford personnel assigned a dosimeter with the exception of identified neutron workers who are assigned the HCND. The HSD is used to measure the shallow, eye, and deep dose equivalent of record from beta and photon radiation. Although not intended for recording dose from neutron radiation, the dosimeter has a neutron-sensitive TLD600 phosphor for neutron detection capability. The neutron response is intended to identify personnel who may need to wear the HCND which has superior neutron dose capabilities and more recently has been used as the basis for assignment of neutron dose of record for individuals receiving less than 100 mrem of neutron dose per year. 


\subsubsection{Dosimeter Design}

The HSD was designed according to HED specifications, and became commercially available as the Harshaw 8825. The dosimeter card contains TLD-700 phosphors in positions one, two, and three and a TLD-600 phosphor in position four. Table 3.1 provides a summary of the respective filtration for each dosimeter position. Figure 3.1 provides a schematic view of the dosimeter. More detailed information is available in PNL-MA-842. The HSD has no filters on the backside. A rose-colored viewing window is centered on the backside of the dosimeter holder. The viewing window is used to electronically read the permanent identification number of the card enclosed within the holder.

Table 3.1 Description of Filtration Used in the Hanford Standard Dosimeter (8825).

\begin{tabular}{|c|c|c|c|c|}
\hline \multirow{2}{*}{$\begin{array}{l}\text { Dosimeter } \\
\text { Position }\end{array}$} & \multirow{2}{*}{$\begin{array}{l}\text { Phosphor } \\
\text { Type }\end{array}$} & \multirow{2}{*}{$\begin{array}{l}\text { Thickness, mm } \\
\text { (mass density) }\end{array}$} & \multicolumn{2}{|c|}{ Total Holder Filtration $^{(a)}$} \\
\hline & & & Front & Back \\
\hline 1 & TLD-700 & $\begin{array}{l}0.38 \\
\left(100 \mathrm{mg} / \mathrm{cm}^{2}\right)\end{array}$ & $\begin{array}{l}242 \mathrm{mg} / \mathrm{cm}^{2} \text { ABS plastic } \\
\text { plus } 91 \mathrm{mg} / \mathrm{cm}^{2} \text { copper }\end{array}$ & $\begin{array}{l}173 \mathrm{mg} / \mathrm{cm}^{2} \\
\text { ABS }\end{array}$ \\
\hline 2 & TLD-700 & $\begin{array}{l}0.38 \\
\left(100 \mathrm{mg} / \mathrm{cm}^{2}\right)\end{array}$ & $\begin{array}{l}1000 \mathrm{mg} / \mathrm{cm}^{2} \\
\text { ABS and PTFE plastic }\end{array}$ & $\begin{array}{l}173 \mathrm{mg} / \mathrm{cm}^{2} \\
\mathrm{ABS}\end{array}$ \\
\hline 3 & TLD-700 & $\begin{array}{l}0.15 \\
\left(40 \mathrm{mg} / \mathrm{cm}^{2}\right)\end{array}$ & $\begin{array}{l}17 \mathrm{mg} / \mathrm{cm}^{2} \\
\text { Teflon and Mylar }\end{array}$ & $\begin{array}{l}173 \mathrm{mg} / \mathrm{cm}^{2} \\
\mathrm{ABS}\end{array}$ \\
\hline 4 & TLD-600 & $\begin{array}{l}0.38 \\
\left(100 \mathrm{mg} / \mathrm{cm}^{2}\right)\end{array}$ & $\begin{array}{l}240 \mathrm{mg} / \mathrm{cm}^{2} \\
\text { ABS plastic plus } \\
463 \mathrm{mg} / \mathrm{cm}^{2} \text { tin }\end{array}$ & $\begin{array}{l}173 \mathrm{mg} / \mathrm{cm}^{2} \\
\mathrm{ABS}\end{array}$ \\
\hline \multicolumn{5}{|c|}{$\begin{array}{l}\text { (a) Values include Teflon }(2 \text { mil }) \text { used to enclose chips. } \\
\text { ABS = Acrylonitrile-butadiene-styrene } \\
\text { PTFE = Polytetrafluorethylene }\end{array}$} \\
\hline
\end{tabular}

\subsubsection{Neutron Dose Algorithm}

The HSD neutron dose is calculated from the response of the TLD-600 chip after subtraction of the estimated beta and photon signal. The HSD algorithm identifies the type(s) of radiation to which a dosimeter was exposed by comparing adjusted element ratios with those observed to have known radiation exposures. Generally, information from all four chips is used to calculate the shallow, eye and deep dose from beta/photon radiation. However, there are situations where neutrons are detected by the TLD-600 chip in position 4 and the value of this chip cannot be used for photon energy discrimination. The algorithm sets a flag if the value of chip 4 (i.e., TLD-600) indicates neutron exposure. When neutrons are detected, the algorithm calculates neutron dose using a neutron calibration factor determined from the facility calibration code supplied by the user when the dosimeter is returned for processing. Calibration factors based on bare ${ }^{252} \mathrm{Cf}$, moderated ${ }^{252} \mathrm{Cf}$, or field measurements are available. When no information is available from the user, the algorithm defaults to use of the bare ${ }^{252} \mathrm{Cf}$ calibration factor as a conservative measure. The respective algorithm steps are illustrated in Figure 3.2. 


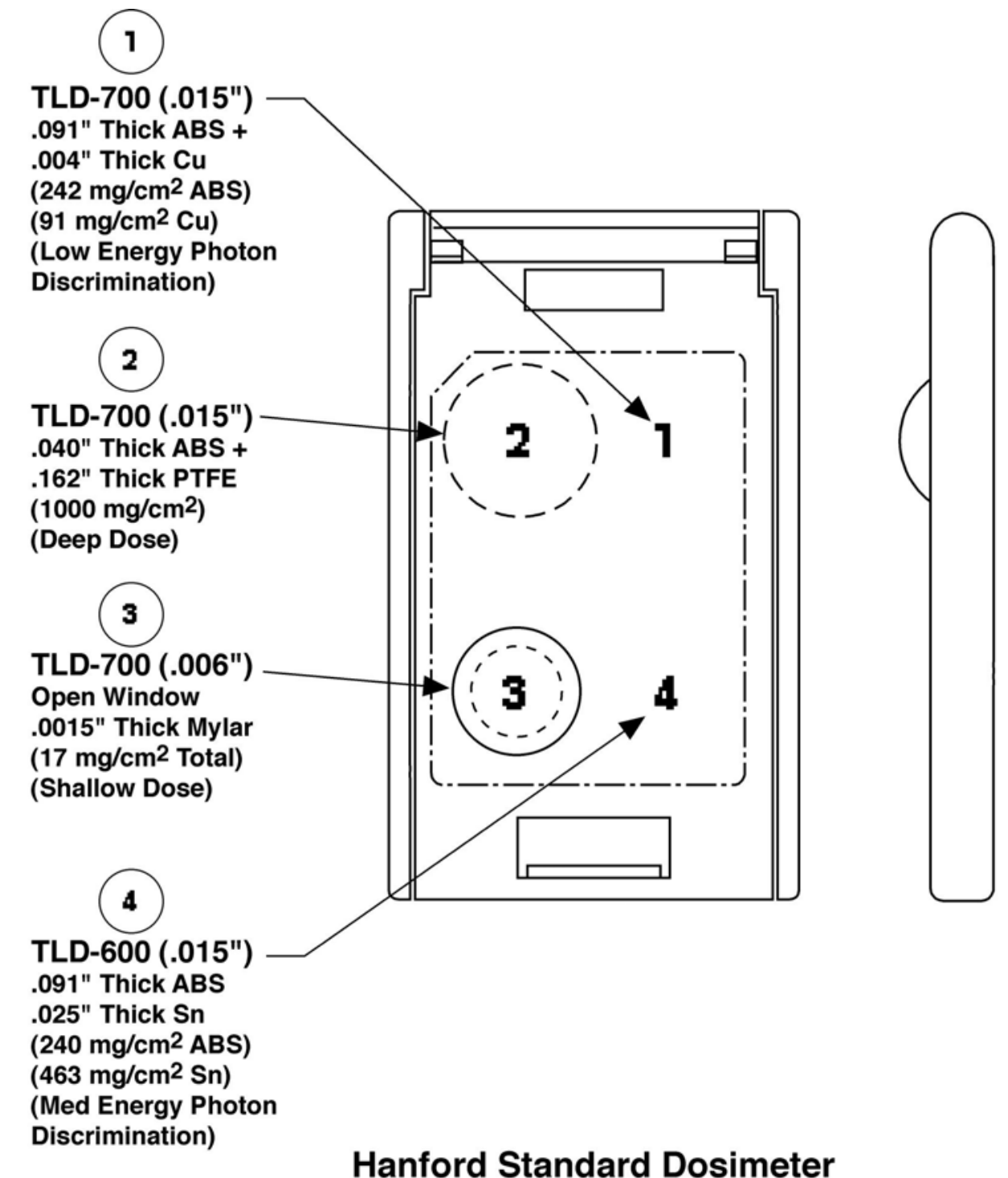

39502026.3

Figure 3.1. Hanford Standard Dosimeter Schematic 


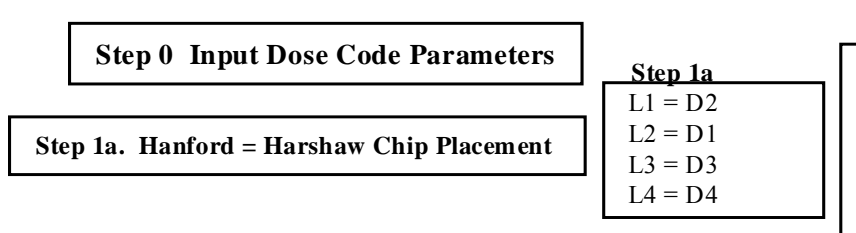

Step 1b. Define Variables

\begin{tabular}{|ll}
$\mathrm{L} 12=\mathrm{L} 1 / \mathrm{L} 2$ & $\mathrm{~L} 41=\mathrm{L} 4 / \mathrm{L} 1$ \\
$\mathrm{~L} 31=\mathrm{L} 3 / \mathrm{L} 1$ & $\mathrm{~L} 43=\mathrm{L} 4 / \mathrm{L} 3$ \\
$\mathrm{~L} 32=\mathrm{L} 3 / \mathrm{L} 2$ & $\mathrm{~L} 3 / \mathrm{L} 2<0.7$ \\
$\mathrm{~L} 14=\mathrm{L} 1 / \mathrm{L} 4$ & $\mathrm{~L} 2-\mathrm{L} 3>0.01$
\end{tabular}

Step 3. Photon Contribution to Potential Neutron Response

IF L $12<1$, THEN L $12=1 ;$ IF L $12>5$, THEN L $12=5$ $\mathrm{x}=\mathrm{L} 1 / \mathrm{L} 2$

IF (default_HEPH $=$ Cs-137 THEN

$\mathrm{F}(\mathrm{x})=1 /\left(-2.12+3.46 \mathrm{x}-0.34 \mathrm{x}^{2}\right)$

ELSE,

$\mathrm{F}(\mathrm{x})=1 /\left(-1.7+3.46 \mathrm{x}-0.34 \mathrm{x}^{2}\right)$
Step 0

Code Option $=$ Hanford, DOELAP, NVLAP, etc

High Energy Photon Code (HEPH Type $)=0,10,11,14,28$

Gamma + Neutron Code (Default_HEPH) $=12,13,15,29$

Beta Code $($ Beta_Type $)=30,31,49$

Neutron Code (Neutron_Type) $=50,51,52,69$

Step 2. QC Flag for “Question Chip Data”

IF $\{$ L $32<0.7 \&[L 3>0.01, \mathrm{~L} 2>0.01,(\mathrm{~L} 2-\mathrm{L} 3)>0.01]$;

L3 $1<0.7 \&[\mathrm{~L} 3>0.01, \mathrm{~L} 1>0.01,(\mathrm{~L} 1-\mathrm{L} 3)>0.01]$;

$\mathrm{L} 31<12 \&[\mathrm{~L} 3>0.01, \mathrm{~L} 1>0.01, \mathrm{~L} 2>0.01]$;

L $31>3.2 *$ L32;

$\mathrm{L} 31>[16-(0.29 * \mathrm{~L} 32)] ;$ OR

$\mathrm{L} 31<[0.31 * 132]\}$

THEN Set Flag “Question Chip Data”

Step 4. Set Flag for "Neutron Detected"

IF $[\mathrm{L} 4 / \mathrm{L} 1-\mathrm{F}(\mathrm{x}) 60.20\} \&(\mathrm{~L} 4-\mathrm{F}(\mathrm{x}) * \mathrm{~L} 1]>0.01]$

THEN; Set Flag "Neutrons Detected"

Steps 5-9. Evaluate Beta/Photon Field Components

Step 10. Neutron Dose Component

Step 10a.

IF Neutron Dose Selected in Step 0 and If Step 4, "Neutrons Detected" = TRUE, THEN proceed with Step 10a.
Step 10a

IF (Neutron_Type $=51$ (bare Cf-252), THEN K $_{\mathrm{nd}}=1.16$ IF (Neutron_Type $=52(\mathrm{D} 2)$ Moderate Cf-252), THEN K $\mathrm{nd}=9.51$ IF (Neutron_Type $=69$ (User Input), THEN K $\mathrm{nd}_{\text {- }}=$ User Input

Step 10b. Calculate Dose

\begin{tabular}{|l|} 
Step $10 \mathrm{~b}$ \\
$\mathrm{H}_{\mathrm{n}}=(\mathrm{L} 4-\mathrm{F}(\mathrm{x}) * \mathrm{~L} 1) / \mathrm{K}_{\mathrm{nd}}$
\end{tabular}

Step 10c. IF Neutron Dose Not Selected in Step 0 and

If Step 4, "Neutrons Detected" = TRUE, THEN proceed with Step 10c.

\begin{tabular}{|l|} 
Step $10 \mathrm{c}$ \\
$\mathrm{H}_{\mathrm{n}}=(\mathrm{L} 4-\mathrm{F}(\mathrm{x}) * \mathrm{~L} 1) / \mathrm{K}_{\mathrm{nd}}, \mathrm{K}_{\mathrm{nd}}=\mathrm{U}$ ser Input
\end{tabular}

\section{Figure 3.2. HSD Neutron Dose Algorithm}




\subsubsection{HSD Neutron Dose Calibration}

The HSD has been calibrated to bare ${ }^{252} \mathrm{Cf}, \mathrm{D}_{2} \mathrm{O}$-moderated ${ }^{252} \mathrm{Cf}$, AmBe neutrons, and has passed DOELAP performance testing with both californium sources. However, when no information is provided by the user as to which calibration to use, the algorithm applies the bare

${ }^{252} \mathrm{Cf}$ calibration as a conservative default. This calibration was determined under low-scatter conditions to fission spectra from a bare source. The calibration spectrum contains substantially more energetic neutrons than are present in the highly scattered neutron spectra that are often encountered in PFP workplace conditions. Because of this, HSD-measured neutron dose based on the default neutron calibration is expected to substantially over-estimate the actual neutron dose.

\subsection{Hanford Combination Neutron Dosimeter}

The HCND is assigned to Hanford personnel identified as working with neutron radiation. The HCND is used to record the shallow, eye, deep, and neutron dose of record for Hanford employees working in neutron radiation fields. The dosimeter consists of three components:

- a beta-photon (8825) TLD

- an albedo neutron (8816) TLD

- a TED (not presently in routine use).

The beta/photon and the albedo neutron TLD are known commercially as the Harshaw 8825 and 8816 dosimeter holders, respectively. In addition, two TED foils (CR-39) are housed in the 8816 holder. Detailed dosimeter specifications are given in PNL-MA-842. The development of the dosimeter design is described by Brackenbush, Baumgartner, and Fix (1991) and Endres et al. (1996). A HCND plastic holder is used to contain all three of these dosimeters, along with the Hanford personnel nuclear accident dosimeter (PNAD).

\subsubsection{Dosimeter Design}

The HCND neutron 8816 dosimeter design was manufactured according to HED specifications as presented in Table 3.2. A diagram of the dosimeter is presented in Figure 3.3. This design provides for three neutron-responsive TLD-600 chips in three different shielding configurations with a single TLD-700 chip to provide beta/photon radiation compensation. This dosimeter design has asymmetric tin/cadmium filtration on both the holder front and back.

The design of the HCND 8825 component is identical to the HSD design shown in Table 3.1 with the single exception that a TLD-700 chip is used in position 4 of the dosimeter card instead of the TLD-600 chip. This change provides for high-quality shallow, eye, and deep dose calculation in the presence of neutron radiation. 
Table 3.2 Description of the Filtration Used in the Hanford Combination Neutron Dosimeter (8816) Component

\begin{tabular}{|c|c|c|c|c|}
\hline \multirow{2}{*}{$\begin{array}{l}\text { Dosimeter } \\
\text { Position }\end{array}$} & \multirow{2}{*}{ Phosphor Type } & \multirow{2}{*}{$\begin{array}{l}\text { Thickness, mm } \\
\text { (mass density) }\end{array}$} & \multicolumn{2}{|c|}{ Total Holder Filtration ${ }^{(a)}$} \\
\hline & & & Front & Back \\
\hline 1 & TLD-700 & $\begin{array}{l}0.38 \\
\left(100 \mathrm{mg} / \mathrm{cm}^{2}\right)\end{array}$ & $\begin{array}{l}464 \mathrm{mg} / \mathrm{cm}^{2} \mathrm{Sn} \text { plus } \\
80 \mathrm{mg} / \mathrm{cm}^{2} \text { ABS plastic }\end{array}$ & $\begin{array}{l}464 \mathrm{mg} / \mathrm{cm}^{2} \mathrm{Sn} \text { plus } \\
80 \mathrm{mg} / \mathrm{cm}^{2} \text { ABS plastic }\end{array}$ \\
\hline 2 & TLD-600 & $\begin{array}{l}0.38 \\
\left(100 \mathrm{mg} / \mathrm{cm}^{2}\right)\end{array}$ & $\begin{array}{l}461 \mathrm{mg} / \mathrm{cm}^{2} \mathrm{Cd} \text { plus } \\
80 \mathrm{mg} / \mathrm{cm}^{2} \text { ABS plastic }\end{array}$ & $\begin{array}{l}464 \mathrm{mg} / \mathrm{cm}^{2} \mathrm{Sn} \text { plus } \\
80 \mathrm{mg} / \mathrm{cm}^{2} \text { ABS plastic }\end{array}$ \\
\hline 3 & TLD-600 & $\begin{array}{l}0.38 \\
\left(100 \mathrm{mg} / \mathrm{cm}^{2}\right)\end{array}$ & $\begin{array}{l}464 \mathrm{mg} / \mathrm{cm}^{2} \mathrm{Sn} \text { plus } \\
80 \mathrm{mg} / \mathrm{cm}^{2} \text { ABS plastic }\end{array}$ & $\begin{array}{l}461 \mathrm{mg} / \mathrm{cm}^{2} \mathrm{Cd} \text { plus } \\
80 \mathrm{mg} / \mathrm{cm}^{2} \text { ABS plastic }\end{array}$ \\
\hline 4 & TLD-600 & $\begin{array}{l}0.38 \\
\left(100 \mathrm{mg} / \mathrm{cm}^{2}\right)\end{array}$ & $\begin{array}{l}464 \mathrm{mg} / \mathrm{cm}^{2} \mathrm{Sn} \text { plus } \\
80 \mathrm{mg} / \mathrm{cm}^{2} \text { ABS plastic }\end{array}$ & $\begin{array}{l}464 \mathrm{mg} / \mathrm{cm}^{2} \mathrm{Sn} \text { plus } \\
80 \mathrm{mg} / \mathrm{cm}^{2} \mathrm{ABS} \text { plastic }\end{array}$ \\
\hline
\end{tabular}

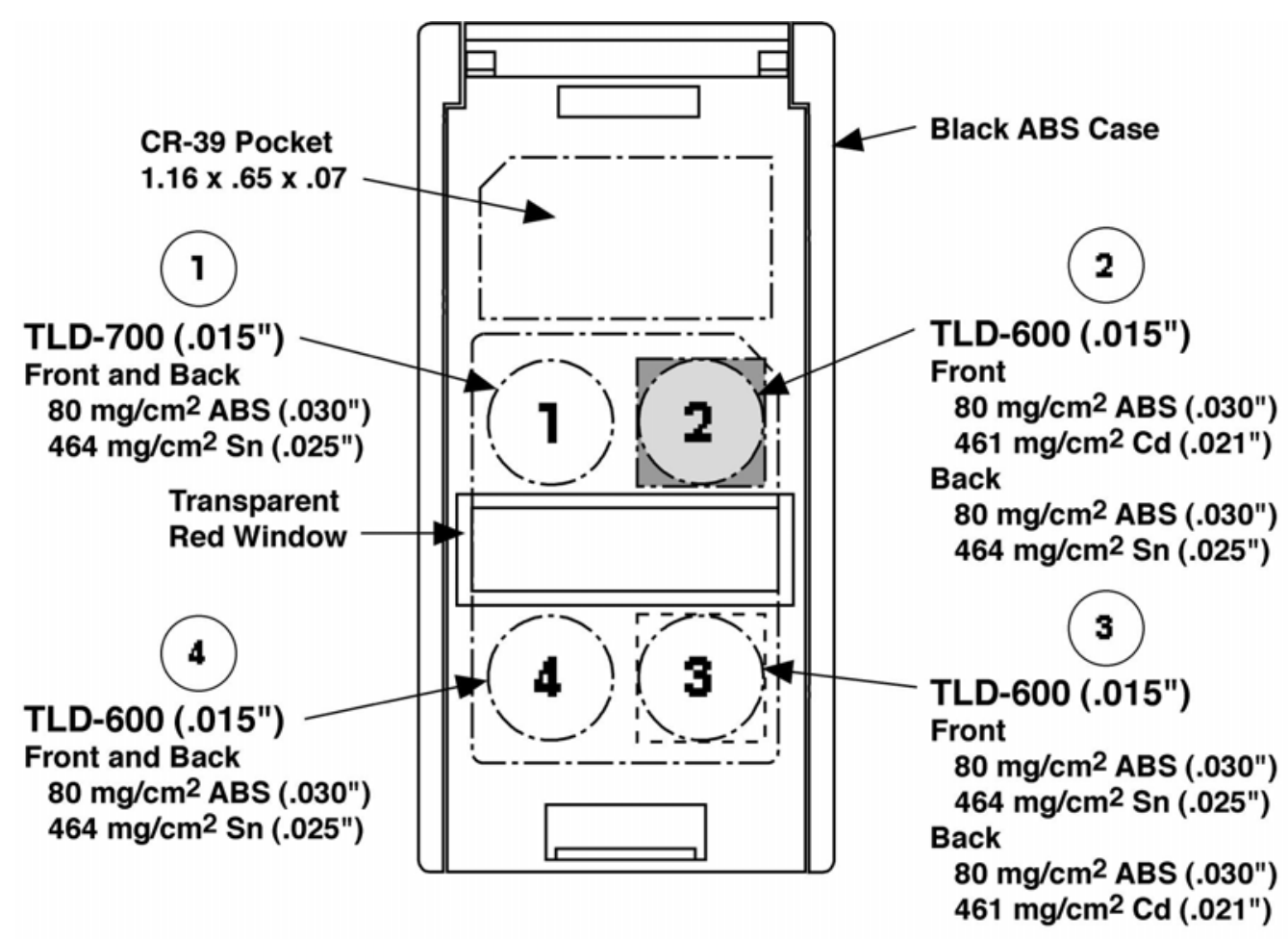

Hanford TL Albedo Neutron Dosimeter

39502026.4

Figure 3.3. Diagram of HCND Neutron 8816 Dosimeter 


\subsubsection{HCND Neutron Dose Algorithm}

There are four neutron dose algorithms available for use with the 8816 TLD component of the HCND. They are referred to as case 0 , case 1, case 2, and case 3; flowcharts are presented for all four algorithms in Figure 3.4, and the algorithm for case 1, which is most relevant to this study, will be described in detail.

The contractors submit dosimeters for processing through REX (the Radiological EXposure system) where they are required to provide a two-digit facility calibration code, a two-digit note code (reason and priority for processing), wear dates, and other wearer information. The facility calibration code and other wearer information is passed to the HED processing lab through an electronic file called RETURN.TXT at the time the dosimeter is physically returned for processing. The facility calibration code indicates the type of radiation environment and tells the external dosimetry data management software which algorithm to apply when performing dose calculations. Because there are 100 possible facility calibration codes and the facility calibration code is used to convey information pertinent to more than one type of dosimeter, more than one facility calibration code may translate to a given case for the 8816 dosimeter based on a system table that interprets facility calibration code.

The initial steps in each algorithm are the same and are as follows:

1. Let $\mathrm{L} 1=\mathrm{D} 1 \quad$ (adjusted reading from chip 1)

$\mathrm{L} 2=\mathrm{D} 2$ (adjusted reading from chip 2)

L3 = D3 (adjusted reading from chip 3)

L4 = D4 (adjusted reading from chip 4)

FORMULA $=0$

(Adjusted readings have units of ${ }^{137} \mathrm{Cs}$ rem equivalent.)

2. Calculate net signal (neutron response) on TLD 600 chips (2, 3, and 4).

$$
\begin{array}{ll}
\mathrm{N} 2=\mathrm{L} 2-\mathrm{L} 1 & \text { if } \mathrm{N} 2<0 ; \mathrm{N} 2=0 \\
\mathrm{~N} 3=\mathrm{L} 3-\mathrm{L} 1 & \text { if N3<0; N3 }=0 \\
\mathrm{~N} 4=\mathrm{L} 4-\mathrm{L} 1 & \text { if N4 }<0 ; \mathrm{N} 4=0
\end{array}
$$




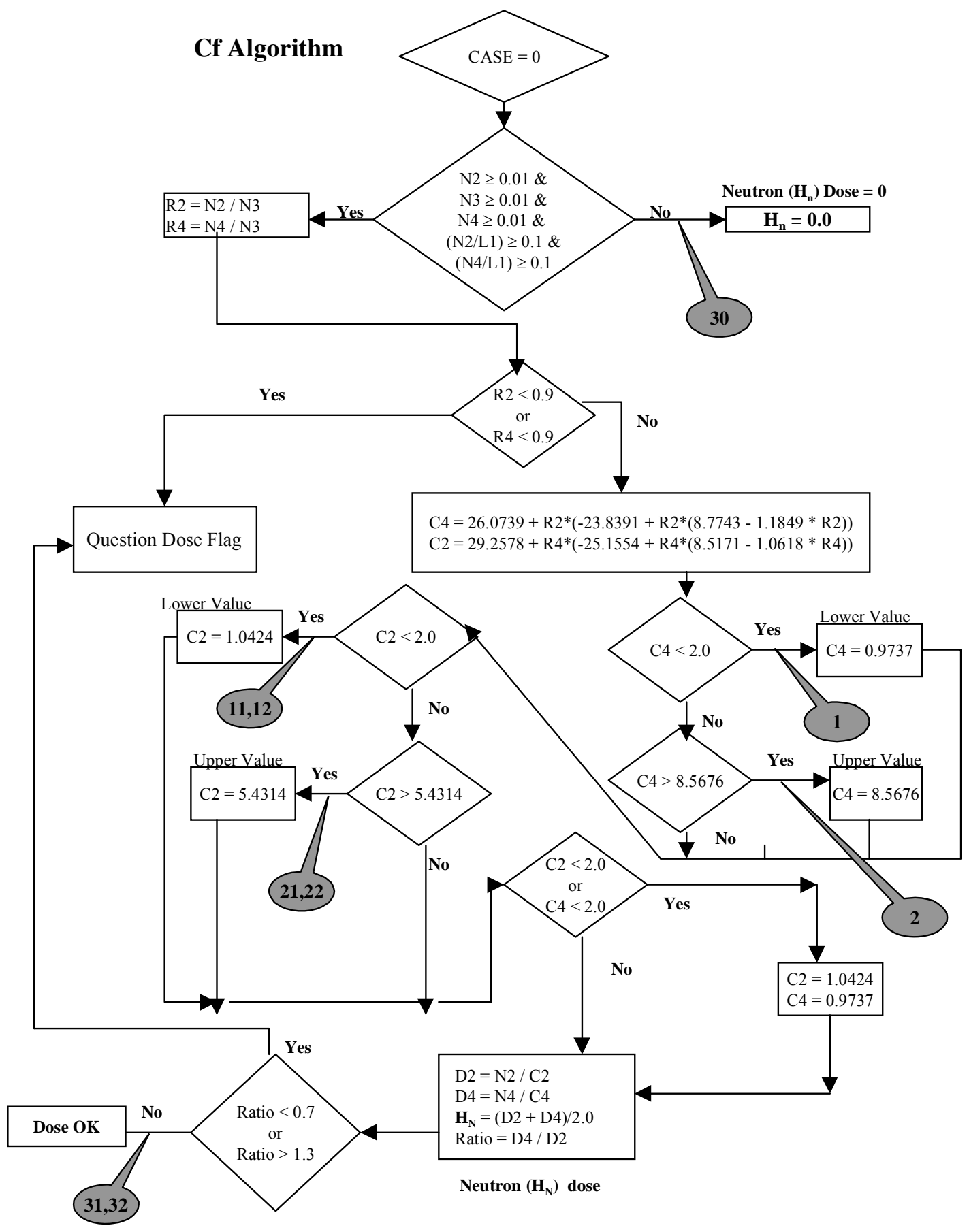

Figure 3.4. HCND Neutron Dose Algorithm 


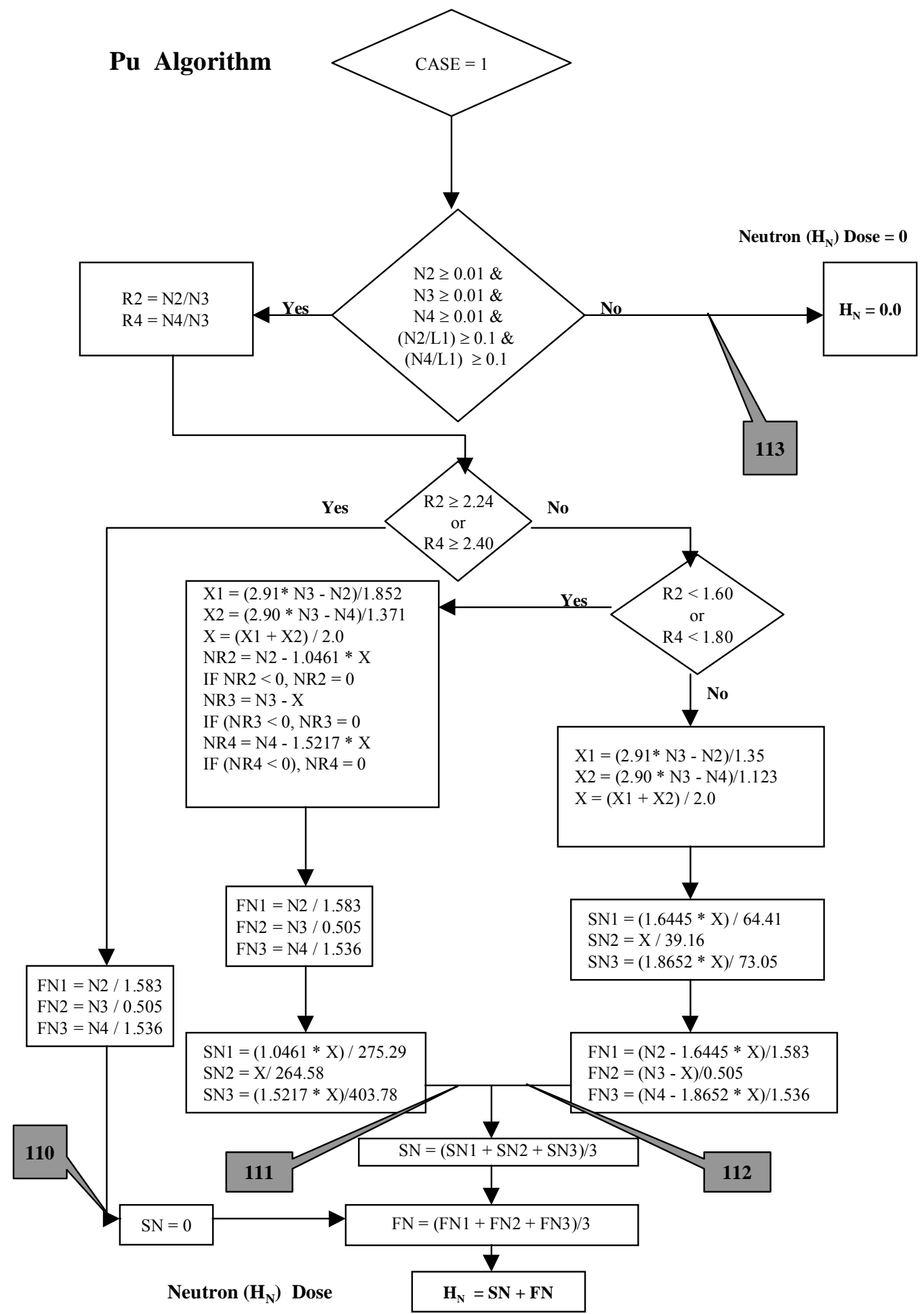

Figure 3.4. Cont'd 

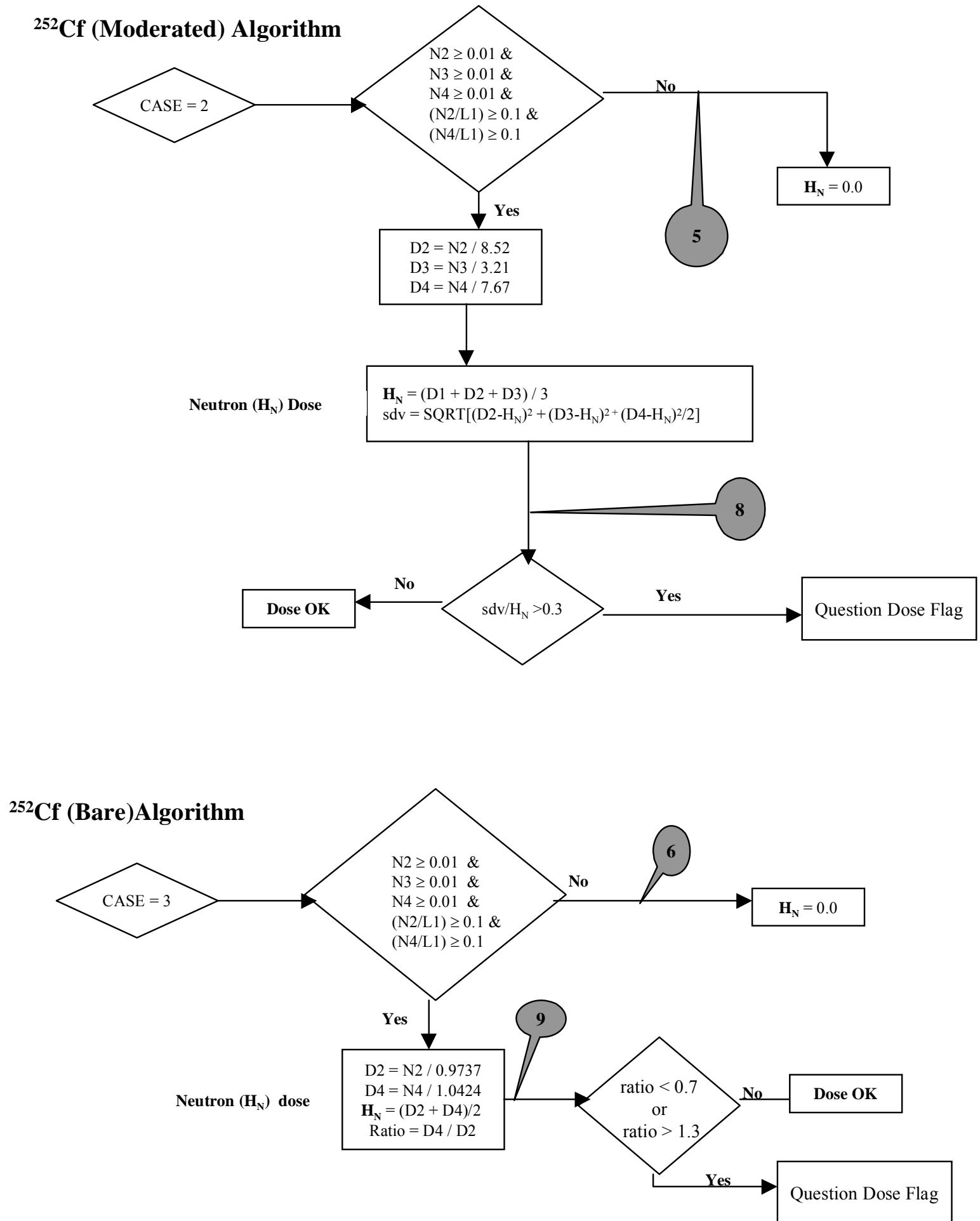

Figure 3.4. Cont'd 


\subsubsection{Californium Algorithm (Case 0)}

When the contractor provides a facility calibration code of " 00 " when returning an HCND 8816 dosimeter, case 0 is used to calculate neutron dose. This is also the default algorithm used when the contractor provides no facility calibration code. As a default, this will generally provide conservative dose results except in cases where the actual neutron spectrum is significantly more energetic than bare californium. This algorithm is intended for use by individuals at Hanford working with ${ }^{252} \mathrm{Cf}$ and other neutron sources or radiation fields characterized by a fission spectrum. The algorithm has the capability to discern neutron energy and the degree of moderation from a bare source, and compensate the dosimeter's response accordingly. Because of this, the energy dependence of this algorithm is considerably less than the energy dependence for a simple (i.e., single element) albedo neutron TLD.

The gamma component of each TLD-600 chip adjusted reading is approximated by the adjusted reading of the TLD 700 element. The gamma-compensated neutron signal on each TLD 600 chip is calculated by subtracting the TLD-700 adjusted reading. The gamma-compensated chip 2/chip 3 ratio and chip 4/chip 3 ratio are used to estimate the neutron energy and the appropriate calibration factors to be applied to the chip 2 and chip 4 readings to obtain neutron dose equivalent. The fitted response functions used in the algorithm to calculate the neutron calibration factor were derived from the responses of the dosimeter on-phantom to a NISTtraceable ${ }^{252} \mathrm{Cf}$ source with varying thicknesses of Plexiglas moderators between the source and dosimeter. The neutron spectra and neutron dose equivalent rates were determined by multisphere and TEPC measurements of the source. The algorithm is presented in Figure 3.4 and its development is described in detail by Endres et al. (1996).

\subsubsection{Plutonium Algorithm (Case 1)}

The plutonium algorithm as described by Endres et al. (1996) was developed based on measurements made at the PFP with a $\mathrm{PuF}_{4}$ source and various thicknesses of acrylic plastic between the source and dosimeters. Dosimeters were mounted on an acrylic plastic phantom, 40 by 40 by $15 \mathrm{~cm}$ ( 15.75 by 15.75 by 6 in.). The thicknesses of plastic shielding used were $2.5 \mathrm{~cm}$ (1 in.), $5 \mathrm{~cm}(2 \mathrm{in}),. 7.6 \mathrm{~cm}(3 \mathrm{in}$.), and $10 \mathrm{~cm}(4 \mathrm{in}$.). The dosimeter response data were separated into three components for developing the algorithm, as follows:

- Unmoderated plutonium neutron spectra. Dosimeter response data from the unmoderated $\mathrm{PuF}_{4}$ source (with no intervening acrylic plastic between the source and dosimeters) at $50 \mathrm{~cm}$ and $100 \mathrm{~cm}$ were used to develop expressions for fast neutron dose equivalent for the "unmoderated" condition. The data for this component generally correspond to R2 $>2.24$ or $\mathrm{R} 4>2.40$. A fast neutron dose component is calculated from each of the net adjusted readings $\mathrm{N} 2, \mathrm{~N} 3$, and $\mathrm{N} 4$ (identified as FN2, FN3, and FN4). The reported neutron dose equivalent is then the average of the three results. This algorithm branch is identified as Formula $=110$, and is presented in Step 3, below.

- Partially moderated plutonium neutron spectra. Dosimeter response data from the $\mathrm{PuF}_{4}$ source with a $2.54-\mathrm{cm}(1 \mathrm{in}$.) slab of plastic between the source and dosimeters, and the 
dosimeters positioned at $50 \mathrm{~cm}$ and $100 \mathrm{~cm}$ from the source were used by Endres et al. (1996) to develop expressions for fast neutron (FN) and slow neutron (SN) dose equivalent for the "partially moderated" condition. The reported neutron dose is then the average of the three SN terms and the three FN terms. The data for this component generally correspond to $1.60<\mathrm{R} 2<2.24$, and $1.80<\mathrm{R} 4<2.40$, and the algorithm branch is identified as Formula $=$ 111 , as presented in Step 4, below.

- Highly moderated plutonium spectra. Dosimeter response data from the $\mathrm{PuF}_{4}$ source with an intervening 7.62-cm (3-in.) slab of plastic and the dosimeters positioned at $50 \mathrm{~cm}$ from the source; and with an intervening 10.16-cm (4-in.) slab of plastic and the dosimeters position at $50 \mathrm{~cm}$ from the source, were used to develop expressions for $\mathrm{FN}$ dose equivalent and $\mathrm{SN}$ dose equivalent. The reported neutron dose is then the average of the three SN terms and the three FN terms. The data for this component generally correspond to $\mathrm{R} 2<1.6$ or $\mathrm{R} 4<1.80$, and the algorithm branch is identified as Formula $=112$, as presented in Step 5, below.

The plutonium algorithm is used when the contractor provides a facility calibration code of " 01 " when returning the dosimeter for processing. The algorithm, as presented in Figure 3.4 and in detail below, is presented in a form that closely matches the calculation steps performed in the external dosimetry data management software. It is possible to algebraically reduce this algorithm to a set of equations in a more compact form. This reduced form is presented by Endres et al. (1996), and the 1996 report also presents a detailed discussion of the development of the algorithm.

1. If $\mathrm{N} 2 / \mathrm{L} 1 \geq 0.10$ and $\mathrm{N} 4 / \mathrm{L} 1 \geq 0.10$ and $\mathrm{N} 2 \geq 0.010$ and $\mathrm{N} 3 \geq 0.010$ and $\mathrm{N} 4 \geq 0.010$, Continue to Step 2.

Else,
$\mathrm{H}_{\mathrm{n}}=0$,
END
FORMULA $=113$ (no dose detected)

2. Calculate the two independent ratios:

$\mathrm{R} 2=\mathrm{N} 2 / \mathrm{N} 3$

$\mathrm{R} 4=\mathrm{N} 4 / \mathrm{N} 3$

3. If $\mathrm{R} 2 \geq 2.24$ or $\mathrm{R} 4 \geq 2.40$, calculate dose as follows: $\quad$ FORMULA $=110$ (hard)

$\mathrm{FN} 1=\mathrm{N} 2 / 1.583$

$\mathrm{FN} 2=\mathrm{N} 3 / 0.505$

$\mathrm{FN} 3=\mathrm{N} 4 / 1.536$

$\mathrm{H}_{\mathrm{n}}=(\mathrm{FN} 1+\mathrm{FN} 2+\mathrm{FN} 3) / 3.0$

4. If $\mathrm{R} 2<1.60$ or $\mathrm{R} 4<1.80$, calculate dose as follows: $\quad$ FORMULA $=111$ (soft)

$\mathrm{X} 1=(2.91 * \mathrm{~N} 3-\mathrm{N} 2) / 1.852$

$\mathrm{X} 2=(2.90 * \mathrm{~N} 3-\mathrm{N} 4) / 1.371$

$\mathrm{X}=(\mathrm{X} 1+\mathrm{X} 2) / 2.0$

$\mathrm{NR} 2=\mathrm{N} 2-1.0461 * \mathrm{X}$ 


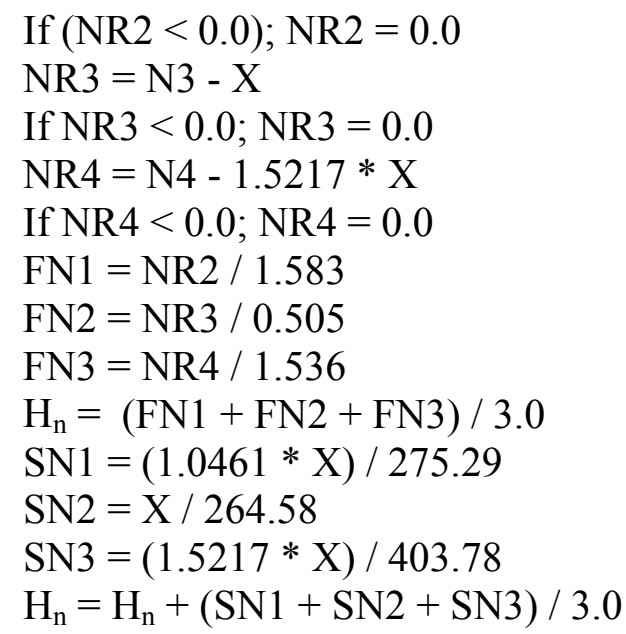

5. Otherwise calculate neutron dose as follows:

FORMULA $=112$ (intermediate)

$$
\begin{aligned}
& \mathrm{X} 1=(2.91 * \mathrm{~N} 3-\mathrm{N} 2) / 1.35 \\
& \mathrm{X} 2=(2.90 * \mathrm{~N} 3-\mathrm{N} 4) / 1.123 \\
& \mathrm{X}=(\mathrm{X} 1+\mathrm{X} 2) / 2.0 \\
& \mathrm{FN} 1=(\mathrm{N} 2-1.6445 * \mathrm{X}) / 1.583 \\
& \mathrm{FN} 2=(\mathrm{N} 3-\mathrm{X}) / 0.505 \\
& \mathrm{FN} 3=(\mathrm{N} 4-1.8652 * \mathrm{X}) / 1.536 \\
& \mathrm{H}_{\mathrm{n}}=(\mathrm{FN} 1+\mathrm{FN} 2+\mathrm{FN} 3) / 3.0 \\
& \mathrm{SN} 1=(1.6445 * \mathrm{X}) / 64.41 \\
& \mathrm{SN} 2=\mathrm{X} / 39.16 \\
& \mathrm{SN} 3=(1.8652 * \mathrm{X}) / 73.05 \\
& \mathrm{H}_{\mathrm{n}}=\mathrm{H}_{\mathrm{n}}+(\mathrm{SN} 1+\mathrm{SN} 2+\mathrm{SN} 3) / 3.0
\end{aligned}
$$

\subsubsection{3 $\underline{\mathrm{D}}_{2} \mathrm{O}$ Moderated ${ }^{252} \mathrm{Cf}$ Algorithm (Case 2)}

This algorithm was developed primarily for NVLAP performance testing where a $\mathrm{D}_{2} \mathrm{O}$ moderator sphere with cadmium cover moderates the neutrons. This algorithm is necessary for performance testing because the californium algorithm (case 0) breaks down when exposed to the moderated source. This breakdown occurs because the spectrum is missing the very component $(<0.4 \mathrm{eV})$ used by the algorithm to discern the degree of moderation. This spectrum, while readily created in a calibration facility, is not encountered in work environments where moderation takes place in hydrogenous materials without cadmium filters. This algorithm basically applies a set of fixed calibration constants to N2, N3, and N4 to obtain neutron dose, and therefore exhibits a large energy dependence.

\subsubsection{Bare ${ }^{252} \mathrm{Cf}$ Algorithm (Case 3)}

This algorithm is used primarily for DOELAP and NVLAP performance testing and in situations where the spectrum is known to be unmoderated fission neutrons. This algorithm basically applies a set of fixed calibration constants to N2 and N4 to obtain neutron dose, and therefore exhibits a large energy dependence. 


\subsection{Hanford Track Etch Dosimeter}

The TED foils in the HCND provide a technique independent from that of the TLD to calculate neutron dose. The CR-39 does not exhibit the severe energy dependence that exists with albedo neutron dosimeters and can provide good results when varied neutron energy spectra are encountered. The CR-39 plastic, with its dense, uniform molecular structure, is susceptible to radiation damage involving scission of the molecular chains. These damage sites produce tracks or "pits" that, when electrochemically etched, can be seen under a microscope. The formation of these tracks is primarily caused by hydrogen recoil with fast neutrons, but can also be caused by alpha particles, protons, and heavy charged particles. Beta and gamma radiation has a low enough LET that a track cannot form, making CR-39 insensitive to these radiation types. To prevent the alpha interaction, a layer of polyethylene covers both sides.

\subsubsection{TED Design}

The TED consists of two CR-39 foils placed one on top of the other, at the top of the TLD 8816 card in the neutron holder with the topside facing towards the front of the dosimeter. The foils are made from clear CR-39 polycarbonate plastic with a thin polyethylene covering. They are approximately $28 \mathrm{~mm}$ long, $16 \mathrm{~mm}$ wide, and $0.64 \mathrm{~mm}$ thick. The polyethylene covering protects the CR-39 from alpha radiation exposure as well as providing a dense source of hydrogen atoms necessary for proton recoil.

\subsubsection{TED Neutron Dose Algorithm}

During the processing of each group of 24 foils, two foils in each batch are exposed to bare ${ }^{252} \mathrm{Cf}$, and two to a blank dose. The results of these four dosimeters are used to calculate a batch calibration factor that relates mrem to track count. The calibration factor has units of $\mathrm{mrem} / \mathrm{tracks} / \mathrm{cm}^{2}$. The two blank foils are used to determine a batch background factor having units of tracks $/ \mathrm{cm}^{2}$. Within the dose range 0-1000 mrem, the number of track counts is directly proportional to neutron dose equivalent received. The neutron dose equivalent in mrem is then calculated by averaging the two foil track counts, subtracting the background factor, and multiplying that result by the calibration factor, as follows:

$$
\mathrm{H}_{\mathrm{n}}=[(\mathrm{T} 1+\mathrm{T} 2) / 2-\mathrm{B}] * \mathrm{C}
$$

where
$\mathrm{H}_{\mathrm{n}}=$ neutron dose equivalent
$\mathrm{T} 1=$ foil 1 track count in tracks $/ \mathrm{cm}^{2}$
$\mathrm{T} 2=$ foil 2 track count in tracks $/ \mathrm{cm}^{2}$
$\mathrm{B}=$ batch background factor in tracks $/ \mathrm{cm}^{2}$
$\mathrm{C}=$ batch calibration factor in $\mathrm{mrem} / \mathrm{tracks} / \mathrm{cm}^{2}$.

The lower energy threshold of CR-39 response to neutrons is approximately $100 \mathrm{keV}$. For this reason, care must be exercised when using CR-39 in highly scattered neutron fields where lowerenergy neutrons may be a significant component of the personnel dose. The PNNL 
measurements in the PFP work environments have shown significant under-response for TEDs in highly moderated neutron fields (Brackenbush, Baumgartner and Fix 1991; Endres et al. 1996). Based on previous Hanford measurements, a range of acceptable values for each of the albedo TLD chip ratios R2 and R4 has been determined, that indicates sufficient hardness in the neutron spectrum for energy-independent dose measurement with CR-39. If R $<1.6$ or R $4<1.8$, then the neutron spectrum is too moderated and significant under-response of the CR-39 is likely. Under these circumstances, the CR-39 foils are not processed. 


\subsection{LOW-SCATTER ROOM MEASUREMENTS}

Before the workplace measurements were conducted, measurements were performed in PNNL's Low-Scatter Room (LSR) in the 318 Building. The LSR contains ${ }^{252} \mathrm{Cf}$ neutron sources that have neutron emission rates traceable to NIST. The room is large enough to have irradiation positions located several meters from the walls and floor, creating a low-scatter condition. The neutron fields are very well characterized, so this facility offers an excellent resource for evaluating the operability of the measurement equipment.

\subsection{TEPC Measurements in the LSR}

The 5-in. TEPC detectors that were used in the workplace measurements were tested in the LSR on June $14-15,1999$. Irradiations were performed at $100 \mathrm{~cm}$ from either of two ${ }^{252} \mathrm{Cf}$ sources:

318-356, with an unscattered dose equivalent rate of $1079 \mathrm{mrem} / \mathrm{h}$ at $100 \mathrm{~cm}$

$318-016$, with an unscattered dose equivalent rate of $3.25 \mathrm{mrem} / \mathrm{h}$ at $100 \mathrm{~cm}$.

The accepted value for the unscattered dose equivalent rate from an unmoderated ${ }^{252} \mathrm{Cf}$ source in the LSR uses the neutron emission rate traceable to NIST and a fluence-to-dose conversion factor, valid for an isotropic, unscattered ${ }^{252} \mathrm{Cf}$ spectrum; however, the geometry conditions in which each source is used in the calibration facility may influence the final interpretation of the dose equivalent rate. Consequently, NIST traceability is "implied" and is strictly preserved only when appropriate corrections are made for effects that depreciate isotropic, free-field conditions. An observable portion of the instrument response in the LSR is due to neutrons scattered by the walls, floor, and ceiling of the calibration room. Based on empirical evaluations, an increase to the delivered dose equivalent rate of approximately 5\% (or alternatively, a decrease of the instrument response of approximately 5\%) gives a more realistic estimate of the apparent dose equivalent rate for the actual irradiation conditions in the LSR specific to this instrument. Making this adjustment is among the prerequisites to preserving traceability to NIST. ${ }^{(1)}$

Source 318-356 produced a higher count rate in the TEPC and was useful for establishing a good ratio between a detector's alpha peak and its proton drop point. The dose rate, however, was higher than the dose rate encountered in workplace neutron fields, so source 318-016 was used to give an indication of detector response in the workplace.

Exposures to neutrons from source 318-356 were typically conducted for 5 to 10 minutes to obtain sufficient counts for an accurate measurement. Exposures to neutrons from source 318016 were longer, as much as two hours, but counting statistics were poorer than for the more intense source. The detectors were connected to the same electronic modules, including preamplifier, Nuclear Instrument Module (NIM) high voltage, NIM amplifier, NIM analog-todigital converter (ADC), and multichannel analyzer (MCA) that were used in the workplace measurements. The MCA data for each measurement were transferred to a computer, and the measurements were analyzed using the computer code TEPC_NG. A summary of the results of the 5-in. TEPC measurements is given in Table 4.1. Detailed TEPC_NG outputs are presented

1) Personal Communication with R.K. Piper, PNNL Calibration Research and Accreditation 
in Appendix A. As a result of these measurements, TEPC 1171 was not used in the workplace measurements.

Table 4.1. Summary of 5-in. TEPC Measurements in the LSR

\begin{tabular}{|c|c|c|c|}
\hline Detector ID & $\begin{array}{c}\text { Measured } \\
\mathbf{m r e m} / \mathbf{h}\end{array}$ & $\begin{array}{c}\text { Accepted } \\
\mathbf{m r e m} / \mathbf{h}\end{array}$ & $\begin{array}{c}\text { Percent } \\
\text { Difference }\end{array}$ \\
\hline 185 & 1040 & 1079 & $-3.6 \%$ \\
\hline 185 & 3.49 & 3.25 & $+7.4 \%$ \\
\hline 504 & 1180 & 1079 & $+9.4 \%$ \\
\hline 504 & 3.78 & 3.25 & $+16.3 \%$ \\
\hline 1170 & 1170 & 1079 & $+8.4 \%$ \\
\hline 1170 & 3.79 & 3.25 & $+16.6 \%$ \\
\hline 1171 & 1340 & 1079 & $+24 \%$ \\
\hline 1171 & 3.94 & 3.25 & $+21 \%$ \\
\hline 1172 & 1060 & 1079 & $-1.8 \%$ \\
\hline 1172 & 3.33 & 3.25 & $+2.5 \%$ \\
\hline 1173 & 1190 & 1079 & $+10.3 \%$ \\
\hline 1173 & 3.53 & 3.25 & $+8.6 \%$ \\
\hline
\end{tabular}

Table 4.1 compares TEPC results with the accepted unscattered, free-field dose equivalent rates for the sources in the LSR. The percent differences for each measurement could be reduced by approximately $5 \%$ to account for room scatter, source anisotropy, and other effects.

The two $1 / 2$-in. TEPC detectors used in this study were also exposed in the LSR, in measurements similar to those for the 5-in. TEPCs. On July 9-13, 1999, the detectors were exposed at $100 \mathrm{~cm}$ from source 318-356, which at that time had an accepted dose equivalent rate of $1057 \mathrm{mrem} / \mathrm{h}$ (unscattered).

On August 20, they were again exposed to the same source, which now had a nominal unscattered dose equivalent rate of $1028 \mathrm{mrem} / \mathrm{h}$ at $1 \mathrm{~m}$. The August 20 measurements used short counting times to approximate the number of events that would be counted in a typical workplace measurement. For calibration purposes, the best detector resolution is usually obtained when at least 100,000 neutron counts are collected in the MCA. A reasonable calibration can be performed when about 20,000 neutron counts are collected. However, it was anticipated that in the workplace, the $1 / 2$-in. TEPC detectors might only be able to collect a few thousand neutron counts in a reasonable counting time period. Thus the short counts were conducted to see how reliably the $1 / 2$-in. TEPCs could estimate dose equivalents from a known source. Table 4.2 presents the results of the $1 / 2$-in. TEPC measurements, stated in terms of integral dose rather than dose rate to show the effect of count duration. Appendix A presents the outputs of the TEPC_NG analyses of these measurements. 
Table 4.2. Summary of 1/2-in. TEPC Measurements in the LSR

\begin{tabular}{|c|c|c|c|c|}
\hline $\begin{array}{c}\text { Detector } \\
\text { ID }\end{array}$ & $\begin{array}{c}\text { Measured } \\
\text { mrem }\end{array}$ & $\begin{array}{c}\text { Accepted } \\
\text { mrem }\end{array}$ & $\begin{array}{c}\text { Percent } \\
\text { Difference }\end{array}$ & $\begin{array}{c}\text { Total Neutron } \\
\text { Counts }\end{array}$ \\
\hline 1074 & 1510 & 1580 & -4.4 & 23,500 \\
\hline 1074 & 357 & 301 & +19. & 5,460 \\
\hline 1122 & 1030 & 1062 & -3.0 & 15,900 \\
\hline 1122 & 126 & 110 & +14.5 & 1,900 \\
\hline 1122 & 271 & 228 & +19. & 4,020 \\
\hline
\end{tabular}

\subsection{Sphere Measurements in the LSR}

The LiI(Eu) detector inside 3- and 8-in. polyethylene spheres was exposed to the unmoderated ${ }^{252} \mathrm{Cf}$ source $318-016$ on June 15,1999 , when the unscattered dose equivalent rate was 3.25 $\mathrm{mrem} / \mathrm{h}$ at $100 \mathrm{~cm}$. Counting times ranged from 1000 to 5370 seconds to ensure sufficient counts for good counting statistics. Two different LiI(Eu) detectors were used in the LSR measurements. For each count, the data were collected in an MCA and recorded on computer disk. The area under the neutron peak was found by smoothing the spectrum in the region of the peak and fitting a gaussian shape to the smoothed data. The area under this fitted shape and above a fitted exponential background was then determined. This method provided consistency in determining peak area from run to run. The LiI $(\mathrm{Eu})$ data measured in the LSR are presented in Table 4.3.

Table 4.3. Sphere Measurements in the LSR

\begin{tabular}{|c|c|c|c|c|c|c|}
\hline $\begin{array}{c}\text { Detector } \\
\text { ID }\end{array}$ & $\begin{array}{c}\text { Sphere } \\
\text { Diameter }\end{array}$ & $\begin{array}{c}\text { Count } \\
\text { Time } \\
\text { (sec) }\end{array}$ & $\begin{array}{c}\text { Net Peak } \\
\text { Area } \\
\text { (cts) }\end{array}$ & $\begin{array}{c}\text { Count } \\
\text { rate } \\
\text { (c/s) }\end{array}$ & $\begin{array}{c}\text { Ratio, } \\
\text { 8-in. / } \\
\text { 3-in. }\end{array}$ & $\begin{array}{c}\text { 8-in. Response } \\
\text { (mrem/h per } \\
\text { c/s) }\end{array}$ \\
\hline WA83751 & 3 in & 5370 & 88,587 & 16.5 & & \\
\hline WA83751 & 8 in & 1000 & 50,785 & 50.8 & 3.08 & 0.0640 \\
\hline WA83752 & 3 in & 1147 & 16,166 & 14.1 & & \\
\hline WA83752 & 8 in & 1436 & 61,083 & 42.5 & 3.02 & 0.0764 \\
\hline
\end{tabular}

The average ratio for these two detectors was 3.05, which is indicative of an unmoderated fission spectrum, and the average 8-in response was $0.0702(\mathrm{mrem} / \mathrm{h} \mathrm{per} \mathrm{c} / \mathrm{s})$. These values were used to modify the coefficients of Equation 2.5. The form of Equation 2.5 is a straight line: the slope should remain the same for different detectors, but the intercept could be changed to account for a difference in detector sensitivities. Using the values determined from these LSR measurements, the equation applicable to this study would be as follows:

$$
\mathrm{CF}=0.0354+0.114 \mathrm{R}
$$




\subsection{BTI Bubble Detector Measurements in the LSR}

Six BTI bubble detectors were used in this study. On July 13, 1999, they were exposed to neutrons from an unmoderated ${ }^{252} \mathrm{Cf}$ source in the LSR to check their performance in a wellcharacterized field. Source 318-356 was used for these irradiations. This source produced an unscattered dose equivalent rate of $1057 \mathrm{mrem} / \mathrm{h}$ or $17.6 \mathrm{mrem} / \mathrm{minute}$ at $100 \mathrm{~cm}$, the irradiation position for the detectors. The bubble detectors were irradiated for 3 minutes, to deliver 52.85 mrem to the detectors, and the bubbles were counted. The six detectors were then recompressed to collapse all the bubbles, and the detectors were then exposed to a series of irradiations, counting the bubbles after each step in the series. The first step was 1 minute, for $17.6 \mathrm{mrem}$; then a second minute of exposure, for a total of $36.2 \mathrm{mrem}$; then another minute for a total of $52.85 \mathrm{mrem}$.

Two methods were available for counting bubbles in an exposed dosimeter: inspection by eye and automated counting. When counting the bubbles by eye, typically the bubbles in the detector were counted three times, and the mean of these three counts was recorded (when the number of bubbles was below 25, only one count would be made). The automated system, provided by BTI, involved a camera and image recognition software that counted the bubbles. When counting automatically, three or four counts would be made, with the detector rotated relative to the camera each time, and the mean of these counts was recorded.

The detectors used in this study had sensitivities, determined for each detector individually by the manufacturer, ranging from 0.67 to 0.75 bubbles per mrem. Table 4.4 summarizes the results of the LSR exposures for the bubble detectors. 
Table 4.4 Response of BTI Bubble Detectors in LSR

\begin{tabular}{|c|c|c|c|c|c|c|c|c|}
\hline $\begin{array}{c}\text { Detector } \\
\text { ID }\end{array}$ & $\begin{array}{c}\text { (Inspect } \\
\text { by eye) } \\
\text { bubbls } \\
\text { countd }\end{array}$ & $\begin{array}{c}\text { (Auto- } \\
\text { mated) } \\
\text { bubbles } \\
\text { counted }\end{array}$ & $\begin{array}{c}\text { Detector } \\
\text { Sens. } \\
\text { Bubbles } \\
\text { /mrem }\end{array}$ & $\begin{array}{c}\text { Counted } \\
\text { by eye } \\
\text { mrem }\end{array}$ & $\begin{array}{c}\text { Auto- } \\
\text { mated } \\
\text { count } \\
\text { mrem }\end{array}$ & $\begin{array}{c}\text { Deliverd } \\
\text { mrem }\end{array}$ & $\begin{array}{c}\text { (by eye) } \\
\text { \% diff }\end{array}$ & $\begin{array}{c}\text { Automated } \\
\text { \% diff }\end{array}$ \\
\hline & & & & & & & & \\
\hline 121487 & 36 & 48 & 0.72 & 51.4 & 67.1 & 52.9 & -2.8 & 27.0 \\
\hline 119504 & 45 & 51 & 0.69 & 68.1 & 73.9 & 52.9 & 28.9 & 39.9 \\
\hline 121292 & 42 & 49 & 0.67 & 64.2 & 73.6 & 52.9 & 21.4 & 39.3 \\
\hline 121529 & 34 & 40 & 0.68 & 50.0 & 58.3 & 52.9 & -5.4 & 10.4 \\
\hline 121022 & 43 & 48 & 0.74 & 54.1 & 65.3 & 52.9 & 2.3 & 23.6 \\
\hline 123685 & 50 & 55 & 0.75 & 61.3 & 73.3 & 52.9 & 16.1 & 38.8 \\
\hline & & & & & & & & \\
\hline 121487 & 9 & & 0.72 & 12.5 & 0.0 & 17.6 & -29.0 & \\
\hline 123685 & 13 & & 0.75 & 17.3 & 0.0 & 17.6 & -1.5 & \\
\hline 121292 & 9 & & 0.67 & 13.4 & 0.0 & 17.6 & -23.7 & \\
\hline 121529 & 8 & & 0.68 & 11.8 & 0.0 & 17.6 & -33.2 & \\
\hline 121022 & 12 & & 0.74 & 16.2 & 0.0 & 17.6 & -7.9 & \\
\hline 119504 & 16 & & 0.69 & 23.2 & 0.0 & 17.6 & 31.8 & \\
\hline & & & & & & & & \\
\hline 121487 & 16 & & 0.72 & 22.2 & 0.0 & 35.2 & -36.9 & \\
\hline 123685 & 24 & & 0.75 & 32.0 & 0.0 & 35.2 & -9.2 & \\
\hline 121292 & 17 & & 0.67 & 25.4 & 0.0 & 35.2 & -28.0 & \\
\hline 121529 & 16 & & 0.68 & 23.5 & 0.0 & 35.2 & -33.2 & \\
\hline 121022 & 22 & & 0.74 & 29.7 & 0.0 & 35.2 & -15.6 & \\
\hline 119504 & 26 & & 0.69 & 37.7 & 0.0 & 35.2 & 6.9 & \\
\hline & & & & & & & & \\
\hline 121487 & 36 & 45 & 0.72 & 52.8 & 63.0 & 52.9 & -0.1 & 19.1 \\
\hline 123685 & 38 & 52 & 0.75 & 45.3 & 68.9 & 52.9 & -14.2 & 30.3 \\
\hline 121292 & 35 & 38 & 0.67 & 53.7 & 56.7 & 52.9 & 1.7 & 7.3 \\
\hline 121529 & 28 & 36 & 0.68 & 44.1 & 52.5 & 52.9 & -16.5 & -0.8 \\
\hline 121022 & 38 & 45 & 0.74 & 52.7 & 60.8 & 52.9 & -0.3 & 15.1 \\
\hline 119504 & 38 & 50 & 0.69 & 53.6 & 72.5 & 52.9 & 1.5 & 37.1 \\
\hline
\end{tabular}

\subsection{REMbrandt Measurements in the LSR}

The REMBrandt survey meter was exposed to unmoderated neutrons from ${ }^{252} \mathrm{Cf}$ source \#318016 in the LSR on July 16, 1999. On this date the source produced an unscattered neutron field with a dose equivalent rate of $3.18 \mathrm{mrem} / \mathrm{h}$ at $100 \mathrm{~cm}$ and $12.7 \mathrm{mrem} / \mathrm{h}$ at $50 \mathrm{~cm}$. The instrument was first positioned at $100 \mathrm{~cm}$ from the source and data were collected for approximately 20 minutes. The instrument was then set at $50 \mathrm{~cm}$ from the source and data were collected for approximately 36 minutes. The instrument was then removed from the LSR and the measurement data were downloaded to a computer disk using the vendor's computer code. The data were fed into a spreadsheet, and the total dose was summed over a time interval that was within the time that the source was up. This integral dose was divided by the time to get a dose equivalent rate. The dose equivalent rates determined by the REMBrandt are shown in Table 4.5. 
Table 4.5. Response of REMBrandt in LSR

\begin{tabular}{|c|c|c|c|c|}
\hline $\begin{array}{c}\text { Distance from } \\
\text { source } \\
\text { (cm) }\end{array}$ & $\begin{array}{c}\text { Irradiation } \\
\text { time } \\
\text { (hrs) }\end{array}$ & $\begin{array}{c}\text { Integral dose } \\
\text { equivalent } \\
\text { (mrem) }\end{array}$ & $\begin{array}{c}\text { Measured dose } \\
\text { equivalent rate } \\
\text { (mrem/h) }\end{array}$ & $\begin{array}{c}\text { Accepted dose } \\
\text { equivalent rate } \\
\text { (mrem/h) }\end{array}$ \\
\hline 100 & 0.332 & 1.62 & 4.88 & 3.18 \\
\hline 50 & 0.591 & 11.44 & 19.36 & 12.7 \\
\hline
\end{tabular}




\subsection{WORKPLACE MEASUREMENTS}

This chapter describes dosimeter and TEPC measurements in PFP workplaces. The whole body measurements were done to validate the performance of the HSD and HCND in PFP workplace conditions based on comparative measurements between the dosimeter and TEPC measured dose. The extremity measurements were made to determine neutron-to-gamma ratios that would be effective for extremity exposures in glovebox operations.

\subsection{Whole Body Measurements}

The whole body measurements used 5-in. diameter TEPCs to assess the neutron dose equivalent rates at a number of workplace locations, and compared these values with the responses of HCND and HSD dosimeters exposed at the same locations on water-filled phantoms.

Dosimeters were exposed on each of the four sides of each phantom to account for variations in neutron spectra and dose.

There are variations in the neutron energy spectra encountered at the PFP because of variations in shielding and types of material present, which includes $\mathrm{PuO}_{2}$, plutonium metal, $\mathrm{PuF}_{4}$, and mixed oxide fuel rods containing plutonium. Exposure conditions range from essentially no neutron shielding when the plutonium is physically handled to massive neutron shielding with several feet of concrete and iron. The neutron energy spectra encountered range from "hard" spectra, which are essentially fission spectra from the unshielded plutonium, to "soft" low-energy spectra encountered behind the massive shields in the storage vaults, behind water walls, and behind other neutron shields that have been installed to reduce the dose to workers.

\subsubsection{Measurement Locations}

Ten locations for comparative TEPC and dosimeter measurements were selected based on the potential for worker neutron exposure and a variety of neutron energy conditions. The locations chosen were as follows:

- Two locations in Room 235A-3, near Hood 9A. Neutrons are emitted from plutonium holdup inside the hood, and this location is typical of many worker exposure situations. A water wall is located approximately $5 \mathrm{ft}$. $(1.5 \mathrm{~m})$ to the north of the hood, and a concrete wall is located approximately $4 \mathrm{ft}$. $(1.2 \mathrm{~m})$ south of the hood. The water and concrete provide neutron moderation. Measurement locations were chosen next to the water wall and next to the concrete wall, as illustrated in Figure 5.1.

- Two locations were chosen in Vault 1 of 2736ZB. One location was in the aisle between two cabinets; the other was against a wall next to the corridor. The location between the cabinets was exposed to neutrons with a relatively high-energy distribution. The location next to the wall would receive a component of moderated neutrons scattered off the wall. The measurement locations in Vault 1 are shown in Figure 5.2.

- Two locations were chosen in Vault 2 of 2736ZB, one between two cabinets and one against the wall next to the corridor. The energy characteristics of these two locations should be 
similar to the two locations in Vault 1. The measurement locations in Vault 2 are shown in Figure 5.3.

- Two locations were chosen in Vault 4 of 2736ZB, one between two cabinets and one against a wall. The energy characteristics of these two locations should be similar to the two locations in Vault 1 and the two locations in Vault 2. The measurement locations in Vault 4 are shown in Figure 5.4.

- Two locations were chosen in the vault corridor of 2736ZB, one outside Vault 1 and the other outside Vault 3 . These locations were chosen to provide relatively low-energy neutron fields, because any neutrons at this location had to pass through thick concrete walls. The locations in the vault corridor are shown in Figure 5.5.

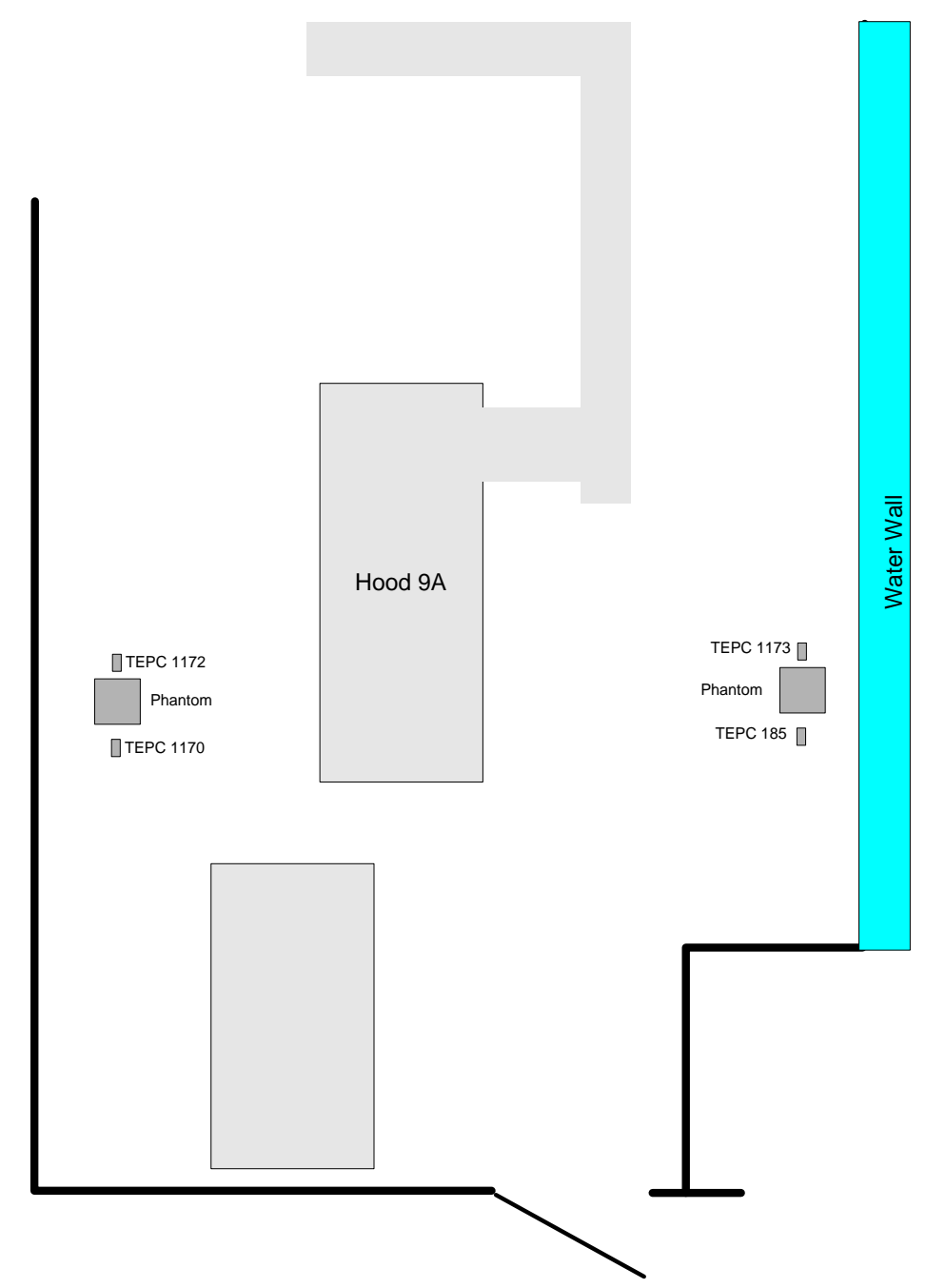

Figure 5.1. Measurement Locations in Room 235A-3 


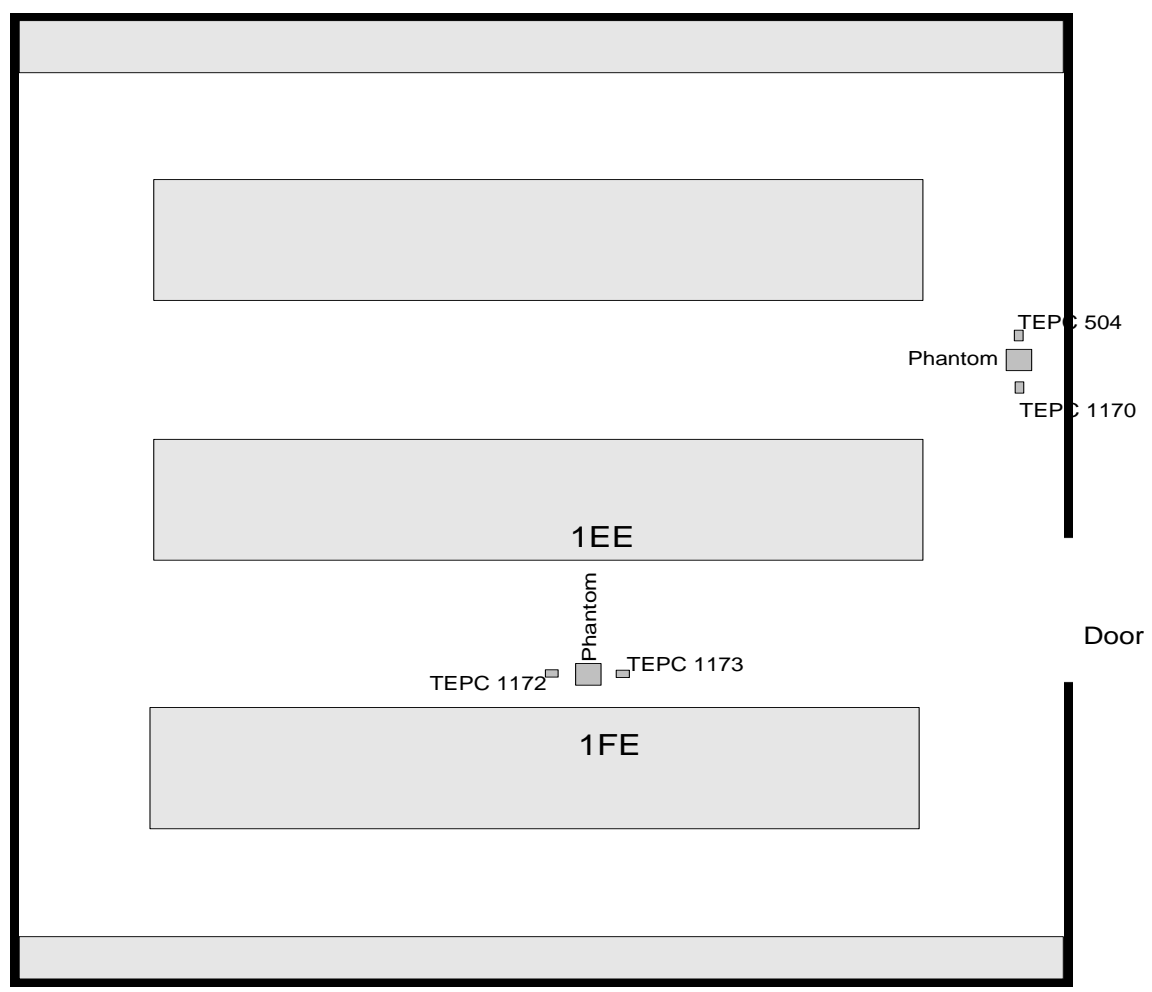

Figure 5.2. Measurement Locations in Vault 1

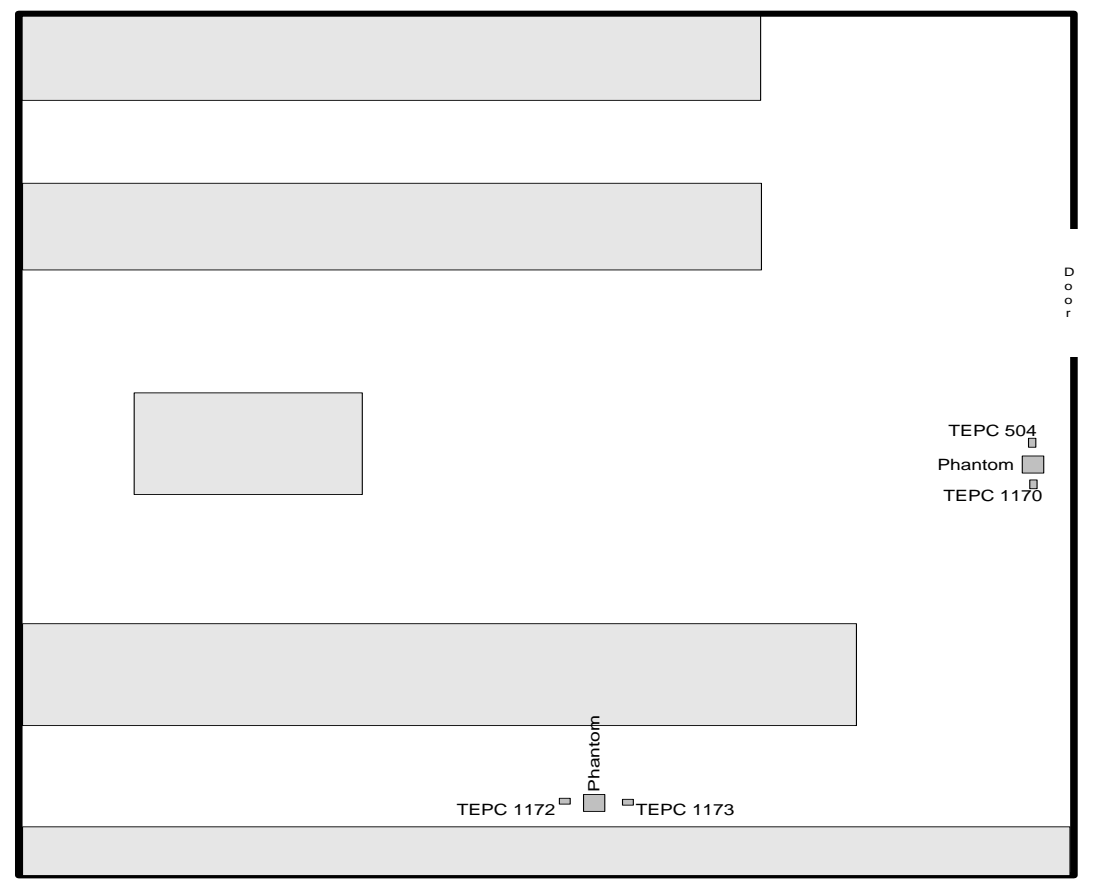

Figure 5.3. Measurement Locations in Vault 2 


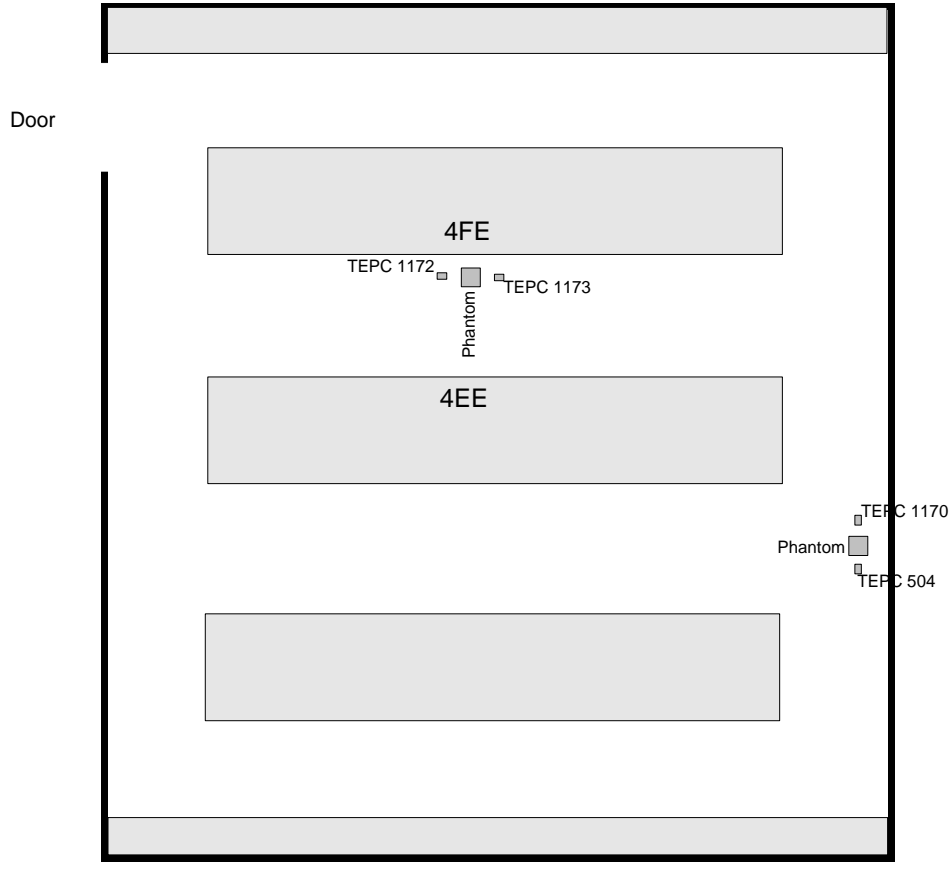

Figure 5.4. Measurement Locations in Vault 4 


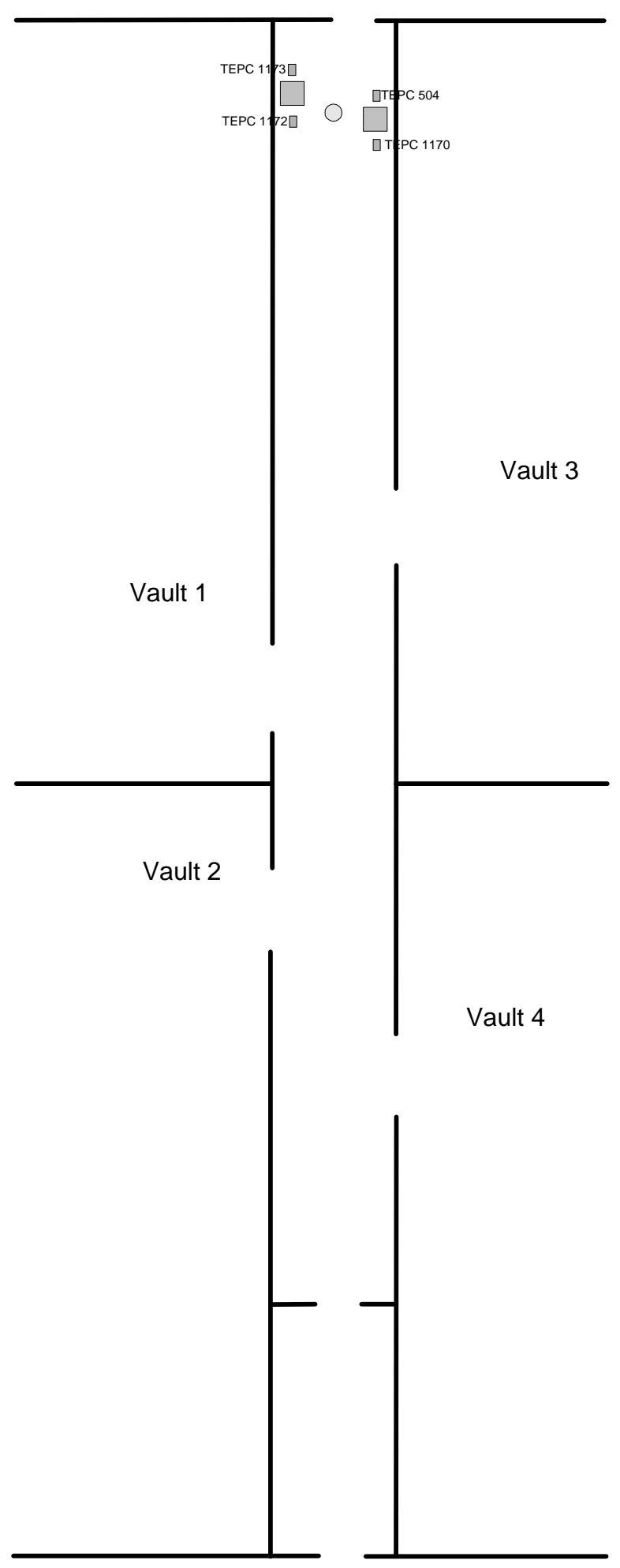

Figure 5.5. Measurement Locations in the Vault Corridor 


\subsubsection{Equipment Setup and Data Collection}

At each location, a water-filled phantom was placed on a stand so that the center of the phantom was approximately $40 \mathrm{in} .(102 \mathrm{~cm})$ above the floor. The phantom had thin plastic walls and dimensions of $25 \mathrm{~cm}$ by $25 \mathrm{~cm}$ by $34 \mathrm{~cm}$ high. A packet of dosimeters was positioned on each of the four vertical faces of the phantom. Each packet held three 8816 and three HSD dosimeters. The packets were oriented so that the three 8816 dosimeters were side-by-side across the top of the packet, and the three HSD dosimeters were below the 8816 dosimeters. The 8816 dosimeters were configured the same as they are in a HCND, with the addition of two TED foils. While TED foils are not currently incorporated in HCNDs used for routine worker monitoring, TED response was a focus of this study, so they were included in the workplace measurements. The neutron insensitive 8825BP dosimeter typically used in the HCND package was not included in this study. Placing dosimeters on all four faces of the phantom provided an indication of the directionality of the radiation field at the measurement location and ensured that at least one packet would be facing the "source."

Dosimeters were exposed on-phantom at each location for a time period long enough to give an exposure of at least $100 \mathrm{mrem}$ on each dosimeter. In some high-dose-rate areas, 5 or 6 hours was sufficient to give this exposure; more commonly the exposures were 18 or 20 hours long. In the low-dose-rate areas in the vault corridor, the exposure was 90 hours long. Control dosimeters were used with each dosimeter packet, accompanying the dosimeters whenever they were not in the exposure position, to ensure that an unexpectedly high background that may have been encountered during storage or transport could not influence the measured results. After the conclusion of all 10 measurements, the exposed dosimeters, including TLD and TED components, were read out by HED staff to determine the gamma and neutron dose equivalent.

Two 5-in. TEPC detectors were set up at each phantom location. The detectors were mounted on tripods and positioned so the center of the detector was at the same height as the center of the phantom. The detectors were positioned close to the phantoms, with the distance from the detector centers to the phantom center ranging from 12 to 15 in. (30 to $38 \mathrm{~cm}$ ). The TEPC detectors were allowed to accumulate data for the same duration as the dosimeter exposures. Signals from the TEPC were collected in a MCA, then transferred to a computer for archiving and analysis. For each TEPC measurement, a dose equivalent rate was determined using the computer code TEPC_NG. The dose equivalent rates measured by the two TEPC detectors at each location could be expected to agree with each other to within about $15 \%$ if the neutron field was uniform. In some cases the disagreement was larger than that because of a gradient in the neutron field.

Sphere measurements were made in most locations. For these measurements, a stand to accommodate the sphere was briefly positioned in place of a TEPC detector (TEPC data collection was stopped during the sphere measurement). A LiI(Eu) detector was placed in the center of a 3-in. diameter polyethylene sphere positioned in the stand, and a data spectrum was collected in the MCA, then stored on computer disk. The 3-in. sphere was then replaced with an 8-in. diameter sphere and another MCA spectrum was recorded. After these measurements, the sphere stand was removed and the TEPC replaced and TEPC data collection continued. The areas of the neutron peaks in the MCA spectra from the two $\mathrm{LiI}(\mathrm{Eu})$ counts were determined and 
divided by the count time to give neutron count rates.

The response as a function of neutron energy of a thermal neutron detector inside an 8-in. sphere is similar to the variability of dose equivalent. Thus this count rate can be used as an indicator of dose equivalent rate, when compared to the values found in the LSR calibrations. Also, the ratio of 8 -in. count rate to 3 -in. count rate varies with neutron energy, so this ratio can be used to obtain some energy information about the neutron field.

A Snoopy survey meter was used at each location to check the dose equivalent rate at the phantom position and to check the variability of the dose rates over the area occupied by the phantom and TEPCs.

Two other neutron detectors were investigated in this study. Three BTI bubble detectors (model BD-PND, with a sensitivity of approximately 0.7 bubbles per mrem) were exposed at eight of the locations, and the Apfel REMBrandt survey meter was exposed at seven locations. The bubble detectors were either attached to a corner of a phantom or positioned adjacent to a TEPC.

Exposure of the bubble detectors was usually planned to be in the range of 40 to $70 \mathrm{mrem}$ (based on the Snoopy reading) to provide a number of bubbles that could be accurately read by eye.

After the exposures, the bubbles in each of the three detectors were counted and recorded and the detectors recompressed for the next use.

The REMBrandt instrument was placed on the table next to the phantom, and it was allowed to collect data for up to half of the exposure time for each phantom in the room. The shorter exposure times were sufficient for the sensitivity of the instrument, and this method allowed it to make measurements at both phantom locations in the room. After the measurements, the instrument data were downloaded to computer disk using the vendor's software. The data were imported into a spreadsheet, and the total dose equivalent for several hours' exposure was summed in the spreadsheet, then divided by the total count time to get a representative dose equivalent rate. This method ensured that the data were representative of only the time that the instrument was in the measurement position and excluded transport time.

\subsubsection{Measurement Results and Data Analysis}

This section presents the results of measurements performed with the dosimeters on water phantoms.

\subsubsection{Dose Equivalent Rates}

The results of the measurements performed near the phantoms are recorded in Table 5.1. This table lists the dose equivalent rates at each location as determined by the two TEPC detectors (the TEPC results are listed individually), and compares these values with the dose equivalent rates determined by other instruments. The outputs of the TEPC_NG analyses for these measurements are presented in Appendix B. 
Table 5.1. Neutron Dose Equivalent Rates Measured at the Phantoms

\begin{tabular}{|c|c|c|c|c|c|c|c|c|}
\hline Room & Location & $\begin{array}{c}\text { TEPC } \\
(\mathrm{mrem} / \mathrm{h})\end{array}$ & $\begin{array}{c}\text { TEPC } \\
\text { (mrem/h) }\end{array}$ & $\begin{array}{c}\text { Snoopy } \\
\text { (mrem/h) }\end{array}$ & $\begin{array}{c}\text { 8-in } \\
\text { Sphere } \\
(\text { mrem/h) }\end{array}$ & \begin{tabular}{|c} 
Bubble \\
Detectors \\
(avg of 3 ) \\
(mrem/h)
\end{tabular} & $\begin{array}{c}\text { REM- } \\
\text { Brandt } \\
\text { (cal 1) } \\
\text { (mrem/h) }\end{array}$ & $\begin{array}{c}\text { REM- } \\
\text { Brandt } \\
\text { (cal 2) } \\
\text { (mrem/h) }\end{array}$ \\
\hline $235 \mathrm{~A}-3$ & North & 7.27 & 6.45 & 6 & 9.2 & 8.1 & -- & --- \\
\hline $235 \mathrm{~A}-3$ & South & 8.84 & & 7 & 8.9 & 8.7 & --- & ---- \\
\hline Vault 4 & $\begin{array}{l}\text { Between } \\
\text { cabinets }\end{array}$ & 32.5 & 33.4 & 40 & 50.0 & 17.1 & 40.5 & 26.5 \\
\hline Vault 4 & $\begin{array}{l}\text { Back } \\
\text { wall }\end{array}$ & 18.8 & 20.2 & 16 & 26.3 & 10.6 & 15.4 & 10.1 \\
\hline Vault 1 & $\begin{array}{l}\text { Between } \\
\text { cabinets }\end{array}$ & 8.34 & 12.1 & 12 & --- & --- & --- & --- \\
\hline Vault 1 & $\begin{array}{c}\text { Corridor } \\
\text { wall }\end{array}$ & 3.91 & 4.50 & 4 & --- & --- & 6.34 & 4.15 \\
\hline Vault 2 & $\begin{array}{c}\text { Back } \\
\text { cabinet }\end{array}$ & 44.4 & 53.4 & 50 & 59.0 & 34.0 & 54.8 & 35.8 \\
\hline Vault 2 & $\begin{array}{c}\text { Corridor } \\
\text { wall }\end{array}$ & 20.4 & 27.7 & 20 & 24.5 & 30.7 & 21.8 & 14.3 \\
\hline $\begin{array}{l}\text { Vault } \\
\text { Corridor }\end{array}$ & $\begin{array}{c}\text { By } \\
\text { Vault } 3\end{array}$ & 1.26 & 1.19 & 1 & $1.59^{(\mathrm{a})}$ & 0.63 & 1.79 & 1.17 \\
\hline $\begin{array}{c}\text { Vault } \\
\text { Corridor }\end{array}$ & $\begin{array}{c}\text { By } \\
\text { Vault 1 }\end{array}$ & 0.85 & 0.89 & 1 & $1.59^{(\mathrm{a})}$ & 0.46 & 1.4 & 0.92 \\
\hline \multicolumn{9}{|c|}{ (a) The sphere was set in a position halfway between the two phantom locations for the Vault Corridor. } \\
\hline \multicolumn{9}{|c|}{$\begin{array}{l}\text { Notes: } \\
\text { - The value reported for the BTI bubble detectors is the average reading for the three exposed } \\
\text { detectors. For some measurement locations (such as Vault } 2 \text {, by the corridor wall), there was a } \\
\text { wide variation in readings from individual detectors; for other locations the agreement was } \\
\text { excellent. Detailed results for individual detectors are shown in Appendix C. } \\
\text { - For the REMBrandt, two results are shown. "Cal 1" indicates the dose equivalent rate obtained } \\
\text { using the calibration factor, } 133 \text {, supplied by the vendor. "Cal } 2 \text { " indicates the dose equivalent } \\
\text { rate obtained using a calibration factor, } 87 \text {, derived during this study from the LSR irradiations. }\end{array}$} \\
\hline
\end{tabular}

\subsubsection{Sphere Ratios}

The sphere ratios for the seven locations in which they were taken are presented in Table 5.2. 
Table 5.2. Sphere Ratios, Using 8-in and 3-in Sphere Measurements

\begin{tabular}{|c|c|c|}
\hline Room & Location & Ratio, 8” / 3” \\
\hline $235 \mathrm{~A}-3$ & North & 1.14 \\
\hline $235 \mathrm{~A}-3$ & South & 1.03 \\
\hline Vault 4 & Between cabinets & 0.89 \\
\hline Vault 4 & Back wall & 0.71 \\
\hline Vault 2 & Back cabinet & 1.46 \\
\hline Vault 2 & Corridor wall & 1.03 \\
\hline Vault Corridor & Middle of corridor & 0.64 \\
\hline
\end{tabular}

\subsubsection{Dosimeter Results}

Table 5.3 presents a summary of the neutron and gamma (deep) dose equivalent rates measured with the 8816 TLD, 8816 TED, and HSD dosimeters, and compares them with the neutron dose equivalent rates determined by the TEPCs. The neutron dose equivalent results from the 8816 TLD were calculated using the plutonium algorithm developed primarily for use in PFP environs. The neutron dose equivalent results from the 8816 TED were calculated based on a calibration of the CR-39 electrochemical etch process to an unmoderated ${ }^{252} \mathrm{Cf}$ source. The reported results are based on the average result from both CR-39 foils in the 8816 holder. The neutron dose equivalent results from the HSD were calculated based on calibration of the HSD to an unmoderated ${ }^{252} \mathrm{Cf}$ source. The gamma (deep) dose results from the HSD were calculated as would normally be done when neutrons are detected with the HSD. Table 5.3 shows the dosimeter results as an average of three dosimeters exposed on the same phantom face in each location. Detailed dosimeter-by-dosimeter results, including adjusted chip responses, are presented in Appendix D.

The dosimeter results for one set of dosimeters in Vault 2, the one exposed by the wall facing TEPC 504, are marked with an asterisk because one strip of tape failed and the packet became partially unsecured from the phantom sometime during the 18.7-hour exposure. At the time of removal from the vault, this packet was hanging down from the phantom. For the time that it was untaped, it was in approximately the correct position, but had no moderator behind it, so the HCND and HSD neutron doses are certainly too low. The HSD gamma and TED neutron results are also not a correct indication of the dose at the phantom face, but the discrepancies would not be as serious as they would be for the albedo neutron dosimeters. 
Table 5.3. Summary of on-Phantom Dosimeter Responses

\begin{tabular}{|c|c|c|c|c|c|c|c|c|}
\hline Room & Location & $\begin{array}{c}\text { Dosimeter } \\
\text { placement on- } \\
\text { phantom }\end{array}$ & $\begin{array}{c}8816 \text { TLD } \\
\text { neutron } \\
\text { (mrem/h) }\end{array}$ & $\begin{array}{c}8816 \text { TED } \\
\text { neutron } \\
\text { (mrem/h) }\end{array}$ & $\begin{array}{c}\text { HSD } \\
\text { neutron } \\
(\mathrm{mrem} / \mathrm{h})\end{array}$ & $\begin{array}{c}\text { HSD } \\
\text { gamma } \\
(\mathrm{mrem} / \mathrm{h})\end{array}$ & $\begin{array}{c}\text { TEPC } \\
\text { neutron } \\
(\mathrm{mrem} / \mathrm{h})\end{array}$ & $\begin{array}{c}\text { TEPC } \\
\text { neutron } \\
(\mathrm{mrem} / \mathrm{h})\end{array}$ \\
\hline $235 \mathrm{~A}-3$ & North & Facing TEPC 1173 & 3.40 & 1.58 & 24.2 & 3.11 & 7.27 [T1173] & 6.45 [T185] \\
\hline $235 \mathrm{~A}-3$ & North & Facing water wall & 5.34 & 0.49 & 19.9 & 0.70 & 7.27 & 6.45 \\
\hline $235 \mathrm{~A}-3$ & North & Facing TEPC 185 & 5.51 & 0.46 & 21.5 & 1.07 & 7.27 & 6.45 \\
\hline $235 \mathrm{~A}-3$ & North & Facing hood & 6.65 & 3.50 & 29.5 & 4.52 & 7.27 & 6.45 \\
\hline $235 \mathrm{~A}-3$ & South & Facing hood & 7.41 & 3.12 & 35.8 & 2.18 & 8.84 [T1170] & 7.15 [T1172] \\
\hline $235 \mathrm{~A}-3$ & South & Facing TEPC 1170 & 4.16 & 1.18 & 27.6 & 1.26 & 8.84 & 7.15 \\
\hline $235 \mathrm{~A}-3$ & South & Facing wall & 4.17 & 0.53 & 25.1 & 0.55 & 8.84 & 7.15 \\
\hline $235 \mathrm{~A}-3$ & South & Facing TEPC 1172 & 5.65 & 1.09 & 28.0 & 1.21 & 8.84 & 7.15 \\
\hline Vault 1 & Between Cabinets & Facing Cabn 1EE & 17.1 & 2.03 & 94.3 & 1.48 & 8.34 [T1172] & 12.1[T1173] \\
\hline Vault 1 & Between Cabinets & Facing TEPC 1172 & 14.2 & 1.40 & 75.7 & 1.49 & 8.34 & 12.1 \\
\hline Vault 1 & Between Cabinets & Facing Cabn 1FE & 23.3 & 4.60 & 149.0 & 1.90 & 8.34 & 12.1 \\
\hline Vault 1 & Between Cabinets & Facing TEPC 1173 & 19.7 & 1.55 & 92.97 & 1.64 & 8.34 & 12.1 \\
\hline Vault 1 & Corridor Wall & Away from wall & 7.67 & 1.09 & 44.9 & 0.60 & 3.91 [T504] & 4.50 [T1170] \\
\hline Vault 1 & Corridor Wall & Facing TEPC 504 & 5.30 & 0.54 & 38.8 & 0.51 & 3.91 & 4.50 \\
\hline Vault 1 & Corridor Wall & Facing wall & 4.25 & 0.39 & 37.4 & 0.46 & 3.91 & 4.50 \\
\hline Vault 1 & Corridor Wall & Facing TEPC 1170 & 8.49 & 1.31 & 50.2 & 0.61 & 3.91 & 4.50 \\
\hline Vault 2 & Between Cabinets & Facing aisle & 26.4 & 14.4 & 108 & 42.8 & 44.4 [T1172] & 53.4 [T1173] \\
\hline Vault 2 & Between Cabinets & Facing TEPC 1173 & 21.7 & 10.2 & 107 & 54.6 & 44.4 & 53.4 \\
\hline Vault 2 & Between Cabinets & Facing wall cabnt & 23.0 & 11.4 & 95.2 & 59.9 & 44.4 & 53.4 \\
\hline Vault 2 & Between Cabinets & Facing TEPC 1172 & 26.2 & 14.1 & 112 & 50.3 & 44.4 & 53.4 \\
\hline Vault 2 & By wall & Away from wall & 29.2 & 8.65 & 96.0 & 22.3 & $20.4[\mathrm{~T} 504]$ & 27.7 [T1170] \\
\hline Vault 2 & By wall & Facing TEPC 504 & $10.5 *$ & 3.73 & $81.7 *$ & 8.20 & 20.4 & 27.7 \\
\hline Vault 2 & By wall & Facing wall & 18.7 & 2.14 & 90.3 & 6.13 & 20.4 & 27.7 \\
\hline
\end{tabular}


Table 5.3 Summary of on-Phantom Dosimeter Responses

\begin{tabular}{|c|c|c|c|c|c|c|c|c|}
\hline Room & Location & $\begin{array}{c}\text { Dosimeter } \\
\text { placement on- } \\
\text { phantom }\end{array}$ & $\begin{array}{c}\text { 8816 TLD } \\
\text { neutron } \\
\text { (mrem/h) }\end{array}$ & $\begin{array}{c}\text { 8816 TED } \\
\text { neutron } \\
\text { (mrem/h) }\end{array}$ & $\begin{array}{c}\text { HSD } \\
\text { neutron } \\
(\mathrm{mrem} / \mathrm{h})\end{array}$ & $\begin{array}{c}\text { HSD } \\
\text { gamma } \\
(\mathrm{mrem} / \mathrm{h})\end{array}$ & $\begin{array}{c}\text { TEPC } \\
\text { neutron } \\
(\mathrm{mrem} / \mathrm{h})\end{array}$ & $\begin{array}{c}\text { TEPC } \\
\text { neutron } \\
(\mathbf{m r e m} / \mathrm{h})\end{array}$ \\
\hline Vault 2 & By wall & Facing TEPC 1170 & 19.0 & 7.48 & 100 & 18.8 & 20.4 & 27.7 \\
\hline Vault 4 & Between Cabinets & Facing TEPC 1172 & 53.3 & 9.31 & 239 & 13.2 & 32.5 [T1172] & 33.4 [T1173] \\
\hline Vault 4 & Between Cabinets & Facing Cabn 4FE & 43.4 & 7.09 & 232 & 5.71 & 32.5 & 33.4 \\
\hline Vault 4 & Between Cabinets & Facing TEPC 1173 & 50.2 & 7.09 & 193 & 24.6 & 32.5 & 33.4 \\
\hline Vault 4 & Between Cabinets & Facing Cabn 4EE & 63.9 & 14.5 & 258 & 22.8 & 32.5 & 33.4 \\
\hline Vault 4 & Back Wall & Away from wall & 46.9 & 7.12 & 231 & 3.70 & 18.8 [T504] & $20.2[\mathrm{~T} 1170]$ \\
\hline Vault 4 & Back Wall & Facing TEPC 1170 & 30.7 & 3.60 & 162 & 2.54 & 18.8 & 20.2 \\
\hline Vault 4 & Back Wall & Facing wall & 14.4 & 0.82 & 146 & 1.87 & 18.8 & 20.2 \\
\hline Vault 4 & Back Wall & Facing TEPC 504 & 31.1 & 3.01 & 188 & 2.62 & 18.8 & 20.2 \\
\hline Vault Corridr & By Vault 1 & Facing corridor & 1.99 & 0.24 & 19.14 & 0.21 & 0.85 [T1172] & 0.89 [T1173] \\
\hline Vault Corridr & By Vault 1 & Facing TEPC 1172 & 1.38 & 0.18 & 16.9 & 0.22 & 0.85 & 0.89 \\
\hline Vault Corridr & By Vault 1 & Facing TEPC 1173 & 1.11 & 0.21 & 17.3 & 0.23 & 0.85 & 0.89 \\
\hline Vault Corridr & By Vault 1 & Facing wall & 1.93 & 0.10 & 13.9 & 0.21 & 0.85 & 0.89 \\
\hline Vault Corridr & By Vault 3 & Facing corridor & 1.67 & 0.18 & 16.5 & 0.25 & $1.26[\mathrm{~T} 504]$ & $1.19[\mathrm{~T} 1170]$ \\
\hline Vault Corridr & By Vault 3 & Facing TEPC 504 & 2.37 & 0.13 & 18.9 & 0.27 & 1.26 & 1.19 \\
\hline Vault Corridr & By Vault 3 & Facing wall & 1.87 & 0.37 & 26.6 & 0.33 & 1.26 & 1.19 \\
\hline Vault Corridr & By Vault 3 & Facing TEPC 1170 & 1.75 & 0.19 & 19.0 & 0.29 & 1.26 & 1.19 \\
\hline
\end{tabular}


The ratio of TLD response to TEPC measured dose rate ranged from 0.2 to 3.16 for individual 8816 dosimeters, with an average ratio of 1.27. Table 5.4 presents the ratio of the average result for three dosimeters on a given phantom face to the average TEPC dose rate for the phantom location. For 8816 TLDs, the ratio ranged from 0.44 to 2.40 with an average of 1.27.

Table 5.4. Comparison of TEPC Results and Dosimeter Results, Presented for each Phantom Face

\begin{tabular}{|c|c|c|c|c|c|}
\hline Location & \begin{tabular}{|c|} 
Packet \\
No.
\end{tabular} & On-Phantom Placement & $\begin{array}{c}8816 \text { TLD/ } \\
\text { TEPC }\end{array}$ & $\begin{array}{l}8816 \text { TED/ } \\
\text { TEPC }\end{array}$ & $\begin{array}{l}\text { HSD/ } \\
\text { TEPC }\end{array}$ \\
\hline 235A-3 North & 5 & West - facing TEPC 1173 & 0.50 & 0.23 & 3.52 \\
\hline 235A-3 North & 6 & North - facing water wall & 0.78 & 0.07 & 2.90 \\
\hline 235A-3 North & 7 & East - facing TEPC 185 & 0.80 & 0.07 & 3.13 \\
\hline 235A-3 North & 9 & South - Facing hood & 0.97 & 0.51 & 4.30 \\
\hline 235A-3 South & 1 & North - Facing hood & 0.93 & 0.39 & 4.47 \\
\hline 235A-3 South & 2 & East - to TEPC 1170 & 0.52 & 0.15 & 3.46 \\
\hline 235A-3 South & 3 & West - to TEPC 1172 & 0.71 & 0.14 & 3.50 \\
\hline 235A-3 South & 4 & South - Facing wall & 0.52 & 0.07 & 3.14 \\
\hline Vault 1: betw cabinets & 21 & facing cabinet $1 \mathrm{EE}$ & 1.67 & 0.20 & 9.23 \\
\hline Vault 1: betw cabinets & 22 & facing TEPC1172 & 1.39 & 0.14 & 7.41 \\
\hline Vault 1: betw cabinets & 23 & facing cabn $1 \mathrm{FE}$ & 2.28 & 0.45 & 14.59 \\
\hline Vault 1 : betw cabinets & 24 & facing TEPC1173 & 1.93 & 0.15 & 9.10 \\
\hline Vault 1: by corridor wall & 17 & away from wall & 1.82 & 0.26 & 10.68 \\
\hline Vault 1: by corridor wall & 18 & facing TEPC504 & 1.26 & 0.13 & 9.22 \\
\hline Vault 1: by corridor wall & 19 & facing wall & 1.01 & 0.09 & 8.89 \\
\hline Vault 1: by corridor wall & 20 & facing TEPC1170 & 2.02 & 0.31 & 11.93 \\
\hline Vault 2 - Betw Cabinets & 25 & to aisle & 0.54 & 0.30 & 2.22 \\
\hline Vault 2 - Betw Cabinets & 26 & to TEPC 1173 & 0.44 & 0.21 & 2.20 \\
\hline Vault 2 - Betw Cabinets & 27 & to wall cabinet & 0.47 & 0.23 & 1.95 \\
\hline Vault 2 - Betw Cabinets & 28 & to TEPC 1172 & 0.54 & 0.29 & 2.29 \\
\hline Vault 2 - by wall & 29 & away from wall & 1.21 & 0.36 & 3.99 \\
\hline Vault 2 - by wall & $30 *$ & to TEPC 504 & $0.44 *$ & $0.16^{*}$ & $3.40^{*}$ \\
\hline Vault 2 - by wall & 31 & to wall & 0.78 & 0.09 & 3.76 \\
\hline Vault 2 - by wall & 32 & to TEPC 1170 & 0.79 & 0.31 & 4.17 \\
\hline Vault 4 - Back Wall & 8 & Away from wall & 2.40 & 0.37 & 11.83 \\
\hline Vault 4 - Back Wall & 10 & facing TEPC 1170 & 1.58 & 0.18 & 8.28 \\
\hline Vault 4 - Back Wall & 11 & toward wall & 0.74 & 0.04 & 7.51 \\
\hline Vault 4 - Back Wall & 12 & facing TEPC 504 & 1.60 & 0.15 & 9.65 \\
\hline Vault 4 betw cabinets & 13 & facing TEPC1172 & 1.62 & 0.28 & 7.24 \\
\hline Vault 4 betw cabinets & 14 & facing TEPC1173 & 1.52 & 0.22 & 5.87 \\
\hline Vault 4 betw cabinets & 15 & facing $4 \mathrm{FE}$ & 1.32 & 0.22 & 7.05 \\
\hline Vault 4 betw cabinets & 16 & facing 4EE & 1.94 & 0.44 & 7.82 \\
\hline Vault Cor by V1 & 33 & to corridor & 2.28 & 0.28 & 22.00 \\
\hline Vault Cor by V1 & 34 & to TEPC 1172 & 1.58 & 0.20 & 19.44 \\
\hline Vault Cor by V1 & 35 & to TEPC 1173 & 1.27 & 0.24 & 19.90 \\
\hline Vault Cor by V1 & 3 & to wall & 2.21 & 0.11 & 15.97 \\
\hline Vault Cor by V3 & 37 & to corridor & 1.36 & 0.15 & 13.50 \\
\hline Vault Cor by V3 & 38 & to TEPC 504 & 1.94 & 0.11 & 15.39 \\
\hline Vault Cor by V3 & 39 & to wall & 1.52 & 0.30 & 21.71 \\
\hline
\end{tabular}


Table 5.4 Comparison of TEPC Results and Dosimeter Results, Presented for each Phantom Face.

\begin{tabular}{|c|c|c|c|c|c|}
\hline Location & $\begin{array}{c}\text { Packet } \\
\text { No. }\end{array}$ & On-Phantom Placement & $\begin{array}{c}\text { 8816 TLD/ } \\
\text { TEPC }\end{array}$ & $\begin{array}{c}\text { 8816 TED/ } \\
\text { TEPC }\end{array}$ & $\begin{array}{c}\text { HSD/ } \\
\text { TEPC }\end{array}$ \\
\hline & & & & & \\
\hline Vault Cor by V3 & 40 & to TEPC 1170 & 1.43 & 0.16 & 15.54 \\
\hline Minimum & & & & & \\
\hline Maximum & & & 2.44 & 0.04 & 1.95 \\
\hline Mean & & 1.27 & 0.51 & 22.00 \\
\hline
\end{tabular}

The comparisons presented in Table 5.4 are not necessarily a good reflection of how the TLD responds in actual working conditions. It is rare that a worker stands at one location, facing one direction for the entire dosimeter wear period. It is even less likely that the direction the worker faces is consistently away from the "source." A more useful indicator of dosimeter performance in the PFP environments studied can be obtained by comparing the average response of all dosimeters on a phantom with the average TEPC dose rate at the phantom location. The results are presented in Tables 5.5 and 5.6. An even better indicator would have been to rotate each phantom 90 degrees at regular intervals during its exposure cycle such that equal exposure is received in each of the four orientations. This would simulate a randomly oriented worker. Because this was not done, the equivalent result was achieved by taking the average reading for each chip position in the 8816 s on a given phantom. These four composite chip responses were then used as input to the 8816 algorithm to calculate the neutron dose response for a "composite" 8816 TLD at each phantom location. In Table 5.5, the average TEPC result for each phantom location is presented along with the composite 8816 TLD result, the mean 8816 TLD result, the mean 8816 TED result, and the mean HSD result. The standard deviations are also presented to provide an indication of uncertainty in the TLD data. Because only two TEPC results are involved in the average, the standard deviation is not presented for the TEPC mean. However, in most cases the two TEPC readings comprising the TEPC average were in good agreement, indicating that the free field neutron dose gradient was not large and that the use of an average TEPC dose rate was valid. For the phantom location described as "Vault 2 - by wall," the dosimeters from the packet that fell off the phantom (packet 30) were not included in any of the TLD or TED response calculations. 
Table 5.5. Summary of Dosimeter Response, Presented by Phantom Location

\begin{tabular}{|c|c|c|c|c|c|c|c|c|c|c|}
\hline \multirow[b]{2}{*}{ Location } & \multirow{2}{*}{$\begin{array}{c}\text { TEPC } \\
\text { (neutron } \\
\text { mrem/h) }\end{array}$} & \multirow{2}{*}{$\begin{array}{c}\text { 8816 TLD } \\
\text { (neutron } \\
\text { mrem/h) }\end{array}$} & \multicolumn{2}{|c|}{$\begin{array}{c}8816 \text { TLD } \\
\text { (neutron } \mathrm{mrem} / \mathrm{h} \text { ) }\end{array}$} & \multicolumn{2}{|c|}{$\begin{array}{c}8816 \text { TED } \\
\text { (neutron mrem/h) }\end{array}$} & \multicolumn{2}{|c|}{$\begin{array}{c}\text { HSD TLD } \\
\text { (neutron mrem/h) }\end{array}$} & \multicolumn{2}{|c|}{$\begin{array}{c}\text { HSD TLD } \\
\text { (gamma mrem/h) }\end{array}$} \\
\hline & & & Mean & Stdev & Mean & Stdev & Mean & Stdev & Mean & Stdev \\
\hline 235A-3 North & 6.86 & 3.01 & 5.22 & 1.60 & 1.51 & 1.30 & 23.74 & 3.94 & 2.35 & 1.64 \\
\hline 235A-3 South & 8.00 & 2.76 & 5.35 & 2.51 & 1.48 & 1.03 & 29.11 & 4.33 & 1.30 & 0.62 \\
\hline Vault 1: betw cabinets & 10.22 & 18.62 & 18.60 & 4.00 & 2.40 & 1.37 & 103.02 & 29.04 & 1.63 & 0.20 \\
\hline Vault 1: by corridor wall & 4.21 & 6.43 & 6.43 & 2.08 & 0.83 & 0.41 & 42.80 & 5.41 & 0.54 & 0.08 \\
\hline Vault 2 - Betw Cabinets & 48.90 & 24.32 & 24.30 & 6.02 & 12.50 & 2.03 & 105.72 & 8.16 & 51.88 & 7.00 \\
\hline Vault 2 - by wall & 24.05 & 26.10 & 22.29 & 7.63 & 6.09 & 3.06 & 95.57 & 5.61 & 15.72 & 7.38 \\
\hline Vault 4 - Back Wall & 19.50 & 30.76 & 30.77 & 14.20 & 3.64 & 2.41 & 181.68 & 34.10 & 2.68 & 0.69 \\
\hline Vault 4 betw cabinets & 32.95 & 52.70 & 52.70 & 9.53 & 9.50 & 3.23 & 230.53 & 26.42 & 16.58 & 8.09 \\
\hline Vault Cor by V1 & 0.87 & 1.60 & 1.60 & 0.72 & 0.18 & 0.06 & 16.82 & 2.02 & 0.22 & 0.01 \\
\hline Vault Cor by V3 & 1.23 & 1.92 & 1.92 & 0.48 & 0.22 & 0.10 & 20.25 & 4.18 & 0.29 & 0.03 \\
\hline
\end{tabular}


The TLD/TEPC ratios are presented in Table 5.6. The average 8816 TLD/TEPC ratio varies between 0.50 and 1.84 with a mean value of 1.28 for all locations. The composite $8816 \mathrm{TLD} / \mathrm{TEPC}$ ratio varies between 0.34 and 1.84 with a mean value of 1.23 for all locations. As can be seen, the 8816 TED consistently under-responded with an average TED/TEPC ratio of 0.22 and the HSD consistently over-responded with an average TLD/TEPC ratio of 8.57.

Table 5.6. Ratios of Dosimeter Responses to TEPC Dose Rates, Presented by Phantom Location

\begin{tabular}{|c|c|c|c|c|}
\hline Location & $\begin{array}{c}\text { Composite } \\
\text { 8816 TLD / } \\
\text { TEPC }\end{array}$ & $\begin{array}{c}\text { Average 8816 } \\
\text { TLD / TEPC }\end{array}$ & $\begin{array}{c}\text { Average 8816 } \\
\text { TED / TEPC }\end{array}$ & $\begin{array}{c}\text { Average HSD } \\
\text { TLD / TEPC }\end{array}$ \\
\hline 235A-3 North & 0.44 & 0.76 & 0.22 & 3.46 \\
\hline 235A-3 South & 0.34 & 0.67 & 0.18 & 3.64 \\
\hline Vault 1: betw cabinets & 1.82 & 1.82 & 0.23 & 10.08 \\
\hline Vault 1: by corridor wall & 1.53 & 1.53 & 0.20 & 10.18 \\
\hline Vault 2 - Betw Cabinets & 0.50 & 0.50 & 0.26 & 2.16 \\
\hline Vault 2 - by wall & 1.09 & 0.93 & 0.25 & 3.97 \\
\hline Vault 4 - Back Wall & 1.58 & 1.58 & 0.19 & 9.32 \\
\hline Vault 4 betw cabinets & 1.60 & 1.60 & 0.29 & 7.00 \\
\hline Vault Cor by V1 & 1.84 & 1.84 & 0.21 & 19.33 \\
\hline Vault Cor by V3 & 1.56 & 1.56 & 0.18 & 16.53 \\
\hline & & & & \\
\hline Minimum & 0.34 & 0.50 & 0.18 & 2.16 \\
\hline Maximum & 1.84 & 1.84 & 0.29 & 19.33 \\
\hline Mean & 1.23 & 1.28 & 0.22 & 8.57 \\
\hline \multicolumn{4}{|l|}{}
\end{tabular}

One unexpected result that can be observed in Tables D.1 and D.2 for the HCND exposures is the number of occurrences where HCNDs from the same packet produced chip responses that were only moderately different from each other, but were analyzed to give dose equivalents substantially different from each other. As an example, Table 5.7 shows the exposure results for two pairs of HCND dosimeters exposed together on the phantom in the south location of Room 235A-3:

Table 5.7. Chip Readings and Evaluated Doses from Selected HCND Dosimeters

\begin{tabular}{|c|c|c|c|c|c|c|}
\hline \multirow[b]{2}{*}{ Packet } & \multirow[b]{2}{*}{$\begin{array}{c}\text { Dosimeter } \\
\text { Card } \\
\text { ID }\end{array}$} & \multicolumn{4}{|c|}{ Adjusted chip readings } & \multirow[b]{2}{*}{$\begin{array}{c}\text { Neutron } \\
\text { Dose Eq, } \\
\text { mrem }\end{array}$} \\
\hline & & Chip 1 & Chip 2 & Chip 3 & Chip 4 & \\
\hline 1 & 4051048 & 27.29 & 573.98 & 348.77 & 658.69 & 79.17 \\
\hline 1 & 4007608 & 34.94 & 614.47 & 349.69 & 738.75 & 177.78 \\
\hline 3 & 4050749 & 2307 & 40699 & 25681 & 52475 & 8328 \\
\hline 3 & 4007288 & 20.55 & 420.43 & 271.59 & 529.44 & 156.17 \\
\hline
\end{tabular}


In packet 1, the two dosimeters were exposed side-by-side on the same side of a phantom, and the variation in similar chip readings from one dosimeter to the next shows the minor discrepancies that would be expected in an actual field measurement. The Chip 2 responses are 7\% different from each other, the Chip 3 responses are nearly identical, and the Chip 4 responses are $12 \%$ different from each other. However, the evaluated doses do not agree well - one value is 2.2 times larger than the other. They were both analyzed with algorithm branch 112 .

In packet 3, the two dosimeters again exhibited similar chip responses, with the Chip 3 pairs showing only a $5.8 \%$ disagreement. However, the algorithm chose two different branches: card 4050749 was analyzed using branch 112, and card 4007288 was analyzed using branch 111, producing an evaluated dose that is 1.9 times higher than its similarly exposed dosimeter.

There were only three packets (out of 40 exposed) where two different algorithm branches were employed, so in most cases the discrimination between algorithm branches was good. There were at least 10 packets, however, where a factor of two difference could be observed in dosimeter pairs with similar chip responses, similar to the packet 1 example in Table 5.7. 


\subsection{Extremity Measurements}

This set of measurements was made to validate the assessment of neutron doses to extremities during glovebox operations. Neutron dose equivalent rates were measured inside the fingers of a glove exposed to plutonium sources, and extremity dosimeters (finger rings) were also exposed inside these gloves. The gamma dose rates recorded by the finger rings can be compared with neutron dose equivalent rates, and used to determine neutron-to-gamma ratios. The measurements were performed under controlled experimental conditions to ensure that the results can be applied to a variety of workplace conditions.

\subsubsection{Sources}

Six different cans containing plutonium sources were used for these measurements. They were chosen to be representative of the sources that produce significant neutron extremity exposures to Hanford workers. The six sources were all encased in multiple nesting cans (either three or four cans per source), with the outer can measuring 7 in. $(17.8 \mathrm{~cm})$ high and 4.125 in. $(10.5 \mathrm{~cm})$ in diameter. The six sources can be generally characterized as follows:

- " $6 \%$ oxide," plutonium oxide source with approximately $6 \%{ }^{240} \mathrm{Pu}$

- “ $12 \%$ oxide," plutonium oxide source with approximately $12 \%{ }^{240} \mathrm{Pu}$

- “20\% oxide," plutonium oxide source with approximately $20 \%{ }^{240} \mathrm{Pu}$

- "Metal," plutonium metal with approximately $17 \%{ }^{240} \mathrm{Pu}$

- "Oxide with $\mathrm{Pb}$ shield," plutonium oxide with approximately $17 \%{ }^{240} \mathrm{Pu}$, packaged in a container with a .125 -in. thick lead shield,

- "Oxide with $\mathrm{Pb}$ foil," plutonium oxide with approximately $17 \%{ }^{240} \mathrm{Pu}$ and isotopic ratios identical to the " $17 \%$ oxide with $\mathrm{Pb}$ ", but packaged in a container with a thin lead foil shield (about .02-in. lead).

The characteristics of each source are given in Table 5.8. Isotopic compositions are decayed from the assay dates to September 1999.

Table 5.8. Characteristics of Measured Source Cans

\begin{tabular}{|c|c|c|c|c|c|c|c|}
\hline & Sample mass & \multicolumn{5}{|c|}{ Percentage isotopic composition (by weight) } \\
\cline { 3 - 8 } Source & $\mathbf{( g ~ P u )}$ & ${ }^{238} \mathbf{P u}$ & ${ }^{239} \mathbf{P u}$ & ${ }^{240} \mathbf{P u}$ & ${ }^{241} \mathbf{P u}$ & ${ }^{242} \mathbf{P u}$ & ${ }^{241} \mathbf{A m}$ \\
\hline $6 \%$ oxide & 602 & 0.28 & 93.083 & 5.928 & 0.37 & 0.03 & 0.31 \\
\hline $12 \%$ oxide & 559 & 0.044 & 86.540 & 11.621 & 0.42 & 0.20 & 1.17 \\
\hline 20 oxide & 642 & .35 & 74.134 & 20.105 & 1.39 & .996 & 3.02 \\
\hline Metal & 2181 & .0553 & 81.907 & 16.974 & .657 & .407 & 2.181 \\
\hline Oxide with $\mathrm{Pb}$ shield & 658 & 0.640 & 73.914 & 15.506 & 2.11 & 1.52 & 6.31 \\
\hline Oxide with Pb foil & 618 & 0.638 & 73.890 & 15.763 & 2.14 & 1.303 & 6.26 \\
\hline
\end{tabular}




\subsubsection{Equipment Setup and Data Collection}

The measurement equipment was set up on a table in Room 637 of 2736ZB in the PFP complex. The table is approximately $135 \mathrm{~cm}$ above the floor.

A rack was constructed to hold the extremity measurement instruments, as shown in Figure 5.6. The instrument rack was designed to hold a portion of a lead-lined glove, identical to those used in gloveboxes at PFP. The glove was supplied by North Safety Products (product \#8YLY3032). The glove is made of 30-mil-thick neoprene, and the lead layer provides attenuation equivalent to a 0.1 -mm-thick sheet of lead.

The glove was oriented on the rack with the fingers pointed down and instruments were inserted in the four glove fingers. The rack provided adjustments to position the glove at any desired position above the surface.

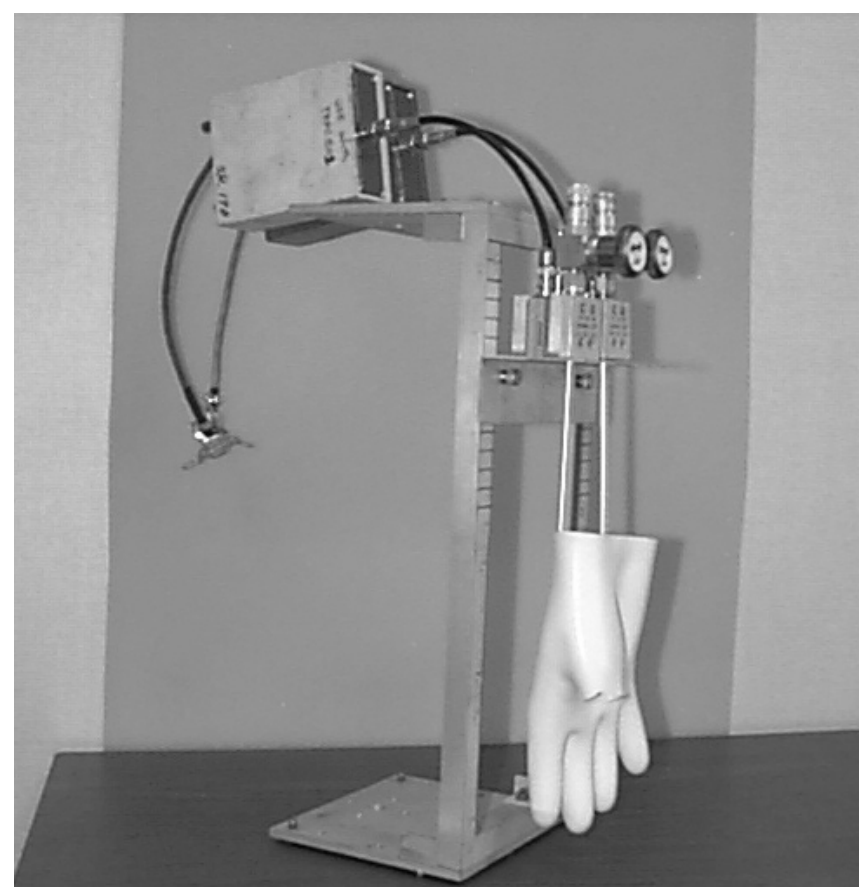

Figure 5.6. Instrument Rack for Extremity Measurements

Inserting instruments inside the glove fingers ensured that the measurements would be typical of exposures received by extremities of workers at PFP gloveboxes. In each of the four fingers, extremity dosimeters were wrapped around the cylindrical neutron detectors (either TEPCs or bubble detectors). The dosimeters were oriented with the sensitive chips facing the radiation source, so they would record the same gamma dose that would be received by an operator handling the same source. The neutron detectors were sensitive to neutrons in a region that would be typical of the volume occupied by the operator's finger. Thus the comparison of dosimeter responses with neutron detector responses will be an excellent analog to the reading of an operator's extremity dosimeter compared with the neutron dose received by the finger wearing the dosimeter. Five 
extremity dosimeters were placed in each finger to maximize the counting statistics.

For each measurement, the rack was positioned on the table, so that the glove fingers were approximately 15 to $20 \mathrm{~cm}$ from the surface of the source can. Half-inch TEPC detectors were positioned in the index and ring fingers of the glove (as shown in Figure 5.6). Five extremity dosimeters were wrapped around the barrel of each TEPC before they were inserted into the glove fingers. A cable extended from each detector to a preamplifier on top of the rack, and a cable bundle led from the preamplifier to the NIM electronics rack, containing the high voltage supplies, amplifiers, and ADCs. Signals from the ADC were transmitted to the MCA for data collection. For each measurement, data collection was initiated in the MCA after the source can was positioned in front of the glove, and the time for start of exposure of the dosimeters was recorded.

Bubble detectors were exposed in the middle and little fingers of the glove. Five extremity dosimeters were wrapped around a spacer tube, which was then placed on a bubble detector. At the beginning of each count, the piston of the bubble detector was removed to activate the detector; it was then inserted into a glove finger, and the time for start of the exposure was recorded for each.

A vertical wooden rod with five dosimeters wrapped around it was positioned next to the little finger of the glove, at the same distance from the can surface as the finger. This set of dosimeters provided the opportunity for a comparison with the dosimeters in the little finger to show the effectiveness of the leaded glove at shielding gamma radiation.

A 5-in. TEPC detector was positioned on the table next to the rack, at a distance of 30.5 $\mathrm{cm}$ from the source can (measured from can centerline to detector centerline). This detector collected data for the entire exposure time. A Snoopy neutron survey instrument was also positioned $30.5 \mathrm{~cm}$ from the can (centerline-to-centerline) to measure the neutron dose equivalent rate, and a CP survey instrument was positioned by the glove fingertips to measure the gamma dose rate near this position.

Exposures were at least 20 hours per source can (some exposures were as long as 3 days), because the small TEPC detectors are not sensitive instruments, and the extremity dosimeter responses also benefited from long exposures. At the completion of the exposure, the source can was removed from the table, and end-of-exposure times were recorded for the bubble detectors and extremity dosimeters. The detectors were removed from the glove fingers to allow changeout of the dosimeters.

Data collection for each TEPC was terminated when the source can was removed, and the MCA spectra were recorded onto computer disk. The TEPCs were then positioned to activate the internal alpha calibration sources, which were used to determine the proton drop point. MCA spectra with the alpha sources activated were collected for 5 to 10 minutes, and the spectra were then stored on computer disk.

\subsubsection{Measurement Results and Data Analysis}

This section presents the results of the extremity measurements. 


\subsubsection{Neutron Dose Equivalent Rates}

The computer code TEPC_NG was used to analyze the MCA spectra collected from the TEPC detectors. For the $1 / 2$-in. detectors, the results of calibration measurements with the internal alpha source were used to find the proton drop point, because collected neutron counts were generally too low to provide a well-defined proton drop point in the spectrum collected on the MCA. For TEPC measurements that did not provide a welldeveloped proton drop point, it was set to 1.05 times the peak channel for the alpha measurement, matching the ratio found in LSR calibration measurements.

TEPC 1074 exhibited an unexpected non-zero count rate from its alpha source. Apparently, when used in the vertical position, the alpha shutter was open slightly, allowing a few alphas to sneak into the sensitive volume of the detector. However, this additional alpha-generated background was mathematically corrected. The area under the unintentional alpha peak was determined above the "background" of the neutron spectrum. An idealized peak with this area was subtracted from the collected spectral data, channel by channel, leaving an adjusted spectrum. This adjusted spectrum could then be analyzed by TEPC_NG to determine the neutron dose equivalent rate. A comparison of the alpha-adjusted TEPC analyses for TEPC 1074 to the results for TEPC 1122 , exposed during the same measurement, showed similar results for the two detectors. Thus this alpha adjustment was able to provide a reliable TEPC analysis, but with a greater uncertainty than the measurement for TEPC 1122 .

The exposed bubble detectors were read out in the automated counting system. Although the LSR tests of the bubble detector showed better performance when the bubbles were counted by eye rather than by machine, the long exposures in the extremity study produced so many bubbles that they could not be counted by eye.

Table 5.9 presents the measured neutron dose equivalent rates for the extremity study. Appendix E contains detailed outputs from the TEPC_NG runs that were used to analyze the TEPC results. Appendix $\mathrm{C}$ contains detailed information on bubble dosimeter counts. 
Table 5.9 Neutron Dose Equivalent Rates, Extremity Measurements

\begin{tabular}{|c|c|c|c|c|c|c|}
\hline \multirow[b]{2}{*}{ Source Can } & \multicolumn{6}{|c|}{ Measured Neutron Dose Equivalent Rate (mrem/h) } \\
\hline & $\begin{array}{c}\text { Snoopy } \\
30.5 \mathrm{~cm} \text { dist. }\end{array}$ & $\begin{array}{c}\text { 5-in TEPC } \\
30.5 \mathrm{~cm} \text { dist. }\end{array}$ & $\begin{array}{c}\text { TEPC } 1074 \\
\text { Index Finger }\end{array}$ & $\begin{array}{l}\text { Bubble Det'r } \\
\text { Middle Finger }\end{array}$ & $\begin{array}{l}\text { TEPC } 1122 \\
\text { Ring Finger }\end{array}$ & $\begin{array}{l}\text { Bubble Det'r } \\
\text { Little Finger }\end{array}$ \\
\hline $6 \%$ Oxide & 5 & --- & 13.1 & 5.52 & 10.6 & 5.41 \\
\hline $12 \%$ Oxide & 1.8 & 2.55 & 5.72 & 2.63 & 5.34 & 1.97 \\
\hline $20 \%$ Oxide & 4 & 6.32 & 11.2 & 8.15 & 10.9 & 7.14 \\
\hline Metal & 7 & 8.50 & 15.3 & $7.65^{*}$ & 14.7 & $8.30 *$ \\
\hline 17\% Oxide with $\mathrm{Pb}$ Foil & --- & 3.93 & 8.82 & 5.1 & 8.93 & 5.0 \\
\hline $\begin{array}{l}17 \% \text { Oxide with } \mathrm{Pb} \\
\text { Shield }\end{array}$ & 1.1 & 1.07 & 3.25 & 1.99 & 2.69 & 2.08 \\
\hline
\end{tabular}




\subsubsection{Extremity Dosimeter Results}

The extremity dosimeters were read out to determine the gamma dose to each finger inside the leaded glove. The results are presented in Table 5.10. Detailed dosimeter results are presented in Appendix F.

Table 5.10. Gamma Dose Rates Derived From Extremity Dosimeter Exposures

\begin{tabular}{|c|c|c|c|}
\hline Source Can & Glove Finger & $\begin{array}{c}\text { Gamma } \\
\text { dose rate }(\mathrm{mrem} / \mathrm{h})\end{array}$ & $\begin{array}{c}\text { Standard deviation } \\
(\mathrm{mrem} / \mathrm{h})\end{array}$ \\
\hline $6 \%$ Oxide & Index & 33.3 & 3.9 \\
\hline $6 \%$ Oxide & Middle & 40.7 & 2.0 \\
\hline $6 \%$ Oxide & Ring & 32.8 & 2.4 \\
\hline $6 \%$ Oxide & Little & 34.5 & 4.2 \\
\hline \multirow[t]{2}{*}{$6 \%$ Oxide } & None & $5.4^{*}$ & 0.7 \\
\hline & & \multicolumn{2}{|c|}{ * Dosimeters moved away from glove during exposu } \\
\hline $12 \%$ Oxide & Index & 36.8 & 5.2 \\
\hline $12 \%$ Oxide & Middle & 44.2 & 7.0 \\
\hline $12 \%$ Oxide & Ring & 45.1 & 4.9 \\
\hline $12 \%$ Oxide & Little & 43.6 & 12.3 \\
\hline $12 \%$ Oxide & None & 75.1 & 8.3 \\
\hline $20 \%$ Oxide & Index & 118 & 14 \\
\hline 20\% Oxide & Middle & 136 & 18 \\
\hline $20 \%$ Oxide & Ring & 128 & 19 \\
\hline $20 \%$ Oxide & Little & 134 & 5 \\
\hline $20 \%$ Oxide & None & (no measurement) & (no measurement) \\
\hline Metal & Index & 31.6 & 4.0 \\
\hline Metal & Middle & 35.3 & 4.5 \\
\hline Metal & Ring & 32.1 & 4.0 \\
\hline Metal & Little & 36.7 & 6.1 \\
\hline Metal & None & 53.7 & 4.1 \\
\hline $17 \%$ Oxide with $\mathrm{Pb}$ Foil & Index & 33.4 & 1.9 \\
\hline $17 \%$ Oxide with $\mathrm{Pb}$ Foil & Middle & 36.3 & 8.7 \\
\hline 17\% Oxide with $\mathrm{Pb}$ Foil & Ring & 37.6 & 2.7 \\
\hline 17\% Oxide with $\mathrm{Pb}$ Foil & Little & 36.5 & 5.0 \\
\hline $17 \%$ Oxide with $\mathrm{Pb}$ Foil & None & 54.4 & 2.4 \\
\hline $17 \%$ Oxide with $\mathrm{Pb}$ & Index & 4.99 & 0.49 \\
\hline $17 \%$ Oxide with $\mathrm{Pb}$ & Middle & 6.27 & 0.53 \\
\hline $17 \%$ Oxide with $\mathrm{Pb}$ & Ring & 6.12 & 0.41 \\
\hline $17 \%$ Oxide with $\mathrm{Pb}$ & Little & 5.80 & 0.31 \\
\hline $17 \%$ Oxide with $\mathrm{Pb}$ & None & 3.56 & 0.25 \\
\hline
\end{tabular}

\subsubsection{Neutron-to-Gamma Ratios for Extremity Doses}

The data in Tables 5.9 and 5.10 were combined to determine neutron/gamma ratios. The ratio was determined for each glove finger and for each source can individually, and the results were presented in Table 5.11. The table includes separate columns for TEPC 
measurements and for bubble detector measurements. (An entry of "NM" indicates no measurement.)

Table 5.11. Neutron/Gamma Ratios Inside A Leaded Glove

\begin{tabular}{|c|c|c|c|}
\hline Source Can & Glove Finger & $\begin{array}{c}\text { TEPC } \\
\text { Neutron/Gamma } \\
\text { Ratio }\end{array}$ & $\begin{array}{c}\text { Bubble Detector } \\
\text { Neutron/Gamma } \\
\text { Ratio }\end{array}$ \\
\hline $6 \%$ Oxide & Index & 0.394 & NM(a) \\
\hline $6 \%$ Oxide & Middle & NM & 0.136 \\
\hline $6 \%$ Oxide & Ring & 0.324 & NM \\
\hline $6 \%$ Oxide & Little & NM & 0.157 \\
\hline $6 \%$ Oxide & Can Average & 0.36 & 0.15 \\
\hline $12 \%$ Oxide & Index & 0.155 & NM \\
\hline $12 \%$ Oxide & Middle & NM & 0.060 \\
\hline $12 \%$ Oxide & Ring & 0.118 & NM \\
\hline $12 \%$ Oxide & Little & NM & 0.045 \\
\hline $12 \%$ Oxide & Can Average & 0.14 & 0.052 \\
\hline $20 \%$ Oxide & Index & 0.095 & NM \\
\hline $20 \%$ Oxide & Middle & NM & 0.060 \\
\hline $20 \%$ Oxide & Ring & 0.085 & NM \\
\hline $20 \%$ Oxide & Little & NM & 0.053 \\
\hline $20 \%$ Oxide & Can Average & 0.090 & 0.057 \\
\hline Metal & Index & 0.484 & NM \\
\hline Metal & Middle & NM & 0.217 \\
\hline Metal & Ring & 0.458 & NM \\
\hline Metal & Little & NM & 0.226 \\
\hline Metal & Can Average & 0.47 & 0.22 \\
\hline $17 \%$ Oxide with $\mathrm{Pb}$ Foil & Index & 0.264 & NM \\
\hline $17 \%$ Oxide with $\mathrm{Pb}$ Foil & Middle & NM & 0.141 \\
\hline $17 \%$ Oxide with $\mathrm{Pb}$ Foil & Ring & 0.238 & NM \\
\hline $17 \%$ Oxide with $\mathrm{Pb}$ Foil & Little & NM & 0.137 \\
\hline $17 \%$ Oxide with $\mathrm{Pb}$ Foil & Can Average & 0.25 & 0.14 \\
\hline $17 \%$ Oxide with $\mathrm{Pb}$ & Index & 0.652 & NM \\
\hline $17 \%$ Oxide with $\mathrm{Pb}$ & Middle & NM & 0.318 \\
\hline $17 \%$ Oxide with $\mathrm{Pb}$ & Ring & 0.440 & NM \\
\hline $17 \%$ Oxide with $\mathrm{Pb}$ & Little & NM & 0.358 \\
\hline 17\% Oxide with $\mathrm{Pb}$ & Can Average & 0.55 & 0.34 \\
\hline
\end{tabular}




\subsection{CONCLUSIONS AND RECOMMENDATIONS}

The study derived conclusions about neutron dose equivalent rates; neutron energies; the performance of dosimeters, REMBrandt and bubble detectors; and extremity neutron-togamma ratios, as discussed below.

\subsection{Neutron Dose Equivalent Rates}

The TEPC detectors were the primary instruments used by this study for determining neutron dose equivalent rates. Because the TEPC has a TE response to neutrons, the assessment of neutron dose equivalent is not affected by the neutron energy spectrum; it will be just as valid for a well-moderated spectrum as it is for an unmoderated ${ }^{252} \mathrm{Cf}$ source in a calibration facility. Thus, the 5 -in. detectors used in the whole body study provided a good indication of the neutron dose equivalent rate that a person would be exposed to when standing in that position. The $1 / 2$-in. detectors used in the extremity measurements provided a good indication of the neutron dose rate that would be received by an operator's finger when working in a glovebox.

The TEPCs used in this study were exposed in the 318 Building Calibration Laboratory LSR to check their performance and verify that they can accurately measure neutron dose equivalents. Table 4.1 showed that the 5 -in. detectors used in the workplace measurements, when exposed to the more intense source, gave dose equivalent rates that ranged from $3.6 \%$ lower to $10.3 \%$ higher than the accepted rate for the unmoderated ${ }^{252} \mathrm{Cf}$ source, ignoring the contribution of effects such as room scatter and source anisotropy. These percentage differences should be adjusted downward by approximately $5 \%$ to reflect the influence of these secondary effects. For detectors exposed to the less intense source, the disagreement with the accepted value was as much as $16.6 \%$. These results indicate that the TEPCs will determine dose equivalent rates that are typically within $20 \%$ of the accepted values. When these detectors were used in the workplace measurements, on either sides of a phantom, the agreement between the two detectors was excellent.

Table 4.2 shows that the two $1 / 2$-in. TEPCs used in the study also gave dose equivalent rates very close to the accepted value for exposure to an unmoderated ${ }^{252} \mathrm{Cf}$ source. For high count rates, the results were within $5 \%$ of the accepted value; for exposures in the range of a few hundred mrem, similar to the exposures they received in the extremity study, they gave results within $20 \%$ of the accepted value. In the extremity measurements in $2736 \mathrm{ZB}$, TEPCs exposed to the same source gave similar results. For two source cans, the agreement between detectors was about $24 \%$; for the other four cans it was $7 \%$ or less.

For the workplace measurements, under ideal counting conditions the results of 5-in. TEPC measurements are usually accurate to within $7 \%$. The uncertainty of a measurement would be larger than that if the detector recorded a small number of neutron events, as happened with the $1 / 2$-inch detectors used in the extremity measurements. 
When all measurement uncertainties are considered, it is reasonable to assign an overall uncertainty of $\pm 20 \%$ to the workplace dose equivalent measurements.

One of the concerns about a set of measurements such as this is the possibility of the variation of radiation field with time during the measurements. The measurements were long, ranging from a few hours to a few days. Other activities were occurring during the measurements, and it is possible that a source was moved during an exposure, modifying the dose rates at that point. This was a particular concern during the extremity measurements, when the counting lasted for several days. It is possible that another can, which was an intense source of neutrons or gammas, may have been moved close to the measurement table, disrupting either the neutron count rate or the gamma dosimeter exposure. A 5-in. TEPC was positioned near the glove, but further from the source can than the glove fingers. This detector would have indicated if a significant fraction of the neutron counts were originating from behind the glove, as may occur if another source were used nearby. Because this behavior was never seen, we can be reasonably certain that no gross sources of interference were present. It does not guarantee that the neutron and gamma fields were uniform, however.

\subsection{Neutron Energies}

True neutron spectrometry was not performed in this study. An indication of neutron energies in the measurement locations could be obtained from the 8-in.-to-3-in. sphere ratios. The measurements described by Endres et al. (1996) showed that sphere ratios increased as neutron energies increased, because higher energy neutrons are more effective than lower energy neutrons at penetrating through the thick layer of plastic in the 8 -in. sphere to reach the detector at the center of the sphere, while in the 3 -in. sphere higher energy neutrons become less effective at producing counts because the smaller amount of moderation produced fewer neutrons with thermal energies that would interact with the detector. The study found that the sphere ratio can range from 3.0 or higher for an unmoderated fission spectrum to 0.5 or lower for a well-moderated spectrum.

The measurements recorded in Section 4.2 confirmed that a sphere ratio of 3.0 is typical of a fission spectrum with little or no scatter. This ratio was seen in the LSR measurements using the unmoderated ${ }^{252} \mathrm{Cf}$ source. No measurements in PFP gave ratios nearly this high, which is understandable because there was some concrete in the vicinity of all measurements made in this study.

In Room 235A-3 the two sphere measurement ratios were similar to each other, 1.14 and 1.03. These ratios indicate some neutron moderation and some unscattered neutrons were present.

Neutron energies were highest in Vault 2, as indicated by sphere ratios. The location by the back cabinet had a ratio of 1.46 , the highest seen in a work location in this study. The Vault 2 location by the corridor wall had a ratio of 1.03 , indicating a spectrum similar to 
that in Room 235A-3, with a greater contribution from low-energy neutrons than observed at the position near the cabinets.

The neutron energies in Vault 4 were lower than those in Vault 2. The ratio between the cabinets was 0.89 , which shows a substantially lower energy distribution than both measurement locations in Vault 2. The location in Vault 4 near the wall had a ratio of 0.71 , showing a large component of moderated neutrons.

The lowest neutron energies were seen in the Vault Corridor, with a ratio of 0.64 . Any neutrons in the corridor must pass through concrete walls, and while this will not necessarily provide a completely moderated spectrum, it resulted in lower neutron energies than those seen elsewhere.

In summary, measurements indicated that neutron energies in the workplace locations selected for evaluation were significantly moderated, indicative of the scattering that occurs in the extensive shielding used throughout PFP work areas. These neutron energies are important to the dosimeter and instrument response characteristics. Notably, these radiation fields have a substantial number of neutrons with energies below the response threshold for the TED. The TLD responds easily to these neutron energies but accurate calibration and dose interpretation can be difficult.

\subsection{Bubble Detector Performance}

The exposures of the bubble detectors in the LSR, as reported in Table 4.4, showed that the bubble detectors could typically give results within $30 \%$ of the accepted value when at least 35 bubbles were collected. For detectors with less than 50 bubbles, reading the detectors by eye gave more accurate results than automated reading of the detectors. This discrepancy may be an indication that the settings for the image recognition software were not optimized; this optimization was not attempted in this study.

For exposures in the whole body study, the performance of the bubble detectors was not quite as good, as is shown in Table 5.1 and in Appendix C. The bubble detectors sometimes read higher, sometimes lower, than the TEPCs, but there was often poor agreement between the three bubble detectors as shown in Appendix C. Part of the reason for the poor agreement among the bubble detectors was poor counting statistics: the highest number of bubbles recorded for the whole body measurements was 52, which would have an associated uncertainty of $14 \%$ from counting statistics. Many of the bubble detector readings had less than 20 bubbles, which would have a counting statistics uncertainty of $22 \%$.

Another possible cause of poor agreement between the bubble detectors and the TEPC was the placement of these detectors around the phantom - often they were positioned on three corners of the phantom and may have seen different neutron intensities. 
When the bubble detectors were exposed inside the leaded glove in the extremity study, there was usually good agreement between the two bubble detectors (the counting statistics were better than in the whole body measurement, and there was no shielding from phantoms), but the bubble detectors consistently gave lower dose equivalent rates than the TEPCs.

This study's observations about the performance of the bubble detectors should be considered as preliminary with respect to their possible use at Hanford. Further study should be conducted, especially with hands-on experience by the PFP Radiological Control staff, before a decision is made. Optimization of automated counting equipment should be investigated as the technology is investigated. One unique feature of this measurement system is the method of counting bubbles. Counting by eye is convenient, because it does not require the use of bulky equipment, and it can be done accurately by a person with some experience. However, counting bubbles is an individual skill, and it is quite likely that several people counting the same detector would get different results.

One operational concern is the requirement to select the dosimeter model with a sensitivity appropriate for the expected range of neutron doses.

Bubble dosimetry is still a promising technology for use as supplemental neutron dosimetry for Hanford, and further investigation would be valuable.

\subsection{REMBrandt Performance}

Table 4.5 shows that the REMBrandt survey meter over-responded by about $53 \%$ in the LSR when exposed to neutrons from an unmoderated ${ }^{252} \mathrm{Cf}$ source. The vendor indicated that this over-response was caused by his previous calibration, which was to an $\mathrm{AmBe}$ source with higher neutron energies than ${ }^{252} \mathrm{Cf}$. However, even with updated calibration factors from the vendor, there was an over-response. It should be possible, however, to derive calibration factors for Hanford using LSR exposures, so this study derived a new calibration factor of 87, rather than the vendor's original value of 133 . Both calibration factors were used in the field measurements.

Table 5.1 shows that, using the original calibration factor of 133, the REMBrandt has responses similar to the Snoopy. Using the calibration factor of 87, the REMBrandt under-responded for high dose rates (greater than $10 \mathrm{mrem} / \mathrm{h}$ ), and was very close to the TEPC measurements for low dose rates (less than $5 \mathrm{mrem} / \mathrm{h}$ ).

This study indicates that the REMBrandt warrants additional testing for suitability of use in Hanford environments. Its lightweight could be a major advantage over moderatorbased survey instruments. There are probably ergonomic issues and operational issues with this new design, but the instrument is in its early stages of development and the vendor is willing to work on the system's design. 


\subsection{Dosimeter Performance}

\subsubsection{Whole Body Dosimeter Performance}

In this study, the TEPC was used as the instrument that determined the reference neutron dose equivalent rate for comparison with the dosimeter response. The TEPC is well suited for this role, because its response is TE and it can determine reliable results independent of the neutron energy field. Comparing the TEPC results with dosimeter results has a limitation, however, due to the presence of the phantom used for dosimeter irradiation and the consequent disruption of the neutron radiation field. The TEPC detects neutrons as a free-in-air volume with no shield or moderator to disrupt the neutron field. Under parallel beam geometry this approximates the maximum dose equivalent in a phantom. Albedo dosimeters, on the other hand, must be exposed on-phantom, and the bulk of the phantom will disrupt the neutron field. For a broad parallel beam this disruption should make no difference, but in a multi-directional radiation, such as an isotropic neutron field, the phantom will shield neutrons incident on its "back" side from reaching the dosimeter, and thus will produce a response that cannot be easily compared with a TEPC response in the same field. These multi-directional fields are probably more common in the workplace than broad parallel beams.

The HCND performed well for evaluating neutron dose equivalent. For the dosimeters exposed on-phantom, there was usually good agreement among the three dosimeters exposed on each face of a phantom, but there were a number of instances when dosimeters in the same packet produced results that did not agree with each other as well as should be expected. It looked like the disagreements could be traced to the plutonium algorithm used for converting chip responses to dose equivalent. In many cases there was poor agreement between the dosimeters exposed on one face of a phantom compared with those exposed on another face of the phantom in the same location. This face-toface disagreement was an indication of the directionality of the beam. The dosimeter element ratios, and thus the algorithm response of the 8816 , are confounded when a significant fraction of the neutron fluence passes through the phantom from the backside. Because workers are not likely to be facing away from the source all of the time, the errors introduced by this feature of the algorithm are likely to be less than the worst errors seen in the present study where some of the packets were facing away from the radiation source all the time.

Overall, the 8816 neutron TLDs showed a combined positive bias of 1.3 , based on a comparison of 8816 TLD and TEPC dose equivalent rate. The ratio of the average TLD response for each phantom to the average TEPC dose equivalent rate at the phantom location ranged from 0.5 to 1.8 with a mean value of 1.3 . However, for individual dosimeters, some dose results were under-reported by a factor of 5 . It should be noted that dose equivalent, such as that measured by a TEPC, can overestimate effective dose equivalent by as much as a factor of two (DOE 1998). The effective dose equivalent is the basis for the risk-based system of limits promulgated in 10CFR835. 
The 8816 TED component did much better than the TLD in terms of precision for neutrons. The TED component of this dosimeter consistently underestimated the neutron dose, however. This bias is expected in highly scattered neutron fields, resulting in substantially degraded neutron energy spectra, and because of the angular response characteristics associated with the TED thin rectangular foil. The TED bias would be expected to be relatively small for higher energy neutrons (greater than the response threshold of about $100 \mathrm{keV}$ ) because of its relatively flat energy response, and for exposure conditions that are predominantly anterior-posterior.

The HSD was always high, in some cases by as much as a factor of 18 , compared with the TEPC for measuring neutron dose equivalent. Since this is a single element dosimeter there is no option but to use a single calibration factor. It may be possible to choose a single factor on the basis of these measurements which would produce negligible bias overall but the variability would be substantially larger than that seen for the 8816 TLD or TED.

The 8816 plutonium algorithm was developed by comparing the responses of TLDs and TEPCs in directional radiation fields created with point sources. Under these conditions, which are closer to a parallel beam geometry, the TEPC and TLD both "see" the same fluence. An algorithm developed under these conditions will inherently under-respond relative to the TEPC when TLD response on-phantom is compared with TEPC under isotropic field conditions. The 8816 plutonium algorithm appears to require some adjustment to correct cases of under-reported dose.

\subsubsection{Extremity Dosimeter Performance}

Internal agreement among each batch of similarly exposed dosimeters was excellent. Twelve of the batches of five similarly exposed dosimeters had standard deviations smaller than $10 \%$ of the mean value; 15 had standard deviations between 10 and $20 \%$, and two had standard deviations between 20 and 30\%. Thus it is reasonable to assume that the measured gamma dose rates show good repeatability.

\subsection{Extremity Neutron to Gamma Ratios}

Measuring neutron doses to extremities is a very challenging task, and it is not routinely attempted directly. For situations where workers' extremities are exposed to both gamma and neutron radiation, the total extremity dose is typically evaluated by measuring only the gamma dose (typically with a gamma extremity dosimeter) and applying a correction factor, the neutron-to-gamma ratio, to the gamma dose to arrive at the total extremity dose. This study measured neutron-to-gamma ratios for six representative cans of plutonium, providing PFP staff with a sound technical basis for assessing total extremity dose using Hanford ring dosimeters worn inside gloves with the same lead and rubber density thickness as the gloves in this study. 
The rack holding a portion of a lead-lined glove for the extremity study provided an excellent method of determining the neutron-to-gamma ratio that would be experienced at a worker's finger. The gamma measurement is exactly the same in the study as it would be for a glovebox worker, because it was measured using finger rings worn inside the glove with the TLD chip pointing toward the radiation source. Because the neutron detector resides in the position that would be occupied by a finger, it provides an excellent estimate of the neutron exposure that would be received by a worker's finger under the same conditions. Thus this comparison provides an excellent estimate of the extremity neutron-to-gamma ratio. While the individual neutron and gamma dose rates are functions of the distance between the detector and the radiation source, the estimate of the ratio did not depend on this distance, so it was not necessary to carefully measure the distance between each glove finger and the source can.

The measurement could be adversely affected, however, if there was significant anisotropy in the radiation emission from a source can. Anisotropy should not be a serious problem with neutron emission, because there should not have been substantial amounts of neutron shielding or moderator inside a can, but it could be a problem with gamma emission if the distribution of gamma attenuators in a source was asymmetrical. It should also be recognized that the effective neutron-to-gamma ratios might be quite different for individuals directly handling cans of material if the glove is different from that used in this study. Table 5.10 presents data comparing ring response under glove (little finger) and ring response under no glove (next to little finger at same distance from source). The data indicate that the gloves may have a photon attenuation effect as large as $42 \%$. Use of gloves with greater lead shielding than the gloves used in the present study would result in an underestimate of neutron dose because of reduced ring response relative to the neutron dose received.

Two methods were used for the neutron measurement, in the extremity study: a $1 / 2$-in. TEPC and a bubble detector. For every measurement, the bubble detector responded lower than the TEPC. The ratio of dose equivalent rates measured by the two different devices ranged from 0.42 up to 0.69 . The bubble detectors were used in this study because they are relatively easy to use (compared with a TEPC) and may provide a convenient method for checking the neutron-to-gamma ratio for further investigations. Because they consistently under-responded relative to the TEPC, however, they are not recommended for determining neutron-to-gamma ratios.

The measurements of neutron dose rates for the six cans produced a pattern that was not expected. For the $6 \%, 12 \%$, and $20 \%$ oxide cans, all cans had approximately the same mass of plutonium, so it was expected that the neutron dose rates would increase as ${ }^{240} \mathrm{Pu}$ content increased. These measurements did not follow that pattern: the $6 \%$ oxide had the highest neutron dose rates.

The neutron ratios reported under the TEPC column in Table 5.11 are suitable for use in neutron extremity dose assessment, provided the assessment is based on use of the Hanford ring in gloves of the same type as used in this study. The values range from 0.09 
up to 0.65 . These values are influenced by factors such as ${ }^{240} \mathrm{Pu}$ content, ${ }^{241} \mathrm{Am}$ content, presence or absence of low-Z material for $(\alpha, n)$ generation (oxides vs metals, for example), or the internal gamma shielding, or gamma shielding in the glove. When applying a neutron-to-gamma ratio to any plutonium can, it will be necessary to select a can from the six that were characterized in this study, choosing one that should be representative of the new can. Knowledge of the can's contents, including the characteristics just mentioned, is essential for making a proper selection.

These ratios do not represent dose rate ratios as would be observed with survey instruments, but rather are empirically derived correction factors to be used to correct gamma ring results for unmeasured neutron dose when worn in the specific glove type used in this study. Changes in lead loading or glove thickness from those used in this study could alter the photon attenuation effect, which is accounted for in the observed neutron-gamma ratios. Therefore, changes in a supplier of gloves and or makes of gloves should include an assessment of potential changes in attenuation effect and its impact on the validity of the neutron-to-gamma ratios in use at PFP. Where possible, procurements of replacement gloves for glove boxes should include careful specifications of lead loading, specifically the density thickness of lead and of rubber, to match the gloves used as the basis for this study.

\subsection{Recommendations}

Several recommendations concerning dose assessment can be supported by the results of this study:

- Further investigation of the suitability of the BTI bubble detector for use as a supporting real-time personnel neutron monitor and the REMBrandt for use as a neutron survey instrument in Hanford neutron environments would be valuable. These instruments possess technical attributes of a direct-responding, tissue-like response that is expected to provide superior performance, compared with albedo or track-etch dosimeters, once the technology is fully developed.

- The plutonium algorithm of the HCND needs to be studied and if possible improved to prevent occurrences where similar chip responses can produce different evaluated neutron dose equivalents.

- The following neutron-to-gamma ratios would be suitable for extremity dose assessment:

0.36 for sources similar to the " $6 \%$ oxide" can

0.14 for sources similar to the " $12 \%$ oxide" can

0.090 for sources similar to the " $20 \%$ oxide" can

0.47 for sources similar to the "metal" can

0.25 for sources similar to the " $17 \%$ oxide" can with .02-inch lead foil shielding 
0.55 for sources similar to the " $17 \%$ oxide" can with heavy lead shielding.

- The proper application of these ratios to specific workplace conditions must consider factors such as the type of material in a can, the internal shielding of the can, and the thickness of shielding in the glovebox glove. These ratios are appropriate only for Hanford ring dosimeters worn inside the same type of leadlined glove used in this study.

- These measurements showed that highly scattered neutron fields exist in PFP work locations. The significant dependence of albedo-type dosimeters (e.g., HCND and HSD) on neutron energy is well documented. As noted in the DOE Standard, Guide of Good Practices for Occupational Radiological Protection in Plutonium Facilities, validation studies of dosimeter performance should be performed periodically and whenever there are major operational changes. A schedule should be adopted to repeat this study every 2 to 3 years at a minimum, so that up-to-date validation data are available. 


\subsection{REFERENCES}

10 CFR 835. 1993. US Department of Energy, "Occupational Radiation Protection; Final Rule.” US Code of Federal Regulations.

52 CFR 2822-2834. 1987. US Department of Energy, "Federal Radiation Protection Guidance to Federal Agencies for Occupational Exposure; Approval of the Environmental Protection Agency Recommendations." US Code of Federal Regulations.

American National Standards Institute (ANSI). 1993. American National Standard Personnel Dosimetry Performance - Criteria for Testing. ANSI N13.11, New York, New York.

Brackenbush, L. W., G. W. R. Endres, J. M. Selby, and E. J. Vallario. 1980. Personnel Neutron Dosimetry at Department of Energy Facilities. PNL-3213, Pacific Northwest Laboratory, Richland, Washington.

Brackenbush, L. W., W. V. Baumgartner, and J. J. Fix. 1991. Response of TLD-Albedo and Nuclear Track Dosimeters Exposed to Plutonium Sources. PNL-7881, Pacific Northwest Laboratory, Richland, Washington.

Brackenbush, L. W., and R. I. Scherpelz. 1984. "SPUNIT, A Code for Multisphere Unfolding." In Computer Applications in Heath Physics, R. L. Kathren, D. P. Higby, and M. A. McKinney, eds., pp 4.1-4.6. Proceedings of the Seventh Midyear Topical Symposium of the Health Physics Society, Columbia Chapter of the Health Physics Society, Richland, Washington.

Brackenbush, L. W., and L. G. Faust. 1970. Neutron Spectra of Plutonium Compounds. Part 1: ${ }^{3} \mathrm{He}$ and ${ }^{6} \mathrm{Li}$ Spectrometer Measurements. BNW-1262, Pacific Northwest Laboratory, Richland, Washington.

Bramblett, R. L., R. I. Ewing, and T. W. Bonner. 1960. "A New Type of Neutron Spectrometer." Nuclear Instruments and Methods 9:1-12.

Cummings, F.M. 1984. TACI - A Code for Interactive Analysis of Neutron Data Produced by a Tissue Equivalent Proportional Counter. PNL-5136, Pacific Northwest National Laboratory, Richland, Washington.

Doroshenko, J. J., S. N. Kraitor, T. V. Kuznetsova, K. K. Kushnereva, and E. S. Lonov. 1997. "New Methods for Measuring Neutron Spectra with Energy from $0.4 \mathrm{eV}$ to 10 MeV by Track and Activation Detectors." Nuclear Technology 33:296-304

Endres, A. W., L. W. Brackenbush, W. V. Baumgartner, J. J. Fix, and B. A. Rathbone. 1996. Response of the Hanford Combination Neutron Dosimeter in Plutonium Environments. PNNL-10516, Pacific Northwest National Laboratory, Richland, Washington. 
Hankins, D. E., S. G. Homann, and J. Westermark. 1989. Personnel Neutron Dosimetry Using Electrochemically Etched Cr-39 Foils. UCRL-53833, Rev. 1, Lawrence

Livermore National Laboratory, Livermore, California.

Ing, H., and S. Makra. 1978. Compendium of Neutron Spectra in Criticality Accident Dosimetry. Technical Report Series No. 180, International Atomic Energy Agency, Vienna.

International Commission on Radiological Protection (ICRP). 1991. “1990

Recommendations of the International Commission on Radiological Protection." ICRP publication 60, Annals of the ICRP. Pergamon Press, Oxford, England.

International Commission on Radiological Protection (ICRP). 1987. "Data for Use in Protection Against External Radiation." ICRP publication 51, Annals of the ICRP. Pergamon Press, Oxford, England.

International Commission on Radiological Protection (ICRP). 1977. Recommendations of the International Commission on Radiological Protection. ICRP publication 26, Annals of the ICRP. Pergamon Press, Oxford, England.

International Commission on Radiation Units and Measurements (ICRU). 1983. “Microdosimetry." ICRU Report No. 36, ICRU Publications, Bethesda, Maryland.

Johnson, T. L., and S. G. Gorbics. 1981. "An Iterative Perturbation Method for Unfolding Neutron Spectra from Bonner Sphere Data.” Health Physics 41 (6):859.

Kellerer, A. M. 1969. “Analysis of Patterns of Energy Deposition.” In Proceedings of the Second Symposium on Microdosimetry, Stresa, Italy, pp. 107-134. Office for Official Publications of the European Community, Luxembourg.

National Council on Radiation Protection and Measurements (NCRP). 1971. Protection Against Neutron Radiation. NCRP Report No. 38, Bethesda, Maryland.

Piesch, E., and B. Burgkhardt. 1978. "The Role of an Analyzer Type Albedo Dosimeter in Routine Monitoring and the Current Situation for the Calibration Technique." In Seventh DOE Workshop on Personnel Neutron Dosimetry, pp. 25-37. PNL-2807, Pacific Northwest Laboratory, Richland, Washington.

Routi, T. J., and J. V. Samdberg. 1987. General Purpose unfolding program LOUH178 with Linear and Non-linear Regularization. Report TKK-A359, Helsinki University of Technology, Department of Technical Physics, Otaneimi, Finland.

Schwartz, R. B., and C. M. Eisenhauer. 1982. Procedures for Calibrating Neutron Personnel Dosimeters. NBS Special Publication No. 633, U.S. National Bureau of Standards, Washington, D. C. 
U.S. Department of Energy (DOE). 1998. DOE Standards, Guide of Good Practices for Occupational Radiological Protection in Plutonium Facilities. DOE-STD-1128-98, Washington, D. C.

U.S. Department of Energy (DOE). 1994. U.S. Department of Energy Radiological Control Manual. DOE/EH-0256T, Revision 1, Washington, D.C.

U.S. Department of Energy (DOE). 1986. Department of Energy Standard for the Performance Testing of Personnel Dosimeters. DOE/EH-0027, Washington, D.C. 
APPENDIX A

TEPC OUTPUTS FOR LOW SCATTER ROOM MEASUREMENTS 
Program TEPC_NG

Page 1

INPUT FILE NAME: t185cf2.txt

FILE TITLE: TEPC 185 at $100 \mathrm{~cm}$ from unmod Cf -356 6/15/99

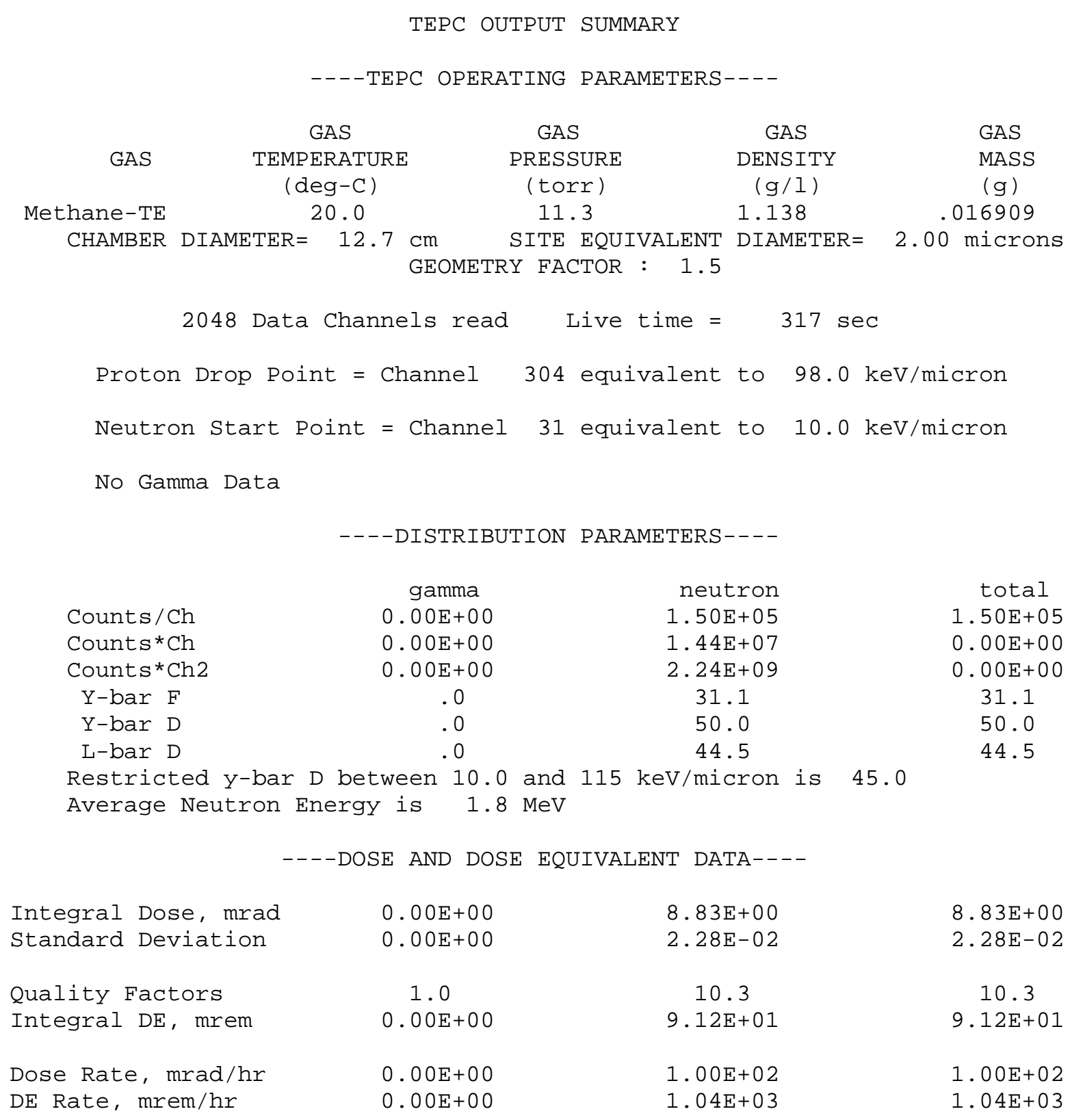


INPUT FILE NAME: t185cf4.txt

FILE TITLE: TEPC 185 at $100 \mathrm{~cm}$ from Unmod Cf252 \#318-016. 6/15/99

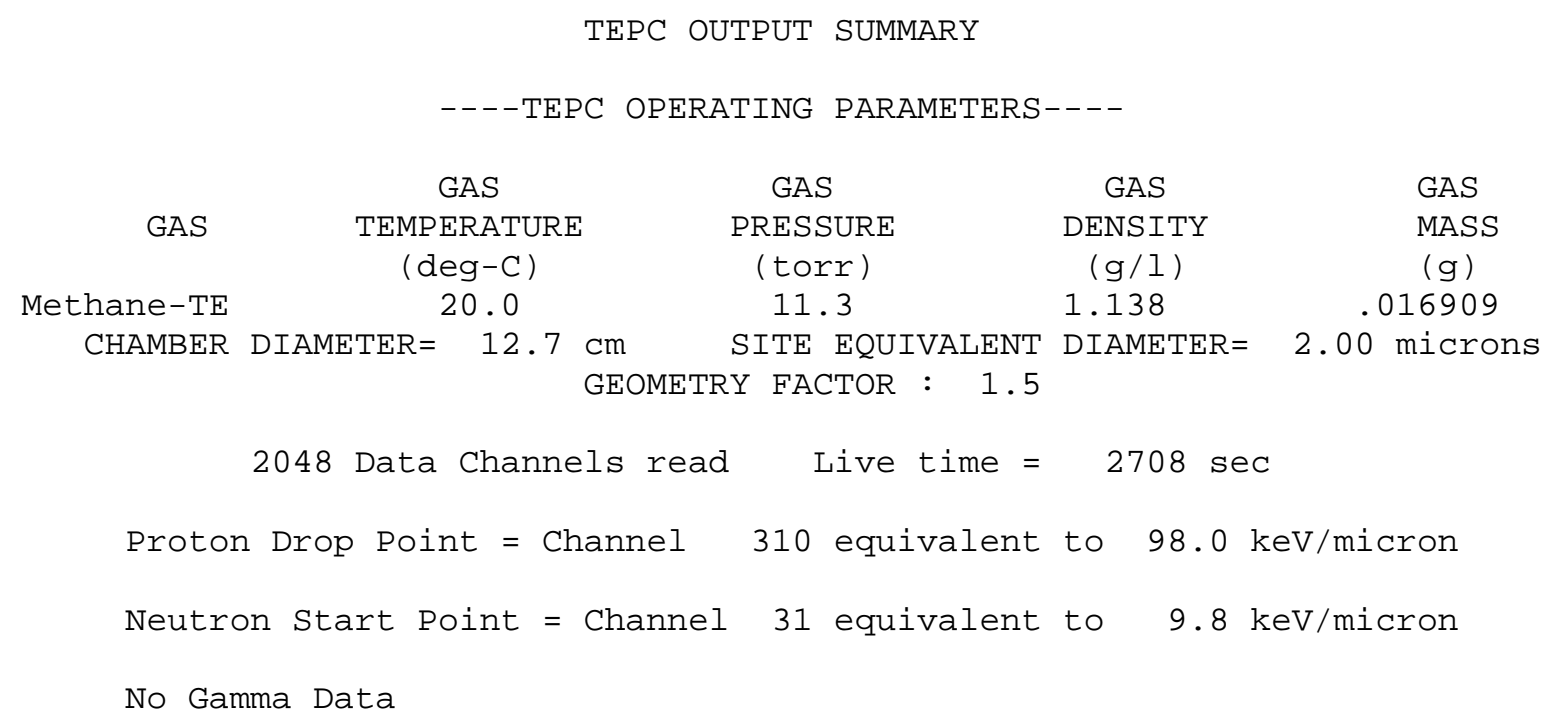

$\begin{array}{lccc} & \text { gamma } & \text { neutron } & \text { total } \\ \text { Counts/Ch } & 0.00 \mathrm{E}+0 \odot & 4.21 \mathrm{E}+03 & 4.21 \mathrm{E}+03 \\ \text { Counts }{ }^{*} \text { Ch } & 0.00 \mathrm{E}+0 \odot & 4.17 \mathrm{E}+05 & 0.00 \mathrm{E}+00 \\ \text { Counts }{ }^{*} \text { Ch2 } & 0.00 \mathrm{E}+00 & 7.13 \mathrm{E}+07 & 0.00 \mathrm{E}+00 \\ \text { Y-bar F } & .0 & 31.4 & 31.4 \\ \text { Y-bar D } & .0 & 54.0 & 54.0 \\ \text { L-bar D } & .0 & 48.0 & 48.0\end{array}$

Restricted $y$-bar $D$ between 9.8 and $115 \mathrm{keV} / \mathrm{micron}$ is 44.7 Average Neutron Energy is $1.8 \mathrm{MeV}$

DOSE AND DOSE EQUIVALENT DATA----

\begin{tabular}{|c|c|c|c|}
\hline Integral Dose, mrad & $\odot . \odot \odot \mathrm{E}+\odot \odot$ & $2.50 \mathrm{E}-01$ & $2.5 \odot E-01$ \\
\hline Standard Deviation & $\odot . \odot \odot \mathrm{E}+\odot \odot$ & $3.86 \mathrm{E}-03$ & $3.86 \mathrm{E}-03$ \\
\hline Quality Factors & 1.0 & 10.5 & 10.5 \\
\hline Integral $\mathrm{DE}$, mrem & $\odot . \odot \odot E+\odot \odot$ & $2.62 \mathrm{E}+\odot \odot$ & $2.62 \mathrm{E}+\odot \odot$ \\
\hline Dose Rate, $\mathrm{mrad} / \mathrm{hr}$ & $\odot . \odot \odot E+\odot \odot$ & $3.33 E-01$ & $3.33 E-01$ \\
\hline DE Rate, mrem/hr & $\odot . \odot \odot E+\odot \odot$ & $3.49 \mathrm{E}+\odot \odot$ & $3.49 \mathrm{E}+\odot \odot$ \\
\hline
\end{tabular}


Program TEPC_NG

Page 1

INPUT FILE NAME: t504cf1.txt

FILE TITLE: TEPC 504 at $100 \mathrm{~cm}$ from Unmod Cf -356 6/15/99

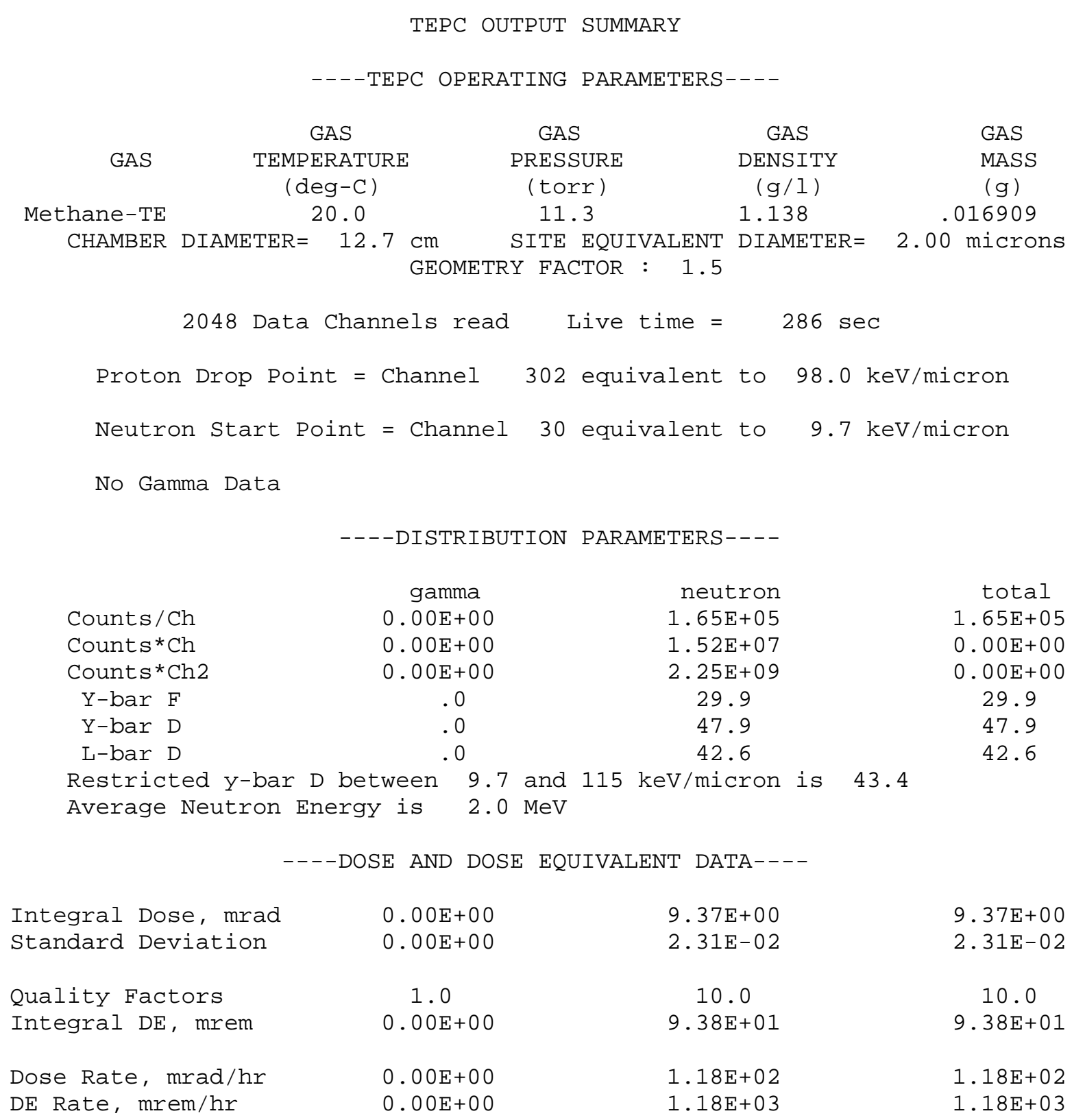


Program TEPC_NG

Version: December, 1989

INPUT FILE NAME: t504cf3.txt

FILE TITLE: TEPC 504 at $100 \mathrm{~cm}$ from unmod Cf -016 6/15/99

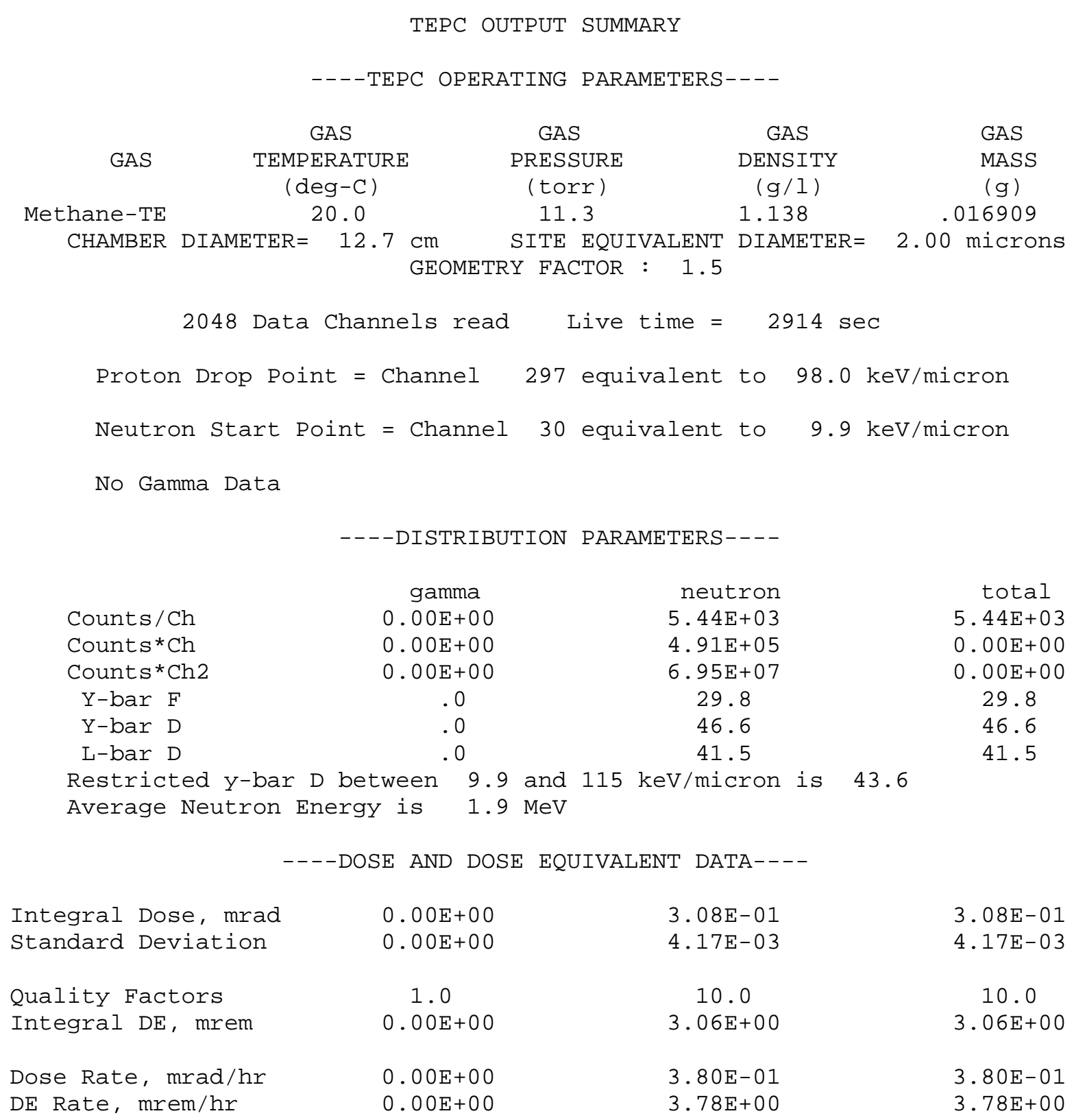


Program TEPC_NG

Page 1

INPUT FILE NAME: t70cf1.txt

Version: December, 1989

FILE TITLE: TEPC 1170 at $100 \mathrm{~cm}$ from unmod Cf -356

TEPC OUTPUT SUMMARY

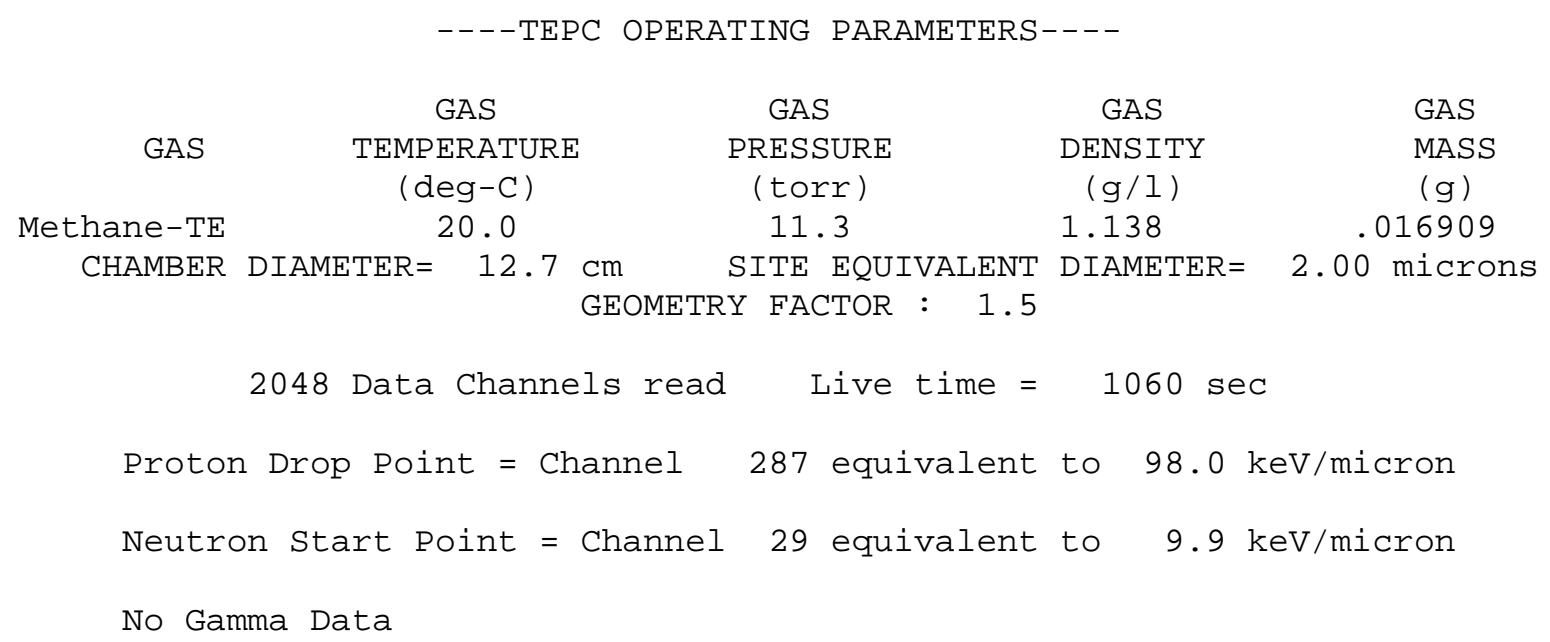

Integral Dose, mrad

Standard Deviation

Quality Factors

Integral DE, mrem

Dose Rate, $\mathrm{mrad} / \mathrm{hr}$

DE Rate, $\mathrm{mrem} / \mathrm{hr}$ $\odot . \odot \odot E+\odot \odot$

$\odot . \odot \odot E+\odot \odot$

1.0

$\odot . \odot \odot E+\odot \odot$

$\odot . \odot \odot E+\odot \odot$

$\odot . \odot \odot \mathrm{E}+\odot \odot$
3. $40 \mathrm{E}+01$

$4.43 E-02$

10.1

3. $44 \mathrm{E}+02$

1. $16 \mathrm{E}+02$

1. $17 \mathrm{E}+03$
3. $40 \mathrm{E}+01$

4 . $43 \mathrm{E}-02$

10.1

$3.44 \mathrm{E}+02$

1. $16 \mathrm{E}+02$

$1.17 \mathrm{E}+03$ 
Program TEPC_NG

Page 1

INPUT FILE NAME: t70cf3.txt

FILE TITLE:TEPC 1170 at $100 \mathrm{~cm}$ from unmod Cf252 -016. 6/15/99

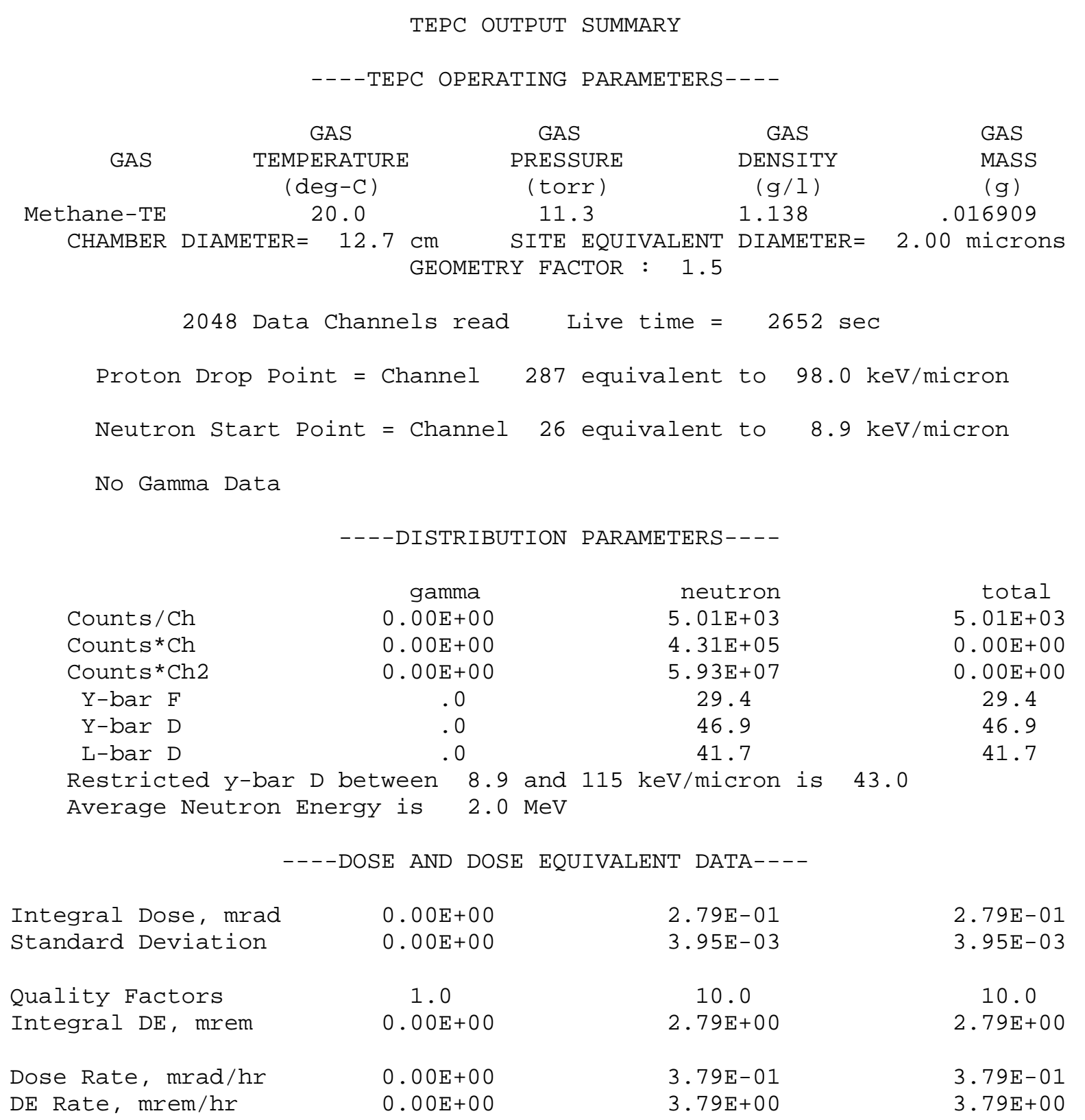


Program TEPC_NG

Page 1

INPUT FILE NAME: t71cf1.txt

FILE TITLE: TEPC 1171 at $100 \mathrm{~cm}$ from unmod Cf -356 6/15/99

TEPC OUTPUT SUMMARY

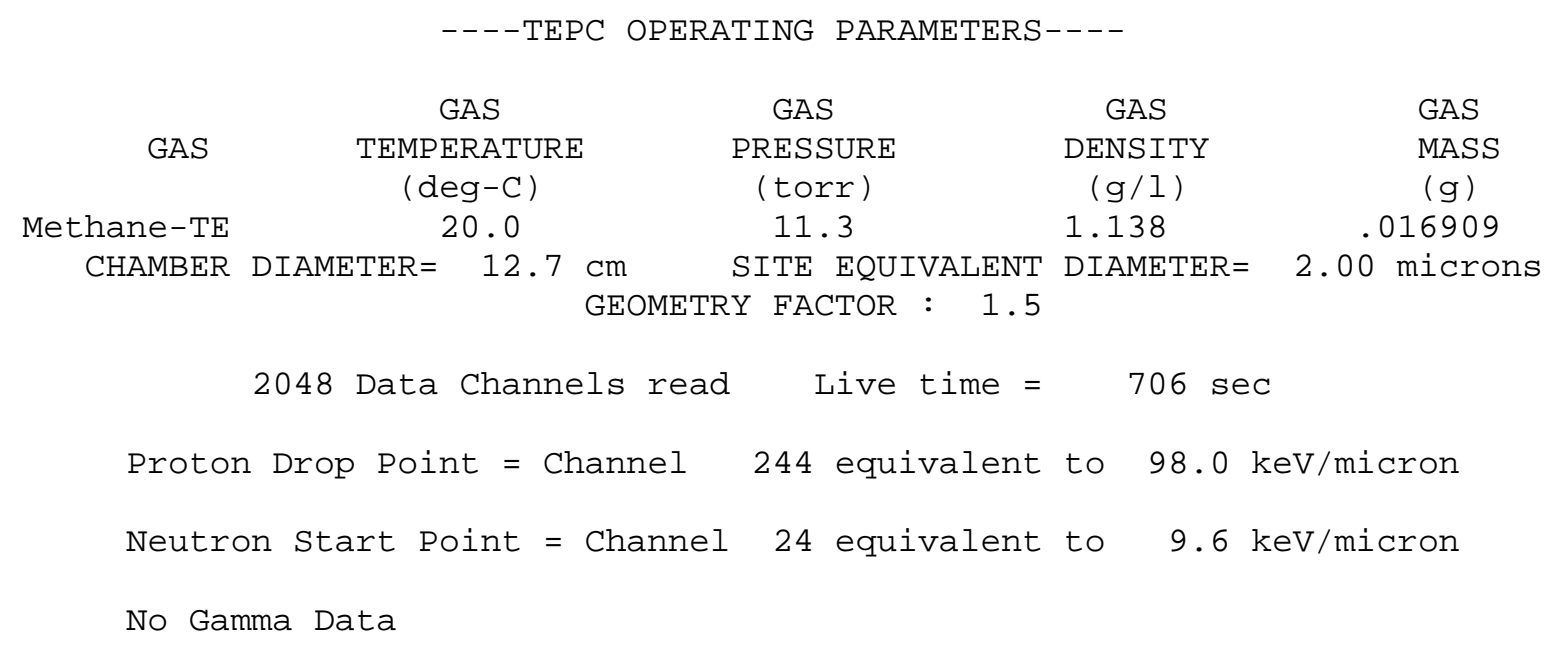

Integral Dose, mrad

Standard Deviation

Quality Factors

Integral DE, mrem

Dose Rate, $\mathrm{mrad} / \mathrm{hr}$

DE Rate, mrem/hr $\odot . \odot \odot E+\odot \odot$

$\odot . \odot \odot E+\odot \odot$

1.0

$\odot . \odot \odot E+\odot \odot$

$\odot .0 \odot E+\odot \odot$

$\odot . \odot \odot E+\odot \odot$
2. $52 \mathrm{E}+01$

3. $87 \mathrm{E}-02$

10.4

2. $62 \mathrm{E}+02$

1. $28 \mathrm{E}+02$

1. $34 \mathrm{E}+03$
2. $52 \mathrm{E}+01$

3. $87 \mathrm{E}-02$

10.4

2. $62 \mathrm{E}+02$

1. $28 \mathrm{E}+02$

1. $34 \mathrm{E}+03$ 
INPUT FILE NAME: t71cf3.txt

FILE TITLE: TEPC 1171 at $100 \mathrm{~cm}$ from unmod Cf -016 6/15/99

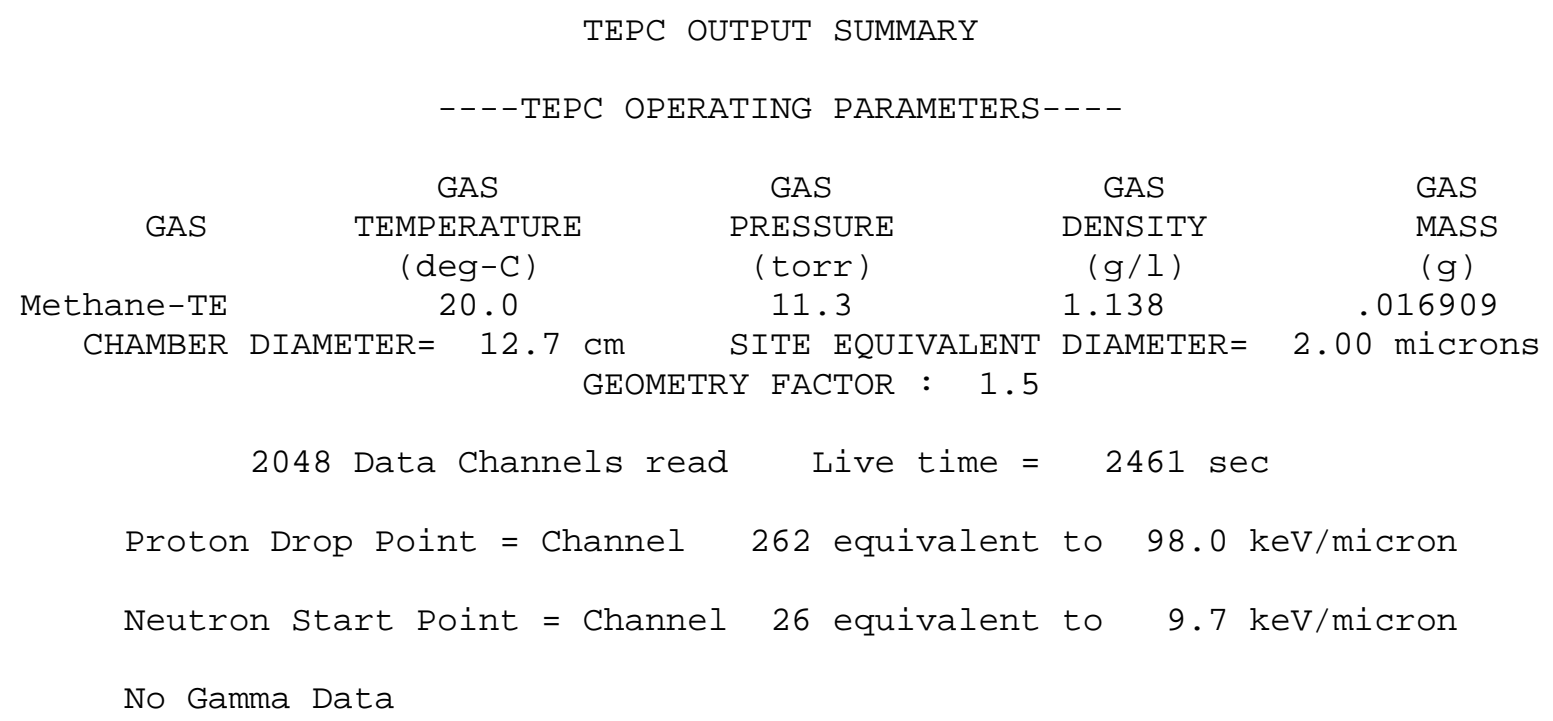

$\begin{array}{lccc} & \text { gamma } & \text { neutron } & \text { total } \\ \text { Counts } / \text { Ch } & 0.00 \mathrm{E}+0 \odot & 4.57 \mathrm{E}+03 & 4.57 \mathrm{E}+03 \\ \text { Counts }{ }^{*} \text { Ch } & 0.00 \mathrm{E}+0 \odot & 3.73 \mathrm{E}+05 & 0.00 \mathrm{E}+00 \\ \text { Counts }{ }^{*} \text { Ch2 } & 0.00 \mathrm{E}+0 \odot & 4.82 \mathrm{E}+07 & 0.00 \mathrm{E}+00 \\ \text { Y-bar F } & .0 & 30.5 & 30.5 \\ \text { Y-bar D } & .0 & 48.4 & 48.4 \\ \text { L-bar D } & .0 & 43.0 & 43.0\end{array}$

Restricted $y$-bar $D$ between 9.7 and $115 \mathrm{keV} / \mathrm{micron}$ is 44.3

Average Neutron Energy is $1.9 \mathrm{MeV}$

DOSE AND DOSE EQUIVALENT DATA----

\begin{tabular}{|c|c|c|c|}
\hline Integral Dose, mrad & $\odot . \odot \odot \mathrm{E}+\odot \odot$ & $2.64 \mathrm{E}-01$ & $2.64 \mathrm{E}-01$ \\
\hline Standard Deviation & $\odot . \odot \odot \mathrm{E}+\odot \odot$ & $3.91 \mathrm{E}-03$ & $3.91 \mathrm{E}-03$ \\
\hline Quality Factors & 1.0 & 10.2 & 10.2 \\
\hline Integral $\mathrm{DE}$, mrem & $\odot . \odot \odot E+\odot \odot$ & $2.69 \mathrm{E}+\odot \odot$ & $2.69 \mathrm{E}+\odot \odot$ \\
\hline Dose Rate, $\mathrm{mrad} / \mathrm{hr}$ & $\odot . \odot \odot E+\odot \odot$ & $3.87 \mathrm{E}-01$ & $3.87 \mathrm{E}-01$ \\
\hline DE Rate, mrem/hr & $\odot . \odot \odot E+\odot \odot$ & $3.94 \mathrm{E}+0 \odot$ & $3.94 \mathrm{E}+\odot \odot$ \\
\hline
\end{tabular}


Program TEPC_NG

Version: December, 1989

INPUT FILE NAME: t72_cf56.txt

FILE TITLE: TEPC 1172, $100 \mathrm{~cm}$ from Unmod Cf $-356.6 / 14 / 99$

TEPC OUTPUT SUMMARY

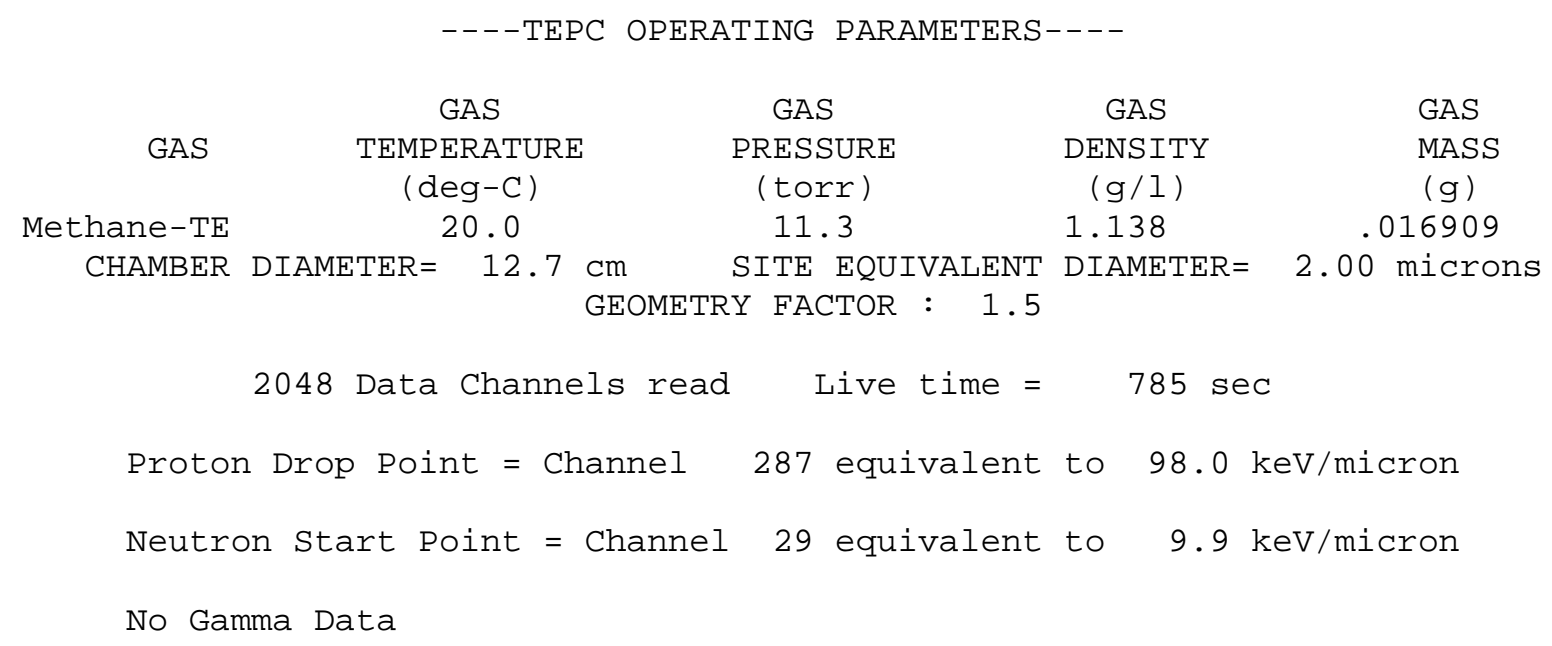

Integral Dose, mrad

Standard Deviation

Quality Factors

Integral DE, mrem

Dose Rate, $\mathrm{mrad} / \mathrm{hr}$

DE Rate, $\mathrm{mrem} / \mathrm{hr}$ $\odot . \odot \odot E+\odot \odot$

$\odot . \odot \odot E+\odot \odot$

1.0

$\odot . \odot \odot E+\odot \odot$

$\odot .0 \odot E+\odot \odot$

$\odot . \odot \odot E+\odot \odot$
2. $32 \mathrm{E}+01$

3. $61 \mathrm{E}-02$

9.9

2. $30 \mathrm{E}+02$

1. $06 \mathrm{E}+02$

1. $06 \mathrm{E}+03$
2. $32 \mathrm{E}+01$

3. $61 \mathrm{E}-02$

9.9

2. $30 \mathrm{E}+\mathrm{O} 2$

1. $06 \mathrm{E}+02$

1. $06 \mathrm{E}+03$ 
Program TEPC_NG

Page 1

INPUT FILE NAME: t72cf4.txt

FILE TITLE: TEPC 1172 at $100 \mathrm{~cm}$ from Unmod Cf -016 6/15/99

TEPC OUTPUT SUMMARY

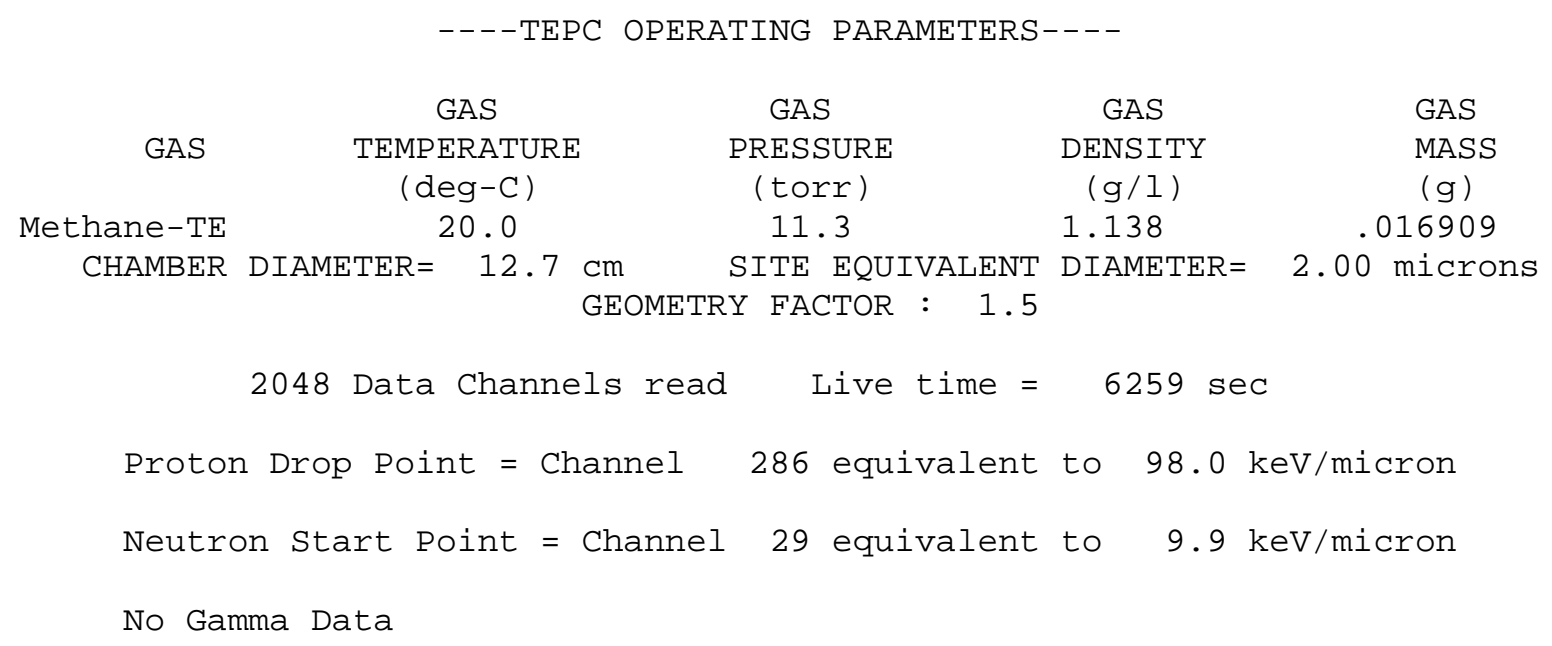

Integral Dose, mrad

Standard Deviation

Quality Factors

Integral DE, mrem

Dose Rate, $\mathrm{mrad} / \mathrm{hr}$

DE Rate, $\mathrm{mrem} / \mathrm{hr}$ $\odot . \odot \odot E+\odot \odot$

$\odot . \odot \odot E+\odot \odot$

1.0

$\odot . \odot \odot E+\odot \odot$

$\odot . \odot \odot E+\odot \odot$

$\odot . \odot \odot E+\odot \odot$
5. 85E- 01

$5.72 \mathrm{E}-03$

9.9

$5.78 \mathrm{E}+\odot \odot$

3. 36E- 01

3. $33 \mathrm{E}+00$
5. $85 \mathrm{E}-01$

$5.72 \mathrm{E}-03$

9.9

$5.78 \mathrm{E}+00$

3. $36 \mathrm{E}-01$

3. $33 \mathrm{E}+00$ 
Program TEPC_NG

Page 1

INPUT FILE NAME: t73cf1.txt

FILE TITLE: TEPC 1173 at $100 \mathrm{~cm}$ from unmod Cf -356 6/14/99

TEPC OUTPUT SUMMARY

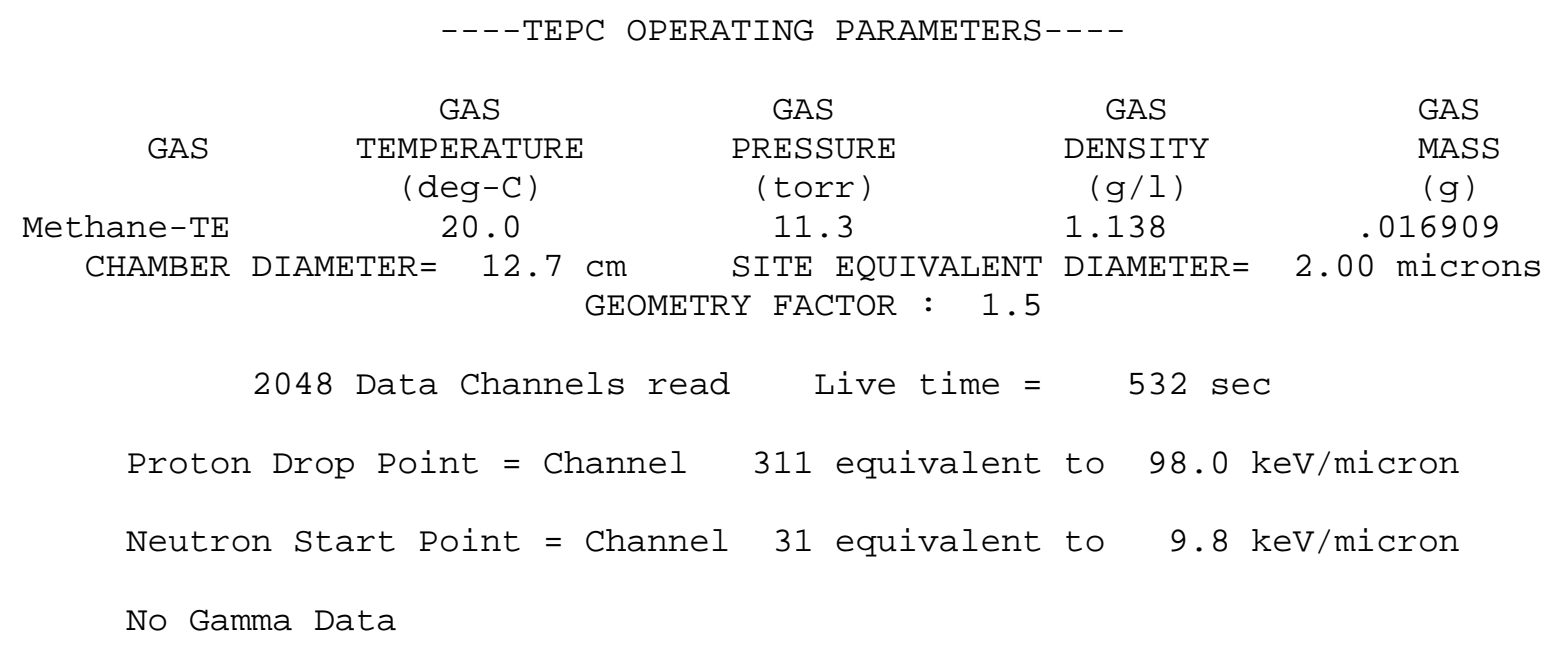

Integral Dose, mrad

Standard Deviation

Quality Factors

Integral DE, mrem

Dose Rate, $\mathrm{mrad} / \mathrm{hr}$

DE Rate, mrem/hr $\odot . \odot \odot \mathrm{E}+\odot \odot$

$\odot . \odot \odot E+\odot \odot$

1.0

$\odot . \odot \odot E+\odot \odot$

$\odot .0 \odot E+\odot \odot$

$\odot . \odot \odot E+\odot \odot$
1. $73 \mathrm{E}+01$

$3.16 \mathrm{E}-02$

10.2

$1.76 \mathrm{E}+02$

1.17E+02

1. $19 \mathrm{E}+03$
1. $73 \mathrm{E}+01$

3. 16E- -2

10.2

1. $76 \mathrm{E}+02$

1. $17 \mathrm{E}+02$

1. $19 \mathrm{E}+03$ 
Program TEPC_NG

Page 1

INPUT FILE NAME: t73cf4.txt

FILE TITLE: TEPC 1173 at $100 \mathrm{~cm}$ from Unmod Cf -016 6/15/99

TEPC OUTPUT SUMMARY

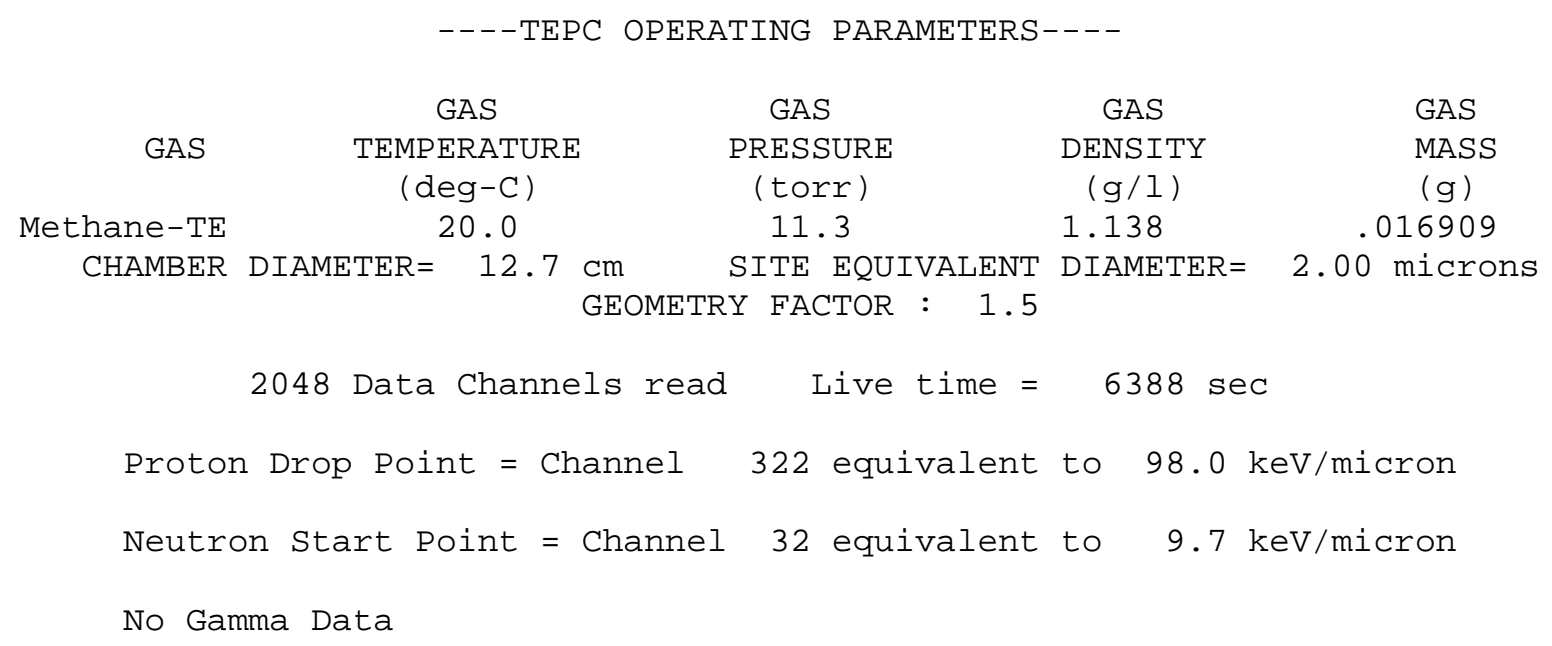

Integral Dose, mrad

Standard Deviation

Quality Factors

Integral DE, mrem

Dose Rate, $\mathrm{mrad} / \mathrm{hr}$

DE Rate, mrem/hr

\begin{abstract}
$\odot .0 \odot E+\odot \odot$
\end{abstract}
$\odot . \odot \odot E+\odot \odot$

1.0

$\odot . \odot \odot E+\odot \odot$

$\odot .0 \odot E+\odot \odot$

$\odot . \odot \odot E+\odot \odot$
$6.29 \mathrm{E}-01$

$5.95 \mathrm{E}-03$

9.9

6. $26 \mathrm{E}+\odot \odot$

3. $54 \mathrm{E}-01$

3. $53 \mathrm{E}+00$
6. $29 \mathrm{E}-01$

$5.95 \mathrm{E}-03$

9.9

$6.26 \mathrm{E}+\odot \odot$

3. $54 \mathrm{E}-01$

$3.53 \mathrm{E}+00$ 


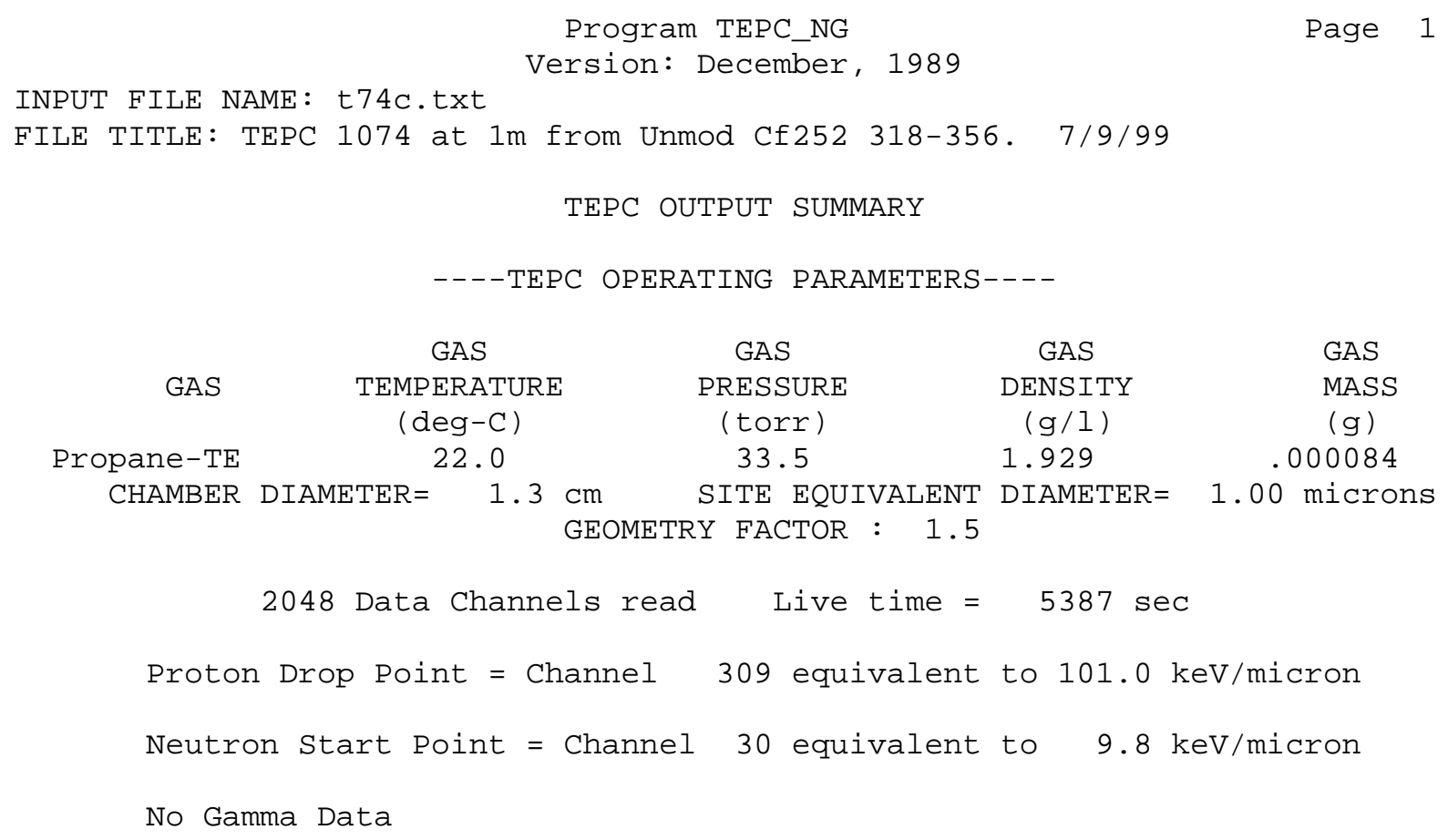

Integral Dose, mrad

Standard Deviation

Quality Factors

Integral DE, mrem

Dose Rate, $\mathrm{mrad} / \mathrm{hr}$

DE Rate, mrem/hr
$\odot . \odot \odot E+\odot \odot$
$\odot . \odot \odot E+\odot \odot$
1.0
$\odot . \odot \odot E+\odot \odot$
$\odot . \odot \odot E+\odot \odot$
$\odot . \odot \odot E+\odot \odot$

1. $42 \mathrm{E}+02$

9. $26 \mathrm{E}-01$

10.7

1. $51 \mathrm{E}+03$

9. $49 \mathrm{E}+01$

1. $01 \mathrm{E}+03$
1. $42 \mathrm{E}+02$

9. $26 \mathrm{E}-01$

10.7

$1.51 \mathrm{E}+03$

9. $49 \mathrm{E}+01$

1. $01 \mathrm{E}+03$ 


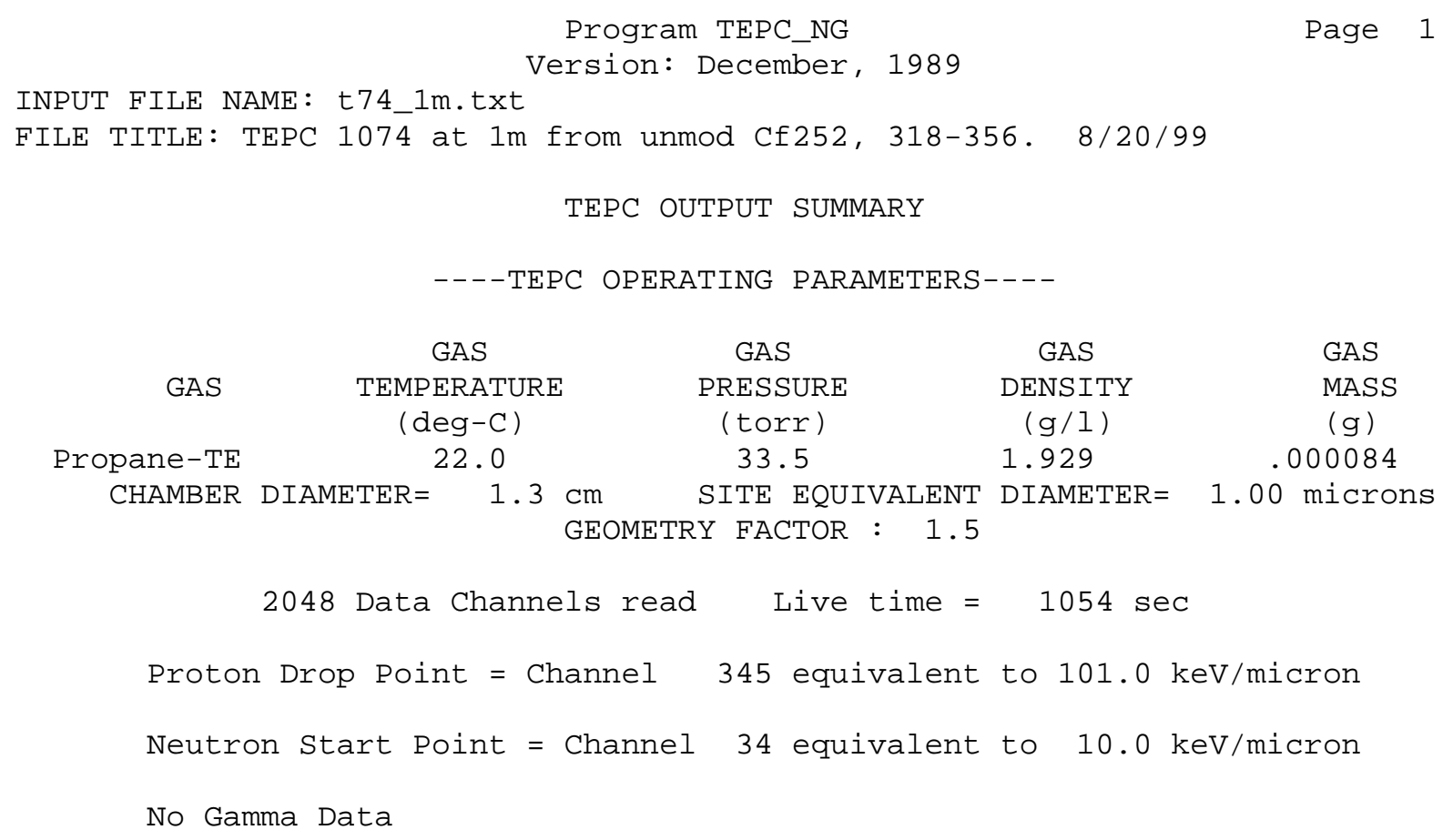

Integral Dose, mrad

Standard Deviation

Quality Factors

Integral DE, mrem

Dose Rate, $\mathrm{mrad} / \mathrm{hr}$

DE Rate, mrem/hr
$\odot .0 \odot E+\odot \odot$
$\odot . \odot \odot E+\odot \odot$
1.0
$\odot . \odot \odot E+\odot \odot$
$\odot . \odot \odot E+\odot \odot$
$\odot . \odot \odot E+\odot \odot$

3. $34 \mathrm{E}+01$

4. 52E- 01

10.7

3. $57 \mathrm{E}+02$

1. $14 \mathrm{E}+02$

1. $22 \mathrm{E}+03$
3. $34 \mathrm{E}+01$

4. $52 \mathrm{E}-01$

10.7

3. $57 \mathrm{E}+02$

1. $14 \mathrm{E}+02$

1. $22 \mathrm{E}+03$ 
Program TEPC_NG

Version: December, 1989

Page 1

INPUT FILE NAME: t22e.txt

FILE TITLE: TEPC 1122 at $100 \mathrm{~cm}$ from Unmod Cf252 318-356, LSR 7/13

TEPC OUTPUT SUMMARY

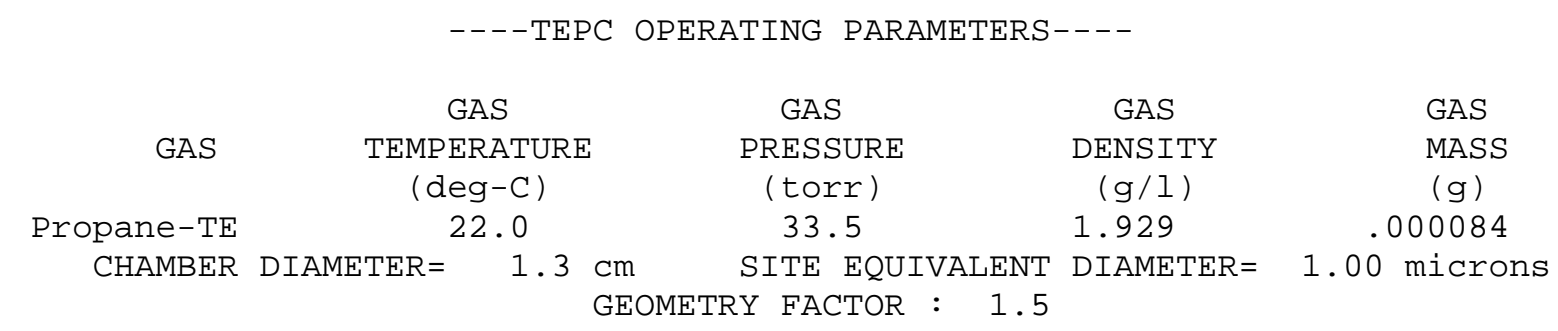

2048 Data Channels read Live time $=3618 \mathrm{sec}$

Proton Drop Point $=$ Channel 297 equivalent to $101.0 \mathrm{keV} / \mathrm{micron}$

Neutron Start Point $=$ Channel 29 equivalent to $9.9 \mathrm{keV} / \mathrm{micron}$

No Gamma Data

- - - -DISTRIBUTION PARAMETERS- - -

$\begin{array}{lccc} & \text { gamma } & \text { neutron } & \text { total } \\ \text { Counts } / \text { Ch } & \odot . \odot \odot \mathrm{E}+\odot \odot & 1.59 \mathrm{E}+\odot 4 & 1.59 \mathrm{E}+\odot 4 \\ \text { Counts }{ }^{*} \text { Ch } & 0.00 \mathrm{E}+\odot \odot & 1.50 \mathrm{E}+\odot 6 & 0.00 \mathrm{E}+\odot \odot \\ \text { Counts }{ }^{*} \text { Ch2 } & \odot . \odot \odot \mathrm{E}+\odot \odot & 2.47 \mathrm{E}+\odot 8 & 0.0 \odot \mathrm{E}+\odot \odot \\ \text { Y-bar F } & . \odot & 32.0 & 32.0 \\ \text { Y-bar D } & . \odot & 56.0 & 56.0 \\ \text { L-bar D } & . \odot & 49.8 & 49.8\end{array}$

Restricted $\mathrm{y}$-bar $\mathrm{D}$ between 9.9 and $115 \mathrm{keV} / \mathrm{micron}$ is 45.5

Average Neutron Energy is $1.7 \mathrm{MeV}$

----DOSE AND DOSE EQUIVALENT DATA----

Integral Dose, mrad

Standard Deviation

Quality Factors

Integral DE, mrem

Dose Rate, $\mathrm{mrad} / \mathrm{hr}$

DE Rate, $\mathrm{mrem} / \mathrm{hr}$ $\odot . \odot \odot \mathrm{E}+\odot \odot$

$\odot . \odot \odot E+\odot \odot$

1.0

$\odot .00 \mathrm{E}+\odot \odot$

$\odot . \odot \odot E+\odot \odot$

$\odot .0 \odot E+\odot \odot$
9. $67 \mathrm{E}+01$

7. 66E-01

10.7

1. $03 \mathrm{E}+03$

9. $63 \mathrm{E}+01$

1. $03 E+03$
9. $67 \mathrm{E}+01$

7. $66 \mathrm{E}-01$

10.7

1. $03 \mathrm{E}+03$

9. $63 \mathrm{E}+01$

1. $03 \mathrm{E}+03$ 
Program TEPC_NG

Version: December, 1989

INPUT FILE NAME: t22_1ma.txt

FILE TITLE: TEPC 1122 at 1m from unmod Cf252 srce in LSR. Short count

TEPC OUTPUT SUMMARY

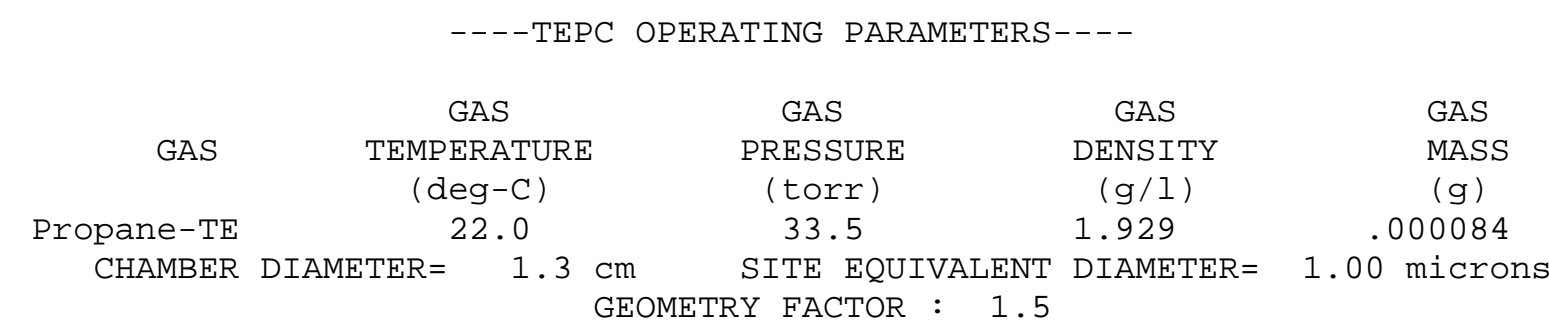

2048 Data Channels read Live time $=386 \mathrm{sec}$

Proton Drop Point $=$ Channel 302 equivalent to $101.0 \mathrm{keV} / \mathrm{micron}$

Neutron Start Point $=$ Channel 29 equivalent to $9.7 \mathrm{keV} / \mathrm{micron}$

No Gamma Data

- - - -DISTRIBUTION PARAMETERS - - - -

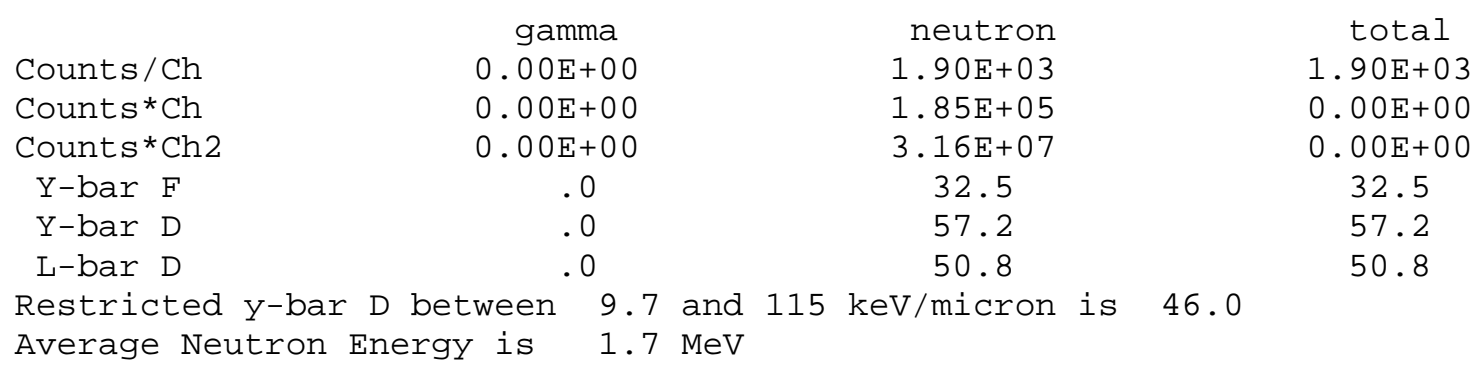

----DOSE AND DOSE EQUIVALENT DATA----

Integral Dose, mrad

Standard Deviation

Quality Factors

Integral DE, mrem

Dose Rate, $\mathrm{mrad} / \mathrm{hr}$

DE Rate, mrem/hr $\odot . \odot \odot E+\odot \odot$

$\odot . \odot \odot E+\odot \odot$

1.0

$\odot . \odot \odot E+\odot \odot$

$\odot .0 \odot E+\odot \odot$

$\odot . \odot \odot E+\odot \odot$
1. $17 \mathrm{E}+01$

2. $69 \mathrm{E}-01$

10.8

1. $26 \mathrm{E}+02$

1. $.9 \mathrm{E}+02$

1. $18 \mathrm{E}+03$
1. $17 \mathrm{E}+01$

2. $69 \mathrm{E}-01$

10.8

1. $26 \mathrm{E}+02$

1. $\odot 9 \mathrm{E}+\odot 2$

$1.18 \mathrm{E}+03$ 
INPUT FILE NAME: t22_1mb.txt

FILE TITLE: TEPC 1122 at $1 \mathrm{~m}$ from unmod Cf252, 318-356 in LSR. 8/20/9

TEPC OUTPUT SUMMARY

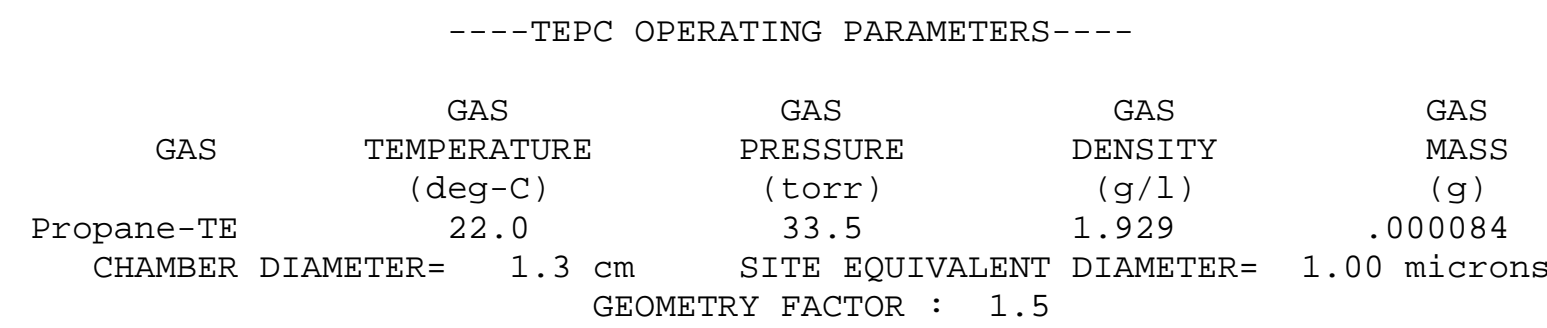

2048 Data Channels read Live time $=797 \mathrm{sec}$

Proton Drop Point $=$ Channel 302 equivalent to $101.0 \mathrm{keV} / \mathrm{micron}$

Neutron Start Point $=$ Channel 29 equivalent to $9.7 \mathrm{keV} / \mathrm{micron}$

No Gamma Data

- - - - DISTRIBUTION PARAMETERS - - -

\begin{tabular}{|c|c|c|c|}
\hline & gamma & neutron & total \\
\hline Counts/Ch & $\odot . \odot \odot E+\odot \odot$ & $4.02 E+03$ & $4.02 E+\odot 3$ \\
\hline Counts* Ch & $\odot . \odot \odot E+\odot \odot$ & $3.94 \mathrm{E}+05$ & $\odot .0 \odot \mathrm{E}+\odot$ \\
\hline Counts ${ }^{*}$ Ch2 & $\odot . \odot \odot E+\odot \odot$ & $7.08 E+07$ & $\odot .00 \mathrm{E}+\odot$ \\
\hline $\mathrm{Y}$-bar $\mathrm{F}$ & .0 & 32.8 & 32.8 \\
\hline$Y$-bar D &.$\odot$ & 60.1 & 60.1 \\
\hline L-bar D & .0 & 53.4 & 53.4 \\
\hline
\end{tabular}

Restricted $y$-bar $D$ between 9.7 and $115 \mathrm{keV} / \mathrm{micron}$ is 46.3

Average Neutron Energy is $1.6 \mathrm{MeV}$

---DOSE AND DOSE EQUIVALENT DATA----

Integral Dose, mrad

Standard Deviation

Quality Factors

Integral DE, mrem

Dose Rate, $\mathrm{mrad} / \mathrm{hr}$

DE Rate, mrem/hr $\odot . \odot \odot E+\odot \odot$

$\odot .0 \odot E+\odot \odot$

1.0

$\odot .00 \mathrm{E}+\odot \odot$

$\odot .0 \odot E+\odot \odot$

$\odot . \odot \odot E+\odot \odot$
2. $50 \mathrm{E}+01$

3. $94 \mathrm{E}-01$

10.8

$2.71 \mathrm{E}+02$

1. $13 \mathrm{E}+02$

1. $22 \mathrm{E}+03$
2. $50 \mathrm{E}+01$

3. $94 \mathrm{E}-01$

10.8

2. $71 \mathrm{E}+02$

1. $13 \mathrm{E}+02$

1. $22 \mathrm{E}+03$ 
APPENDIX B

TEPC RESULTS FOR WHOLE BODY MEASUREMENTS 
Program TEPC_NG

Version: December, 1989

INPUT FILE NAME: h9ant73.txt

FILE TITLE: TEPC 1173 on North Side of Hood 9A, rm 235A-3, PFP. 6/18/

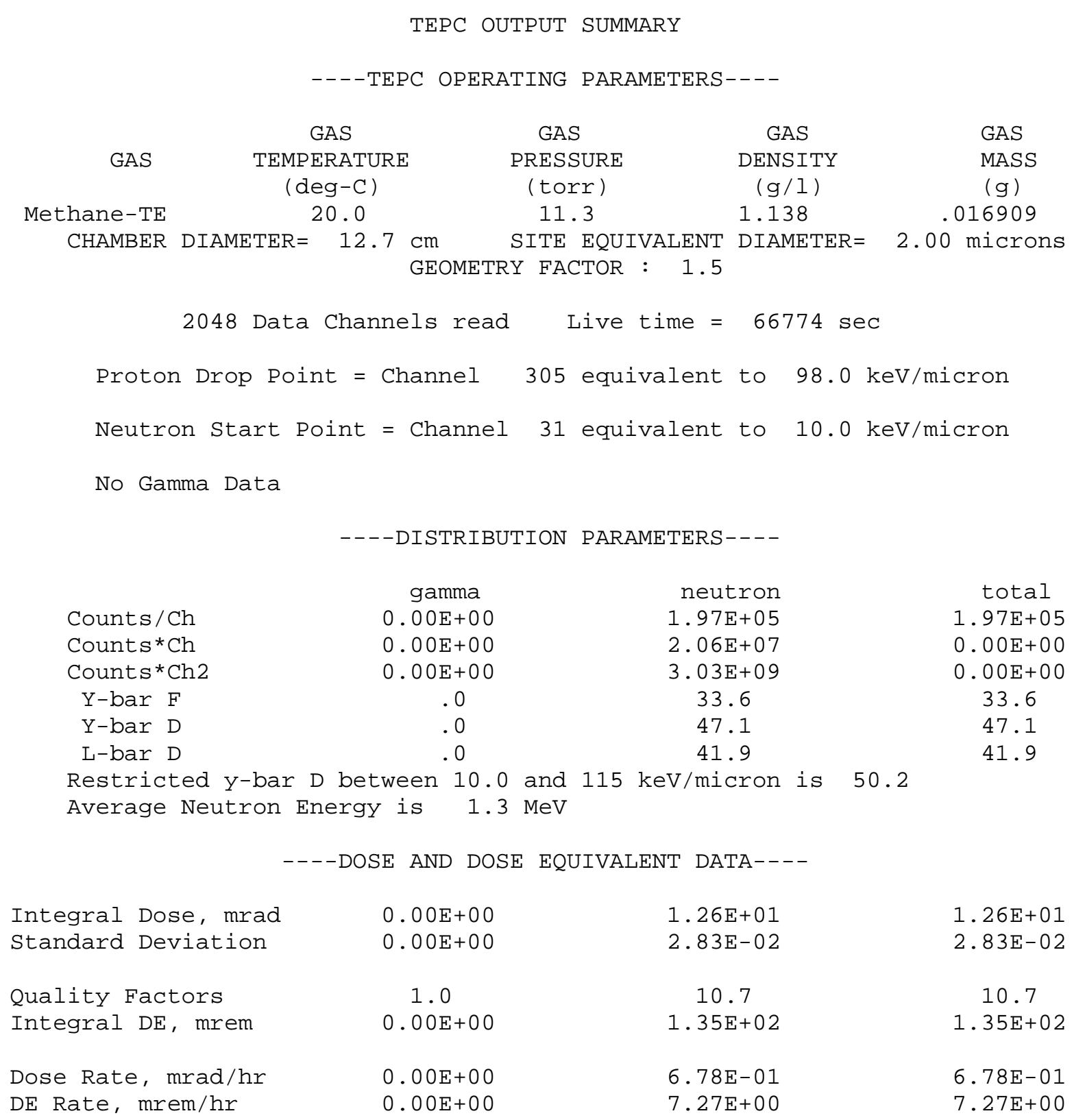

B. 1 
INPUT FILE NAME: h9ant85.txt

Version: December, 1989

FILE TITLE: TEPC 185 at north side of Hood 9A, Rm 235A-3, PFP. 6/18/9

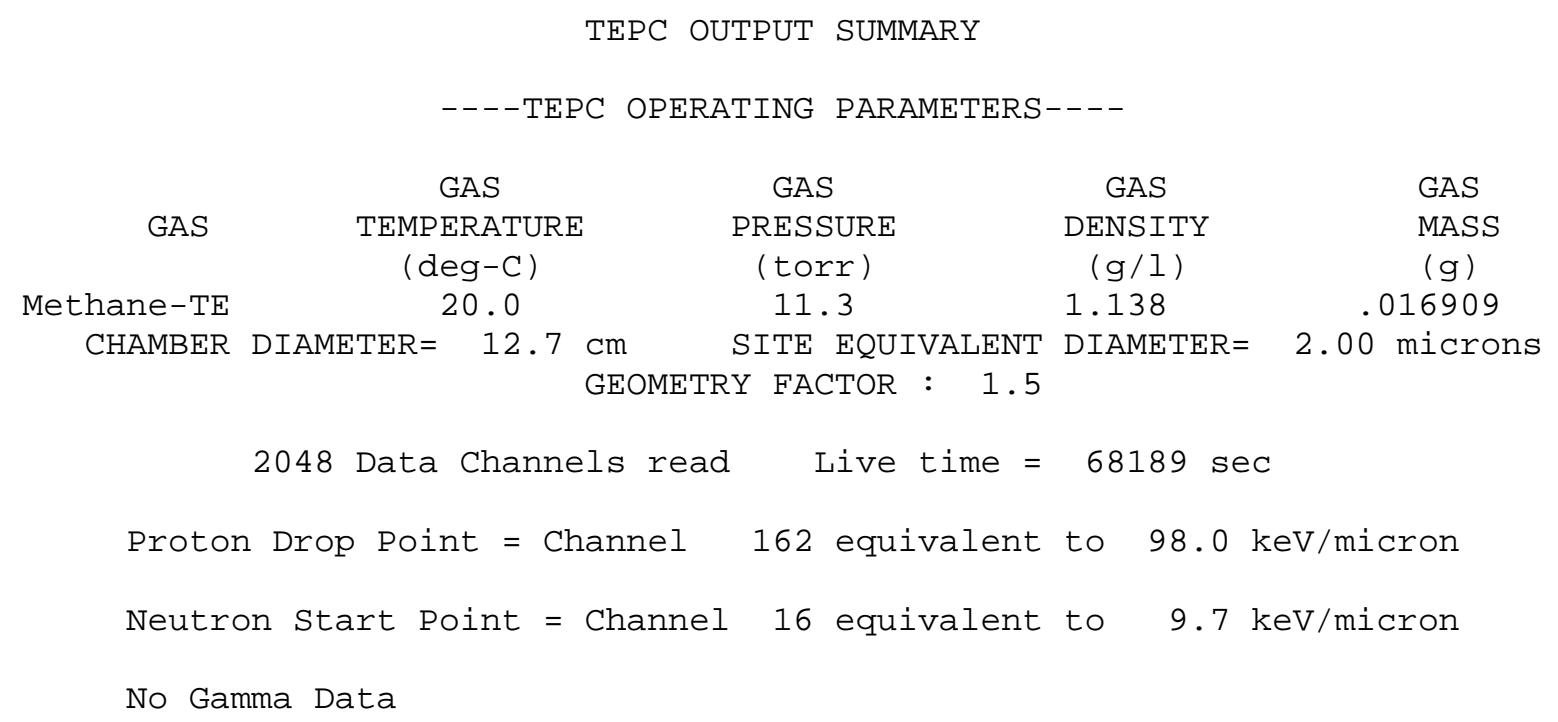

Integral Dose, mrad

Standard Deviation

Quality Factors

Integral DE, mrem

Dose Rate, $\mathrm{mrad} / \mathrm{hr}$

DE Rate, $\mathrm{mrem} / \mathrm{hr}$
$\odot . \odot \odot E+\odot \odot$
$\odot . \odot \odot E+\odot \odot$
1.0
$\odot . \odot \odot E+\odot \odot$
$\odot . \odot \odot E+\odot \odot$
$\odot .00 \mathrm{E}+\Theta \odot$

1. $14 \mathrm{E}+01$

2. 74E- 02

10.8

1. $22 \mathrm{E}+02$

6. $00 \mathrm{E}-01$

6. $45 \mathrm{E}+00$
1. $14 \mathrm{E}+01$

2. 74E-02

10.8

1. $22 \mathrm{E}+\mathrm{O} 2$

6. $\odot \odot \mathrm{E}-01$

$6.45 \mathrm{E}+00$ 
INPUT FILE NAME: h9ast70.txt

Version: December, 1989

FILE TITLE: TEPC 1170 on south side of Hood 9A, Rm 235A-3, PFP. 6/18/

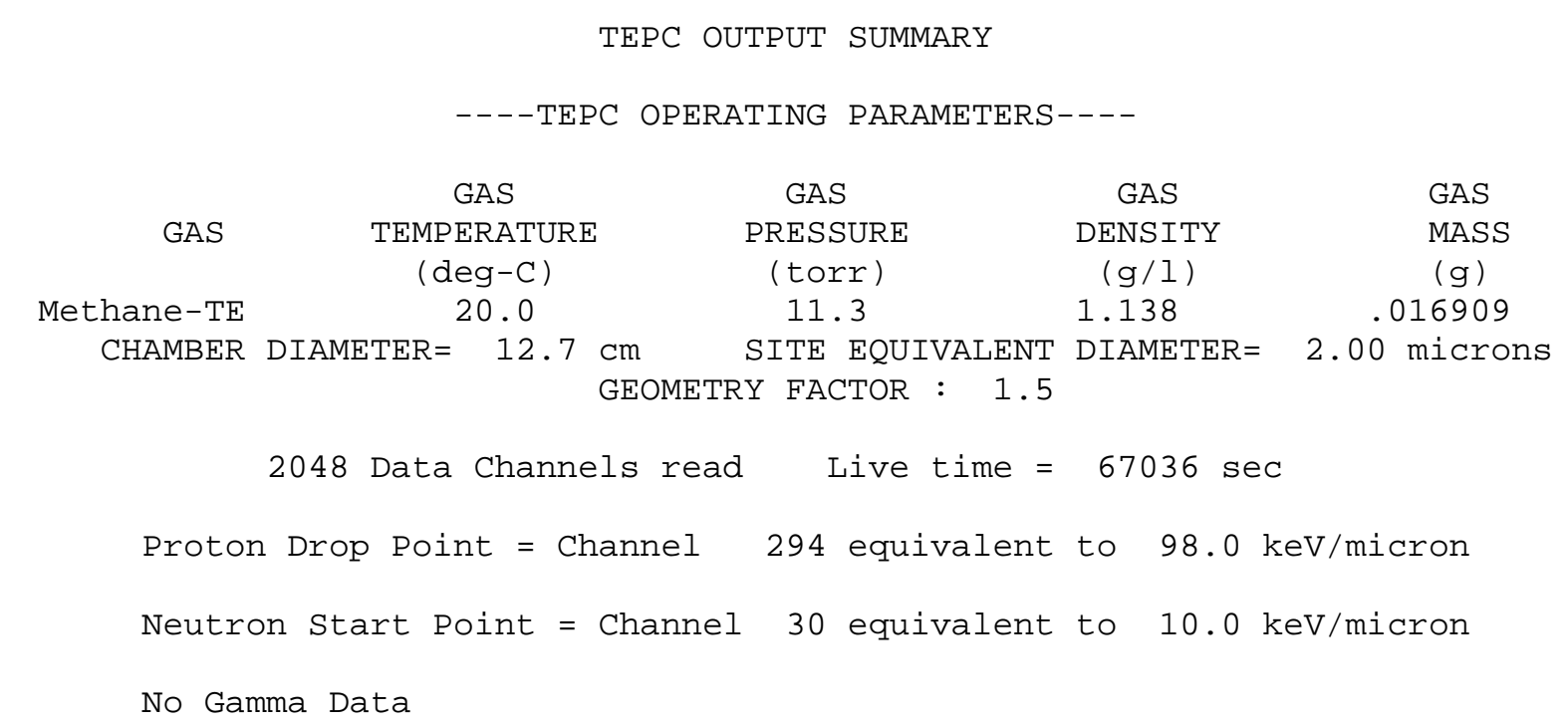

Integral Dose, mrad

Standard Deviation

Quality Factors

Integral DE, mrem

Dose Rate, $\mathrm{mrad} / \mathrm{hr}$

DE Rate, mrem/hr
$\odot .00 \mathrm{E}+\odot \odot$
$\odot . \odot \odot E+\odot \odot$
1.0
$\odot . \odot \odot E+\odot \odot$
$\odot .00 \mathrm{E}+0 \odot$
$\odot .00 \mathrm{E}+\Theta \odot$

1. $49 \mathrm{E}+01$

3. $20 \mathrm{E}-02$

11.0

1. $65 \mathrm{E}+02$

8. $01 \mathrm{E}-01$

8. 84E+००
1. $49 \mathrm{E}+01$

3. $20 \mathrm{E}-02$

11.0

1. $65 \mathrm{E}+02$

8. $01 E-01$

8. $84 \mathrm{E}+00$ 
INPUT FILE NAME: h9ast72.txt

FILE TITLE: TEPC 1172 on south side of Hood 9A, Rm 235A-3, PFP. 6/18/

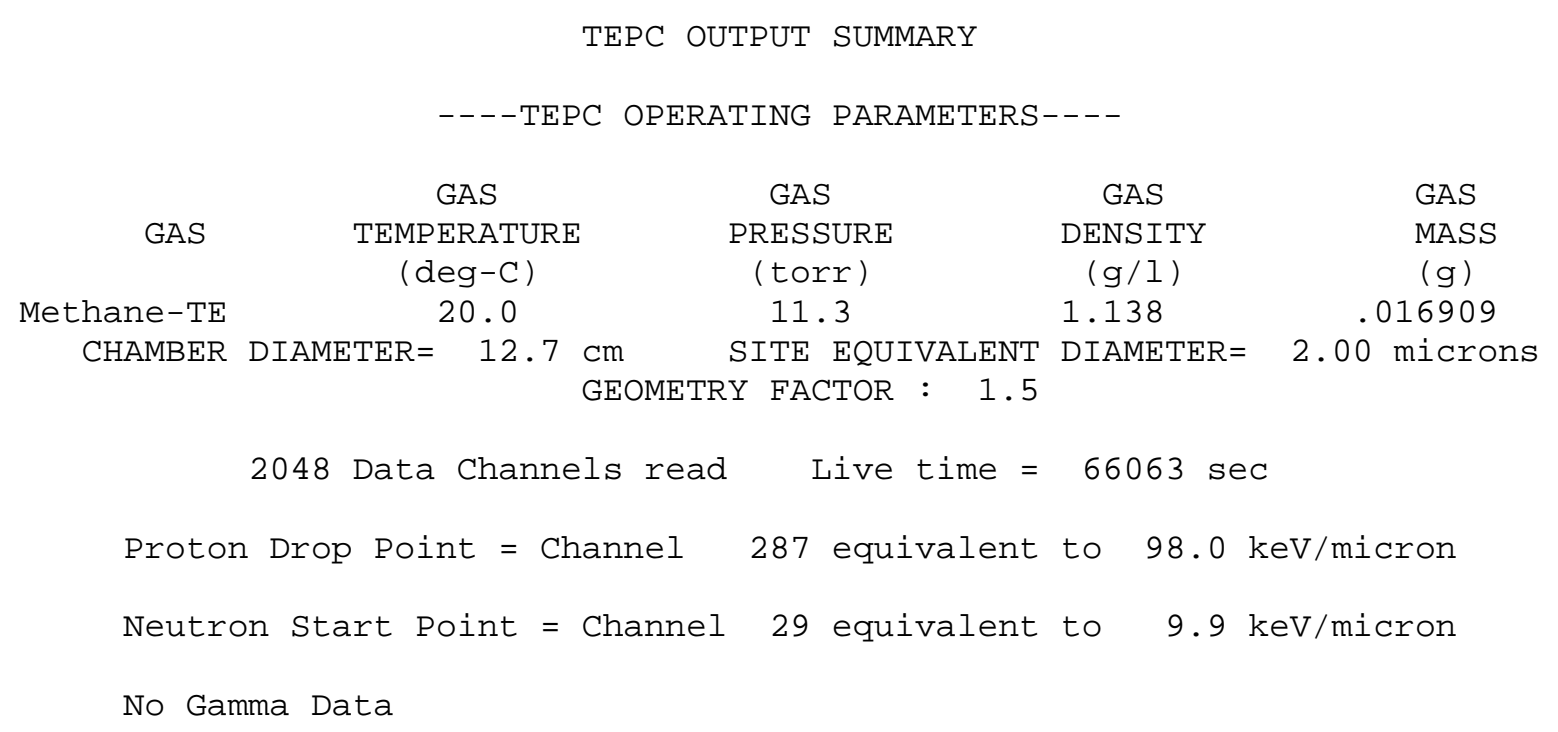

Integral Dose, mrad

Standard Deviation

Quality Factors

Integral DE, mrem

Dose Rate, $\mathrm{mrad} / \mathrm{hr}$

DE Rate, mrem/hr
$\odot .0 \odot E+\odot \odot$
$\odot .0 \odot E+\odot \odot$
1.0
$\odot . \odot \odot E+\odot \odot$
$\odot . \odot \odot E+\odot \odot$
$\odot .0 \odot E+\odot \odot$

1. $22 \mathrm{E}+01$

2. $83 \mathrm{E}-02$

10.8

1. $31 \mathrm{E}+02$

6. 63E- 01

7. $15 \mathrm{E}+00$
1. $22 \mathrm{E}+01$

2. 83E- 02

10. 8

1. $31 \mathrm{E}+02$

6. 63E- 01

$7.15 \mathrm{E}+00$ 
INPUT FILE NAME: t72v4r3.txt

FILE TITLE: TEPC 1172 in PFP Vault 4, between cabinets. 7/19/99

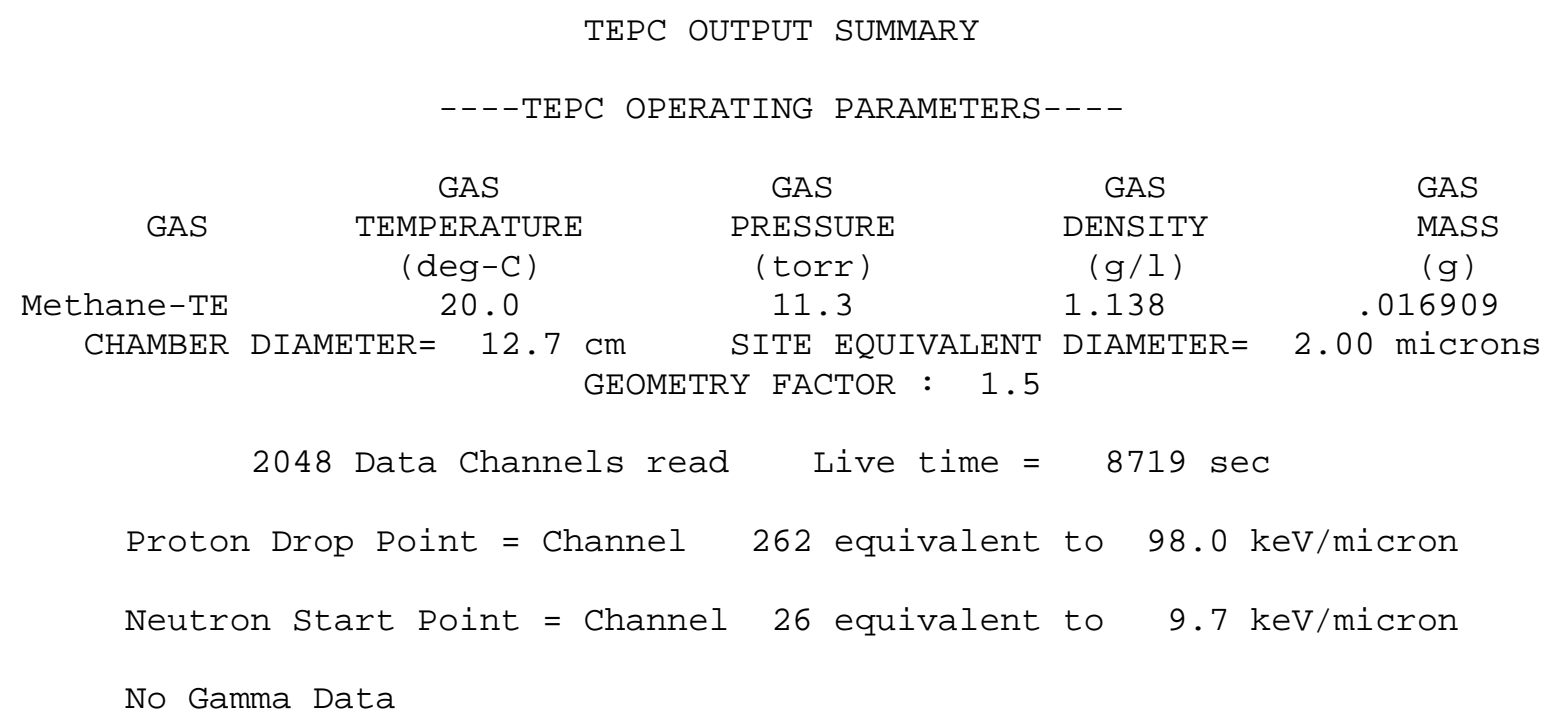

Integral Dose, mrad

Standard Deviation

Quality Factors

Integral DE, mrem

Dose Rate, $\mathrm{mrad} / \mathrm{hr}$

DE Rate, mrem/hr

\begin{abstract}
$\odot .00 \mathrm{E}+\odot \odot$
\end{abstract}
$\odot . \odot \odot E+\odot \odot$

1.0

$\odot . \odot \odot E+\odot \odot$

$\odot . \odot \odot E+\odot \odot$

$\odot .00 \mathrm{E}+\odot \odot$
$7.50 \mathrm{E}+0 \odot$

$2.15 \mathrm{E}-02$

10.5

7. $87 \mathrm{E}+01$

$3.10 \mathrm{E}+00$

3. $25 \mathrm{E}+01$
7. $50 \mathrm{E}+00$

$2.15 \mathrm{E}-02$

10.5

7. $87 \mathrm{E}+01$

$3.10 \mathrm{E}+00$

3. $25 \mathrm{E}+01$ 
Program TEPC_NG

Version: December, 1989

INPUT FILE NAME: t73v4r3.txt

FILE TITLE: TEPC 1173 in PFP Vault 4, between cabinets. 7/19/99

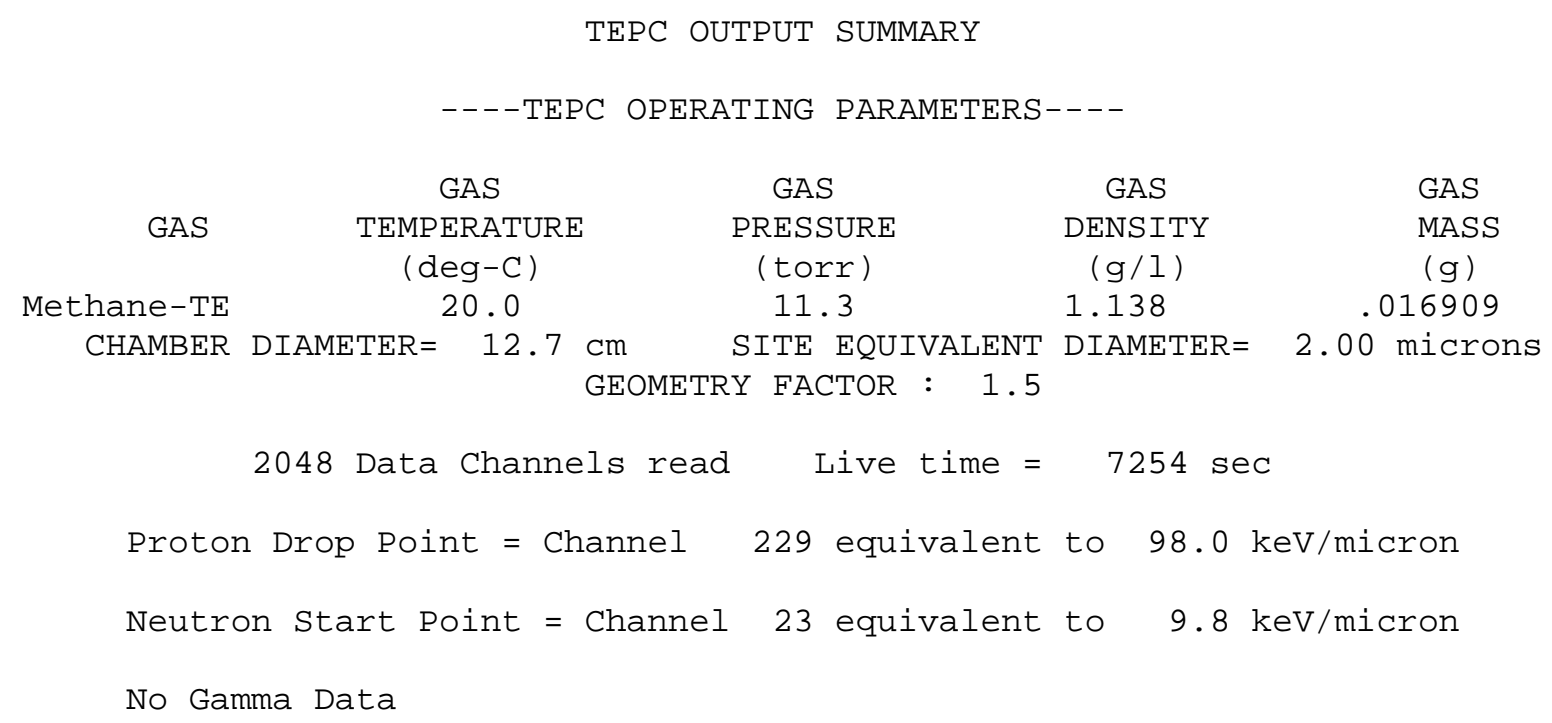

46.9

41.7

Restricted $\mathrm{y}$-bar $\mathrm{D}$ between 9.8 and $115 \mathrm{keV} / \mathrm{micron}$ is 47.1

Average Neutron Energy is $1.6 \mathrm{MeV}$

DOSE AND DOSE EQUIVALENT DATA----

\begin{tabular}{|c|c|c|c|}
\hline Integral Dose, mrad & $\odot . \odot \odot E+\odot \odot$ & $6.49 \mathrm{E}+\odot \odot$ & $6.49 \mathrm{E}+0 \odot$ \\
\hline Standard Deviation & $\odot .00 \mathrm{E}+\odot \odot$ & $1.98 \mathrm{E}-02$ & 1. $98 \mathrm{E}-02$ \\
\hline Quality Factors & 1.0 & 10.4 & 10.4 \\
\hline Integral $\mathrm{DE}$, mrem & $\odot . \odot \odot E+\odot \odot$ & $6.74 \mathrm{E}+01$ & $6.74 \mathrm{E}+01$ \\
\hline Dose Rate, $\mathrm{mrad} / \mathrm{hr}$ & $\odot .0 \odot E+\odot \odot$ & $3.22 \mathrm{E}+0 \odot$ & 3. $22 \mathrm{E}+0 \odot$ \\
\hline
\end{tabular}


Program TEPC_NG

Version: December, 1989

INPUT FILE NAME: t504v4r3.txt

FILE TITLE: TEPC 504 in PFP Vault 4, at Back Wall. 7/19/99

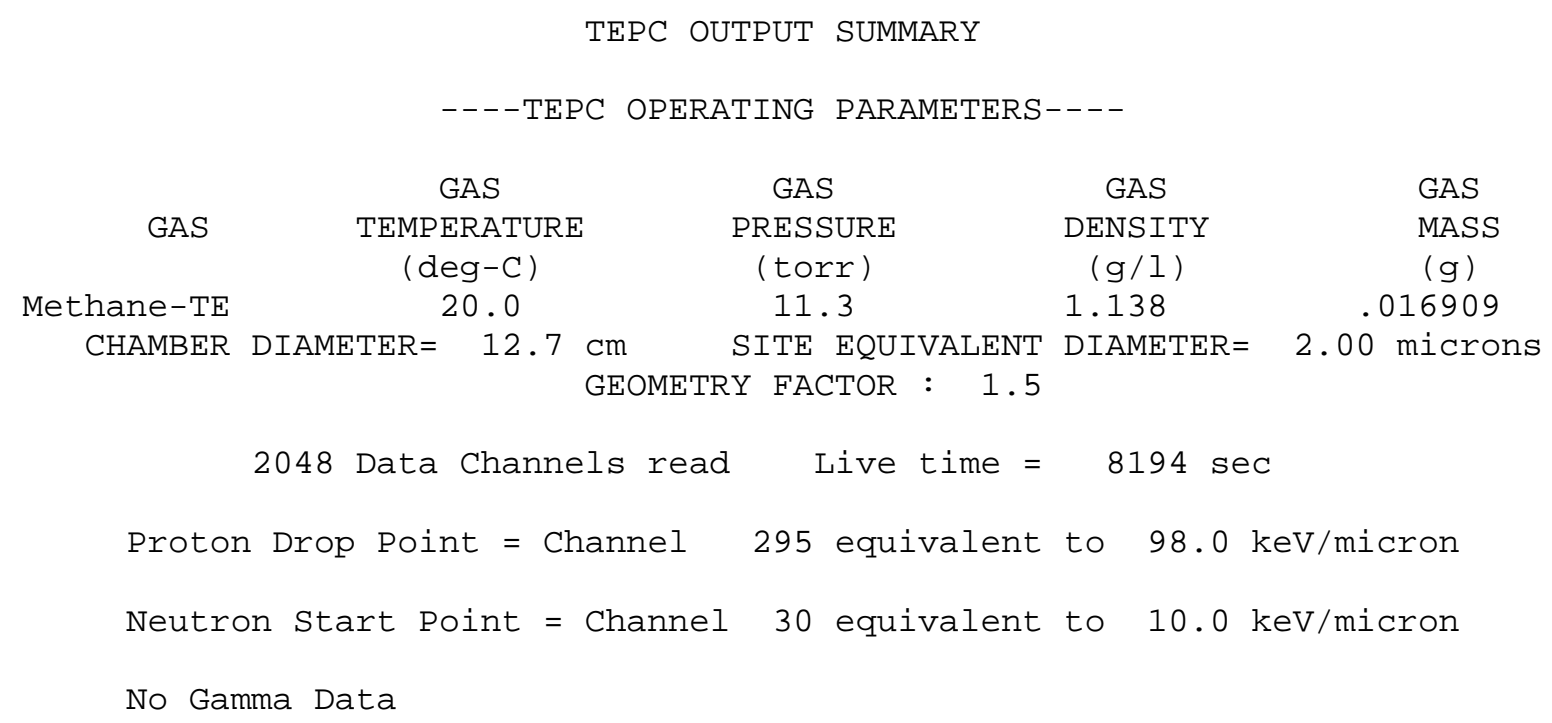

Integral Dose, mrad

Standard Deviation

Quality Factors

Integral DE, mrem

Dose Rate, $\mathrm{mrad} / \mathrm{hr}$

DE Rate, $\mathrm{mrem} / \mathrm{hr}$
$\odot . \odot \odot E+\odot \odot$

\begin{abstract}
$\odot . \odot \odot E+\odot \odot$
\end{abstract}
1.0
$\odot . \odot \odot E+\odot \odot$
$\odot .00 E+0 \odot$
$\odot .00 \mathrm{E}+\odot \odot$

4. $00 \mathrm{E}+\odot \odot$

1. $60 \mathrm{E}-02$

10.7

4. $27 \mathrm{E}+01$

$1.76 \mathrm{E}+00$

1. $88 \mathrm{E}+01$
4. $.0 \mathrm{E}+\odot \odot$

1. $60 \mathrm{E}-02$

10. 7

4. $27 \mathrm{E}+01$

1. $76 \mathrm{E}+0 \odot$

1. $88 \mathrm{E}+01$ 
INPUT FILE NAME: t70v4r3.txt

FILE TITLE: TEPC 1170 in PFP Vault 4, at Back Wall. 7/19/99

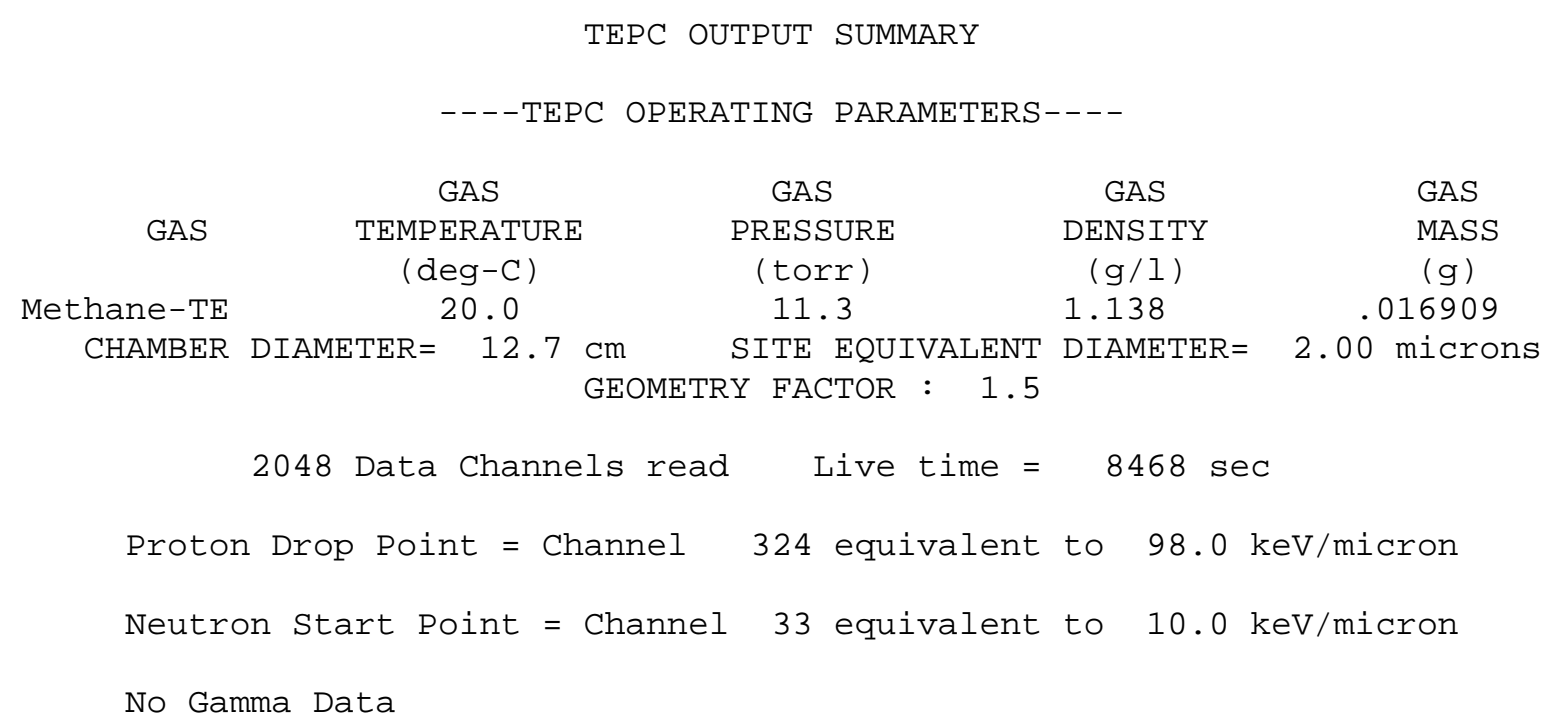

\begin{tabular}{|c|c|c|c|}
\hline & gamma & neutron & total \\
\hline Counts/Ch & $\odot . \odot \odot \mathrm{E}+\odot \odot$ & $7.15 E+04$ & $7.15 \mathrm{E}+04$ \\
\hline Counts ${ }^{*} \mathrm{Ch}$ & $\odot . \odot \odot E+\odot \odot$ & $7.83 E+06$ & $\odot . \odot \odot E+\odot \odot$ \\
\hline Counts ${ }^{*} \mathrm{Ch} 2$ & $\odot . \odot \odot \mathrm{E}+\odot \odot$ & $1.25 \mathrm{E}+09$ & $\odot . \odot \odot E+\odot \odot$ \\
\hline$Y$-bar F & .0 & 33.1 & 33.1 \\
\hline Y-bar D & .0 & 48.2 & 48.2 \\
\hline L-bar D & .0 & 42.9 & 42.9 \\
\hline
\end{tabular}

Restricted $\mathrm{y}$-bar $\mathrm{D}$ between 10.0 and $115 \mathrm{keV} / \mathrm{micron}$ is 48.8 Average Neutron Energy is $1.4 \mathrm{MeV}$

----DOSE AND DOSE EQUIVALENT DATA----

Integral Dose, mrad

Standard Deviation

Quality Factors

Integral DE, mrem

Dose Rate, $\mathrm{mrad} / \mathrm{hr}$

DE Rate, mrem/hr
$\odot . \odot \odot E+\odot \odot$
$\odot .00 \mathrm{E}+\odot \odot$
1.0
$\odot . \odot \odot E+\odot \odot$
$\odot . \odot \odot E+\odot \odot$
$\odot . \odot \odot \mathrm{E}+\odot \odot$

$4.49 \mathrm{E}+0 \odot$

$1.68 \mathrm{E}-02$

10.6

4. $76 \mathrm{E}+01$

1. $91 \mathrm{E}+00$

2. $02 \mathrm{E}+01$
4. $49 \mathrm{E}+\odot \odot$

$1.68 \mathrm{E}-02$

10.6

4. $76 \mathrm{E}+01$

1. $91 \mathrm{E}+00$

2. $02 \mathrm{E}+01$ 
INPUT FILE NAME: t72v1.txt

Version: December, 1989

FILE TITLE: TEPC 1172 in PFP 2736ZB Vault 1, Between Cabinets. 7/20/9

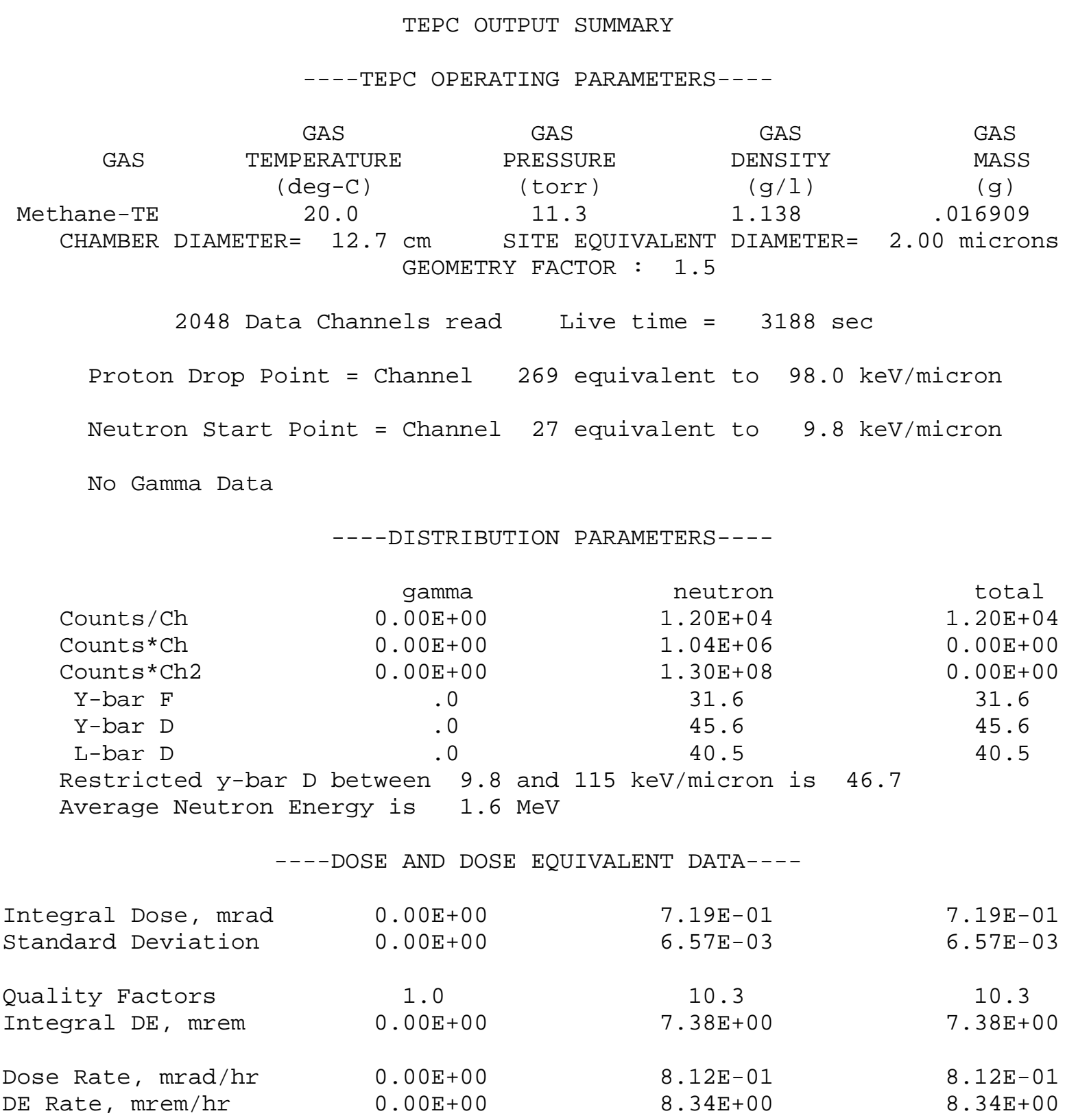


Program TEPC_NG

Version: December, 1989

INPUT FILE NAME: t73v1.txt

FILE TITLE: TEPC 1173 in PFP 2736ZB Vault 1, between Cabinets. 7/20/9

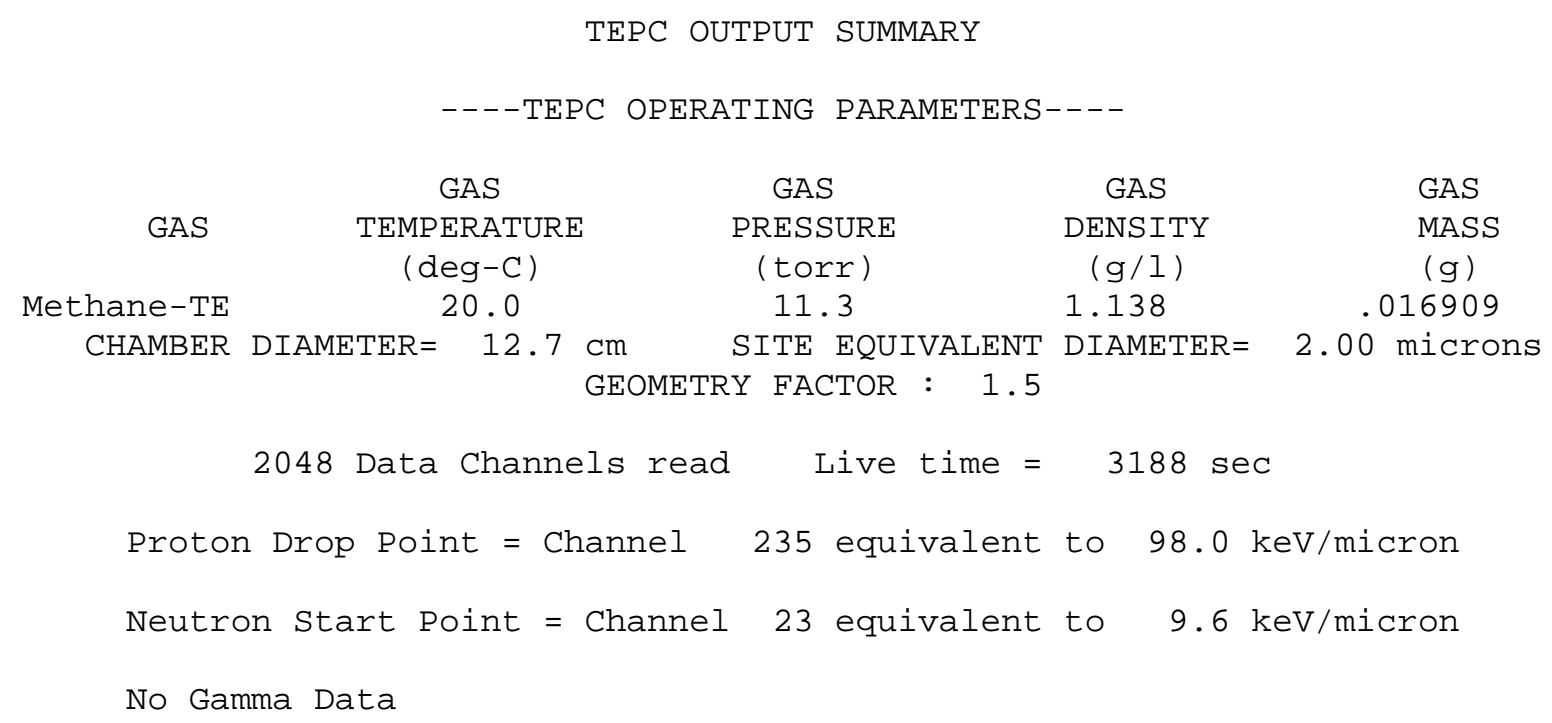

Integral Dose, mrad

Standard Deviation

Quality Factors

Integral DE, mrem

Dose Rate, $\mathrm{mrad} / \mathrm{hr}$

DE Rate, $\mathrm{mrem} / \mathrm{hr}$

\begin{abstract}
$\odot .0 \odot E+\odot \odot$
\end{abstract}
$\odot .0 \odot E+\odot \odot$

1.0

$\odot . \odot \odot E+\odot \odot$

$\odot .00 \mathrm{E}+\odot \odot$

$\odot .00 \mathrm{E}+\odot \odot$

\section{1. $04 \mathrm{E}+00$}

7. $94 \mathrm{E}-03$

10.4

1. $07 \mathrm{E}+01$

$1.17 \mathrm{E}+00$

1. $21 \mathrm{E}+01$
1. $04 \mathrm{E}+00$

7. $94 \mathrm{E}-03$

10.4

1. $07 \mathrm{E}+01$

$1.17 \mathrm{E}+0 \odot$

1. $21 \mathrm{E}+01$ 
Program TEPC_NG

Page 1

INPUT FILE NAME: t504v1.txt

FILE TITLE: TEPC 504 by Corridor Wall, PFP Vault 1. 7/20/99

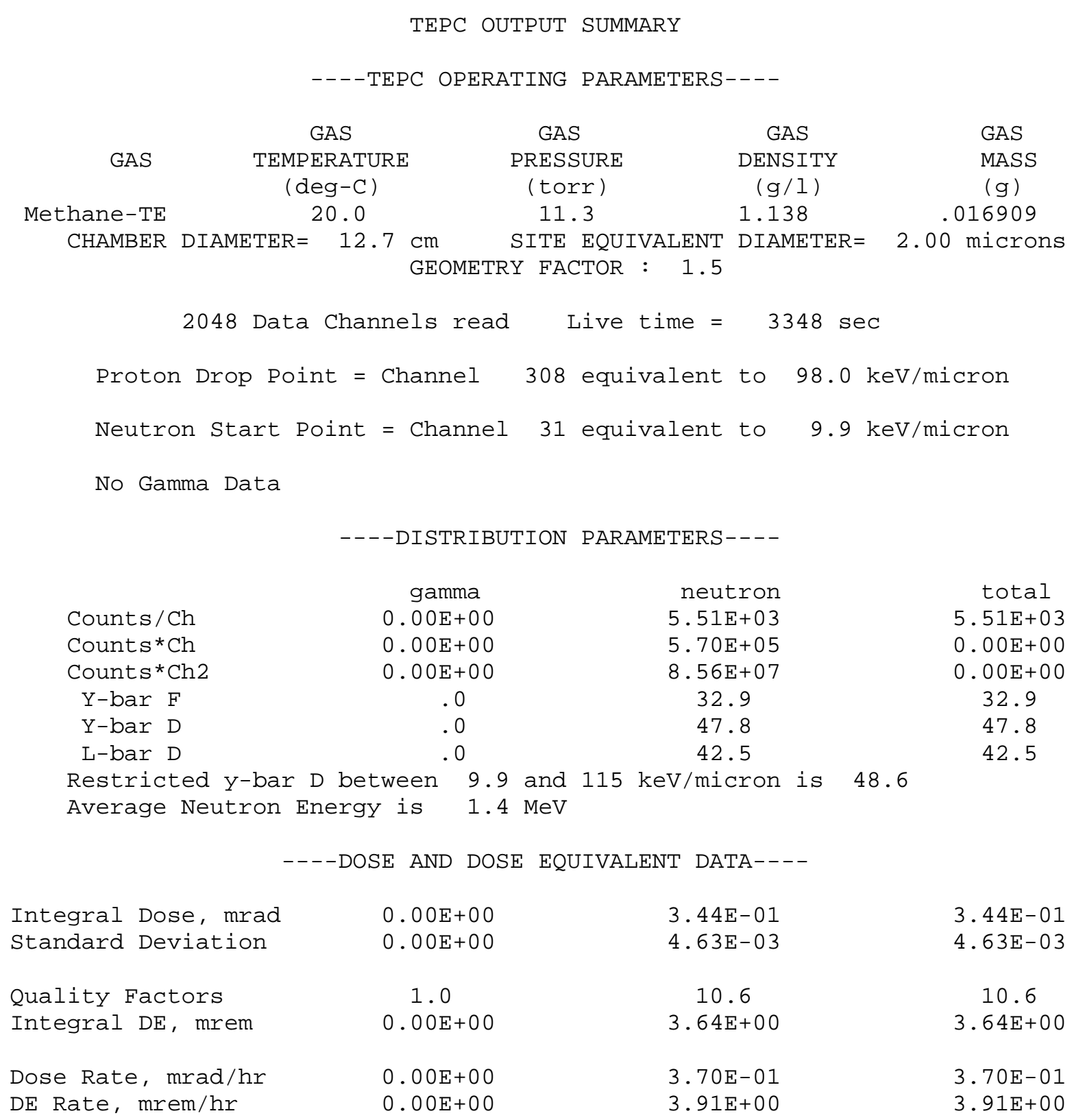


Program TEPC_NG

Version: December, 1989

INPUT FILE NAME: t70v1.txt

FILE TITLE: TEPC 1170 at Corridor wall, PFP 2736ZB Vault 1. 7/20/99

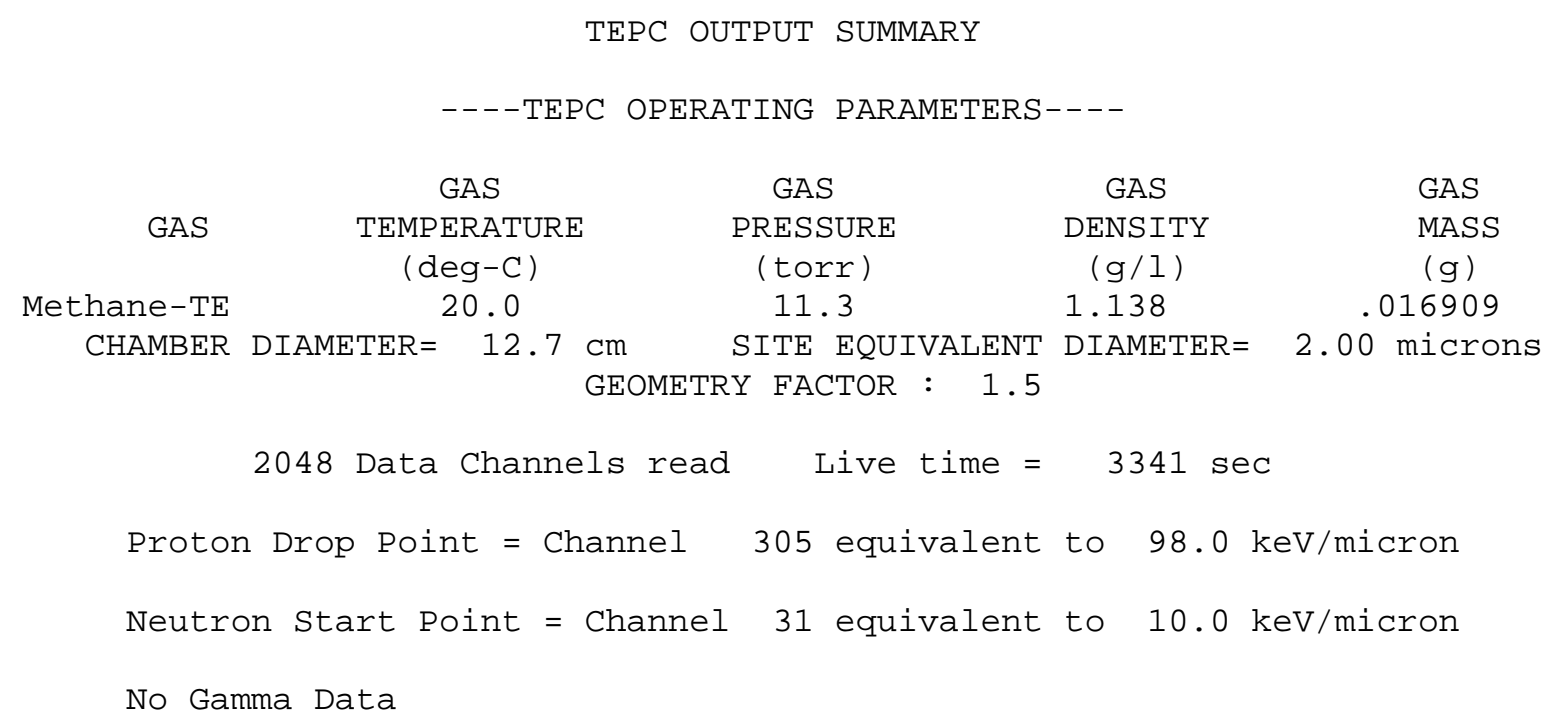

34.1

50.9

45.2

total

$5.93 \mathrm{E}+03$

$\odot .00 \mathrm{E}+\odot \odot$

$\odot . \odot \odot \mathrm{E}+\odot \odot$

34.1

50.9

45.2

Restricted $\mathrm{y}$-bar $\mathrm{D}$ between 10.0 and $115 \mathrm{keV} / \mathrm{micron}$ is 50.0

Average Neutron Energy is $1.3 \mathrm{MeV}$

\section{DOSE AND DOSE EQUIVALENT DATA----}

\begin{tabular}{|c|c|c|c|}
\hline Integral Dose, mrad & $\odot . \odot \odot E+\odot \odot$ & $3.83 E-01$ & $3.83 E-01$ \\
\hline Standard Deviation & $\odot . \odot \odot E+\odot \odot$ & 4. $97 \mathrm{E}-\odot 3$ & 4. $97 \mathrm{E}-\odot 3$ \\
\hline Quality Factors & 1.0 & 10.9 & 10.9 \\
\hline Integral $\mathrm{DE}$, mrem & $\odot . \odot \odot E+\odot \odot$ & $4.17 \mathrm{E}+0 \odot$ & $4.17 \mathrm{E}+0 \odot$ \\
\hline Dose Rate, $\mathrm{mrad} / \mathrm{hr}$ & $\odot . \odot \odot E+\odot \odot$ & $4.13 E-01$ & $4.13 E-01$ \\
\hline DE Rate, mrem/hr & $\odot . \odot \odot E+\odot \odot$ & $4.5 \odot E+\odot \odot$ & $4.5 \odot E+\odot \odot$ \\
\hline
\end{tabular}


Program TEPC_NG

Version: December, 1989

INPUT FILE NAME: t72v2btw.txt

FILE TITLE: TEPC 1172 between cabinets, Vault 2 2736-ZB. 7/26/99

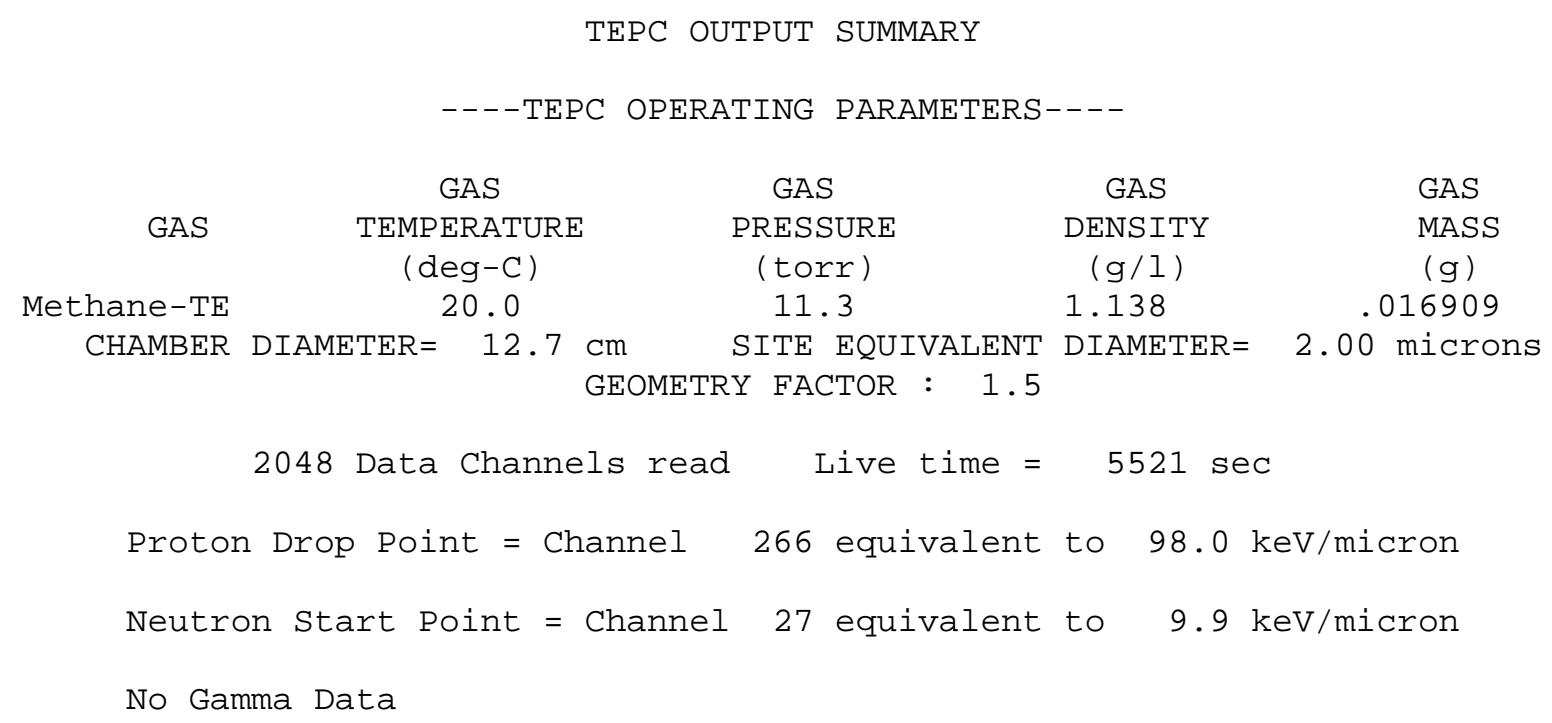

Integral Dose, mrad

Standard Deviation

Quality Factors

Integral DE, mrem

Dose Rate, $\mathrm{mrad} / \mathrm{hr}$

DE Rate, $\mathrm{mrem} / \mathrm{hr}$
$\odot . \odot \odot E+\odot \odot$
$\odot . \odot \odot E+\odot \odot$
1.0
$\odot . \odot \odot E+\odot \odot$
$\odot . \odot \odot E+\odot \odot$
$\odot .00 \mathrm{E}+\odot \odot$

6. $62 \mathrm{E}+00$

1. $98 \mathrm{E}-02$

10.3

6. $80 \mathrm{E}+01$

4. 32E+00

4. $44 \mathrm{E}+01$
$6.62 \mathrm{E}+00$

1. $98 \mathrm{E}-02$

10.3

6. $80 \mathrm{E}+01$

4. $32 \mathrm{E}+00$

4. $44 \mathrm{E}+01$ 
INPUT FILE NAME: t73v2btw.txt

FILE TITLE: TEPC 1173, 2736-ZB Vault 2, between cabinets. 7/26/99

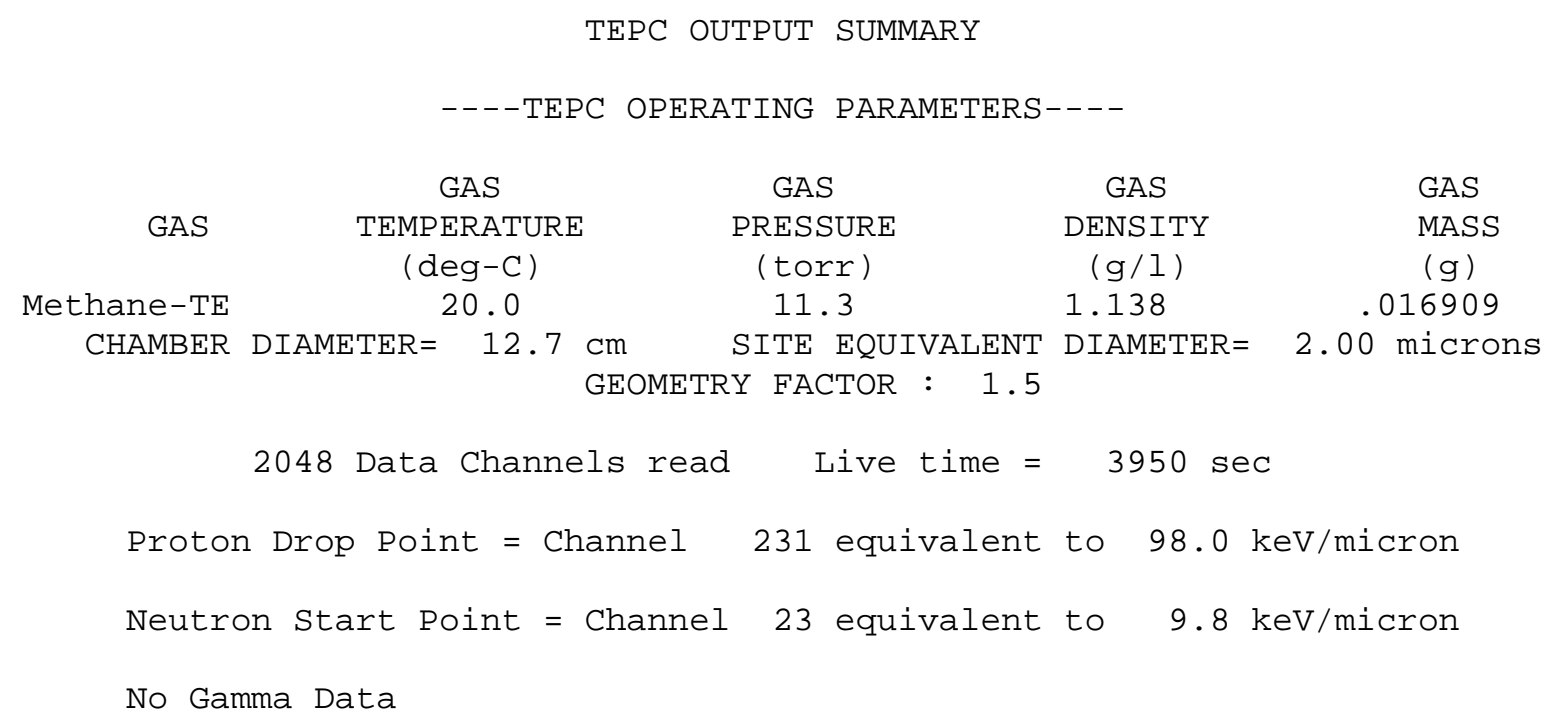

Integral Dose, mrad

Standard Deviation

Quality Factors

Integral DE, mrem

Dose Rate, $\mathrm{mrad} / \mathrm{hr}$

DE Rate, $\mathrm{mrem} / \mathrm{hr}$
$\odot .00 \mathrm{E}+\odot \odot$
$\odot .00 \mathrm{E}+\odot \odot$
1.0
$\odot . \odot \odot E+\odot \odot$
$\odot . \odot \odot E+\odot \odot$
$\odot .00 \mathrm{E}+\Theta \odot$

\section{$5.80 \mathrm{E}+00$}

1. 81E-02

10.1

$5.86 \mathrm{E}+01$

$5.29 \mathrm{E}+0 \odot$

5. $34 \mathrm{E}+01$
$5.80 \mathrm{E}+00$

$1.81 \mathrm{E}-02$

10.1

$5.86 \mathrm{E}+01$

$5.29 \mathrm{E}+0 \odot$

5. $34 \mathrm{E}+01$ 
INPUT FILE NAME: t504v2wl.txt

FILE TITLE: TEPC 504 in Vault 2, Corridor Wall. 2736-ZB. 7/26/99

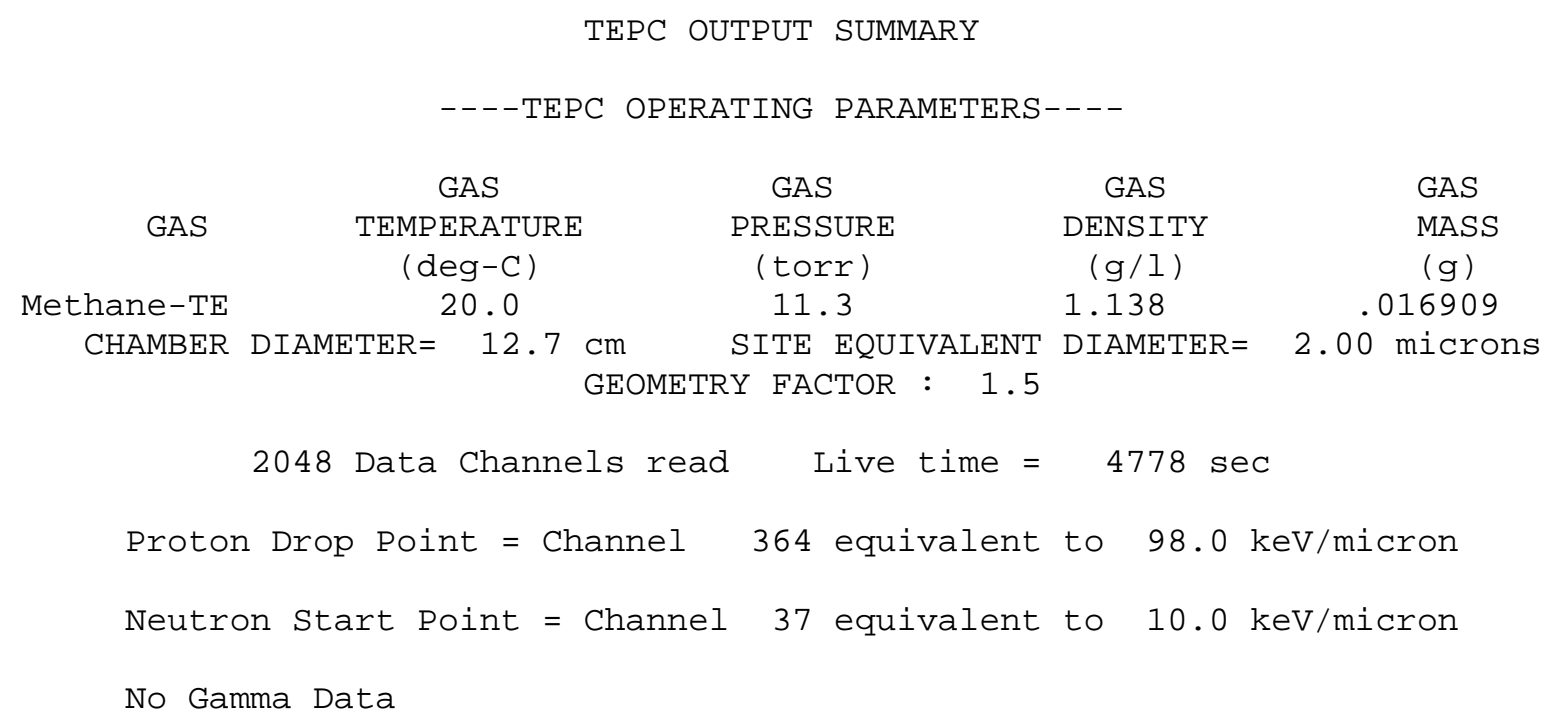

Integral Dose, mrad

Standard Deviation

Quality Factors

Integral DE, mrem

Dose Rate, $\mathrm{mrad} / \mathrm{hr}$

DE Rate, mrem/hr
$\odot .00 E+\odot \odot$
$\odot .00 \mathrm{E}+\odot \odot$
1.0
$\odot . \odot \odot E+\odot \odot$
$\odot . \odot \odot E+\odot \odot$
$\odot .00 \mathrm{E}+\Theta \odot$

$2.57 \mathrm{E}+00$

1. $27 \mathrm{E}-02$

10.6

$2.71 \mathrm{E}+01$

1. $93 \mathrm{E}+00$

2. $\odot 4 \mathrm{E}+01$
$2.57 \mathrm{E}+00$

1. $27 \mathrm{E}-02$

10.6

2. $71 \mathrm{E}+01$

1. $93 \mathrm{E}+00$

2. $04 \mathrm{E}+01$ 
Program TEPC_NG

Page 1

INPUT FILE NAME: t70v2wal.txt

FILE TITLE: TEPC 1170, Vault 2 Corridor wall. 2736-ZB. 7/26/99

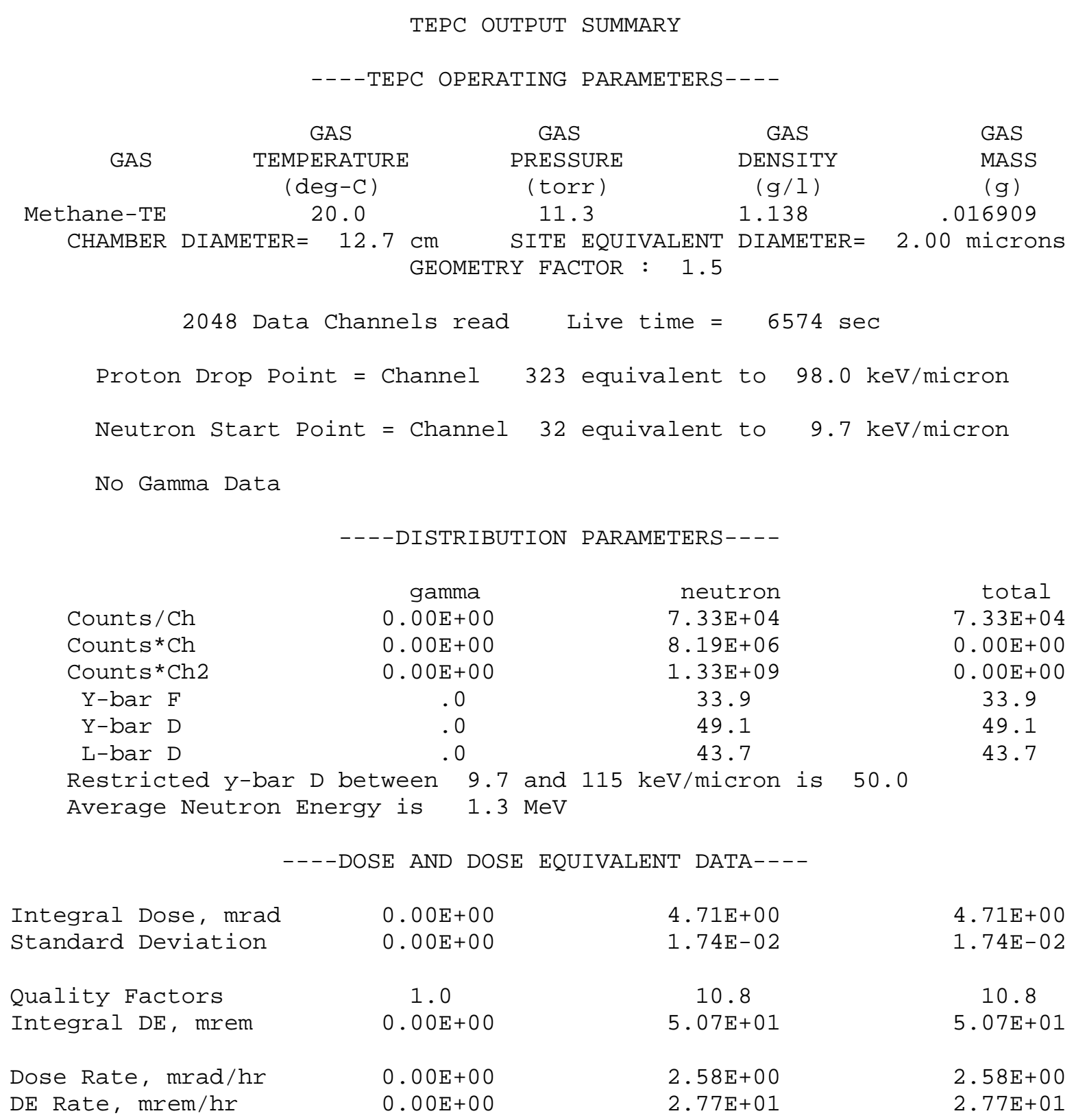


Program TEPC_NG

Version: December, 1989

INPUT FILE NAME: t504vcor.txt

FILE TITLE: TEPC 504 in the 2736ZB Vault Corridor - by Vault $3.8 / 2 / 9$

TEPC OUTPUT SUMMARY

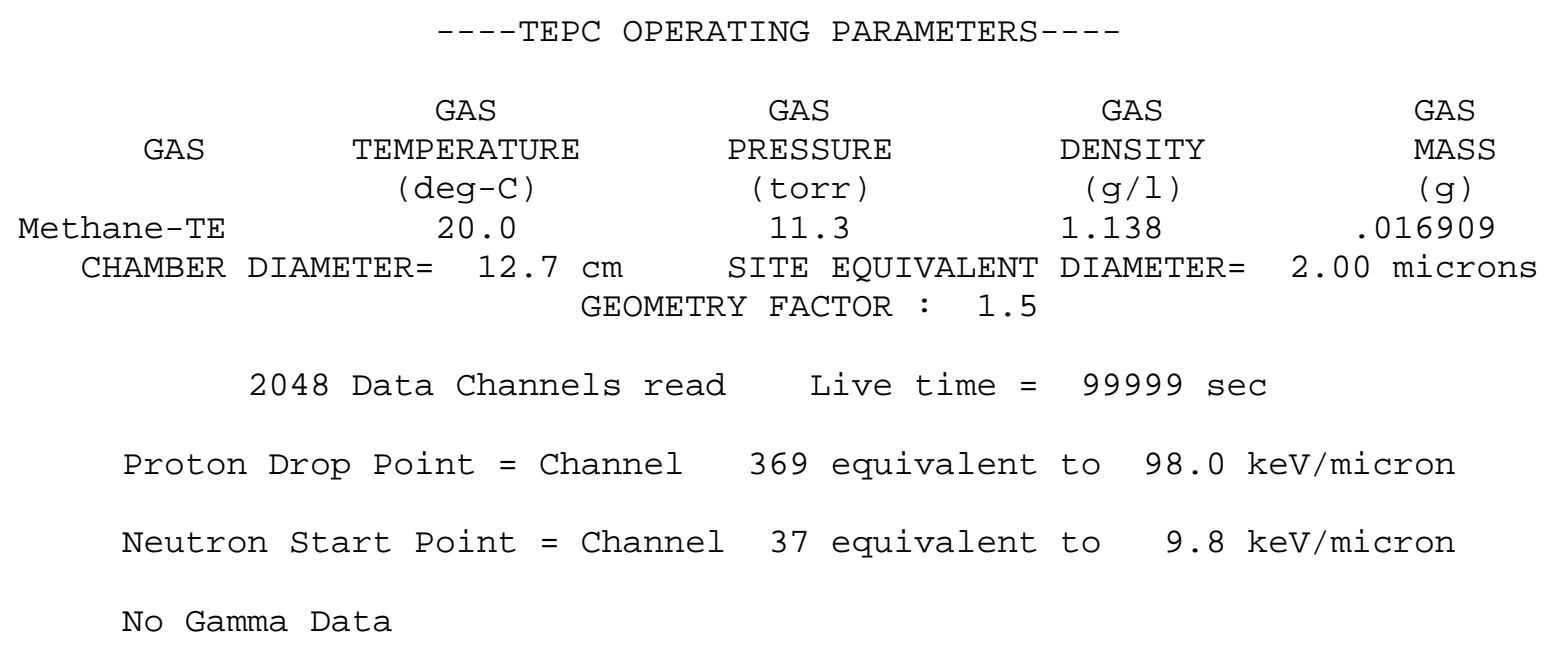

Integral Dose, mrad

Standard Deviation

Quality Factors

Integral DE, mrem

Dose Rate, $\mathrm{mrad} / \mathrm{hr}$

DE Rate, $\mathrm{mrem} / \mathrm{hr}$ $\odot .00 \mathrm{E}+\odot \odot$

$\odot . \odot \odot E+\odot \odot$

1.0

$\odot . \odot \odot E+\odot \odot$

$\odot .00 E+\odot \odot$

$\odot . \odot \odot E+\odot \odot$
$3.33 \mathrm{E}+00$

1. $43 \mathrm{E}-02$

10.5

3. $49 \mathrm{E}+01$

1. $20 \mathrm{E}-01$

1. $26 \mathrm{E}+00$
$3.33 \mathrm{E}+00$

1. $43 \mathrm{E}-02$

10.5

3. $49 \mathrm{E}+01$

1. $20 \mathrm{E}-01$

$1.26 \mathrm{E}+0 \odot$ 
Program TEPC_NG

Version: December, 1989

Page 1

INPUT FILE NAME: t70vcor.txt

FILE TITLE: TEPC 1170 in 2736ZB Vault Corridor, by Vault 3. 8/2/99

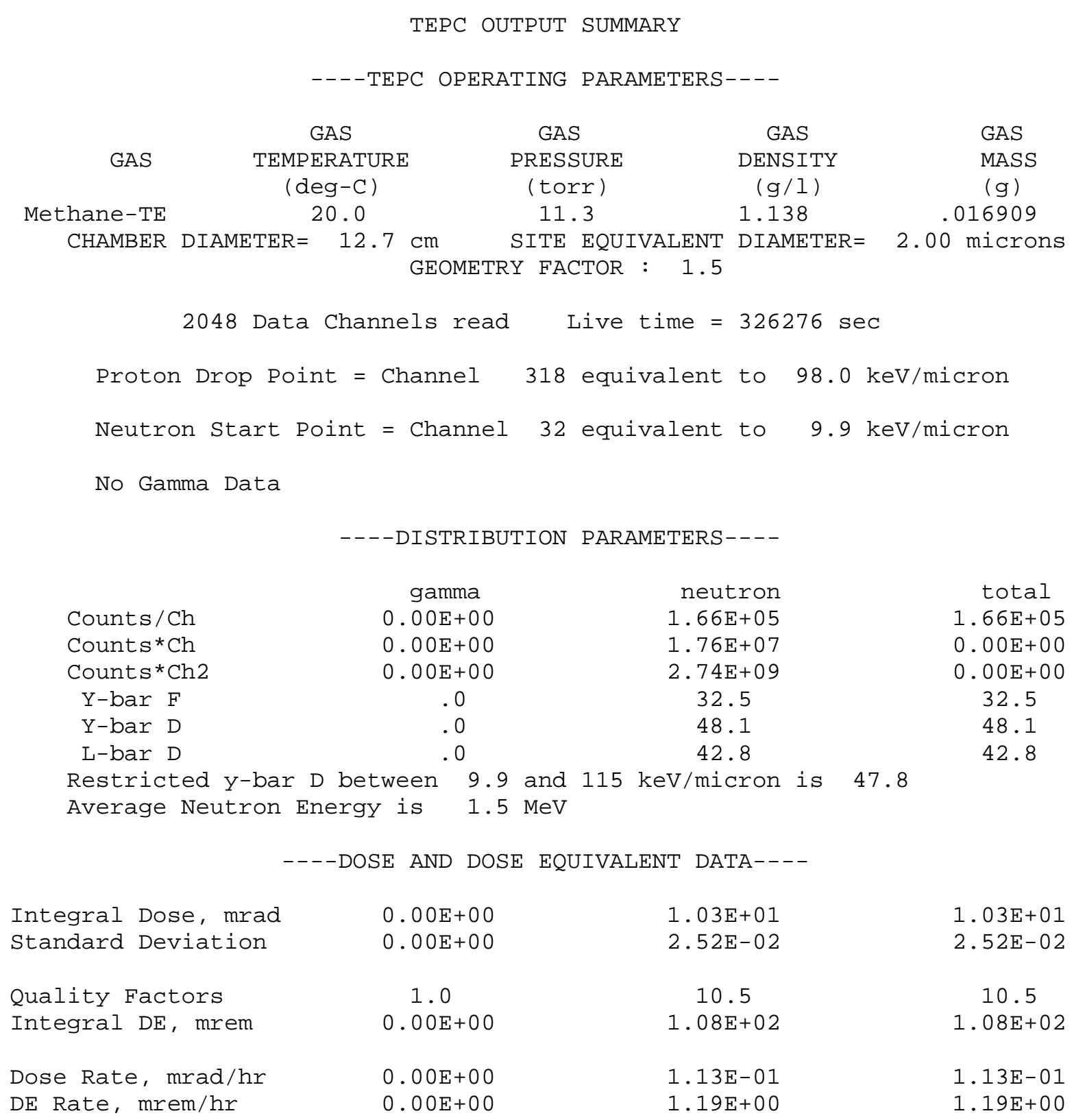


Program TEPC_NG

Version: December, 1989

INPUT FILE NAME: t72vcor.txt

FILE TITLE: TEPC 1172 in 2736ZB Vault Corridor, by Vault 1. 8/2/99

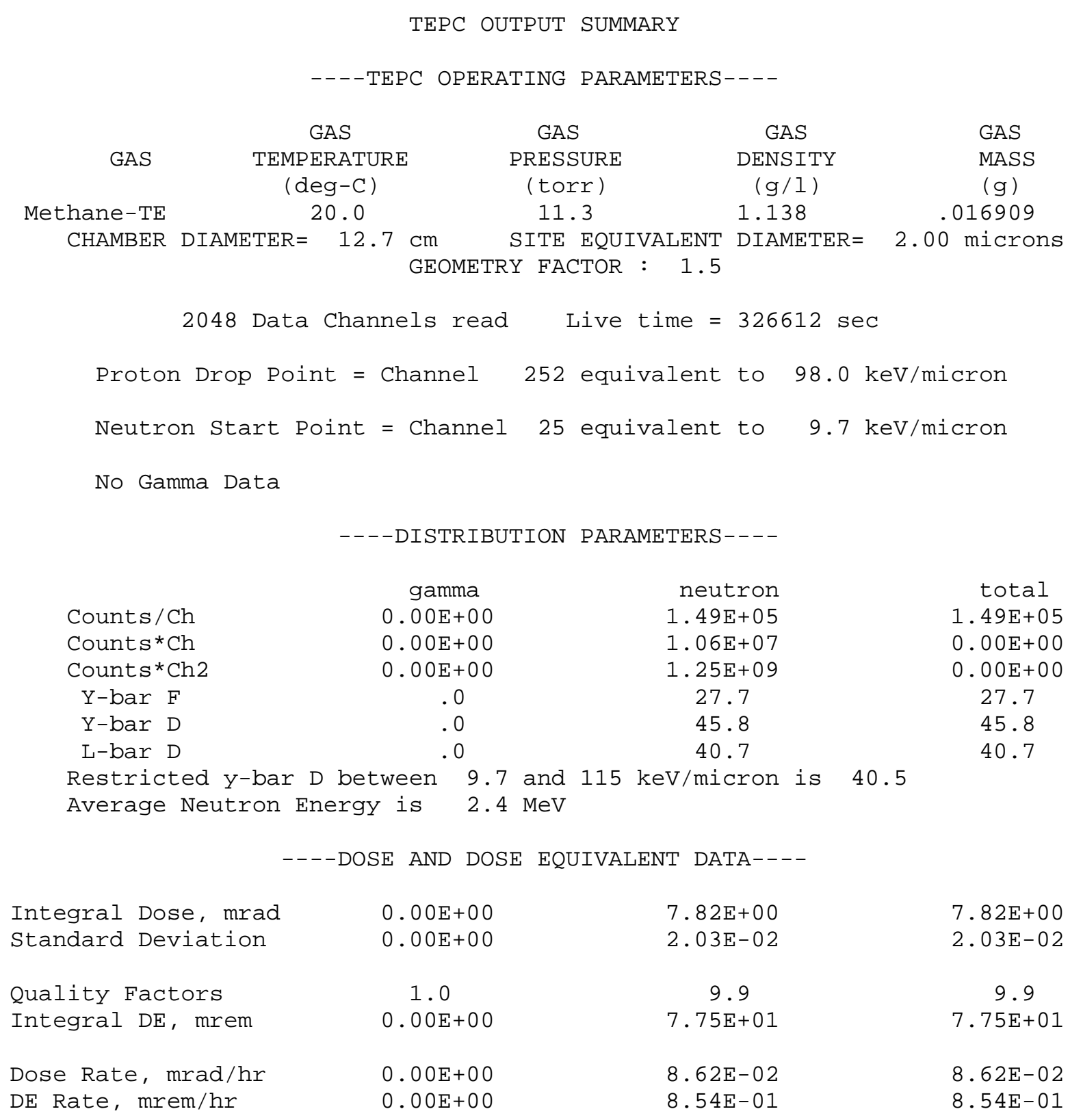


Program TEPC_NG

Version: December, 1989

Page 1

INPUT FILE NAME: t73vcor.txt

FILE TITLE: TEPC 1173 in 2736ZB Vault Corridor, by Vault $1.8 / 2 / 99$

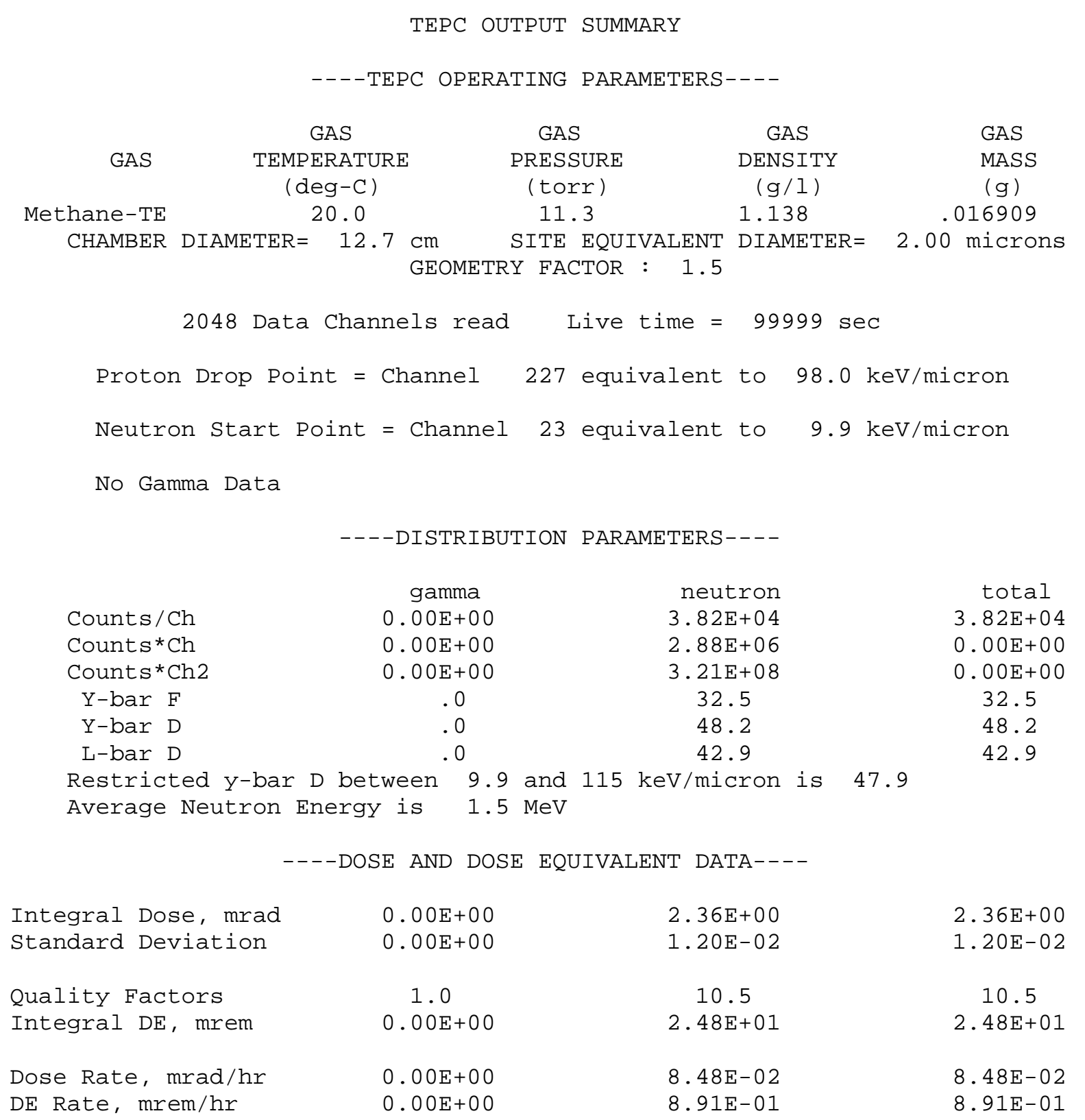


APPENDIX C

RESULTS OF BUBBLE DETECTOR MEASUREMENTS 
Table C.1. Results of bubble detector measurements - whole body study

\begin{tabular}{|c|c|c|c|c|c|c|}
\hline $\begin{array}{c}\text { Bubble } \\
\text { Detector } \\
\text { ID }\end{array}$ & Location & $\begin{array}{l}\text { Bubbles } \\
\text { counted }\end{array}$ & $\begin{array}{c}\text { Sensitivity } \\
\text { (bubbles / } \\
\text { mrem) }\end{array}$ & $\begin{array}{c}\text { Measured } \\
\text { dose } \\
\text { equivalent } \\
\text { (mrem) }\end{array}$ & $\begin{array}{l}\text { Exposure } \\
\text { time (hrs) }\end{array}$ & $\begin{array}{c}\text { Dose } \\
\text { equivalent } \\
\text { rate } \\
(\mathrm{mrem} / \mathrm{h})\end{array}$ \\
\hline 121292 & Rm 235A-3 South & 52 & 0.67 & 77.1 & 7.3 & 10.5 \\
\hline 121487 & Rm 235A-3 South & 47 & 0.72 & 65.7 & 7.3 & 9.0 \\
\hline 121022 & Rm 235A-3 South & 36 & 0.74 & 48.2 & 7.3 & 6.6 \\
\hline 123685 & Rm 235A-3 North & 49 & 0.75 & 65.8 & 7.3 & 9.0 \\
\hline 119504 & Rm 235A-3 North & 46 & 0.69 & 67.1 & 7.3 & 9.2 \\
\hline 121529 & Rm 235A-3 North & 31 & 0.68 & 45.6 & 7.3 & 6.2 \\
\hline 123685 & Vault 4 Betw Cabinets & 16 & 0.75 & 24.0 & 1.4 & 16.7 \\
\hline 121487 & Vault 4 Betw Cabinets & 18 & 0.72 & 26.4 & 1.4 & 18.4 \\
\hline 119504 & Vault 4 Betw Cabinets & 17 & 0.69 & 23.2 & 1.4 & 16.2 \\
\hline 121022 & Vault 4 at Back Wall & 17 & 0.74 & 23.0 & 2.2 & 10.6 \\
\hline 121292 & Vault 4 at Back Wall & 18 & 0.67 & 25.4 & 2.2 & 11.7 \\
\hline 121529 & Vault 4 at Back Wall & 15 & 0.68 & 20.6 & 2.2 & 9.5 \\
\hline 121529 & Vault 2, Cor. Wall & 23 & 0.68 & 35.3 & 1.2 & 29.4 \\
\hline 119504 & Vault 2, Cor. Wall & 6 & 0.69 & 8.7 & 1.2 & 7.2 \\
\hline 123685 & Vault 2, Cor. Wall & 48 & 0.75 & 66.7 & 1.2 & 55.6 \\
\hline 121292 & $\begin{array}{l}\text { Vault 2, Betw } \\
\text { Cabinets }\end{array}$ & 10 & 0.67 & 14.9 & 0.5 & 30.9 \\
\hline 121022 & $\begin{array}{c}\text { Vault 2, Betw } \\
\text { Cabinets }\end{array}$ & 9 & 0.74 & 12.2 & 0.5 & 25.2 \\
\hline 121487 & $\begin{array}{c}\text { Vault 2, Betw } \\
\text { Cabinets }\end{array}$ & 14 & 0.72 & 22.2 & 0.5 & 46.0 \\
\hline 121529 & Vlt Corr, by Vlt 1 & 42 & 0.68 & 63.2 & 90.8 & 0.7 \\
\hline 119504 & Vlt Corr, by Vlt 1 & 22 & 0.69 & 30.4 & 90.8 & 0.3 \\
\hline 121292 & Vlt Corr, by Vlt 1 & 19 & 0.67 & 31.3 & 90.8 & 0.3 \\
\hline 123685 & Vlt Corr, by Vlt 3 & 48 & 0.75 & 66.7 & 90.8 & 0.7 \\
\hline 121487 & Vlt Corr, by Vlt 3 & 48 & 0.72 & 66.7 & 90.8 & 0.7 \\
\hline 121022 & Vlt Corr, by Vlt 3 & 30 & 0.74 & 39.2 & 90.8 & 0.4 \\
\hline
\end{tabular}


Table C.2. Results of bubble detector measurements - extremity study.

\begin{tabular}{|c|c|c|c|c|c|c|}
\hline Bubble ID & Location & $\begin{array}{l}\text { Bubbles } \\
\text { counted }\end{array}$ & $\begin{array}{c}\text { Sensitivity } \\
\text { (bubbles / } \\
\text { mrem) }\end{array}$ & $\begin{array}{c}\text { Measured } \\
\text { dose } \\
\text { equivalent } \\
\text { (mrem) }\end{array}$ & $\begin{array}{l}\text { Exposure } \\
\text { time (hrs) }\end{array}$ & \begin{tabular}{|c} 
Dose \\
equivalent \\
rate \\
(mrem/h) \\
\end{tabular} \\
\hline 121022 & $\begin{array}{c}20 \% \text { Oxide - Middle } \\
\text { Finger }\end{array}$ & 159 & 0.74 & 214.9 & 26.37 & 8.15 \\
\hline 123685 & $\begin{array}{c}20 \% \text { Oxide - Little } \\
\text { Finger }\end{array}$ & 141 & 0.75 & 188 & 26.33 & 7.14 \\
\hline 119504 & $\begin{array}{l}12 \% \text { Oxide Middle } \\
\text { Finger }\end{array}$ & 173 & 0.69 & 250 & 95.20 & 2.63 \\
\hline 121529 & $\begin{array}{l}12 \% \text { Oxide Little } \\
\text { Finger }\end{array}$ & 128 & 0.68 & 188 & 95.18 & 1.97 \\
\hline 123685 & \begin{tabular}{|l} 
Metal Middle Finger \\
\end{tabular} & 151 & 0.75 & 201 & 23.58 & 8.54 \\
\hline 119504 & Metal Middle Finger & 210 & 0.69 & 304 & 44.97 & 6.76 \\
\hline 121022 & Metal Little Finger & 177 & 0.74 & 239 & 23.55 & 10.16 \\
\hline 121529 & Metal Little Finger & 197 & 0.68 & 290 & 45.07 & 6.44 \\
\hline 121529 & $\begin{array}{c}\text { 6\% Oxide Middle } \\
\text { Finger }\end{array}$ & 187 & 0.68 & 274 & 49.72 & 5.52 \\
\hline 119504 & $\begin{array}{c}6 \% \text { Oxide Little } \\
\text { Finger } \\
\end{array}$ & 185 & 0.69 & 268 & 49.67 & 5.41 \\
\hline 121022 & \begin{tabular}{|c|}
$17 \%$ Oxide with Foil \\
Middle Finger
\end{tabular} & 174 & 0.74 & 234 & 45.87 & 5.11 \\
\hline 123685 & \begin{tabular}{|c|}
$\begin{array}{c}17 \% \text { Oxide with Foil } \\
\text { Little Finger }\end{array}$ \\
\end{tabular} & 174 & 0.75 & 231 & 45.83 & 5.05 \\
\hline 121529 & $\begin{array}{l}\text { 17\% Oxide with } \mathrm{Pb} \\
\text { Middle Finger }\end{array}$ & 92 & 0.68 & 135 & 67.68 & 1.99 \\
\hline 119504 & $\begin{array}{l}\text { 17\% Oxide with } \mathrm{Pb} \\
\text { Little Finger }\end{array}$ & 97 & 0.69 & 141 & 67.72 & 2.08 \\
\hline
\end{tabular}


APPENDIX D

DOSIMETER RESULTS 
Table D.1 Summary of Dosimeter Results

\begin{tabular}{|c|c|c|c|c|c|c|c|}
\hline Location & $\begin{array}{c}\text { Packet } \\
\text { No. }\end{array}$ & $\begin{array}{c}\text { On-Phantom } \\
\text { Placement }\end{array}$ & \begin{tabular}{|c}
$\begin{array}{c}\text { Exposure } \\
\text { Time } \\
\text { (hrs) }\end{array}$ \\
\end{tabular} & $\begin{array}{c}\text { HCND } \\
\text { Neutron } \\
\text { Dose rate } \\
\text { (mrem/h) } \\
\end{array}$ & \begin{tabular}{|c|}
8816 \\
TED \\
Neutron \\
Dose rate \\
mrem/h \\
\end{tabular} & $\begin{array}{c}\text { HSD } \\
\text { Neutron } \\
\text { Dose rate } \\
\text { (mrem/h) } \\
\end{array}$ & $\begin{array}{c}\text { HSD } \\
\text { Gamma } \\
\text { Dose rate } \\
\text { (mrem/h) } \\
\end{array}$ \\
\hline 235A-3 North & 5 & $\begin{array}{l}\text { West - facing TEPC } \\
1173\end{array}$ & 19.95 & 2.42 & 1.40 & 22.60 & 2.52 \\
\hline 235A-3 North & 5 & $\begin{array}{l}\text { West - facing TEPC } \\
1173\end{array}$ & 19.95 & 5.05 & 1.90 & 26.00 & 3.70 \\
\hline \multirow[t]{2}{*}{ 235A-3 North } & 5 & $\begin{array}{l}\text { West - facing TEPC } \\
1173\end{array}$ & 19.95 & 2.74 & 1.43 & 23.92 & 3.11 \\
\hline & 5 & Avg of 3 & & 3.40 & 1.58 & 24.17 & 3.11 \\
\hline 235A-3 North & 6 & $\begin{array}{l}\text { North - facing water } \\
\text { wall }\end{array}$ & 19.95 & 4.72 & 0.45 & 19.52 & 0.71 \\
\hline 235A-3 North & 6 & $\begin{array}{l}\text { North - facing water } \\
\text { wall }\end{array}$ & 19.95 & 5.54 & 0.33 & 19.65 & 0.65 \\
\hline \multirow[t]{2}{*}{ 235A-3 North } & 6 & $\begin{array}{l}\text { North - facing water } \\
\text { wall }\end{array}$ & 19.95 & 5.75 & 0.70 & 20.43 & 0.74 \\
\hline & 6 & Avg of 3 & & 5.34 & 0.49 & 19.86 & 0.70 \\
\hline 235A-3 North & 7 & $\begin{array}{l}\text { East - facing TEPC } \\
185\end{array}$ & 19.95 & 4.82 & 0.50 & 22.64 & 1.04 \\
\hline 235A-3 North & 7 & $\begin{array}{l}\text { East - facing TEPC } \\
185\end{array}$ & 19.95 & 5.41 & 0.38 & 20.02 & 0.90 \\
\hline \multirow[t]{2}{*}{ 235A-3 North } & 7 & \begin{tabular}{|l|} 
East - facing TEPC \\
185
\end{tabular} & 19.95 & 6.28 & 0.50 & 21.77 & 1.29 \\
\hline & 7 & Avg of 3 & & 5.51 & 0.46 & 21.48 & 1.07 \\
\hline 235A-3 North & 9 & South - Facing hood & 19.95 & 4.91 & 3.53 & 29.74 & 4.52 \\
\hline 235A-3 North & 9 & South - Facing hood & 19.95 & 6.69 & 3.71 & 28.53 & 4.56 \\
\hline \multirow[t]{2}{*}{ 235A-3 North } & 9 & South - Facing hood & 19.95 & 8.35 & 3.26 & 30.13 & 4.47 \\
\hline & 9 & Avg of 3 & & 6.65 & 3.50 & 29.46 & 4.52 \\
\hline 235A-3 South & 1 & North - Facing hood & 19.95 & 3.97 & 3.23 & 33.34 & 2.23 \\
\hline 235A-3 South & 1 & North - Facing hood & 19.95 & 9.35 & 3.08 & 36.65 & 2.15 \\
\hline \multirow[t]{2}{*}{ 235A-3 South } & 1 & North - Facing hood & 19.95 & 8.91 & 3.03 & 37.26 & 2.16 \\
\hline & 1 & Avg of 3 & & 7.41 & 3.12 & 35.75 & 2.18 \\
\hline 235A-3 South & 2 & East - to TEPC 1170 & 19.95 & 2.93 & 0.98 & 29.15 & 1.44 \\
\hline 235A-3 South & 2 & East - to TEPC 1170 & 19.95 & 7.90 & 1.48 & 26.38 & 1.04 \\
\hline \multirow[t]{2}{*}{ 235A-3 South } & 2 & East - to TEPC 1170 & 19.95 & 1.64 & 1.08 & 27.35 & 1.29 \\
\hline & 2 & Avg of 3 & & 4.16 & 1.18 & 27.63 & 1.26 \\
\hline 235A-3 South & 3 & West - to TEPC 1172 & 19.95 & 7.83 & 1.03 & 27.50 & 1.00 \\
\hline 235A-3 South & 3 & West - to TEPC 1172 & 19.95 & 4.96 & 1.13 & 28.88 & 1.26 \\
\hline \multirow[t]{2}{*}{ 235A-3 South } & 3 & West - to TEPC 1172 & 19.95 & 4.17 & 1.10 & 27.49 & 1.38 \\
\hline & 3 & Avg of 3 & & 5.65 & 1.09 & 27.95 & 1.21 \\
\hline 235A-3 South & 4 & South - Facing wall & 19.95 & 4.35 & 0.33 & 25.13 & 0.49 \\
\hline 235A-3 South & 4 & South - Facing wall & 19.95 & 3.60 & 0.68 & 24.23 & 0.57 \\
\hline
\end{tabular}

D. 1 


\begin{tabular}{|c|c|c|c|c|c|c|c|}
\hline \multicolumn{8}{|c|}{ Table D.1 Summary of Dosimeter Results } \\
\hline Location & $\begin{array}{c}\text { Packet } \\
\text { No. }\end{array}$ & $\begin{array}{c}\text { On-Phantom } \\
\text { Placement }\end{array}$ & $\begin{array}{l}\text { Exposure } \\
\text { Time } \\
\text { (hrs) }\end{array}$ & $\begin{array}{c}\text { HCND } \\
\text { Neutron } \\
\text { Dose rate } \\
\text { (mrem/h) }\end{array}$ & $\begin{array}{c}8816 \\
\text { TED } \\
\text { Neutron } \\
\text { Dose rate } \\
\text { mrem/h }\end{array}$ & $\begin{array}{c}\text { HSD } \\
\text { Neutron } \\
\text { Dose rate } \\
\text { (mrem/h) }\end{array}$ & $\begin{array}{c}\text { HSD } \\
\text { Gamma } \\
\text { Dose rate } \\
\text { (mrem/h) }\end{array}$ \\
\hline $235 \overline{\bar{A}-3 \text { South }}$ & 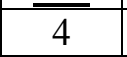 & South - Facing wall & 19.95 & 4.56 & 0.58 & 25.92 & 0.58 \\
\hline & 4 & Avg of 3 & & 4.17 & 0.53 & 25.09 & 0.55 \\
\hline $\begin{array}{l}\text { Vault 1: betw } \\
\text { cabinets }\end{array}$ & 21 & facing cabinet $1 \mathrm{EE}$ & 18.15 & 17.94 & 1.82 & 93.83 & 1.49 \\
\hline $\begin{array}{l}\text { Vault 1: betw } \\
\text { cabinets }\end{array}$ & 21 & facing cabinet $1 \mathrm{EE}$ & 18.15 & 16.04 & 2.51 & 96.24 & 1.53 \\
\hline \multirow{2}{*}{$\begin{array}{l}\text { Vault 1: betw } \\
\text { cabinets }\end{array}$} & 21 & facing cabinet $1 \mathrm{EE}$ & 18.15 & 17.37 & 1.76 & 92.84 & 1.41 \\
\hline & 21 & Avg of 3 & & 17.12 & 2.03 & 94.30 & 1.48 \\
\hline $\begin{array}{l}\text { Vault 1: betw } \\
\text { cabinets }\end{array}$ & 22 & facing TEPC1172 & 18.15 & 15.81 & 1.43 & 75.12 & 1.43 \\
\hline $\begin{array}{l}\text { Vault 1: betw } \\
\text { cabinets }\end{array}$ & 22 & facing TEPC1172 & 18.15 & 12.04 & 1.10 & 73.50 & 1.46 \\
\hline \multirow{2}{*}{$\begin{array}{l}\text { Vault 1: betw } \\
\text { cabinets }\end{array}$} & 22 & facing TEPC1172 & 18.15 & 14.84 & 1.68 & 78.57 & 1.59 \\
\hline & 22 & Avg of 3 & & 14.23 & 1.40 & 75.73 & 1.49 \\
\hline $\begin{array}{l}\text { Vault 1: betw } \\
\text { cabinets }\end{array}$ & 23 & facing cabn $1 \mathrm{FE}$ & 18.15 & 21.43 & 4.30 & 152.49 & 1.95 \\
\hline $\begin{array}{l}\text { Vault 1: betw } \\
\text { cabinets }\end{array}$ & 23 & facing cabn $1 \mathrm{FE}$ & 18.15 & 25.97 & 4.90 & 154.31 & 1.96 \\
\hline \multirow{2}{*}{$\begin{array}{l}\text { Vault 1: betw } \\
\text { cabinets }\end{array}$} & 23 & facing cabn 1FE & 18.15 & 22.64 & 4.60 & 140.39 & 1.79 \\
\hline & 23 & Avg of 3 & & 23.34 & 4.60 & 149.06 & 1.90 \\
\hline $\begin{array}{l}\text { Vault 1: betw } \\
\text { cabinets }\end{array}$ & 24 & facing TEPC1173 & 18.15 & 23.12 & 1.60 & 89.84 & 1.68 \\
\hline $\begin{array}{l}\text { Vault 1: betw } \\
\text { cabinets }\end{array}$ & 24 & facing TEPC1173 & 18.15 & 19.18 & 1.57 & 96.11 & 1.80 \\
\hline \multirow{2}{*}{$\begin{array}{l}\text { Vault 1: betw } \\
\text { cabinets }\end{array}$} & 24 & facing TEPC1173 & 18.15 & 16.78 & 1.49 & 92.97 & 1.45 \\
\hline & 24 & Avg of 3 & & 19.69 & 1.55 & 92.97 & 1.64 \\
\hline $\begin{array}{l}\text { Vault 1: by } \\
\text { corridor wall }\end{array}$ & 17 & away from wall & 18.18 & 6.35 & 1.02 & 44.94 & 0.67 \\
\hline $\begin{array}{l}\text { Vault 1: by } \\
\text { corridor wall }\end{array}$ & 17 & away from wall & 18.18 & 7.07 & 1.16 & 44.73 & 0.57 \\
\hline \multirow{2}{*}{$\begin{array}{l}\text { Vault 1: by } \\
\text { corridor wall }\end{array}$} & 17 & away from wall & 18.18 & 9.60 & 1.10 & 45.05 & 0.55 \\
\hline & 17 & Avg of 3 & & 7.67 & 1.09 & 44.91 & 0.60 \\
\hline $\begin{array}{l}\text { Vault 1: by } \\
\text { corridor wall }\end{array}$ & 18 & facing TEPC504 & 18.18 & 5.30 & 0.55 & 38.51 & 0.57 \\
\hline
\end{tabular}




\begin{tabular}{|c|c|c|c|c|c|c|c|}
\hline \multicolumn{8}{|c|}{ Table D.1 Summary of Dosimeter Results } \\
\hline Location & $\begin{array}{c}\text { Packet } \\
\text { No. }\end{array}$ & $\begin{array}{c}\text { On-Phantom } \\
\text { Placement }\end{array}$ & $\begin{array}{c}\text { Exposure } \\
\text { Time } \\
\text { (hrs) }\end{array}$ & $\begin{array}{c}\text { HCND } \\
\text { Neutron } \\
\text { Dose rate } \\
\text { (mrem/h) }\end{array}$ & \begin{tabular}{|c|}
8816 \\
TED \\
Neutron \\
Dose rate \\
$\mathrm{mrem} / \mathrm{h}$
\end{tabular} & \begin{tabular}{|c|} 
HSD \\
Neutron \\
Dose rate \\
(mrem/h) \\
\end{tabular} & $\begin{array}{c}\text { HSD } \\
\text { Gamma } \\
\text { Dose rate } \\
\text { (mrem/h) }\end{array}$ \\
\hline $\begin{array}{l}\text { Vault 1: by } \\
\text { corridor wall }\end{array}$ & $\overline{18}$ & facing TEPC504 & 18.18 & $\begin{array}{l}5.38 \\
\end{array}$ & 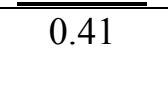 & 38.40 & 0.42 \\
\hline \multirow{2}{*}{$\begin{array}{l}\text { Vault 1: by } \\
\text { corridor wall } \\
\end{array}$} & 18 & Facing TEPC504 & 18.18 & 5.24 & 0.66 & 39.39 & 0.53 \\
\hline & 18 & Avg of 3 & & 5.30 & 0.54 & 38.77 & 0.51 \\
\hline $\begin{array}{l}\text { Vault 1: by } \\
\text { corridor wall }\end{array}$ & 19 & Facing wall & 18.18 & 3.86 & 0.41 & 36.51 & 0.43 \\
\hline $\begin{array}{l}\text { Vault 1: by } \\
\text { corridor wall }\end{array}$ & 19 & Facing wall & 18.18 & 3.24 & 0.25 & 36.37 & 0.55 \\
\hline \multirow{2}{*}{$\begin{array}{l}\text { Vault 1: by } \\
\text { corridor wall }\end{array}$} & 19 & Facing wall & 18.18 & 5.66 & 0.50 & 39.24 & 0.41 \\
\hline & 19 & Avg of 3 & & 4.25 & 0.39 & 37.37 & 0.46 \\
\hline $\begin{array}{l}\text { Vault 1: by } \\
\text { corridor wall }\end{array}$ & 20 & Facing TEPC1170 & 18.18 & 8.76 & 1.32 & 48.81 & 0.63 \\
\hline $\begin{array}{l}\text { Vault 1: by } \\
\text { corridor wall }\end{array}$ & 20 & Facing TEPC1170 & 18.18 & 9.57 & 1.38 & 50.44 & 0.62 \\
\hline \multirow{2}{*}{$\begin{array}{l}\text { Vault 1: by } \\
\text { corridor wall }\end{array}$} & 20 & Facing TEPC1170 & 18.18 & 7.13 & 1.24 & 51.22 & 0.58 \\
\hline & 20 & Avg of 3 & & 8.49 & 1.31 & 50.16 & 0.61 \\
\hline $\begin{array}{l}\text { Vault } 2 \text { - Betw } \\
\text { Cabinets }\end{array}$ & 25 & to aisle & 18.67 & 31.28 & 15.59 & 112.45 & 42.98 \\
\hline $\begin{array}{l}\text { Vault } 2 \text { - Betw } \\
\text { Cabinets }\end{array}$ & 25 & to aisle & 18.67 & 21.40 & 14.84 & 103.26 & 43.71 \\
\hline \multirow{2}{*}{$\begin{array}{l}\text { Vault } 2 \text { - Betw } \\
\text { Cabinets }\end{array}$} & 25 & to aisle & 18.67 & 26.47 & 12.91 & 109.58 & 41.61 \\
\hline & 25 & Avg of 3 & & 26.38 & 14.44 & 108.43 & 42.77 \\
\hline $\begin{array}{l}\text { Vault } 2 \text { - Betw } \\
\text { Cabinets }\end{array}$ & 26 & to TEPC 1173 & 18.67 & 29.06 & 9.32 & 110.56 & 54.75 \\
\hline $\begin{array}{l}\text { Vault } 2 \text { - Betw } \\
\text { Cabinets }\end{array}$ & 26 & to TEPC 1173 & 18.67 & 14.75 & 10.55 & 110.57 & 51.96 \\
\hline \multirow{2}{*}{$\begin{array}{l}\text { Vault } 2 \text { - Betw } \\
\text { Cabinets } \\
\end{array}$} & 26 & to TEPC 1173 & 18.67 & 21.16 & 10.58 & 101.05 & 57.00 \\
\hline & 26 & Avg of 3 & & 21.65 & 10.15 & 107.40 & 54.57 \\
\hline $\begin{array}{l}\text { Vault } 2 \text { - Betw } \\
\text { Cabinets }\end{array}$ & 27 & to wall cabinet & 18.67 & 21.54 & 11.65 & 93.95 & 57.90 \\
\hline $\begin{array}{l}\text { Vault } 2 \text { - Betw } \\
\text { Cabinets }\end{array}$ & 27 & to wall cabinet & 18.67 & 30.97 & 11.03 & 94.65 & 60.53 \\
\hline \multirow{2}{*}{$\begin{array}{l}\text { Vault } 2 \text { - Betw } \\
\text { Cabinets }\end{array}$} & 27 & to wall cabinet & 18.67 & 16.42 & 11.36 & 96.89 & 61.24 \\
\hline & 27 & Avg of 3 & & 22.97 & 11.35 & 95.16 & 59.89 \\
\hline
\end{tabular}




\begin{tabular}{|c|c|c|c|c|c|c|c|}
\hline \multicolumn{8}{|c|}{ Table D.1 Summary of Dosimeter Results } \\
\hline Location & $\begin{array}{c}\text { Packet } \\
\text { No. }\end{array}$ & $\begin{array}{c}\text { On-Phantom } \\
\text { Placement }\end{array}$ & $\begin{array}{l}\text { Exposure } \\
\text { Time } \\
\text { (hrs) }\end{array}$ & $\begin{array}{c}\text { HCND } \\
\text { Neutron } \\
\text { Dose rate } \\
\text { (mrem/h) }\end{array}$ & \begin{tabular}{|c|}
8816 \\
TED \\
Neutron \\
Dose rate \\
mrem/h
\end{tabular} & $\begin{array}{c}\text { HSD } \\
\text { Neutron } \\
\text { Dose rate } \\
\text { (mrem/h) }\end{array}$ & $\begin{array}{c}\text { HSD } \\
\text { Gamma } \\
\text { Dose rate } \\
\text { (mrem/h) }\end{array}$ \\
\hline $\begin{array}{l}\text { Vault } 2 \text { - Betw } \\
\text { Cabinets }\end{array}$ & 28 & to TEPC 1172 & 18.67 & 20.72 & 1414.09 & 102.26 & $4 \quad 48.88$ \\
\hline $\begin{array}{l}\text { Vault } 2 \text { - Betw } \\
\text { Cabinets }\end{array}$ & 28 & to TEPC 1172 & 18.67 & 33.58 & 14.86 & 118.21 & 55.69 \\
\hline \multirow{2}{*}{$\begin{array}{l}\text { Vault } 2 \text { - Betw } \\
\text { Cabinets }\end{array}$} & 28 & to TEPC 1172 & 18.67 & 24.27 & 13.20 & 115.24 & 46.28 \\
\hline & 28 & Avg of 3 & & 26.19 & 14.05 & 111.90 & 50.28 \\
\hline $\begin{array}{l}\text { Vault } 2 \text { - by } \\
\text { wall }\end{array}$ & 29 & Away from wall & 18.73 & 28.16 & 7.66 & 101.20 & 22.33 \\
\hline $\begin{array}{l}\text { Vault } 2 \text { - by } \\
\text { wall }\end{array}$ & 29 & Away from wall & 18.73 & 23.37 & 9.45 & 93.20 & 22.59 \\
\hline \multirow{2}{*}{$\begin{array}{l}\text { Vault } 2 \text { - by } \\
\text { wall }\end{array}$} & 29 & Away from wall & 18.73 & 36.04 & 8.84 & 93.63 & 21.87 \\
\hline & 29 & Avg of 3 & & 29.19 & 8.65 & 96.01 & 22.26 \\
\hline $\begin{array}{l}\text { Vault } 2 \text { - by } \\
\text { wall }\end{array}$ & 30 & to TEPC 504 & 18.73 & 8.57 & 3.66 & 86.22 & 10.47 \\
\hline $\begin{array}{l}\text { Vault } 2 \text { - by } \\
\text { wall }\end{array}$ & 30 & to TEPC 504 & 18.73 & 13.25 & 4.38 & 76.94 & 6.13 \\
\hline \multirow{2}{*}{$\begin{array}{l}\text { Vault } 2 \text { - by } \\
\text { wall }\end{array}$} & 30 & to TEPC 504 & 18.73 & 9.69 & 3.15 & 81.98 & 8.02 \\
\hline & 30 & Avg of 3 & & 10.50 & 3.73 & 81.71 & 8.20 \\
\hline $\begin{array}{l}\text { Vault } 2 \text { - by } \\
\text { wall }\end{array}$ & 31 & to wall & 18.73 & 17.41 & 2.11 & 94.30 & 7.03 \\
\hline $\begin{array}{l}\text { Vault } 2 \text { - by } \\
\text { wall }\end{array}$ & 31 & to wall & 18.73 & 19.67 & 2.16 & 88.59 & 5.64 \\
\hline \multirow{2}{*}{$\begin{array}{l}\text { Vault } 2 \text { - by } \\
\text { wall }\end{array}$} & 31 & to wall & 18.73 & 18.87 & 2.14 & 88.07 & 5.72 \\
\hline & 31 & Avg of 3 & & 18.65 & 2.14 & 90.32 & 6.13 \\
\hline $\begin{array}{l}\text { Vault } 2 \text { - by } \\
\text { wall }\end{array}$ & 32 & to TEPC 1170 & 18.73 & 12.46 & 7.96 & 95.59 & 19.67 \\
\hline $\begin{array}{l}\text { Vault } 2 \text { - by } \\
\text { wall }\end{array}$ & 32 & to TEPC 1170 & 18.73 & 29.42 & 6.73 & 103.56 & 19.14 \\
\hline \multirow{2}{*}{$\begin{array}{l}\text { Vault } 2 \text { - by } \\
\text { wall }\end{array}$} & 32 & to TEPC 1170 & 18.73 & 15.17 & 7.77 & 101.95 & 17.46 \\
\hline & 32 & Avg of 3 & & 19.02 & 7.48 & 100.37 & 18.76 \\
\hline $\begin{array}{l}\text { Vault } 4 \text { - Back } \\
\text { Wall }\end{array}$ & 8 & Away from wall & 5.92 & 46.87 & 6.25 & 226.29 & 3.59 \\
\hline $\begin{array}{l}\text { Vault } 4 \text { - Back } \\
\text { Wall }\end{array}$ & 8 & Away from wall & 5.92 & 34.03 & 7.60 & 237.60 & 3.77 \\
\hline $\begin{array}{l}\text { Vault } 4 \text { - Back } \\
\text { Wall }\end{array}$ & 8 & Away from wall & 5.92 & 59.75 & 7.52 & 228.00 & 3.75 \\
\hline
\end{tabular}




\begin{tabular}{|c|c|c|c|c|c|c|c|}
\hline \multicolumn{8}{|c|}{ Table D.1 Summary of Dosimeter Results } \\
\hline \multirow[t]{2}{*}{ Location } & \begin{tabular}{|c|} 
Packet \\
No. \\
\end{tabular} & $\begin{array}{c}\text { On-Phantom } \\
\text { Placement }\end{array}$ & $\begin{array}{c}\text { Exposure } \\
\text { Time } \\
\text { (hrs) }\end{array}$ & $\begin{array}{c}\text { HCND } \\
\text { Neutron } \\
\text { Dose rate } \\
\text { (mrem/h) }\end{array}$ & \begin{tabular}{|c|}
8816 \\
TED \\
Neutron \\
Dose rate \\
mrem/h
\end{tabular} & $\begin{array}{c}\text { HSD } \\
\text { Neutron } \\
\text { Dose rate } \\
\text { (mrem/h) }\end{array}$ & $\begin{array}{c}\text { HSD } \\
\text { Gamma } \\
\text { Dose rate } \\
\text { (mrem/h) }\end{array}$ \\
\hline & 8 & Avg of 3 & & 46.88 & 7.12 & 230.63 & 3.70 \\
\hline $\begin{array}{l}\text { Vault } 4 \text { - Back } \\
\text { Wall }\end{array}$ & 10 & Facing TEPC 1170 & 5.92 & 27.52 & 3.21 & 149.11 & 2.55 \\
\hline $\begin{array}{l}\text { Vault } 4 \text { - Back } \\
\text { Wall }\end{array}$ & 10 & Facing TEPC 1170 & 5.92 & 34.01 & 4.39 & 170.38 & 2.75 \\
\hline \multirow{2}{*}{$\begin{array}{l}\text { Vault } 4 \text { - Back } \\
\text { Wall }\end{array}$} & 10 & Facing TEPC 1170 & 5.92 & 30.63 & 3.21 & 165.14 & 2.33 \\
\hline & 10 & Avg of 3 & 5.92 & 30.72 & 3.60 & 161.55 & 2.54 \\
\hline $\begin{array}{l}\text { Vault } 4 \text { - Back } \\
\text { Wall }\end{array}$ & 11 & Toward wall & 5.92 & 8.66 & 0.93 & 148.56 & 1.87 \\
\hline $\begin{array}{l}\text { Vault } 4 \text { - Back } \\
\text { Wall }\end{array}$ & 11 & toward wall & 5.92 & 18.01 & 0.76 & 141.90 & 1.93 \\
\hline \multirow{2}{*}{$\begin{array}{l}\text { Vault } 4 \text { - Back } \\
\text { Wall }\end{array}$} & 11 & toward wall & 5.92 & 16.46 & 0.76 & 148.63 & 1.81 \\
\hline & 11 & Avg of 3 & & 14.37 & 0.82 & 146.36 & 1.87 \\
\hline $\begin{array}{l}\text { Vault } 4 \text { - Back } \\
\text { Wall }\end{array}$ & 12 & facing TEPC 504 & 5.92 & 35.67 & 2.79 & 197.89 & 2.66 \\
\hline $\begin{array}{l}\text { Vault } 4 \text { - Back } \\
\text { Wall }\end{array}$ & 12 & facing TEPC 504 & 5.92 & 38.77 & 2.87 & 179.91 & 2.57 \\
\hline \multirow{2}{*}{$\begin{array}{l}\text { Vault } 4 \text { - Back } \\
\text { Wall }\end{array}$} & 12 & facing TEPC 504 & 5.92 & 18.88 & 3.38 & 186.74 & 2.62 \\
\hline & 12 & Avg of 3 & & 31.11 & 3.01 & 188.18 & 2.62 \\
\hline $\begin{array}{l}\text { Vault } 4 \text { betw } \\
\text { cabinets }\end{array}$ & 13 & facing TEPC1172 & 5.62 & 45.54 & 9.43 & 244.48 & 13.07 \\
\hline $\begin{array}{l}\text { Vault } 4 \text { betw } \\
\text { cabinets }\end{array}$ & 13 & facing TEPC1172 & 5.62 & 61.77 & 8.27 & 229.43 & 12.90 \\
\hline \multirow{2}{*}{$\begin{array}{l}\text { Vault } 4 \text { betw } \\
\text { cabinets }\end{array}$} & 13 & facing TEPC1172 & 5.62 & 52.60 & 10.23 & 242.03 & 13.53 \\
\hline & 13 & Avg of 3 & & 53.30 & 9.31 & 238.65 & 13.16 \\
\hline $\begin{array}{l}\text { Vault } 4 \text { betw } \\
\text { cabinets }\end{array}$ & 14 & facing TEPC1173 & 5.62 & 49.24 & 6.76 & 187.52 & 21.51 \\
\hline $\begin{array}{l}\text { Vault } 4 \text { betw } \\
\text { cabinets }\end{array}$ & 14 & facing TEPC1173 & 5.62 & 48.97 & 6.32 & 205.31 & 25.55 \\
\hline \multirow{2}{*}{$\begin{array}{l}\text { Vault } 4 \text { betw } \\
\text { cabinets }\end{array}$} & 14 & facing TEPC1173 & 5.62 & 52.47 & 8.19 & 187.23 & 26.86 \\
\hline & 14 & Avg of 3 & & 50.23 & 7.09 & 193.35 & 24.64 \\
\hline $\begin{array}{l}\text { Vault } 4 \text { betw } \\
\text { cabinets }\end{array}$ & 15 & facing 4FE & 5.62 & 42.35 & 7.30 & 246.85 & 6.07 \\
\hline $\begin{array}{l}\text { Vault } 4 \text { betw } \\
\text { cabinets }\end{array}$ & 15 & facing 4FE & 5.62 & 40.83 & 6.49 & 239.61 & 5.94 \\
\hline
\end{tabular}




\begin{tabular}{|c|c|c|c|c|c|c|c|}
\hline \multicolumn{8}{|c|}{ Table D.1 Summary of Dosimeter Results } \\
\hline Location & $\begin{array}{c}\text { Packet } \\
\text { No. }\end{array}$ & $\begin{array}{c}\text { On-Phantom } \\
\text { Placement }\end{array}$ & $\begin{array}{c}\text { Exposure } \\
\text { Time } \\
\text { (hrs) }\end{array}$ & $\begin{array}{c}\text { HCND } \\
\text { Neutron } \\
\text { Dose rate } \\
\text { (mrem/h) }\end{array}$ & \begin{tabular}{|c|}
8816 \\
TED \\
Neutron \\
Dose rate \\
mrem/h
\end{tabular} & $\begin{array}{c}\text { HSD } \\
\text { Neutron } \\
\text { Dose rate } \\
\text { (mrem/h) }\end{array}$ & $\begin{array}{c}\text { HSD } \\
\text { Gamma } \\
\text { Dose rate } \\
\text { (mrem/h) }\end{array}$ \\
\hline Vault 4 betw & $\overline{15}$ & facing 4FE & 5.62 & 46.88 & 7.47 & 210.68 & 5.11 \\
\hline & 15 & Avg of 3 & & 43.35 & 7.09 & 232.38 & 5.71 \\
\hline $\begin{array}{l}\text { Vault } 4 \text { betw } \\
\text { cabinets }\end{array}$ & 16 & facing 4EE & 5.62 & 74.71 & 14.59 & 253.81 & 23.77 \\
\hline $\begin{array}{l}\text { Vault } 4 \text { betw } \\
\text { cabinets }\end{array}$ & 16 & facing 4EE & 5.62 & 60.21 & 14.68 & 258.74 & 23.27 \\
\hline \multirow{2}{*}{$\begin{array}{l}\text { Vault } 4 \text { betw } \\
\text { cabinets }\end{array}$} & 16 & facing 4EE & 5.62 & 56.83 & 14.23 & 260.69 & 21.39 \\
\hline & 16 & Avg of 3 & & 63.92 & 14.50 & 257.74 & 22.81 \\
\hline Vault Cor by V1 & 33 & to corridor & 90.80 & 2.44 & 0.25 & 18.57 & 0.21 \\
\hline Vault Cor by V1 & 33 & to corridor & 90.80 & 0.92 & 0.25 & 19.91 & 0.21 \\
\hline \multirow[t]{2}{*}{ Vault Cor by V1 } & 33 & to corridor & 90.80 & 2.59 & 0.23 & 18.95 & 0.21 \\
\hline & 33 & Avg of 3 & & 1.99 & 0.24 & 19.14 & 0.21 \\
\hline Vault Cor by V1 & 34 & to TEPC 1172 & 90.80 & 0.51 & 0.15 & 17.28 & 0.21 \\
\hline Vault Cor by V1 & 34 & to TEPC1172 & 90.80 & 1.75 & 0.20 & 17.21 & 0.23 \\
\hline \multirow[t]{2}{*}{ Vault Cor by V1 } & 34 & to TEPC1172 & 90.80 & 1.86 & 0.18 & 16.25 & 0.21 \\
\hline & 34 & Avg of 3 & & 1.38 & 0.18 & 16.92 & 0.22 \\
\hline Vault Cor by V1 & 35 & to TEPC1173 & 90.80 & 1.47 & 0.21 & 18.09 & 0.22 \\
\hline Vault Cor by V1 & 35 & to TEPC1173 & 90.80 & 1.06 & 0.21 & 16.98 & 0.24 \\
\hline \multirow[t]{2}{*}{ Vault Cor by V1 } & 35 & to TEPC 1173 & 90.80 & 0.79 & 0.20 & 16.89 & 0.23 \\
\hline & 35 & Avg of 3 & & 1.11 & 0.21 & 17.32 & 0.23 \\
\hline Vault Cor by V1 & 36 & to wall & 90.80 & 1.48 & 0.10 & 13.81 & 0.20 \\
\hline Vault Cor by V1 & 36 & to wall & 90.80 & 1.55 & 0.10 & 13.92 & 0.21 \\
\hline \multirow[t]{2}{*}{ Vault Cor by V1 } & 36 & to wall & 90.80 & 2.75 & 0.08 & 13.96 & 0.23 \\
\hline & 3 & Avg of 3 & & 1.93 & 0.10 & 13.90 & 0.21 \\
\hline $\begin{array}{l}\text { Vault Corr - by } \\
\text { Vault } 3\end{array}$ & 37 & to corridor & 90.80 & 1.61 & 0.23 & 16.59 & 0.25 \\
\hline Vault Cor by V3 & 37 & to corridor & 90.80 & 2.03 & 0.18 & 16.12 & 0.26 \\
\hline \multirow[t]{2}{*}{ Vault Cor by V3 } & 37 & to corridor & 90.80 & 1.37 & 0.14 & 16.89 & 0.25 \\
\hline & 37 & Avg of 3 & & 1.67 & 0.18 & 16.54 & 0.25 \\
\hline Vault Cor by V3 & 38 & to TEPC 504 & 90.80 & 2.87 & 0.12 & 16.42 & 0.24 \\
\hline Vault Cor by V3 & 38 & to TEPC 504 & 90.80 & 2.01 & 0.14 & 21.61 & 0.29 \\
\hline \multirow[t]{2}{*}{ Vault Cor by V3 } & 38 & to TEPC 504 & 90.80 & 2.24 & 0.14 & 18.52 & 0.28 \\
\hline & 38 & Avg of 3 & & 2.37 & 0.13 & 18.85 & 0.27 \\
\hline Vault Cor by V3 & 39 & to wall & 90.80 & 2.50 & 0.36 & 25.53 & 0.36 \\
\hline Vault Cor by V3 & 39 & to wall & 90.80 & 1.14 & 0.34 & 28.00 & 0.29 \\
\hline \multirow[t]{2}{*}{ Vault Cor by V3 } & 39 & to wall & 90.80 & 1.96 & 0.40 & 26.27 & 0.32 \\
\hline & 39 & Avg of 3 & & 1.87 & 0.37 & 26.60 & 0.33 \\
\hline Vault Cor by V3 & 40 & to TEPC 1170 & 90.80 & 1.84 & 0.19 & 18.04 & 0.30 \\
\hline
\end{tabular}




\begin{tabular}{|c|c|c|c|c|c|c|c|}
\hline \multicolumn{8}{|c|}{ Table D.1 Summary of Dosimeter Results } \\
\hline Location & $\begin{array}{c}\text { Packet } \\
\text { No. }\end{array}$ & $\begin{array}{c}\text { On-Phantom } \\
\text { Placement }\end{array}$ & $\begin{array}{c}\text { Exposure } \\
\text { Time } \\
\text { (hrs) }\end{array}$ & $\begin{array}{c}\text { HCND } \\
\text { Neutron } \\
\text { Dose rate } \\
\text { (mrem/h) }\end{array}$ & \begin{tabular}{|c|}
8816 \\
TED \\
Neutron \\
Dose rate \\
mrem/h
\end{tabular} & $\begin{array}{c}\text { HSD } \\
\text { Neutron } \\
\text { Dose rate } \\
\text { (mrem/h) }\end{array}$ & $\begin{array}{c}\text { HSD } \\
\text { Gamma } \\
\text { Dose rate } \\
\text { (mrem/h) }\end{array}$ \\
\hline Vault Cor by V3 & $\overline{40}$ & to TEPC 1170 & 90.80 & 1.86 & 0.18 & 18.97 & 0.28 \\
\hline \multirow[t]{2}{*}{ Vault Cor by V3 } & 40 & to TEPC 1170 & 90.80 & 1.55 & 0.21 & 20.10 & 0.30 \\
\hline & 40 & Avg of 3 & & 1.75 & 0.19 & 19.04 & 0.29 \\
\hline
\end{tabular}


Table D.2 HCND Dosimeter Response

\begin{tabular}{|c|c|c|c|c|c|c|c|c|c|c|}
\hline \multirow[b]{2}{*}{ Location } & \multirow[b]{2}{*}{$\begin{array}{c}\text { Packet } \\
\#\end{array}$} & \multirow[b]{2}{*}{$\begin{array}{c}\text { Card } \\
\text { ID }\end{array}$} & \multirow[b]{2}{*}{ Formula } & \multicolumn{4}{|c|}{ Adjusted Chip Readings } & \multirow[b]{2}{*}{$\begin{array}{l}\text { Neutron } \\
\text { (mrem) }\end{array}$} & \multirow[b]{2}{*}{$\begin{array}{l}\text { Exp Time } \\
\text { (hrs) }\end{array}$} & \multirow[b]{2}{*}{$\begin{array}{l}\text { Neutron } \\
\text { DE Rate } \\
(\mathrm{mrem} / \mathrm{h})\end{array}$} \\
\hline & & & & Chip 1 & Chip 2 & Chip 3 & Chip 4 & & & \\
\hline 235A-3 South & 1 & 4051048 & 112 & 27 & 574 & 349 & 659 & 79 & 19.95 & 3.97 \\
\hline 235A-3 South & 1 & 4007608 & 112 & 32 & 614 & 350 & 739 & 178 & 19.95 & 8.91 \\
\hline 235A-3 South & 1 & 4006161 & 112 & 29 & 565 & 332 & 739 & 187 & 19.95 & 9.35 \\
\hline 235A-3 South & 2 & 4051032 & 112 & 19 & 448 & 283 & 515 & 33 & 19.95 & 1.64 \\
\hline 235A-3 South & 2 & 4006326 & 112 & 21 & 493 & 299 & 556 & 58 & 19.95 & 2.93 \\
\hline 235A-3 South & 2 & 4006512 & 111 & 25 & 460 & 300 & 565 & 158 & 19.95 & 7.90 \\
\hline 235A-3 South & 3 & 4050709 & 112 & 23 & 440 & 264 & 538 & 99 & 19.95 & 4.96 \\
\hline 235A-3 South & 3 & 4050749 & 112 & 23 & 407 & 257 & 525 & 83 & 19.95 & 4.17 \\
\hline 235A-3 South & 3 & 4007288 & 111 & 21 & 420 & 272 & 529 & 156 & 19.95 & 7.83 \\
\hline 235A-3 South & 4 & 4007039 & 111 & 14 & 394 & 299 & 514 & 87 & 19.95 & 4.35 \\
\hline 235A-3 South & 4 & 4050908 & 111 & 13 & 362 & 271 & 481 & 91 & 19.95 & 4.56 \\
\hline 235A-3 South & 4 & 4050876 & 111 & 12 & 356 & 279 & 477 & 72 & 19.95 & 3.60 \\
\hline 235A-3 North & 5 & 4007320 & 112 & 51 & 453 & 290 & 511 & 48 & 19.95 & 2.42 \\
\hline 235A-3 North & 5 & 4050637 & 112 & 49 & 466 & 294 & 523 & 55 & 19.95 & 2.74 \\
\hline 235A-3 North & 5 & 4050599 & 112 & 44 & 477 & 283 & 539 & 101 & 19.95 & 5.05 \\
\hline 235A-3 North & 6 & 4050882 & 111 & 13 & 335 & 216 & 408 & 115 & 19.95 & 5.75 \\
\hline 235A-3 North & 6 & 4050860 & 111 & 13 & 322 & 211 & 400 & 111 & 19.95 & 5.54 \\
\hline 235A-3 North & 6 & 4006424 & 111 & 14 & 340 & 235 & 418 & 94 & 19.95 & 4.72 \\
\hline 235A-3 North & 7 & 4004320 & 111 & 20 & 344 & 235 & 433 & 108 & 19.95 & 5.41 \\
\hline 235A-3 North & 7 & 4050802 & 111 & 16 & 312 & 212 & 431 & 125 & 19.95 & 6.28 \\
\hline 235A-3 North & 7 & 4003300 & 111 & 17 & 284 & 210 & 405 & 96 & 19.95 & 4.82 \\
\hline 235A-3 North & 9 & 4050741 & 112 & 43 & 505 & 308 & 593 & 98 & 19.95 & 4.91 \\
\hline 235A-3 North & 9 & 4050888 & 112 & 45 & 504 & 297 & 636 & 167 & 19.95 & 8.35 \\
\hline \multirow[t]{2}{*}{ 235A-3 North } & 9 & 4007557 & 112 & 46 & 479 & 297 & 620 & 133 & 19.95 & 6.69 \\
\hline & Control & 4006450 & 113 & 0 & 1 & 0 & 1 & 0 & & \\
\hline Vault 4 - Back Wall & 8 & 4007083 & 111 & 22 & 1004 & 763 & 1291 & 201 & 5.92 & 34.0 \\
\hline Vault 4 - Back Wall & 8 & 4050855 & 111 & 21 & 990 & 685 & 1350 & 354 & 5.92 & 59.7 \\
\hline Vault 4 - Back Wall & 8 & 4002767 & 111 & 23 & 991 & 736 & 1352 & 277 & 5.92 & 46.9 \\
\hline Vault 4 - Back Wall & 10 & 4050647 & 111 & 14 & 625 & 482 & 907 & 181 & 5.92 & 30.6 \\
\hline Vault 4 - Back Wall & 10 & 4000763 & 111 & 15 & 669 & 520 & 931 & 163 & 5.92 & 27.5 \\
\hline
\end{tabular}


Table D.2 HCND Dosimeter Response

\begin{tabular}{|c|c|c|c|c|c|c|c|c|c|c|}
\hline \multirow[b]{2}{*}{ Location } & \multirow[b]{2}{*}{$\begin{array}{c}\text { Packet } \\
\#\end{array}$} & \multirow[b]{2}{*}{$\begin{array}{c}\text { Card } \\
\text { ID }\end{array}$} & \multirow[b]{2}{*}{ Formula } & \multicolumn{4}{|c|}{ Adjusted Chip Readings } & \multirow[b]{2}{*}{$\begin{array}{l}\text { Neutron } \\
\text { (mrem) }\end{array}$} & \multirow[b]{2}{*}{$\begin{array}{l}\text { Exp Time } \\
\text { (hrs) }\end{array}$} & \multirow[b]{2}{*}{$\begin{array}{l}\text { Neutron } \\
\text { DE Rate } \\
(\mathrm{mrem} / \mathrm{h})\end{array}$} \\
\hline & & & & Chip 1 & Chip 2 & Chip 3 & Chip 4 & & & \\
\hline Vault 4 - Back Wall & 10 & 4005149 & 111 & 16 & 751 & 540 & 970 & 201 & 5.92 & 34.0 \\
\hline Vault 4 - Back Wall & 11 & 4002166 & 111 & 13 & 606 & 517 & 892 & 107 & 5.92 & 18.0 \\
\hline Vault 4 - Back Wall & 11 & 4000384 & 111 & 12 & 556 & 521 & 857 & 51 & 5.92 & 8.66 \\
\hline Vault 4 - Back Wall & 11 & 4006094 & 111 & 12 & 548 & 481 & 838 & 97 & 5.92 & 16.5 \\
\hline Vault 4 - Back Wall & 12 & 4001587 & 111 & 17 & 822 & 643 & 1173 & 211 & 5.92 & 35.7 \\
\hline Vault 4 - Back Wall & 12 & 4004979 & 111 & 16 & 762 & 552 & 1033 & 229 & 5.92 & 38.8 \\
\hline \multirow[t]{2}{*}{ Vault 4 - Back Wall } & 12 & 4005668 & 111 & 16 & 681 & 572 & 967 & 112 & 5.92 & 18.9 \\
\hline & Control & 4004319 & 113 & 0 & 0 & 0 & 0 & 0 & & \\
\hline Vault 4 - Betw Cabinets & 13 & 4003683 & 111 & 45 & 962 & 698 & 1241 & 256 & 5.62 & 45.5 \\
\hline Vault 4 - Betw Cabinets & 13 & 4005548 & 111 & 51 & 903 & 666 & 1270 & 295 & 5.62 & 52.6 \\
\hline Vault 4 - Betw Cabinets & 13 & 4005222 & 111 & 55 & 971 & 660 & 1276 & 347 & 5.62 & 61.8 \\
\hline Vault 4 - Betw Cabinets & 14 & 4004879 & 111 & 89 & 923 & 648 & 1157 & 275 & 5.62 & 49.0 \\
\hline Vault 4 - Betw Cabinets & 14 & 4003880 & 111 & 86 & 911 & 639 & 1150 & 277 & 5.62 & 49.2 \\
\hline Vault 4 - Betw Cabinets & 14 & 4006701 & 111 & 81 & 880 & 615 & 1149 & 295 & 5.62 & 52.5 \\
\hline Vault 4 - Betw Cabinets & 15 & 4000453 & 111 & 30 & 956 & 724 & 1289 & 238 & 5.62 & 42.3 \\
\hline Vault 4 - Betw Cabinets & 15 & 4002901 & 111 & 33 & 983 & 744 & 1350 & 263 & 5.62 & 46.9 \\
\hline Vault 4 - Betw Cabinets & 15 & 4002494 & 111 & 30 & 943 & 741 & 1327 & 229 & 5.62 & 40.8 \\
\hline Vault 4 - Betw Cabinets & 16 & 4006047 & 111 & 56 & 1158 & 768 & 1338 & 319 & 5.62 & 56.8 \\
\hline Vault 4 - Betw Cabinets & 16 & 4005920 & 111 & 64 & 1160 & 807 & 1454 & 338 & 5.62 & 60.2 \\
\hline \multirow[t]{2}{*}{ Vault 4 - Betw Cabinets } & 16 & 4002525 & 111 & 63 & 1064 & 739 & 1493 & 420 & 5.62 & 74.7 \\
\hline & Control & 4000817 & 113 & 0 & 0 & 0 & 0 & 0 & & \\
\hline Vault 1 - By Corr Wall & 17 & 4002970 & 111 & 13 & 572 & 444 & 777 & 128 & 18.18 & 7.07 \\
\hline Vault 1 - By Corr Wall & 17 & 4001040 & 111 & 14 & 562 & 462 & 809 & 115 & 18.18 & 6.35 \\
\hline Vault 1 - By Corr Wall & 17 & 4003993 & 111 & 13 & 626 & 461 & 844 & 175 & 18.18 & 9.60 \\
\hline Vault 1 - By Corr Wall & 18 & 4001329 & 111 & 11 & 489 & 410 & 718 & 96 & 18.18 & 5.30 \\
\hline Vault 1 - By Corr Wall & 18 & 4003680 & 111 & 11 & 484 & 395 & 683 & 95 & 18.18 & 5.24 \\
\hline Vault 1 - By Corr Wall & 18 & 4001594 & 111 & 12 & 508 & 410 & 704 & 98 & 18.18 & 5.38 \\
\hline Vault 1 - By Corr Wall & 19 & 4007283 & 111 & 12 & 460 & 385 & 691 & 103 & 18.18 & 5.66 \\
\hline Vault 1 - By Corr Wall & 19 & 4004948 & 111 & 11 & 411 & 380 & 652 & 59 & 18.18 & 3.24 \\
\hline Vault 1 - By Corr Wall & 19 & 4002396 & 111 & 11 & 448 & 387 & 657 & 70 & 18.18 & 3.86 \\
\hline Vault 1 - By Corr Wall & 20 & 4005541 & 111 & 13 & 649 & 509 & 917 & 159 & 18.18 & 8.76 \\
\hline
\end{tabular}


Table D.2 HCND Dosimeter Response

\begin{tabular}{|c|c|c|c|c|c|c|c|c|c|c|}
\hline \multirow[b]{2}{*}{ Location } & \multirow[b]{2}{*}{$\begin{array}{c}\text { Packet } \\
\#\end{array}$} & \multirow[b]{2}{*}{$\begin{array}{c}\text { Card } \\
\text { ID }\end{array}$} & \multirow[b]{2}{*}{ Formula } & \multicolumn{4}{|c|}{ Adjusted Chip Readings } & \multirow[b]{2}{*}{$\begin{array}{l}\text { Neutron } \\
\text { (mrem) }\end{array}$} & \multirow[b]{2}{*}{$\begin{array}{c}\text { Exp Time } \\
(\mathrm{hrs})\end{array}$} & \multirow[b]{2}{*}{$\begin{array}{l}\text { Neutron } \\
\text { DE Rate } \\
(\mathrm{mrem} / \mathrm{h})\end{array}$} \\
\hline & & & & Chip 1 & Chip 2 & Chip 3 & Chip 4 & & & \\
\hline Vault 1 - By Corr Wall & 20 & 4007341 & 111 & 12 & 622 & 484 & 901 & 174 & 18.18 & 9.57 \\
\hline \multirow[t]{3}{*}{ Vault 1 - By Corr Wall } & 20 & 4050901 & 111 & 12 & 543 & 448 & 813 & 130 & 18.18 & 7.13 \\
\hline & Control & 4003275 & 113 & 0 & 0 & 0 & 0 & 0 & & \\
\hline & Control & 4000072 & 113 & 0 & 0 & 0 & 2 & 0 & & \\
\hline Vault 1: Betw Cabinets & 21 & 4050896 & 111 & 29 & 1183 & 868 & 1563 & 315 & 18.15 & 17.4 \\
\hline Vault 1: Betw Cabinets & 21 & 4006145 & 111 & 33 & 1224 & 931 & 1695 & 326 & 18.15 & 17.9 \\
\hline Vault 1: Betw Cabinets & 21 & 4050827 & 111 & 29 & 1076 & 833 & 1532 & 291 & 18.15 & 16.0 \\
\hline Vault 1: Betw Cabinets & 22 & 4007047 & 111 & 32 & 953 & 778 & 1389 & 218 & 18.15 & 12.0 \\
\hline Vault 1: Betw Cabinets & 22 & 4007028 & 111 & 34 & 1056 & 734 & 1303 & 287 & 18.15 & 15.8 \\
\hline Vault 1: Betw Cabinets & 22 & 4050811 & 111 & 33 & 1158 & 823 & 1405 & 269 & 18.15 & 14.8 \\
\hline Vault 1: Betw Cabinets & 23 & 4001229 & 111 & 43 & 1975 & 1422 & 2467 & 471 & 18.15 & 26.0 \\
\hline Vault 1: Betw Cabinets & 23 & 4000637 & 111 & 46 & 1816 & 1475 & 2595 & 389 & 18.15 & 21.4 \\
\hline Vault 1: Betw Cabinets & 23 & 4050693 & 111 & 44 & 1757 & 1431 & 2573 & 411 & 18.15 & 22.6 \\
\hline Vault 1: Betw Cabinets & 24 & 4007108 & 111 & 40 & 1356 & 936 & 1737 & 420 & 18.15 & 23.1 \\
\hline Vault 1: Betw Cabinets & 24 & 4050880 & 111 & 34 & 1181 & 830 & 1523 & 348 & 18.15 & 19.2 \\
\hline \multirow[t]{3}{*}{ Vault 1: Betw Cabinets } & 24 & 4050926 & 111 & 34 & 1134 & 847 & 1535 & 305 & 18.15 & 16.8 \\
\hline & Control & 4004927 & 113 & 0 & 0 & 1 & 0 & 0 & & \\
\hline & Control & 4006058 & 113 & 0 & 0 & 0 & 0 & 0 & & \\
\hline Vault 2: Betw Cabinets & 25 & 4006211 & 112 & 479 & 2245 & 1401 & 2438 & 494 & 18.67 & 26.5 \\
\hline Vault 2: Betw Cabinets & 25 & 4003675 & 112 & 469 & 2266 & 1353 & 2390 & 584 & 18.67 & 31.3 \\
\hline Vault 2: Betw Cabinets & 25 & 4005819 & 112 & 471 & 1884 & 1311 & 2364 & 399 & 18.67 & 21.4 \\
\hline Vault 2: Betw Cabinets & 26 & 4002775 & 112 & 703 & 2285 & 1650 & 2639 & 275 & 18.67 & 14.7 \\
\hline Vault 2: Betw Cabinets & 26 & 4002552 & 112 & 680 & 2444 & 1672 & 2918 & 542 & 18.67 & 29.1 \\
\hline Vault 2: Betw Cabinets & 26 & 4005268 & 112 & 696 & 2290 & 1591 & 2603 & 395 & 18.67 & 21.2 \\
\hline Vault 2: Betw Cabinets & 27 & 4007392 & 112 & 687 & 2331 & 1611 & 2534 & 306 & 18.67 & 16.4 \\
\hline Vault 2: Betw Cabinets & 27 & 4005201 & 112 & 664 & 2338 & 1546 & 2676 & 578 & 18.67 & 31.0 \\
\hline Vault 2: Betw Cabinets & 27 & 4000139 & 112 & 651 & 2168 & 1518 & 2542 & 402 & 18.67 & 21.5 \\
\hline Vault 2: Betw Cabinets & 28 & 4002815 & 112 & 676 & 2311 & 1492 & 2575 & 627 & 18.67 & 33.6 \\
\hline Vault 2: Betw Cabinets & 28 & 4007143 & 112 & 629 & 2390 & 1578 & 2627 & 453 & 18.67 & 24.3 \\
\hline \multirow[t]{2}{*}{ Vault 2: Betw Cabinets } & 28 & 4001420 & 112 & 618 & 2345 & 1620 & 2734 & 387 & 18.67 & 20.7 \\
\hline & Control & 4007391 & 113 & 0 & 0 & 0 & 0 & 0 & & \\
\hline
\end{tabular}

D. 10 
Table D.2 HCND Dosimeter Response

\begin{tabular}{|c|c|c|c|c|c|c|c|c|c|c|}
\hline \multirow[b]{2}{*}{ Location } & \multirow[b]{2}{*}{$\begin{array}{c}\text { Packet } \\
\#\end{array}$} & \multirow[b]{2}{*}{$\begin{array}{l}\text { Card } \\
\text { ID }\end{array}$} & \multirow[b]{2}{*}{ Formula } & \multicolumn{4}{|c|}{ Adjusted Chip Readings } & \multirow[b]{2}{*}{$\begin{array}{l}\text { Neutron } \\
\text { (mrem) }\end{array}$} & \multirow[b]{2}{*}{$\begin{array}{l}\text { Exp Time } \\
\text { (hrs) }\end{array}$} & \multirow[b]{2}{*}{$\begin{array}{l}\text { Neutron } \\
\text { DE Rate } \\
(\mathrm{mrem} / \mathrm{h})\end{array}$} \\
\hline & & & & Chip 1 & Chip 2 & Chip 3 & Chip 4 & & & \\
\hline & Control & 4003646 & 113 & 0 & 0 & 0 & 0 & 0 & & \\
\hline Vault 2 - By Wall & 29 & 4001582 & 111 & 213 & 1578 & 1127 & 1941 & 438 & 18.73 & 23.4 \\
\hline Vault 2 - By Wall & 29 & 4005963 & 111 & 223 & 1674 & 1136 & 2240 & 675 & 18.73 & 36.0 \\
\hline Vault 2 - By Wall & 29 & 4000879 & 111 & 224 & 1507 & 1105 & 2078 & 528 & 18.73 & 28.2 \\
\hline Vault 2 - By Wall & 30 & 4005883 & 111 & 86 & 1145 & 953 & 1563 & 181 & 18.73 & 9.7 \\
\hline Vault 2 - By Wall & 30 & 4000082 & 111 & 92 & 1088 & 945 & 1554 & 161 & 18.73 & 8.6 \\
\hline Vault 2 - By Wall & 30 & 4004309 & 111 & 107 & 1216 & 976 & 1647 & 248 & 18.73 & 13.2 \\
\hline Vault 2 - By Wall & 31 & 4005051 & 111 & 108 & 1213 & 893 & 1635 & 368 & 18.73 & 19.7 \\
\hline Vault 2 - By Wall & 31 & 4001035 & 111 & 82 & 1207 & 954 & 1736 & 326 & 18.73 & 17.4 \\
\hline Vault 2 - By Wall & 31 & 4005964 & 111 & 73 & 1233 & 925 & 1692 & 353 & 18.73 & 18.9 \\
\hline Vault 2 - By Wall & 32 & 4001647 & 111 & 226 & 1653 & 1128 & 2048 & 551 & 18.73 & 29.4 \\
\hline Vault 2 - By Wall & 32 & 4001767 & 112 & 215 & 1639 & 1096 & 2092 & 284 & 18.73 & 15.2 \\
\hline \multirow[t]{3}{*}{ Vault 2 - By Wall } & 32 & 4001519 & 112 & 203 & 1516 & 1000 & 1852 & 233 & 18.73 & 12.5 \\
\hline & Control & 4050839 & 113 & 1 & 0 & 0 & 0 & 0 & & \\
\hline & Control & 4002355 & 113 & 0 & 0 & 0 & 0 & 0 & & \\
\hline Vault Corridor - by V1 & 33 & 4005247 & 111 & 26 & 1190 & 1003 & 1740 & 222 & 90.80 & 2.44 \\
\hline Vault Corridor - by V1 & 33 & 4006737 & 111 & 28 & 1126 & 969 & 1731 & 236 & 90.80 & 2.59 \\
\hline Vault Corridor - by V1 & 33 & 4006209 & 111 & 27 & 1051 & 993 & 1619 & 84 & 90.80 & 0.92 \\
\hline Vault Corridor - by V1 & 34 & 4007540 & 111 & 26 & 1044 & 921 & 1583 & 169 & 90.80 & 1.86 \\
\hline Vault Corridor - by V1 & 34 & 4000927 & 111 & 27 & 931 & 925 & 1493 & 46 & 90.80 & 0.51 \\
\hline Vault Corridor - by V1 & 34 & 4004017 & 111 & 27 & 1109 & 944 & 1569 & 159 & 90.80 & 1.75 \\
\hline Vault Corridor - by V1 & 35 & 4007280 & 111 & 25 & 1038 & 956 & 1523 & 72 & 90.80 & 0.79 \\
\hline Vault Corridor - by V1 & 35 & 4000105 & 111 & 27 & 1038 & 935 & 1567 & 133 & 90.80 & 1.47 \\
\hline Vault Corridor - by V1 & 35 & 4001088 & 111 & 26 & 1024 & 963 & 1589 & 97 & 90.80 & 1.06 \\
\hline Vault Corridor - by V1 & 36 & 4005611 & 111 & 24 & 931 & 735 & 1356 & 250 & 90.80 & 2.75 \\
\hline Vault Corridor - by V1 & 36 & 4000535 & 111 & 24 & 841 & 746 & 1280 & 134 & 90.80 & 1.48 \\
\hline \multirow[t]{2}{*}{ Vault Corridor - by V1 } & 36 & 4001117 & 111 & 25 & 914 & 774 & 1296 & 141 & 90.80 & 1.55 \\
\hline & Control & 4006511 & 113 & 1 & 1 & 0 & 0 & 0 & & \\
\hline Vault Corridor - by V3 & 37 & 4002694 & 111 & 27 & 1049 & 907 & 1477 & 124 & 90.80 & 1.37 \\
\hline Vault Corridor - by V3 & 37 & 4000305 & 111 & 26 & 1089 & 909 & 1483 & 146 & 90.80 & 1.61 \\
\hline Vault Corridor - by V3 & 37 & 4001499 & 111 & 28 & 1045 & 876 & 1498 & 184 & 90.80 & 2.03 \\
\hline
\end{tabular}

D. 11 
Table D.2 HCND Dosimeter Response

\begin{tabular}{|c|c|c|c|c|c|c|c|c|c|c|}
\hline & & & & \multicolumn{4}{|c|}{ Adjusted Chip Readings } & \multirow[b]{2}{*}{$\begin{array}{c}\text { Neutron } \\
\text { (mrem) }\end{array}$} & \multirow[b]{2}{*}{$\begin{array}{c}\text { Exp Time } \\
(\mathrm{hrs})\end{array}$} & \multirow[b]{2}{*}{$\begin{array}{l}\text { Neutron } \\
\text { DE Rate } \\
(\mathrm{mrem} / \mathrm{h})\end{array}$} \\
\hline Location & $\begin{array}{c}\text { Packet } \\
\#\end{array}$ & $\begin{array}{c}\text { Card } \\
\text { ID }\end{array}$ & Formula & Chip 1 & Chip 2 & Chip 3 & Chip 4 & & & \\
\hline Vault Corridor - by V3 & 38 & 4002322 & 111 & 31 & 1249 & 1016 & 1779 & 261 & 90.80 & 2.87 \\
\hline Vault Corridor - by V3 & 38 & 4003465 & 111 & 32 & 1185 & 1019 & 1719 & 183 & 90.80 & 2.01 \\
\hline Vault Corridor - by V3 & 38 & 4003954 & 111 & 29 & 1087 & 904 & 1559 & 203 & 90.80 & 2.24 \\
\hline Vault Corridor - by V3 & 39 & 4002130 & 111 & 36 & 1546 & 1467 & 2368 & 103 & 90.80 & 1.14 \\
\hline Vault Corridor - by V3 & 39 & 4003256 & 111 & 38 & 1648 & 1443 & 2339 & 178 & 90.80 & 1.96 \\
\hline Vault Corridor - by V3 & 39 & 4000006 & 111 & 35 & 1624 & 1422 & 2386 & 227 & 90.80 & 2.50 \\
\hline Vault Corridor - by V3 & 40 & 4004706 & 111 & 31 & 1064 & 999 & 1706 & 141 & 90.80 & 1.55 \\
\hline Vault Corridor - by V3 & 40 & 4000126 & 111 & 33 & 1064 & 1004 & 1758 & 167 & 90.80 & 1.84 \\
\hline Vault Corridor - by V3 & 40 & 4003090 & 111 & 33 & 1240 & 1065 & 1762 & 169 & 90.80 & 1.86 \\
\hline & Control & 4007070 & 113 & 1 & 0 & 0 & 0 & 0 & & \\
\hline & Control & 4003232 & 113 & 0 & 1 & 0 & 1 & 0 & & \\
\hline & Control & 4002390 & 113 & 0 & 0 & 1 & 0 & 0 & & \\
\hline
\end{tabular}


Table D.3. TED Dosimeter Response

\begin{tabular}{|c|c|c|c|c|c|c|c|c|c|c|}
\hline \multirow[b]{2}{*}{ Location } & \multirow[b]{2}{*}{$\begin{array}{c}\text { Packet } \\
\#\end{array}$} & \multirow[b]{2}{*}{ On-Phantom Placement } & \multirow[b]{2}{*}{$\begin{array}{l}\text { Holder } \\
\text { ID }\end{array}$} & \multicolumn{2}{|c|}{ Foil 1} & \multicolumn{2}{|c|}{ Foil 2} & \multicolumn{3}{|c|}{ Both Foils } \\
\hline & & & & $\begin{array}{c}\text { CR-39 } \\
\text { ID }\end{array}$ & $\begin{array}{c}\text { Dose } \\
\text { (mrem) }\end{array}$ & $\begin{array}{c}\text { CR-39 } \\
\text { ID }\end{array}$ & $\begin{array}{c}\text { Dose } \\
\text { (mrem) }\end{array}$ & $\begin{array}{c}\text { Mean } \\
\text { Dose } \\
\text { (mrem) }\end{array}$ & $\begin{array}{c}\% \\
\text { Diff. }\end{array}$ & $\begin{array}{c}\text { Mean } \\
\text { Dose rate } \\
(\mathrm{mrem} / \mathrm{h})\end{array}$ \\
\hline 235A-3 North & 5 & West - facing TEPC 1173 & 4004869 & 11161 & 31 & 11167 & 25 & 28 & 21.4 & 1.40 \\
\hline 235A-3 North & 5 & West - facing TEPC 1173 & 4002047 & 11164 & 38 & 11166 & 38 & 38 & 0.0 & 1.90 \\
\hline 235A-3 North & 5 & West - facing TEPC 1173 & 4004462 & 11151 & 33 & 11169 & 24 & 28.5 & 31.6 & 1.43 \\
\hline 235A-3 North & 6 & North - facing water wall & 4002958 & 11183 & 13 & 11175 & 5 & 9 & 88.9 & 0.45 \\
\hline 235A-3 North & 6 & North - facing water wall & 4004438 & 11157 & 6 & 11163 & 7 & 6.5 & -15.4 & 0.33 \\
\hline 235A-3 North & 6 & North - facing water wall & 4000532 & 11180 & 6 & 11150 & 22 & 14 & -114.3 & 0.70 \\
\hline 235A-3 North & 7 & East - facing TEPC 185 & 4004304 & 11178 & 14 & 11149 & 6 & 10 & 80.0 & 0.50 \\
\hline 235A-3 North & 7 & East - facing TEPC 185 & 4004478 & 11093 & 3 & 11111 & 12 & 7.5 & -120.0 & 0.38 \\
\hline 235A-3 North & 7 & East - facing TEPC 185 & 4004286 & 11148 & 10 & 11152 & 10 & 10 & 0.0 & 0.50 \\
\hline 235A-3 North & 9 & South - Facing hood & 4005325 & 11088 & 75 & 11098 & 66 & 70.5 & 12.8 & 3.53 \\
\hline 235A-3 North & 9 & South - Facing hood & 4004444 & 11086 & 71 & 11091 & 77 & 74 & -8.1 & 3.71 \\
\hline 235A-3 North & 9 & South - Facing hood & 4004394 & 11095 & 61 & 11085 & 69 & 65 & -12.3 & 3.26 \\
\hline 235A-3 South & 1 & North - Facing hood & 4004882 & 11299 & 63 & 11313 & 66 & 64.5 & -4.7 & 3.23 \\
\hline 235A-3 South & 1 & North - Facing hood & 4000403 & 11179 & 69 & 11165 & 54 & 61.5 & 24.4 & 3.08 \\
\hline 235A-3 South & 1 & North - Facing hood & 4001330 & 11168 & 55 & 11174 & 66 & 60.5 & -18.2 & 3.03 \\
\hline 235A-3 South & 2 & East - to TEPC 1170 & 4004537 & 11156 & 18 & 11171 & 21 & 19.5 & -15.4 & 0.98 \\
\hline 235A-3 South & 2 & East - to TEPC 1170 & 4004464 & 11153 & 32 & 11154 & 27 & 29.5 & 16.9 & 1.48 \\
\hline 235A-3 South & 2 & East - to TEPC 1170 & 4001329 & 11173 & 23 & 11162 & 20 & 21.5 & 14.0 & 1.08 \\
\hline 235A-3 South & 3 & West - to TEPC 1172 & 4003058 & 11315 & 23 & 11296 & 18 & 20.5 & 24.4 & 1.03 \\
\hline 235A-3 South & 3 & West - to TEPC 1172 & 4000295 & 11155 & 21 & 11176 & 24 & 22.5 & -13.3 & 1.13 \\
\hline 235A-3 South & 3 & West - to TEPC 1172 & 4001419 & 11160 & 17 & 11158 & 27 & 22 & -45.5 & 1.10 \\
\hline 235A-3 South & 4 & South - Facing wall & 4001149 & 11318 & 4 & 11309 & 9 & 6.5 & -76.9 & 0.33 \\
\hline 235A-3 South & 4 & South - Facing wall & 4004866 & 11308 & 13 & 11302 & 14 & 13.5 & -7.4 & 0.68 \\
\hline 235A-3 South & 4 & South - Facing wall & 4004546 & 11319 & 10 & 11294 & 13 & 11.5 & -26.1 & 0.58 \\
\hline Vault 1: betw cabinets & 21 & facing cabinet $1 \mathrm{EE}$ & 4001686 & 11321 & 38 & 11304 & 28 & 33 & 30.3 & 1.82 \\
\hline Vault 1: betw cabinets & 21 & facing cabinet $1 \mathrm{EE}$ & 4001159 & 11326 & 41 & 11327 & 50 & 45.5 & -19.8 & 2.51 \\
\hline Vault 1: betw cabinets & 21 & facing cabinet $1 \mathrm{EE}$ & 4000166 & 11293 & 34 & 11301 & 30 & 32 & 12.5 & 1.76 \\
\hline Vault 1: betw cabinets & 22 & facing TEPC1172 & 4004867 & 11310 & 20 & 11316 & 32 & 26 & -46.2 & 1.43 \\
\hline Vault 1: betw cabinets & 22 & facing TEPC1172 & 4004571 & 11298 & 18 & 11303 & 22 & 20 & -20.0 & 1.10 \\
\hline Vault 1: betw cabinets & 22 & facing TEPC1172 & 4000509 & 11325 & 30 & 11317 & 31 & 30.5 & -3.3 & 1.68 \\
\hline Vault 1: betw cabinets & 23 & facing cabn $1 \mathrm{FE}$ & 4000103 & 11323 & 83 & 11324 & 73 & 78 & 12.8 & 4.30 \\
\hline
\end{tabular}

D. 13 
Table D.3. TED Dosimeter Response

\begin{tabular}{|c|c|c|c|c|c|c|c|c|c|c|}
\hline \multirow[b]{2}{*}{ Location } & \multirow[b]{2}{*}{$\begin{array}{c}\text { Packet } \\
\#\end{array}$} & \multirow[b]{2}{*}{ On-Phantom Placement } & \multirow[b]{2}{*}{$\begin{array}{l}\text { Holder } \\
\text { ID }\end{array}$} & \multicolumn{2}{|c|}{ Foil 1} & \multicolumn{2}{|c|}{ Foil 2} & \multicolumn{3}{|c|}{ Both Foils } \\
\hline & & & & $\begin{array}{c}\text { CR-39 } \\
\text { ID }\end{array}$ & $\begin{array}{c}\text { Dose } \\
(\mathrm{mrem})\end{array}$ & $\begin{array}{c}\text { CR-39 } \\
\text { ID }\end{array}$ & $\begin{array}{c}\text { Dose } \\
\text { (mrem) }\end{array}$ & $\begin{array}{l}\text { Mean } \\
\text { Dose } \\
\text { (mrem) }\end{array}$ & $\begin{array}{c}\% \\
\text { Diff. }\end{array}$ & \begin{tabular}{|c|} 
Mean \\
Dose rate \\
$(\mathrm{mrem} / \mathrm{h})$
\end{tabular} \\
\hline Vault 1: betw cabinets & 23 & facing cabn $1 \mathrm{FE}$ & 4002926 & 11305 & 77 & 11320 & 101 & 89 & -27.0 & 4.90 \\
\hline Vault 1: betw cabinets & 23 & facing cabn $1 \mathrm{FE}$ & 4000482 & 11307 & 83 & 11297 & 84 & 83.5 & -1.2 & 4.60 \\
\hline Vault 1: betw cabinets & 24 & facing TEPC1173 & 4002059 & 11311 & 28 & 11295 & 30 & 29 & -6.9 & 1.60 \\
\hline Vault 1: betw cabinets & 24 & facing TEPC1173 & 4004449 & 11314 & 30 & 11312 & 27 & 28.5 & 10.5 & 1.57 \\
\hline Vault 1: betw cabinets & 24 & facing TEPC1173 & 4000188 & 11322 & 28 & 11306 & 26 & 27 & 7.4 & 1.49 \\
\hline Vault 1: by corridor wall & 17 & away from wall & 4001364 & 11290 & 16 & 11268 & 21 & 18.5 & -27.0 & 1.02 \\
\hline Vault 1: by corridor wall & 17 & away from wall & 4001422 & 11275 & 23 & 11258 & 19 & 21 & 19.0 & 1.16 \\
\hline Vault 1: by corridor wall & 17 & away from wall & 4001383 & 11274 & 19 & 11281 & 21 & 20 & -10.0 & 1.10 \\
\hline Vault 1: by corridor wall & 18 & facing TEPC504 & 4002893 & 11262 & 9 & 11195 & 11 & 10 & -20.0 & 0.55 \\
\hline Vault 1: by corridor wall & 18 & facing TEPC504 & 4001527 & 11256 & 6 & 11277 & 9 & 7.5 & -40.0 & 0.41 \\
\hline Vault 1: by corridor wall & 18 & facing TEPC504 & 4002852 & 11265 & 10 & 11286 & 14 & 12 & -33.3 & 0.66 \\
\hline Vault 1 : by corridor wall & 19 & facing wall & 4000585 & 11288 & 4 & 11285 & 11 & 7.5 & -93.3 & 0.41 \\
\hline Vault 1: by corridor wall & 19 & facing wall & 4000311 & 11259 & 1 & 11278 & 8 & 4.5 & -155.6 & 0.25 \\
\hline Vault 1 : by corridor wall & 19 & facing wall & 4001567 & 11266 & 4 & 11280 & 14 & 9 & -111.1 & 0.50 \\
\hline Vault 1 : by corridor wall & 20 & facing TEPC1170 & 4003222 & 11272 & 25 & 11283 & 23 & 24 & 8.3 & 1.32 \\
\hline Vault 1: by corridor wall & 20 & facing TEPC1170 & 4002981 & 11263 & 27 & 11267 & 23 & 25 & 16.0 & 1.38 \\
\hline Vault 1: by corridor wall & 20 & facing TEPC1170 & \#REF! & 11292 & 20 & 11300 & 25 & 22.5 & -22.2 & 1.24 \\
\hline Vault 2 - Betw Cabinets & 25 & to aisle & 4003239 & 11182 & 293 & 11222 & 289 & 291 & 1.4 & 15.59 \\
\hline Vault 2 - Betw Cabinets & 25 & to aisle & 4001251 & 11247 & 281 & 11225 & 273 & 277 & 2.9 & 14.84 \\
\hline Vault 2 - Betw Cabinets & 25 & to aisle & 4001280 & 11235 & 245 & 11231 & 237 & 241 & 3.3 & 12.91 \\
\hline Vault 2 - Betw Cabinets & 26 & to TEPC 1173 & 4000547 & 11232 & 180 & 11238 & 168 & 174 & 6.9 & 9.32 \\
\hline Vault 2 - Betw Cabinets & 26 & to TEPC 1173 & 4002936 & 11251 & 203 & 11242 & 191 & 197 & 6.1 & 10.55 \\
\hline Vault 2 - Betw Cabinets & 26 & to TEPC 1173 & 4001731 & 11228 & 193 & 11250 & 202 & 197.5 & -4.6 & 10.58 \\
\hline Vault 2 - Betw Cabinets & 27 & to wall cabinet & 4002986 & 11328 & 208 & 11331 & 227 & 217.5 & -8.7 & 11.65 \\
\hline Vault 2 - Betw Cabinets & 27 & to wall cabinet & 4000234 & 11330 & 193 & 11335 & 219 & 206 & -12.6 & 11.03 \\
\hline Vault 2 - Betw Cabinets & 27 & to wall cabinet & 4002894 & 11142 & 225 & 11126 & 199 & 212 & 12.3 & 11.36 \\
\hline Vault 2 - Betw Cabinets & 28 & to TEPC 1172 & 4000386 & 11249 & 258 & 11221 & 268 & 263 & -3.8 & 14.09 \\
\hline Vault 2 - Betw Cabinets & 28 & to TEPC 1172 & 4002040 & 11351 & 264 & 11348 & 291 & 277.5 & -9.7 & 14.86 \\
\hline Vault 2 - Betw Cabinets & 28 & to TEPC 1172 & 4002069 & 11245 & 247 & 11227 & 246 & 246.5 & 0.4 & 13.20 \\
\hline
\end{tabular}


Table D.3. TED Dosimeter Response

\begin{tabular}{|c|c|c|c|c|c|c|c|c|c|c|}
\hline \multirow[b]{2}{*}{ Location } & \multirow[b]{2}{*}{$\begin{array}{c}\text { Packet } \\
\#\end{array}$} & \multirow[b]{2}{*}{ On-Phantom Placement } & \multirow[b]{2}{*}{$\begin{array}{l}\text { Holder } \\
\text { ID }\end{array}$} & \multicolumn{2}{|c|}{ Foil 1} & \multicolumn{2}{|c|}{ Foil 2} & \multicolumn{3}{|c|}{ Both Foils } \\
\hline & & & & $\begin{array}{c}\text { CR-39 } \\
\text { ID }\end{array}$ & $\begin{array}{c}\text { Dose } \\
\text { (mrem) }\end{array}$ & $\begin{array}{c}\text { CR-39 } \\
\text { ID }\end{array}$ & $\begin{array}{c}\text { Dose } \\
\text { (mrem) }\end{array}$ & $\begin{array}{c}\text { Mean } \\
\text { Dose } \\
\text { (mrem) }\end{array}$ & $\begin{array}{c}\% \\
\text { Diff. }\end{array}$ & \begin{tabular}{|c|} 
Mean \\
Dose rate \\
$(\mathrm{mrem} / \mathrm{h})$
\end{tabular} \\
\hline Vault 2 - by wall & 29 & away from wall & 4001600 & 11102 & 133 & 11132 & 154 & 143.5 & -14.6 & 7.66 \\
\hline Vault 2 - by wall & 29 & away from wall & 4000554 & 11143 & 162 & 11146 & 192 & 177 & -16.9 & 9.45 \\
\hline Vault 2 - by wall & 29 & away from wall & 4004474 & 11113 & 175 & 11124 & 156 & 165.5 & 11.5 & 8.84 \\
\hline Vault 2 - by wall & 30 & to TEPC 504 & 4004521 & 11123 & 72 & 11127 & 65 & 68.5 & 10.2 & 3.66 \\
\hline Vault 2 - by wall & 30 & to TEPC 504 & \#REF! & 11141 & 75 & 11144 & 89 & 82 & -17.1 & 4.38 \\
\hline Vault 2 - by wall & 30 & to TEPC 504 & 4004547 & 11131 & 53 & 11129 & 65 & 59 & -20.3 & 3.15 \\
\hline Vault 2 - by wall & 31 & to wall & 4002848 & 11115 & 36 & 11120 & 43 & 39.5 & -17.7 & 2.11 \\
\hline Vault 2 - by wall & 31 & to wall & 4000424 & 11119 & 46 & 11134 & 35 & 40.5 & 27.2 & 2.16 \\
\hline Vault 2 - by wall & 31 & to wall & 4002959 & 11145 & 42 & 11116 & 38 & 40 & 10.0 & 2.14 \\
\hline Vault 2 - by wall & 32 & to TEPC 1170 & 4001370 & 11114 & 145 & 11122 & 153 & 149 & -5.4 & 7.96 \\
\hline Vault 2 - by wall & 32 & to TEPC 1170 & 4002907 & 11133 & 122 & 11130 & 130 & 126 & -6.3 & 6.73 \\
\hline Vault 2 - by wall & 32 & to TEPC 1170 & 4001479 & 11140 & 137 & 11138 & 154 & 145.5 & -11.7 & 7.77 \\
\hline Vault 4 - Back Wall & 8 & Away from wall & 4001212 & 11181 & 33 & 11177 & 41 & 37 & -21.6 & 6.25 \\
\hline Vault 4 - Back Wall & 8 & Away from wall & 4000353 & 11172 & 40 & 11159 & 50 & 45 & -22.2 & 7.60 \\
\hline Vault 4 - Back Wall & 8 & Away from wall & 4004431 & 11097 & 36 & 11170 & 53 & 44.5 & -38.2 & 7.52 \\
\hline Vault 4 - Back Wall & 10 & facing TEPC 1170 & 4003199 & 11078 & 20 & 11077 & 18 & 19 & 10.5 & 3.21 \\
\hline Vault 4 - Back Wall & 10 & facing TEPC 1170 & 4001209 & 11103 & 28 & 11109 & 24 & 26 & 15.4 & 4.39 \\
\hline Vault 4 - Back Wall & 10 & facing TEPC 1170 & 4003139 & 11094 & 15 & 11107 & 23 & 19 & -42.1 & 3.21 \\
\hline Vault 4 - Back Wall & 11 & toward wall & 4004871 & 11110 & 7 & 11092 & 4 & 5.5 & 54.5 & 0.93 \\
\hline Vault 4 - Back Wall & 11 & toward wall & 4003194 & 11076 & 4 & 11104 & 5 & 4.5 & -22.2 & 0.76 \\
\hline Vault 4 - Back Wall & 11 & toward wall & 4004465 & 11080 & 1 & 11084 & 8 & 4.5 & -155.6 & 0.76 \\
\hline Vault 4 - Back Wall & 12 & facing TEPC 504 & 4000244 & 11101 & 16 & 11082 & 17 & 16.5 & -6.1 & 2.79 \\
\hline Vault 4 - Back Wall & 12 & facing TEPC 504 & 4000098 & 11090 & 16 & 11087 & 18 & 17 & -11.8 & 2.87 \\
\hline Vault 4 - Back Wall & 12 & facing TEPC 504 & 4001160 & 11079 & 18 & 11099 & 22 & 20 & -20.0 & 3.38 \\
\hline Vault 4 betw cabinets & 13 & facing TEPC1172 & 4000578 & 11202 & 37 & 11187 & 69 & 53 & -60.4 & 9.43 \\
\hline Vault 4 betw cabinets & 13 & facing TEPC1172 & 4003134 & 11185 & 39 & 11196 & 54 & 46.5 & -32.3 & 8.27 \\
\hline Vault 4 betw cabinets & 13 & facing TEPC1172 & 4000179 & 11216 & 47 & 11219 & 68 & 57.5 & -36.5 & 10.23 \\
\hline Vault 4 betw cabinets & 14 & facing TEPC1173 & 4001397 & 11212 & 31 & 11189 & 45 & 38 & -36.8 & 6.76 \\
\hline Vault 4 betw cabinets & 14 & facing TEPC1173 & 4000212 & 11207 & 33 & 11190 & 38 & 35.5 & -14.1 & 6.32 \\
\hline Vault 4 betw cabinets & 14 & facing TEPC1173 & 4000090 & 11213 & 36 & 11184 & 56 & 46 & -43.5 & 8.19 \\
\hline Vault 4 betw cabinets & 15 & facing $4 \mathrm{FE}$ & \#REF! & 11264 & 34 & 11261 & 48 & 41 & -34.1 & 7.30 \\
\hline
\end{tabular}


Table D.3. TED Dosimeter Response

\begin{tabular}{|c|c|c|c|c|c|c|c|c|c|c|}
\hline \multirow[b]{2}{*}{ Location } & \multirow[b]{2}{*}{$\begin{array}{c}\text { Packet } \\
\#\end{array}$} & \multirow[b]{2}{*}{ On-Phantom Placement } & \multirow[b]{2}{*}{$\begin{array}{l}\text { Holder } \\
\text { ID }\end{array}$} & \multicolumn{2}{|c|}{ Foil 1} & \multicolumn{2}{|c|}{ Foil 2} & \multicolumn{3}{|c|}{ Both Foils } \\
\hline & & & & $\begin{array}{c}\text { CR-39 } \\
\text { ID }\end{array}$ & $\begin{array}{c}\text { Dose } \\
(\mathrm{mrem})\end{array}$ & $\begin{array}{c}\text { CR-39 } \\
\text { ID }\end{array}$ & $\begin{array}{c}\text { Dose } \\
\text { (mrem) }\end{array}$ & $\begin{array}{l}\text { Mean } \\
\text { Dose } \\
\text { (mrem) }\end{array}$ & $\begin{array}{c}\% \\
\text { Diff. }\end{array}$ & $\begin{array}{c}\text { Mean } \\
\text { Dose rate } \\
(\mathrm{mrem} / \mathrm{h})\end{array}$ \\
\hline Vault 4 betw cabinets & 15 & facing 4FE & 4000326 & 11210 & 31 & 11215 & 42 & 36.5 & -30.1 & 6.49 \\
\hline Vault 4 betw cabinets & 15 & facing 4FE & 4003131 & 11217 & 28 & 11191 & 56 & 42 & -66.7 & 7.47 \\
\hline Vault 4 betw cabinets & 16 & facing 4EE & 4000283 & 11197 & 75 & 11199 & 89 & 82 & -17.1 & 14.59 \\
\hline Vault 4 betw cabinets & 16 & facing 4EE & 4001328 & 11203 & 66 & 11192 & 99 & 82.5 & -40.0 & 14.68 \\
\hline Vault 4 betw cabinets & 16 & facing $4 \mathrm{EE}$ & \#REF! & 11193 & 69 & 11186 & 91 & 80 & -27.5 & 14.23 \\
\hline Vault Corr - by Vault 1 & 33 & to corridor & 4000128 & 11214 & 27 & 11206 & 18 & 22.5 & 40.0 & 0.25 \\
\hline Vault Cor by V1 & 33 & to corridor & 4003095 & 11118 & 24 & 11112 & 21 & 22.5 & 13.3 & 0.25 \\
\hline Vault Cor by V1 & 33 & to corridor & 4001298 & 11147 & 19 & 11128 & 23 & 21 & -19.0 & 0.23 \\
\hline Vault Cor by V1 & 34 & to TEPC1172 & 4002815 & 11125 & 10 & 11121 & 18 & 14 & -57.1 & 0.15 \\
\hline Vault Cor by V1 & 34 & to TEPC1172 & 4000504 & 11139 & 14 & 11117 & 22 & 18 & -44.4 & 0.20 \\
\hline Vault Cor by V1 & 34 & to TEPC1172 & 4000060 & 11135 & 13 & 11136 & 19 & 16 & -37.5 & 0.18 \\
\hline Vault Cor by V1 & 35 & to TEPC1173 & 4001681 & 11188 & 19 & 11198 & 20 & 19.5 & -5.1 & 0.21 \\
\hline Vault Cor by V1 & 35 & to TEPC1173 & 4002937 & 11208 & 12 & 11211 & 26 & 19 & -73.7 & 0.21 \\
\hline Vault Cor by V1 & 35 & to TEPC1173 & 4001647 & 11205 & 17 & 11218 & 19 & 18 & -11.1 & 0.20 \\
\hline Vault Cor by V1 & 36 & to wall & 4001535 & 11200 & 9 & 11201 & 10 & 9.5 & -10.5 & 0.10 \\
\hline Vault Cor by V1 & 36 & to wall & 4001230 & 11204 & 4 & 11209 & 14 & 9 & -111.1 & 0.10 \\
\hline Vault Cor by V1 & 36 & to wall & 4001222 & 11194 & 2 & 11137 & 13 & 7.5 & -146.7 & 0.08 \\
\hline Vault Corr - by Vault 3 & 37 & to corridor & 4002839 & 11237 & 16 & 11246 & 25 & 20.5 & -43.9 & 0.23 \\
\hline Vault Cor by V3 & 37 & to corridor & 4001672 & 11244 & 10 & 11224 & 23 & 16.5 & -78.8 & 0.18 \\
\hline Vault Cor by V3 & 37 & to corridor & 4001467 & 11223 & 18 & 11230 & 8 & 13 & 76.9 & 0.14 \\
\hline Vault Cor by V3 & 38 & to TEPC 504 & 4000232 & 11248 & 9 & 11234 & 13 & 11 & -36.4 & 0.12 \\
\hline Vault Cor by V3 & 38 & to TEPC 504 & 4000153 & 11252 & 11 & 11240 & 14 & 12.5 & -24.0 & 0.14 \\
\hline Vault Cor by V3 & 38 & to TEPC 504 & 4001293 & 11269 & 7 & 11287 & 19 & 13 & -92.3 & 0.14 \\
\hline Vault Cor by V3 & 39 & to wall & 4003205 & 11243 & 31 & 11254 & 34 & 32.5 & -9.2 & 0.36 \\
\hline Vault Cor by V3 & 39 & to wall & 4000086 & 11226 & 20 & 11255 & 42 & 31 & -71.0 & 0.34 \\
\hline Vault Cor by V3 & 39 & to wall & 4001405 & 11253 & 37 & 11233 & 36 & 36.5 & 2.7 & 0.40 \\
\hline Vault Cor by V3 & 40 & to TEPC 1170 & 4002983 & 11279 & 19 & 11229 & 15 & 17 & 23.5 & 0.19 \\
\hline Vault Cor by V3 & 40 & to TEPC 1170 & 4001685 & 11239 & 16 & 11241 & 16 & 16 & 0.0 & 0.18 \\
\hline Vault Cor by V3 & 40 & to TEPC 1170 & 4001616 & 11236 & 12 & 11220 & 27 & 19.5 & -76.9 & 0.21 \\
\hline
\end{tabular}


Table D.4. HSD Dosimeter Response

\begin{tabular}{|c|c|c|c|c|c|c|c|c|c|c|c|c|c|c|c|}
\hline & & & & \multicolumn{4}{|c|}{ Adjusted Chip Counts } & \multicolumn{3}{|c|}{ Shallow } & \multicolumn{3}{|c|}{ Eye } & \multicolumn{2}{|c|}{ Deep } \\
\hline Location & $\begin{array}{c}\text { Packet } \\
\#\end{array}$ & $\begin{array}{l}\text { Card } \\
\text { ID \# }\end{array}$ & $\begin{array}{c}\text { Form- } \\
\text { ula }\end{array}$ & Chip 1 & Chip 2 & Chip 3 & Chip 4 & Beta & Photon & Total & Beta & Photon & Total & $\begin{array}{l}\text { Photon } \\
\text { (mrem) }\end{array}$ & $\begin{array}{c}\text { Neutron } \\
\text { (mrem) }\end{array}$ \\
\hline 235A-3 South & 1 & 4309 & 7303 & 47 & 44 & 46 & 816 & 0 & 46 & 46 & 0 & 44 & 44 & 44 & 665 \\
\hline 235A-3 South & 1 & 40744 & 7303 & 47 & 43 & 47 & 905 & 0 & 47 & 47 & 0 & 43 & 43 & 43 & 743 \\
\hline 235A-3 South & 1 & 21637 & 7303 & 46 & 43 & 44 & 891 & 0 & 44 & 44 & 0 & 43 & 43 & 43 & 731 \\
\hline 235A-3 South & 2 & 22248 & 7303 & 20 & 21 & 21 & 630 & 0 & 21 & 21 & 0 & 21 & 21 & 21 & 526 \\
\hline 235A-3 South & 2 & 32709 & 7303 & 26 & 26 & 26 & 659 & 0 & 26 & 26 & 0 & 26 & 26 & 26 & 546 \\
\hline 235A-3 South & 2 & 17188 & 9111 & 31 & 32 & 36 & 705 & 10 & 29 & 38 & 0 & 29 & 29 & 29 & 582 \\
\hline 235A-3 South & 3 & 41492 & 7303 & 33 & 27 & 29 & 664 & 0 & 29 & 29 & 0 & 27 & 27 & 27 & 548 \\
\hline 235A-3 South & 3 & 26734 & 7303 & 29 & 25 & 26 & 693 & 0 & 26 & 26 & 0 & 25 & 25 & 25 & 576 \\
\hline 235A-3 South & 3 & 21790 & 7303 & 23 & 20 & 20 & 656 & 0 & 20 & 20 & 0 & 20 & 20 & 20 & 549 \\
\hline 235A-3 South & 4 & 33420 & 7303 & 13 & 11 & 12 & 572 & 0 & 12 & 12 & 0 & 11 & 11 & 11 & 483 \\
\hline 235A-3 South & 4 & 42051 & 7303 & 12 & 12 & 12 & 611 & 0 & 12 & 12 & 0 & 12 & 12 & 12 & 517 \\
\hline 235A-3 South & 4 & 18946 & 9111 & 12 & 11 & 13 & 592 & 4 & 10 & 14 & 0 & 10 & 10 & 10 & 501 \\
\hline 235A-3 South & 5 & 12508 & 8111 & 57 & 67 & 79 & 568 & 0 & 56 & 56 & 0 & 55 & 55 & 50 & 451 \\
\hline 235A-3 North & 5 & 34819 & 8111 & 69 & 84 & 96 & 606 & 0 & 67 & 67 & 0 & 66 & 66 & 62 & 477 \\
\hline 235A-3 North & 5 & 20200 & 8111 & 82 & 94 & 106 & 669 & 0 & 78 & 78 & 0 & 76 & 76 & 74 & 519 \\
\hline 235A-3 North & 6 & 6484 & 9111 & 16 & 14 & 17 & 469 & 6 & 13 & 18 & 0 & 13 & 13 & 13 & 392 \\
\hline 235A-3 North & 6 & 40580 & 7303 & 15 & 15 & 15 & 487 & 0 & 15 & 15 & 0 & 15 & 15 & 15 & 408 \\
\hline 235A-3 North & 6 & 4108 & 8111 & 16 & 17 & 20 & 466 & 0 & 15 & 15 & 0 & 15 & 15 & 14 & 389 \\
\hline 235A-3 North & 7 & 30323 & 7303 & 31 & 26 & 25 & 530 & 0 & 26 & 26 & 0 & 26 & 26 & 26 & 434 \\
\hline 235A-3 North & 7 & 13374 & 7303 & 24 & 21 & 21 & 545 & 0 & 21 & 21 & 0 & 21 & 21 & 21 & 452 \\
\hline 235A-3 North & 7 & 29625 & 7303 & 19 & 18 & 18 & 481 & 0 & 18 & 18 & 0 & 18 & 18 & 18 & 399 \\
\hline 235A-3 North & 9 & 1115 & 8111 & 104 & 111 & 131 & 781 & 0 & 99 & 99 & 0 & 96 & 96 & 90 & 593 \\
\hline 235A-3 North & 9 & 43505 & 8111 & 101 & 107 & 123 & 789 & 0 & 96 & 96 & 0 & 92 & 92 & 89 & 601 \\
\hline 235A-3 North & 9 & 36361 & 8111 & 99 & 102 & 115 & 753 & 0 & 94 & 94 & 0 & 91 & 91 & 91 & 569 \\
\hline & Control & 46971 & 9515 & 0 & 0 & 0 & 1 & 0 & 0 & 0 & 0 & 0 & 0 & 0 & 0 \\
\hline Vault 4 - back wall & 8 & 5918 & 7303 & 22 & 21 & 22 & 1574 & 0 & 22 & 22 & 0 & 21 & 21 & 21 & 1339 \\
\hline Vault 4 - back wall & 8 & 22863 & 7303 & 22 & 22 & 21 & 1587 & 0 & 22 & 22 & 0 & 22 & 22 & 22 & 1349 \\
\hline Vault 4 - back wall & 8 & 8912 & 7303 & 22 & 22 & 19 & 1653 & 0 & 22 & 22 & 0 & 22 & 22 & 22 & 1406 \\
\hline Vault 4 - back wall & 10 & 670 & 8111 & 14 & 15 & 11 & 1037 & 0 & 15 & 15 & 0 & 15 & 15 & 15 & 882 \\
\hline Vault 4 - back wall & 10 & 38939 & 7303 & 14 & 14 & 12 & 1147 & 0 & 14 & 14 & 0 & 14 & 14 & 14 & 977 \\
\hline Vault 4 - back wall & 10 & 22844 & 7303 & 17 & 16 & 14 & 1186 & 0 & 16 & 16 & 0 & 16 & 16 & 16 & 1008 \\
\hline Vault 4 - back wall & 11 & 32241 & 7303 & 12 & 11 & 10 & 1031 & 0 & 11 & 11 & 0 & 11 & 11 & 11 & 879 \\
\hline
\end{tabular}


Table D.4. HSD Dosimeter Response

\begin{tabular}{|c|c|c|c|c|c|c|c|c|c|c|c|c|c|c|c|}
\hline & & & & \multicolumn{4}{|c|}{ Adjusted Chip Counts } & \multicolumn{3}{|c|}{ Shallow } & \multicolumn{3}{|c|}{ Eye } & \multicolumn{2}{|c|}{ Deep } \\
\hline Location & $\begin{array}{c}\text { Packet } \\
\#\end{array}$ & $\begin{array}{l}\text { Card } \\
\text { ID \# }\end{array}$ & $\begin{array}{l}\text { Form- } \\
\text { ula }\end{array}$ & Chip 1 & Chip 2 & Chip 3 & Chip 4 & Beta & Photon & Total & Beta & Photon & Total & $\begin{array}{l}\text { Photon } \\
\text { (mrem) }\end{array}$ & $\begin{array}{c}\text { Neutron } \\
\text { (mrem) }\end{array}$ \\
\hline Vault 4 - back wall & 11 & 37609 & 7303 & 10 & 11 & 9 & 1030 & 0 & 11 & 11 & 0 & 11 & 11 & 11 & 879 \\
\hline Vault 4 - back wall & 11 & 33560 & 7303 & 13 & 11 & 11 & 985 & 0 & 11 & 11 & 0 & 11 & 11 & 11 & 840 \\
\hline Vault 4 - back wall & 12 & 26677 & 7303 & 18 & 16 & 17 & 1374 & 0 & 17 & 17 & 0 & 16 & 16 & 16 & 1171 \\
\hline Vault 4 - back wall & 12 & 47161 & 7303 & 15 & 16 & 17 & 1297 & 0 & 17 & 17 & 0 & 16 & 16 & 16 & 1105 \\
\hline \multirow[t]{2}{*}{ Vault 4 - back wall } & 12 & 29919 & 7303 & 16 & 15 & 14 & 1250 & 0 & 15 & 15 & 0 & 15 & 15 & 15 & 1064 \\
\hline & Control & 31706 & 7101 & 0 & 0 & 0 & 0 & 0 & 0 & 0 & 0 & 0 & 0 & 0 & 0 \\
\hline Vault 4 - betw cabinets & 13 & 2852 & 7303 & 73 & 73 & 77 & 1665 & 0 & 77 & 77 & 0 & 73 & 73 & 73 & 1373 \\
\hline Vault 4 - betw cabinets & 13 & 46321 & 7303 & 78 & 76 & 78 & 1653 & 0 & 78 & 78 & 0 & 76 & 76 & 76 & 1359 \\
\hline Vault 4 - betw cabinets & 13 & 3390 & 7303 & 79 & 72 & 71 & 1567 & 0 & 72 & 72 & 0 & 72 & 72 & 72 & 1289 \\
\hline Vault 4 - betw cabinets & 14 & 37832 & 7303 & 147 & 151 & 149 & 1360 & 0 & 151 & 151 & 0 & 151 & 151 & 151 & 1052 \\
\hline Vault 4 - betw cabinets & 14 & 33350 & 7303 & 142 & 143 & 147 & 1478 & 0 & 147 & 147 & 0 & 143 & 143 & 143 & 1153 \\
\hline Vault 4 - betw cabinets & 14 & 27275 & 7303 & 132 & 121 & 114 & 1343 & 0 & 121 & 121 & 0 & 121 & 121 & 121 & 1053 \\
\hline Vault 4 - betw cabinets & 15 & 46440 & 9111 & 34 & 32 & 44 & 1404 & 18 & 29 & 47 & 0 & 29 & 29 & 29 & 1183 \\
\hline Vault 4 - betw cabinets & 15 & 15712 & 7303 & 34 & 33 & 33 & 1594 & 0 & 33 & 33 & 0 & 33 & 33 & 33 & 1346 \\
\hline Vault 4 - betw cabinets & 15 & 3377 & 7303 & 35 & 34 & 36 & 1642 & 0 & 36 & 36 & 0 & 34 & 34 & 34 & 1387 \\
\hline Vault 4 - betw cabinets & 16 & 41215 & 7303 & 115 & 120 & 117 & 1805 & 0 & 120 & 120 & 0 & 120 & 120 & 120 & 1464 \\
\hline Vault 4 - betw cabinets & 16 & 17606 & 7303 & 135 & 134 & 139 & 1787 & 0 & 139 & 139 & 0 & 134 & 134 & 134 & 1426 \\
\hline \multirow[t]{2}{*}{ Vault 4 - betw cabinets } & 16 & 28992 & 7303 & 137 & 131 & 138 & 1816 & 0 & 138 & 138 & 0 & 131 & 131 & 131 & 1453 \\
\hline & Control & 46107 & 7101 & 0 & 0 & 0 & 0 & 0 & 0 & 0 & 0 & 0 & 0 & 0 & 0 \\
\hline Vault 1: Corridor & 17 & 10025 & 7303 & 13 & 12 & 12 & 960 & 0 & 12 & 12 & 0 & 12 & 12 & 12 & 817 \\
\hline Vault 1: Corridor & 17 & 23341 & 9212 & 13 & 12 & 25 & 962 & 15 & 10 & 25 & 2 & 10 & 12 & 10 & 819 \\
\hline Vault 1: Corridor & 17 & 16922 & 9111 & 15 & 12 & 14 & 955 & 5 & 10 & 15 & 1 & 10 & 11 & 10 & 813 \\
\hline Vault 1: Corridor & 18 & 37182 & 9111 & 10 & 9 & 11 & 818 & 4 & 8 & 11 & 0 & 8 & 8 & 8 & 698 \\
\hline Vault 1: Corridor & 18 & 40416 & 7303 & 12 & 10 & 10 & 840 & 0 & 10 & 10 & 0 & 10 & 10 & 10 & 716 \\
\hline Vault 1: Corridor & 18 & 26787 & 7303 & 11 & 10 & 11 & 823 & 0 & 11 & 11 & 0 & 10 & 10 & 10 & 700 \\
\hline Vault 1: Corridor & 19 & 37063 & 9111 & 11 & 8 & 10 & 836 & 4 & 8 & 11 & 0 & 8 & 8 & 8 & 713 \\
\hline Vault 1: Corridor & 19 & 31062 & 7303 & 10 & 10 & 10 & 777 & 0 & 10 & 10 & 0 & 10 & 10 & 10 & 661 \\
\hline Vault 1: Corridor & 19 & 10556 & 9111 & 10 & 9 & 12 & 779 & 5 & 8 & 12 & 0 & 8 & 8 & 8 & 664 \\
\hline Vault 1: Corridor & 20 & 42860 & 9111 & 13 & 12 & 15 & 1092 & 5 & 11 & 16 & 0 & 11 & 11 & 11 & 931 \\
\hline Vault 1: Corridor & 20 & 39602 & 7303 & 12 & 11 & 12 & 1075 & 0 & 12 & 12 & 0 & 11 & 11 & 11 & 917 \\
\hline \multirow[t]{2}{*}{ Vault 1: Corridor } & 20 & 31107 & 7303 & 13 & 11 & 12 & 1041 & 0 & 12 & 12 & 0 & 11 & 11 & 11 & 887 \\
\hline & Control & 36724 & 8212 & 0 & 0 & 0 & 0 & 0 & 0 & 0 & 0 & 0 & 0 & 0 & 0 \\
\hline
\end{tabular}


Table D.4. HSD Dosimeter Response

\begin{tabular}{|c|c|c|c|c|c|c|c|c|c|c|c|c|c|c|c|}
\hline & & & & \multicolumn{4}{|c|}{ Adjusted Chip Counts } & \multicolumn{3}{|c|}{ Shallow } & \multicolumn{3}{|c|}{ Eye } & \multicolumn{2}{|c|}{ Deep } \\
\hline Location & $\begin{array}{c}\text { Packet } \\
\#\end{array}$ & $\begin{array}{l}\text { Card } \\
\text { ID \# }\end{array}$ & $\begin{array}{c}\text { Form- } \\
\text { ula }\end{array}$ & Chip 1 & Chip 2 & Chip 3 & Chip 4 & Beta & Photon & Total & Beta & Photon & Total & $\begin{array}{l}\text { Photon } \\
\text { (mrem) }\end{array}$ & $\begin{array}{l}\text { Neutron } \\
\text { (mrem) }\end{array}$ \\
\hline Vault 1: Betw cabinets & 21 & 42970 & 7303 & 29 & 26 & 29 & 1980 & 0 & 29 & 29 & 0 & 26 & 26 & 26 & 1685 \\
\hline Vault 1: Betw cabinets & 21 & 12091 & 7303 & 31 & 27 & 27 & 2003 & 0 & 27 & 27 & 0 & 27 & 27 & 27 & 1703 \\
\hline Vault 1: Betw cabinets & 21 & 40423 & 7303 & 29 & 28 & 30 & 2054 & 0 & 30 & 30 & 0 & 28 & 28 & 28 & 1747 \\
\hline Vault 1: Betw cabinets & 22 & 13266 & 7303 & 27 & 26 & 28 & 1608 & 0 & 28 & 28 & 0 & 26 & 26 & 26 & 1363 \\
\hline Vault 1: Betw cabinets & 22 & 22465 & 7303 & 29 & 26 & 26 & 1574 & 0 & 26 & 26 & 0 & 26 & 26 & 26 & 1334 \\
\hline Vault 1: Betw cabinets & 22 & 35946 & 7303 & 30 & 29 & 29 & 1683 & 0 & 29 & 29 & 0 & 29 & 29 & 29 & 1426 \\
\hline Vault 1: Betw cabinets & 23 & 43091 & 9111 & 39 & 36 & 41 & 2992 & 11 & 33 & 44 & 0 & 33 & 33 & 33 & 2548 \\
\hline Vault 1: Betw cabinets & 23 & 15081 & 9111 & 43 & 39 & 50 & 3288 & 17 & 36 & 53 & 0 & 36 & 36 & 36 & 2801 \\
\hline Vault 1: Betw cabinets & 23 & 2667 & 9111 & 43 & 39 & 45 & 3250 & 12 & 35 & 47 & 0 & 35 & 35 & 35 & 2768 \\
\hline Vault 1: Betw cabinets & 24 & 25467 & 7303 & 37 & 33 & 33 & 2056 & 0 & 33 & 33 & 0 & 33 & 33 & 33 & 1744 \\
\hline Vault 1: Betw cabinets & 24 & 25743 & 9111 & 32 & 29 & 34 & 1987 & 9 & 26 & 36 & 0 & 26 & 26 & 26 & 1687 \\
\hline Vault 1: Betw cabinets & 24 & 3041 & 7303 & 32 & 30 & 31 & 1922 & 0 & 31 & 31 & 0 & 30 & 30 & 30 & 1631 \\
\hline & Control & 36234 & 7101 & 0 & 0 & 0 & 0 & 0 & 0 & 0 & 0 & 0 & 0 & 0 & 0 \\
\hline & Control & 16222 & 7101 & 0 & 0 & 0 & 0 & 0 & 0 & 0 & 0 & 0 & 0 & 0 & 0 \\
\hline Vault 2: Betw cabinets & 25 & 6409 & 7303 & 817 & 802 & 813 & 3237 & 0 & 813 & 813 & 0 & 802 & 802 & 802 & 2099 \\
\hline Vault 2: Betw cabinets & 25 & 35275 & 7303 & 828 & 777 & 791 & 3149 & 0 & 791 & 791 & 0 & 777 & 777 & 777 & 2046 \\
\hline Vault 2: Betw cabinets & 25 & 22089 & 7303 & 835 & 816 & 821 & 3052 & 0 & 821 & 821 & 0 & 816 & 816 & 816 & 1927 \\
\hline Vault 2: Betw cabinets & 26 & 23553 & 7303 & 1091 & 1064 & 1038 & 3252 & 0 & 1064 & 1064 & 0 & 1064 & 1064 & 1064 & 1886 \\
\hline Vault 2: Betw cabinets & 26 & 14206 & 7303 & 985 & 970 & 958 & 3364 & 0 & 970 & 970 & 0 & 970 & 970 & 970 & 2064 \\
\hline Vault 2: Betw cabinets & 26 & 5804 & 7303 & 961 & 1022 & 998 & 3263 & 0 & 1022 & 1022 & 0 & 1022 & 1022 & 1022 & 2064 \\
\hline Vault 2: Betw cabinets & 27 & 40868 & 7303 & 1104 & 1130 & 1071 & 3110 & 0 & 1130 & 1130 & 0 & 1130 & 1130 & 1130 & 1767 \\
\hline Vault 2: Betw cabinets & 27 & 44135 & 7303 & 1138 & 1143 & 1063 & 3227 & 0 & 1143 & 1143 & 0 & 1143 & 1143 & 1143 & 1809 \\
\hline Vault 2: Betw cabinets & 27 & 31839 & 7303 & 1096 & 1081 & 1018 & 3115 & 0 & 1081 & 1081 & 0 & 1081 & 1081 & 1081 & 1754 \\
\hline Vault 2: Betw cabinets & 28 & 2873 & 7303 & 973 & 912 & 897 & 3127 & 0 & 912 & 912 & 0 & 912 & 912 & 912 & 1909 \\
\hline Vault 2: Betw cabinets & 28 & 31582 & 7303 & 899 & 864 & 893 & 3359 & 0 & 893 & 893 & 0 & 864 & 864 & 864 & 2151 \\
\hline Vault 2: Betw cabinets & 28 & 3064 & 7303 & 978 & 1040 & 1007 & 3445 & 0 & 1040 & 1040 & 0 & 1040 & 1040 & 1040 & 2207 \\
\hline & Control & 3845 & 9515 & 0 & 0 & 0 & 0 & 0 & 0 & 0 & 0 & 0 & 0 & 0 & 0 \\
\hline & Control & 3894 & 6011 & 0 & 0 & 8 & 0 & 11 & 0 & 11 & 1 & 0 & 1 & 0 & 0 \\
\hline Vault 2 - by wall & 29 & 44026 & 7303 & 399 & 410 & 417 & 2417 & 0 & 417 & 417 & 0 & 410 & 410 & 410 & 1754 \\
\hline Vault 2 - by wall & 29 & 16423 & 7303 & 417 & 418 & 424 & 2613 & 0 & 424 & 424 & 0 & 418 & 418 & 418 & 1896 \\
\hline Vault 2 - by wall & 29 & 43120 & 7303 & 420 & 423 & 425 & 2439 & 0 & 425 & 425 & 0 & 423 & 423 & 423 & 1746 \\
\hline Vault 2 - by wall & 30 & 40546 & 9111 & 127 & 127 & 144 & 1798 & 38 & 115 & 153 & 0 & 115 & 115 & 115 & 1441 \\
\hline
\end{tabular}

D.19 
Table D.4. HSD Dosimeter Response

\begin{tabular}{|c|c|c|c|c|c|c|c|c|c|c|c|c|c|c|c|}
\hline & & & & \multicolumn{4}{|c|}{ Adjusted Chip Counts } & \multicolumn{3}{|c|}{ Shallow } & \multicolumn{3}{|c|}{ Eye } & \multicolumn{2}{|c|}{ Deep } \\
\hline Location & $\begin{array}{c}\text { Packet } \\
\#\end{array}$ & $\begin{array}{l}\text { Card } \\
\text { ID \# }\end{array}$ & $\begin{array}{c}\text { Form- } \\
\text { ula }\end{array}$ & Chip 1 & Chip 2 & Chip 3 & Chip 4 & Beta & Photon & Total & Beta & Photon & Total & $\begin{array}{l}\text { Photon } \\
\text { (mrem) }\end{array}$ & $\begin{array}{c}\text { Neutron } \\
\text { (mrem) }\end{array}$ \\
\hline Vault 2 - by wall & 30 & 45659 & 7303 & 145 & 150 & 157 & 1917 & 0 & 157 & 157 & 0 & 150 & 150 & 150 & 1536 \\
\hline Vault 2 - by wall & 30 & 5954 & 7303 & 182 & 196 & 198 & 2036 & 0 & 198 & 198 & 0 & 196 & 196 & 196 & 1615 \\
\hline Vault 2 - by wall & 31 & 40593 & 7303 & 161 & 132 & 132 & 2181 & 0 & 132 & 132 & 0 & 132 & 132 & 132 & 1767 \\
\hline Vault 2 - by wall & 31 & 42560 & 7303 & 120 & 107 & 106 & 2021 & 0 & 107 & 107 & 0 & 107 & 107 & 107 & 1650 \\
\hline Vault 2 - by wall & 31 & 42272 & 7303 & 107 & 106 & 107 & 2031 & 0 & 107 & 107 & 0 & 106 & 106 & 106 & 1660 \\
\hline Vault 2 - by wall & 32 & 25822 & 7303 & 373 & 369 & 368 & 2446 & 0 & 369 & 369 & 0 & 369 & 369 & 369 & 1791 \\
\hline Vault 2 - by wall & 32 & 31145 & 7303 & 373 & 359 & 358 & 2609 & 0 & 359 & 359 & 0 & 359 & 359 & 359 & 1940 \\
\hline Vault 2 - by wall & 32 & 34438 & 7303 & 345 & 327 & 329 & 2542 & 0 & 329 & 329 & 0 & 327 & 327 & 327 & 1910 \\
\hline & Control & 22799 & 7101 & 0 & 0 & 0 & 1 & 0 & 0 & 0 & 0 & 0 & 0 & 0 & 0 \\
\hline & Control & 10825 & 9515 & 0 & 1 & 3 & 0 & 3 & 0 & 3 & 0 & 0 & 0 & 0 & 0 \\
\hline & Control & 46090 & 6011 & 0 & 0 & 5 & 0 & 6 & 0 & 6 & 1 & 0 & 1 & 0 & 0 \\
\hline Vault Corridor - by V1 & 33 & 57774 & 9111 & 25 & 21 & 25 & 2017 & 7 & 19 & 26 & 0 & 19 & 19 & 19 & 1721 \\
\hline Vault Corridor - by V1 & 33 & 42955 & 9111 & 25 & 21 & 25 & 2118 & 7 & 19 & 26 & 0 & 19 & 19 & 19 & 1808 \\
\hline Vault Corridor - by V1 & 33 & 28591 & 9111 & 23 & 21 & 24 & 1976 & 7 & 19 & 26 & 0 & 19 & 19 & 19 & 1686 \\
\hline Vault Corridor - by V1 & 34 & 29821 & 9111 & 24 & 21 & 27 & 1842 & 10 & 19 & 29 & 0 & 19 & 19 & 19 & 1569 \\
\hline Vault Corridor - by V1 & 34 & 36873 & 7303 & 23 & 21 & 23 & 1834 & 0 & 23 & 23 & 0 & 21 & 21 & 21 & 1563 \\
\hline Vault Corridor - by V1 & 34 & 37791 & 9111 & 23 & 21 & 30 & 1733 & 13 & 19 & 32 & 0 & 19 & 19 & 19 & 1476 \\
\hline Vault Corridor - by V1 & 35 & 12335 & 7303 & 23 & 22 & 23 & 1810 & 0 & 23 & 23 & 0 & 22 & 22 & 22 & 1541 \\
\hline Vault Corridor - by V1 & 35 & 6551 & 9111 & 25 & 22 & 26 & 1927 & 8 & 20 & 27 & 0 & 20 & 20 & 20 & 1642 \\
\hline Vault Corridor - by V1 & 35 & 30830 & 7303 & 23 & 21 & 23 & 1799 & 0 & 23 & 23 & 0 & 21 & 21 & 21 & 1533 \\
\hline Vault Corridor - by V1 & 36 & 45443 & 7303 & 23 & 21 & 21 & 1492 & 0 & 21 & 21 & 0 & 21 & 21 & 21 & 1268 \\
\hline Vault Corridor - by V1 & 36 & 41556 & 9111 & 22 & 20 & 25 & 1474 & 8 & 18 & 26 & 0 & 18 & 18 & 18 & 1254 \\
\hline Vault Corridor - by V1 & 36 & 43156 & 9111 & 22 & 21 & 25 & 1488 & 7 & 19 & 26 & 0 & 19 & 19 & 19 & 1264 \\
\hline & Control & 20227 & 9515 & 0 & 0 & 0 & 0 & 0 & 0 & 0 & 0 & 0 & 0 & 0 & 0 \\
\hline & Control & 33482 & 8212 & 0 & 1 & 1 & 1 & 0 & 1 & 1 & 0 & 1 & 1 & 1 & 0 \\
\hline Vault Corridor - by V3 & 37 & 41258 & 7303 & 25 & 23 & 25 & 1722 & 0 & 25 & 25 & 0 & 23 & 23 & 23 & 1464 \\
\hline Vault Corridor - by V3 & 37 & 44338 & 7303 & 25 & 23 & 23 & 1802 & 0 & 23 & 23 & 0 & 23 & 23 & 23 & 1534 \\
\hline Vault Corridor - by V3 & 37 & 40747 & 7303 & 26 & 23 & 25 & 1770 & 0 & 25 & 25 & 0 & 23 & 23 & 23 & 1507 \\
\hline Vault Corridor - by V3 & 38 & 31657 & 7303 & 28 & 27 & 30 & 2303 & 0 & 30 & 30 & 0 & 27 & 27 & 27 & 1962 \\
\hline Vault Corridor - by V3 & 38 & 16530 & 9111 & 28 & 24 & 29 & 1753 & 8 & 22 & 30 & 0 & 22 & 22 & 22 & 1491 \\
\hline Vault Corridor - by V3 & 38 & 41235 & 7303 & 29 & 26 & 27 & 1976 & 0 & 27 & 27 & 0 & 26 & 26 & 26 & 1681 \\
\hline Vault Corridor - by V3 & 39 & 18997 & 7303 & 31 & 29 & 32 & 2796 & 0 & 32 & 32 & 0 & 29 & 29 & 29 & 2385 \\
\hline
\end{tabular}


Table D.4. HSD Dosimeter Response

\begin{tabular}{|c|c|c|c|c|c|c|c|c|c|c|c|c|c|c|c|}
\hline & & & & \multicolumn{4}{|c|}{ Adjusted Chip Counts } & \multicolumn{3}{|c|}{ Shallow } & \multicolumn{3}{|c|}{ Eye } & \multicolumn{2}{|c|}{ Deep } \\
\hline Location & $\begin{array}{c}\text { Packet } \\
\#\end{array}$ & $\begin{array}{l}\text { Card } \\
\text { ID \# }\end{array}$ & $\begin{array}{c}\text { Form- } \\
\text { ula }\end{array}$ & Chip 1 & Chip 2 & Chip 3 & Chip 4 & Beta & Photon & Total & Beta & Photon & Total & $\begin{array}{l}\text { Photon } \\
\text { (mrem) }\end{array}$ & $\begin{array}{c}\text { Neutron } \\
\text { (mrem) }\end{array}$ \\
\hline Vault Corridor - by V3 & 39 & 3385 & 7303 & 34 & 33 & 33 & 2722 & 0 & 33 & 33 & 0 & 33 & 33 & 33 & 2318 \\
\hline Vault Corridor - by V3 & 39 & 7020 & 9111 & 33 & 29 & 35 & 2979 & 11 & 26 & 37 & 0 & 26 & 26 & 26 & 2543 \\
\hline Vault Corridor - by V3 & 40 & 39158 & 7303 & 30 & 26 & 28 & 2023 & 0 & 28 & 28 & 0 & 26 & 26 & 26 & 1722 \\
\hline Vault Corridor - by V3 & 40 & 29151 & 7303 & 30 & 27 & 27 & 1927 & 0 & 27 & 27 & 0 & 27 & 27 & 27 & 1638 \\
\hline Vault Corridor - by V3 & 40 & 41084 & 7303 & 30 & 27 & 28 & 2144 & 0 & 28 & 28 & 0 & 27 & 27 & 27 & 1825 \\
\hline & Control & 29306 & 8212 & 1 & 0 & 0 & 0 & 0 & 0 & 0 & 0 & 0 & 0 & 0 & 0 \\
\hline & Control & 20387 & 8212 & 2 & 1 & 0 & 1 & 0 & 1 & 1 & 0 & 1 & 1 & 1 & 0 \\
\hline
\end{tabular}



APPENDIX E

EXTREMITY TEPC RESULTS 
Program TEPC_NG

Version: December, 1989

Page 1

INPUT FILE NAME: to4ox20b.txt

FILE TITLE: TEPC 504 at 12" from 20\% 0xide can. Rm 637, ZB. 9/7-9/99

TEPC OUTPUT SUMMARY

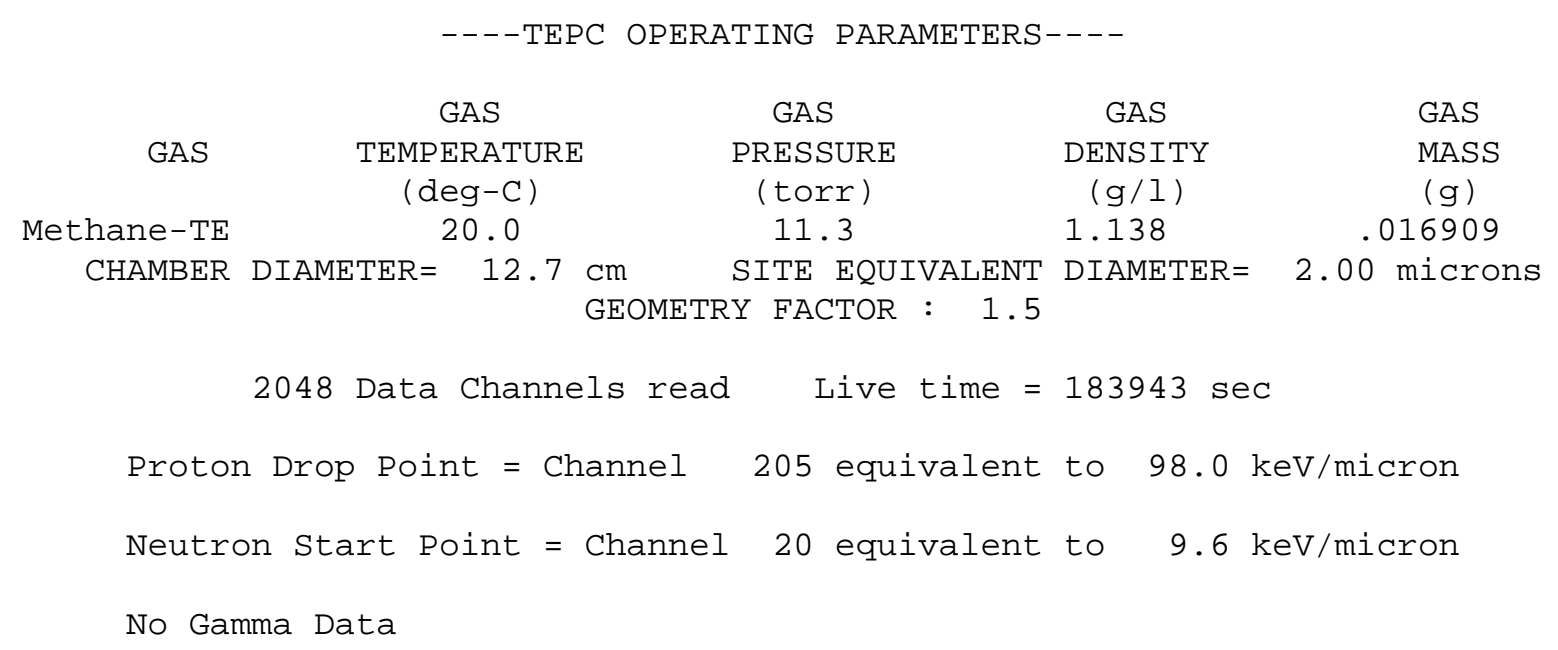

Integral Dose, mrad

Standard Deviation

Quality Factors

Integral DE, mrem

Dose Rate, $\mathrm{mrad} / \mathrm{hr}$

DE Rate, $\mathrm{mrem} / \mathrm{hr}$ $\odot . \odot \odot E+\odot \odot$

$\odot . ~ \odot \odot E+\odot \odot$

1.0

$\odot . \odot \odot E+\odot \odot$

$\odot . \odot \odot E+\odot \odot$

$\odot . \odot \odot E+\odot \odot$
$3.15 \mathrm{E}+01$

4. 43E- 02

10.3

$3.23 \mathrm{E}+02$

6.17E- 01

$6.32 \mathrm{E}+\odot \odot$
$3.15 \mathrm{E}+01$

4. 43E- -2

10.3

3. $23 \mathrm{E}+02$

$6.17 \mathrm{E}-01$

$6.32 \mathrm{E}+0 \odot$ 
Program TEPC_NG

Version: December, 1989

INPUT FILE NAME: t740x2 1.dat

FILE TITLE: TEPC 1074 in Index finger by 20\% oxide, Rm 637 ZB. 9/7-9/9

(728 alpha cts subtracted off)

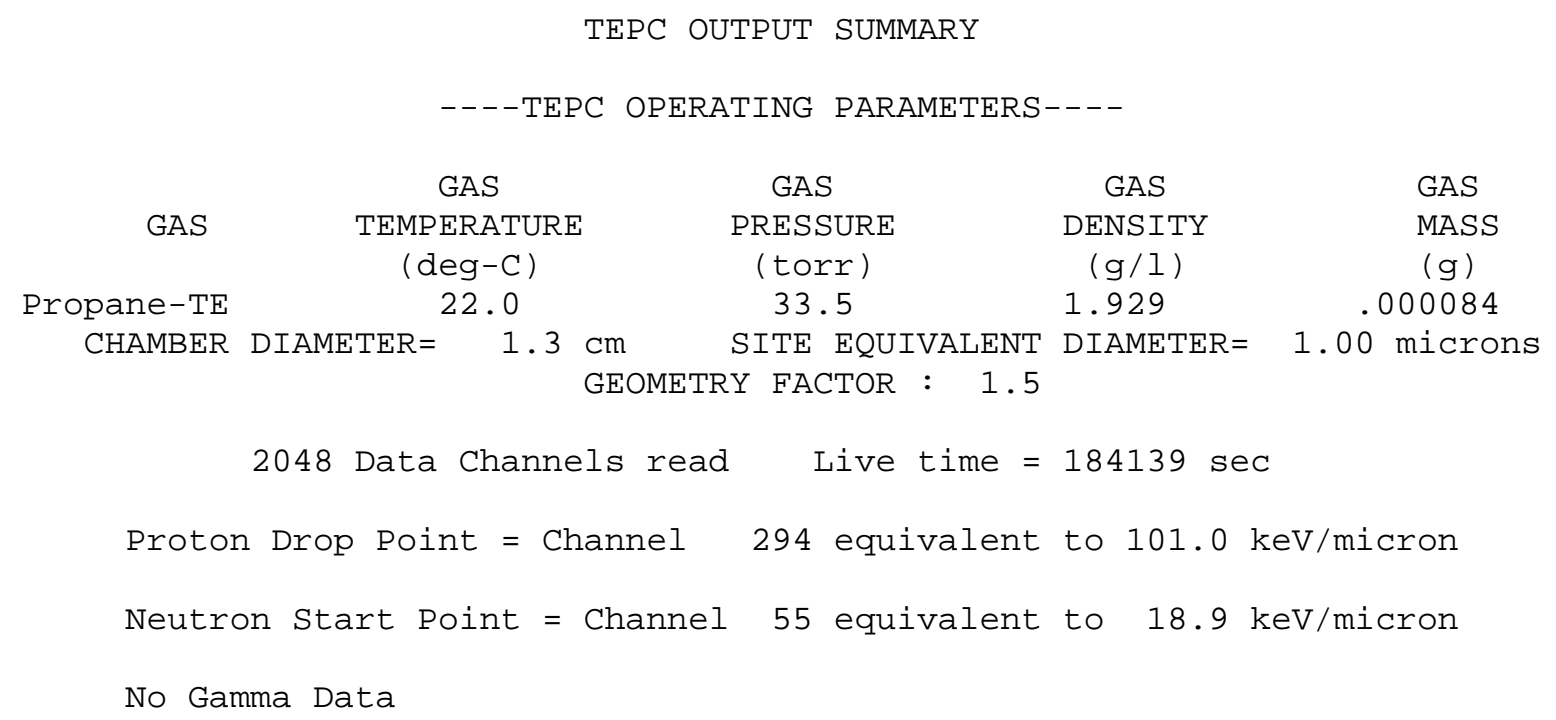

Integral Dose, mrad

Standard Deviation

Quality Factors

Integral DE, mrem

Dose Rate, $\mathrm{mrad} / \mathrm{hr}$

DE Rate, mrem/hr
$\odot . \odot \odot E+\odot \odot$
4. $70 \mathrm{E}+01$
$4.70 \mathrm{E}+01$
$\odot . \odot \odot E+\odot \odot$
$6.23 E-01$
$6.23 E-01$
12.3
12.3
1.0
5. $75 \mathrm{E}+02$
$5.75 \mathrm{E}+02$
$\odot . \odot \odot E+\odot \odot$
$9.18 \mathrm{E}-01$
9. 18E- 01
$\odot . ~ .0 \mathrm{E}+\odot \odot$
1. $12 \mathrm{E}+01$
1. $12 \mathrm{E}+01$ 
Program TEPC_NG

Version: December, 1989

Page 1

INPUT FILE NAME: t220x2 1. dat

FILE TITLE: TEPC 1122 in Ring finger, 20\% 0xide, ZB 637. 9/7-9/99.

(2769 alpha cts subtracted off)

TEPC OUTPUT SUMMARY

- - -TEPC OPERATING PARAMETERS- - -

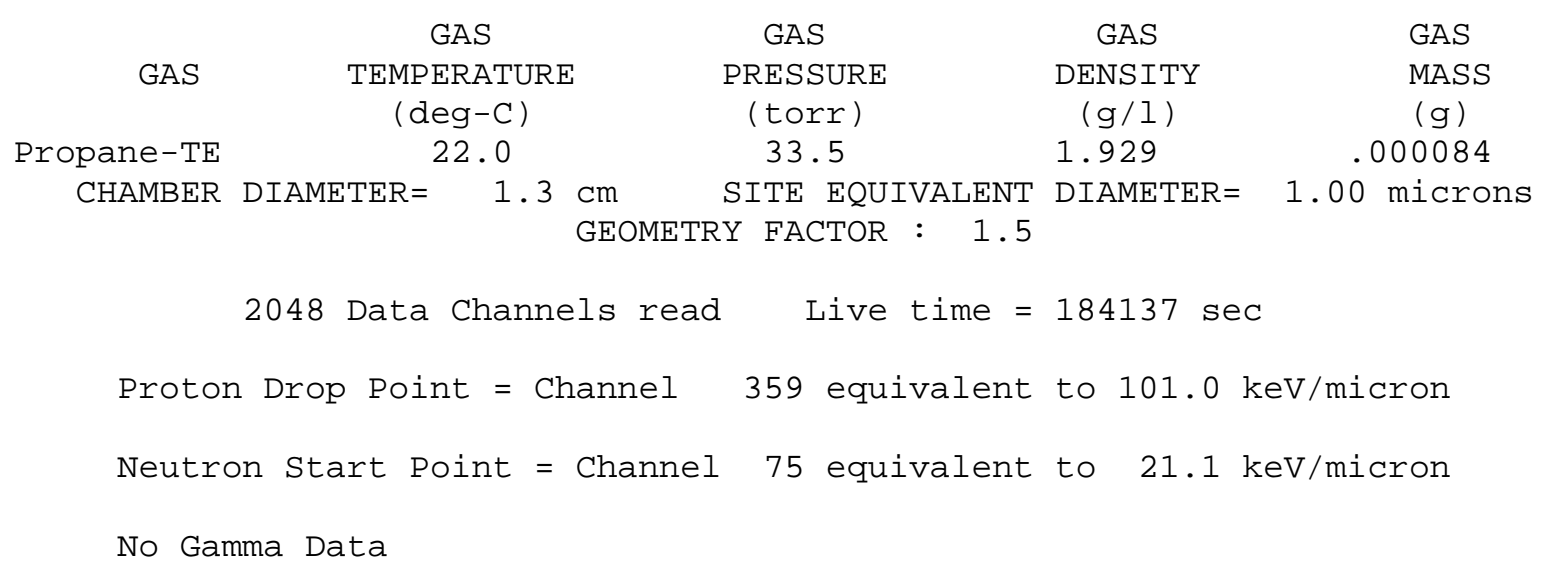

-DISTRIBUTION PARAMETERS - - -

\begin{tabular}{|c|c|c|c|}
\hline & gamma & neutron & total \\
\hline Counts/Ch & $\odot . \odot \odot E+\odot \odot$ & $5.56 \mathrm{E}+03$ & $5.56 \mathrm{E}+03$ \\
\hline Counts ${ }^{*} \mathrm{Ch}$ & $\odot . \odot \odot E+\odot \odot$ & $8.67 \mathrm{E}+05$ & $\odot . \odot \odot E+\odot \odot$ \\
\hline Counts* Ch2 & $\odot . \odot \odot E+\odot \odot$ & $2 . \odot 6 \mathrm{E}+\odot 8$ & $\odot . \odot \odot E+\odot \odot$ \\
\hline Y-bar F & .0 & 43.9 & 43.9 \\
\hline Y-bar D & .0 & 66.8 & 66.8 \\
\hline L-bar D & .0 & 59.4 & 59.4 \\
\hline
\end{tabular}

Restricted $\mathrm{y}$-bar $\mathrm{D}$ between 21.1 and $115 \mathrm{keV} / \mathrm{micron}$ is 58.4

The average energy cannot be calculated

---DOSE AND DOSE EQUIVALENT DATA-.--

\begin{tabular}{|c|c|c|c|}
\hline Integral Dose, mrad & $\odot . \odot \odot E+\odot \odot$ & 4. $63 E+01$ & $4.63 E+01$ \\
\hline Standard Deviation & $\odot . \odot \odot E+\odot \odot$ & $6.21 \mathrm{E}-01$ & $6.21 \mathrm{E}-01$ \\
\hline Quality Factors & 1.0 & 12.1 & 12.1 \\
\hline Integral DE, mrem & $\odot . \odot \odot E+\odot \odot$ & $5.60 E+\Theta 2$ & $5.60 E+\odot 2$ \\
\hline $\begin{array}{l}\text { Dose Rate, } \mathrm{mrad} / \mathrm{hr} \\
\text { DE Rate, } \mathrm{mrem} / \mathrm{hr}\end{array}$ & $\begin{array}{l}\odot . \odot \odot E+\odot \odot \\
\odot . \odot \odot E+\odot \odot\end{array}$ & $\begin{array}{l}\text { 9. } \odot 5 E-01 \\
1.09 E+01\end{array}$ & $\begin{array}{l}9.05 \mathrm{E}-01 \\
1.09 \mathrm{E}+01\end{array}$ \\
\hline
\end{tabular}


INPUT FILE NAME: to40x12b.txt

FILE TITLE: TEPC 504 at 12-in from 0xide 12\% can, ZB. 9/9-13/99

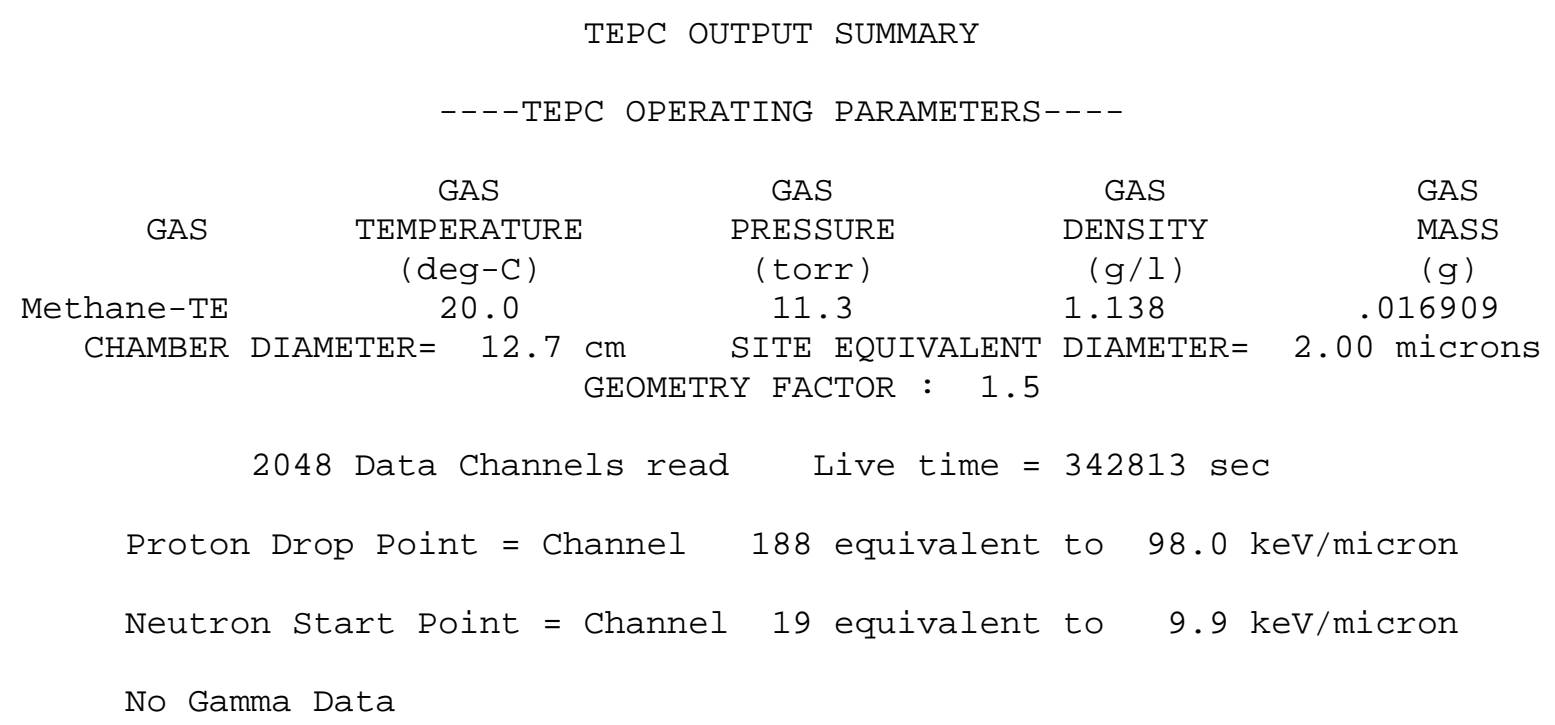

Integral Dose, mrad

Standard Deviation

Quality Factors

Integral DE, mrem

Dose Rate, $\mathrm{mrad} / \mathrm{hr}$

DE Rate, mrem/hr
$\odot .00 \mathrm{E}+\odot \odot$
$\odot . \odot \odot E+\odot \odot$
1.0
$\odot . \odot \odot E+\odot \odot$
$\odot .0 \odot \mathrm{E}+\odot \odot$
$\odot .00 \mathrm{E}+\Theta \odot$

\section{2. $27 \mathrm{E}+01$}

3. $96 \mathrm{E}-02$

10.7

2. $42 \mathrm{E}+02$

2. 39E- 01

2. $55 \mathrm{E}+00$
2. $27 \mathrm{E}+01$

3. $96 \mathrm{E}-02$

10.7

$2.42 \mathrm{E}+\odot 2$

2. 39E- 01

$2.55 \mathrm{E}+0 \odot$ 
Program TEPC_NG

Version: December, 1989

INPUT FILE NAME: t740x1 1.dat

FILE TITLE: TEPC 1074, index finger: 12\% oxide, ZB 637, 9/9-13/99.

(subtracted of 1415 alpha counts)

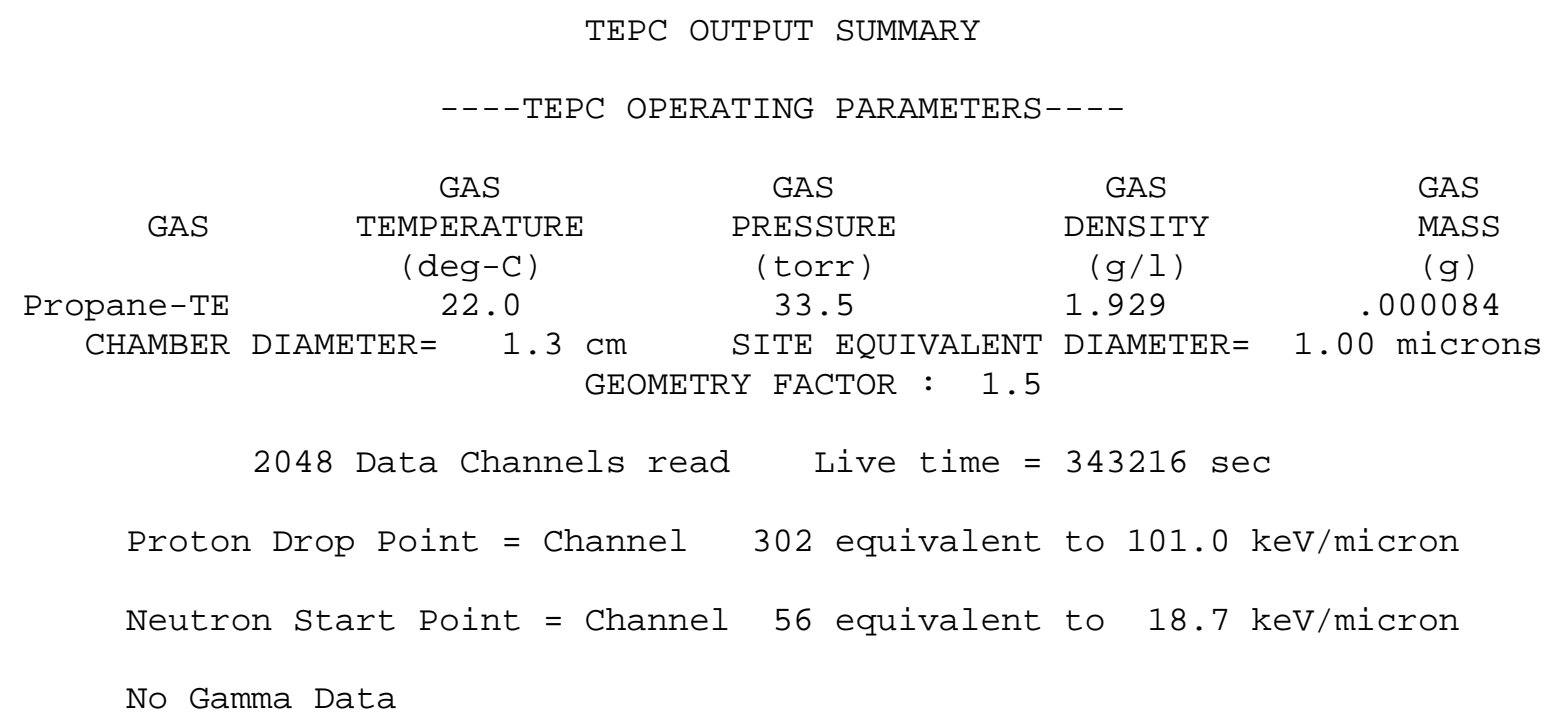

Integral Dose, mrad

Standard Deviation

Quality Factors

Integral DE, mrem

Dose Rate, $\mathrm{mrad} / \mathrm{hr}$

DE Rate, mrem/hr

\begin{abstract}
$\odot . \odot \odot E+\odot \odot$
\end{abstract}
$\odot .00 \mathrm{E}+\Theta \odot$

1.0

$\odot . \odot \odot E+\odot \odot$

$\odot . \odot \odot E+\odot \odot$

$\odot .00 \mathrm{E}+\odot \odot$
4. $29 \mathrm{E}+01$

6. $08 \mathrm{E}-01$

12.7

$5.45 \mathrm{E}+02$

4. $50 \mathrm{E}-01$

$5.72 \mathrm{E}+\odot \odot$
4. $29 \mathrm{E}+01$

$6.08 \mathrm{E}-01$

12.7

$5.45 \mathrm{E}+02$

4. $50 \mathrm{E}-01$

$5.72 \mathrm{E}+\odot \odot$ 
INPUT FILE NAME: t220x12.txt

FILE TITLE:

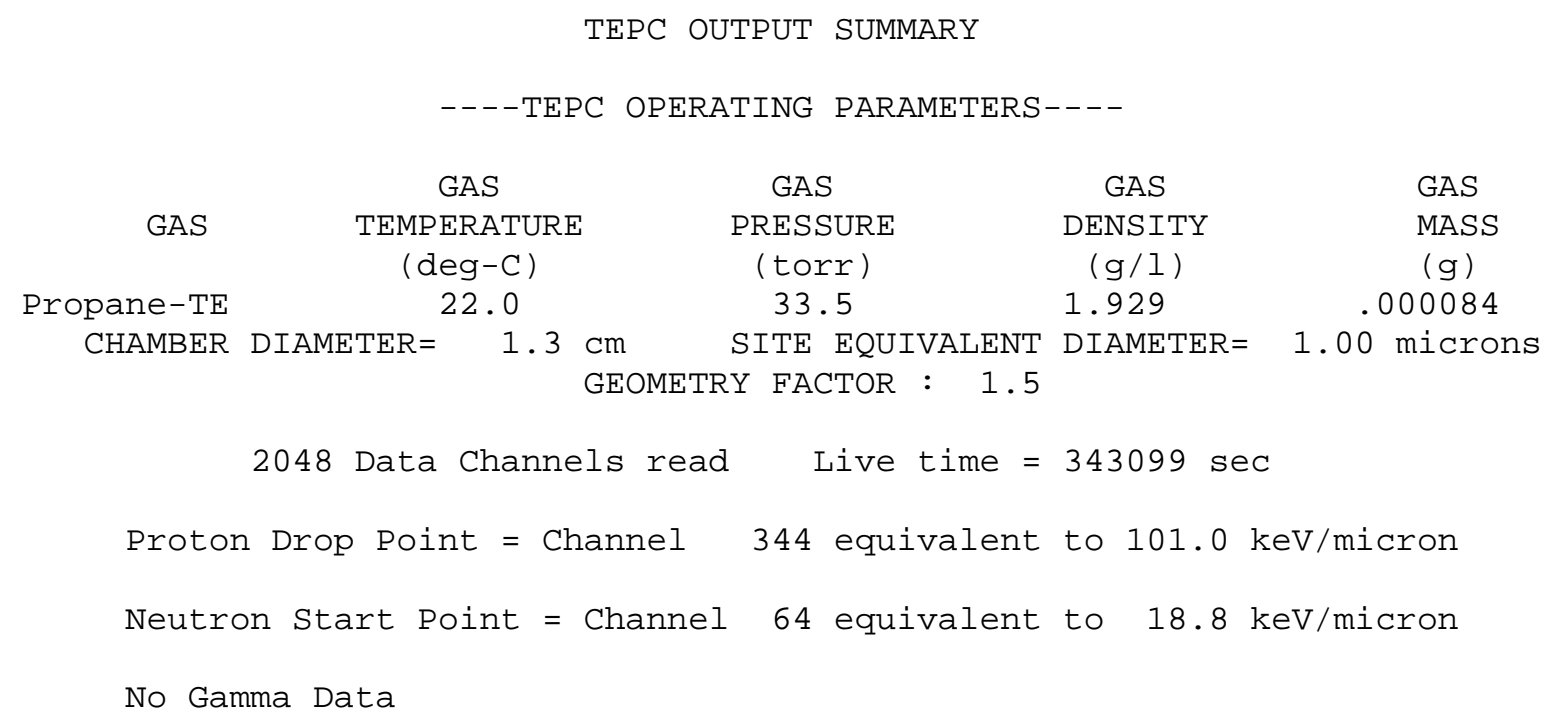

Integral Dose, mrad

Standard Deviation

Quality Factors

Integral DE, mrem

Dose Rate, $\mathrm{mrad} / \mathrm{hr}$

DE Rate, mrem/hr
○. . $0 \odot \mathrm{E}+0 \odot$
$\odot . ~ . ० E+\odot \odot$
1.0
$\odot . \odot \odot E+\odot \odot$
$\odot . \odot \odot E+\odot \odot$
$\odot . ~ .0 E+\odot \odot$

\section{14E+01}

$5.65 E-01$

11.7

4. $83 \mathrm{E}+02$

4. 34E- 01

$5.07 \mathrm{E}+00$
4. 14E+01

$5.65 \mathrm{E}-01$

11.7 $4.83 E+02$

4. 34E- 01

$5.07 \mathrm{E}+0 \odot$ 
Program TEPC_NG

Version: December, 1989

INPUT FILE NAME: to4mtl $1 . t x t$

FILE TITLE: TEPC 504 at 12" from Pu Metal can. 9/13-16/99

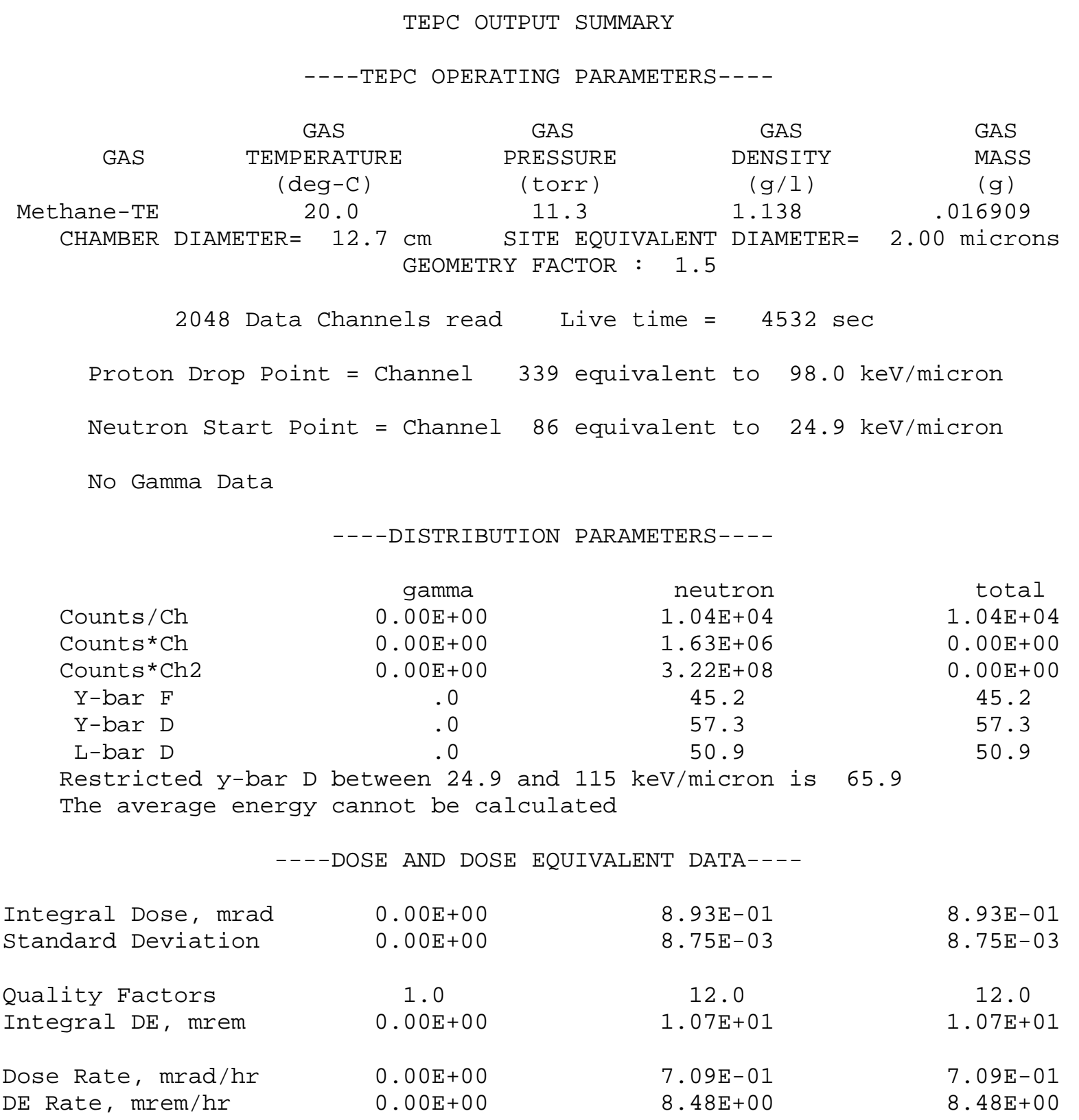


INPUT FILE NAME: t74mtl 1.dat

FILE TITLE: TEPC 1074, index finger: Metal can. ZB 637. 9/13-16/99. (subtracted off 861 alpha counts)

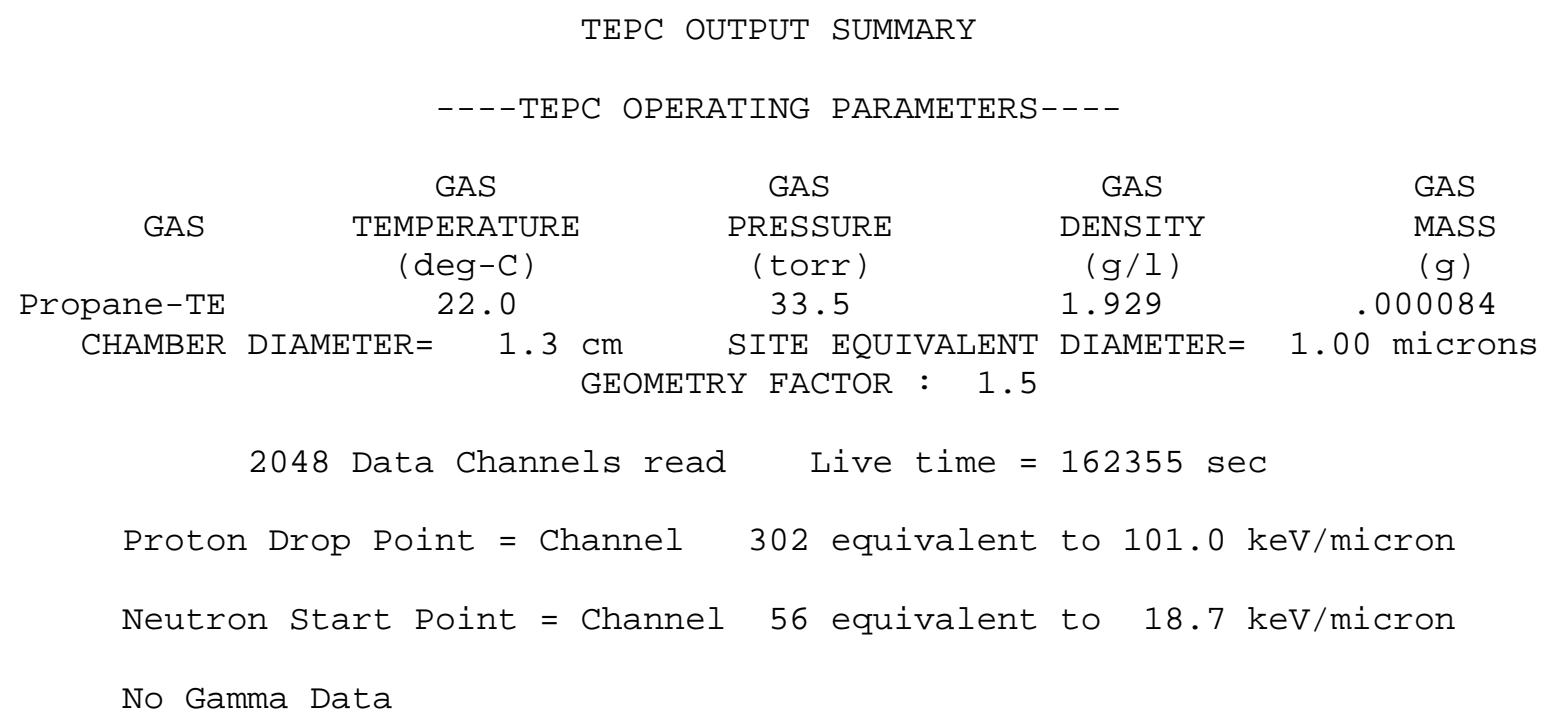

$\begin{array}{lccc} & \text { gamma } & \text { neutron } & \text { total } \\ \text { Counts } / \text { Ch } & 0.00 \mathrm{E}+\odot \odot & 7.36 \mathrm{E}+\odot 3 & 7.36 \mathrm{E}+\odot 3 \\ \text { Counts }{ }^{*} \text { Ch } & 0.0 \odot \mathrm{E}+\odot \odot & 9.23 \mathrm{E}+\odot 5 & 0.00 \mathrm{E}+\odot \odot \\ \text { Counts }{ }^{*} \text { Ch2 } & 0.00 \mathrm{E}+\odot \odot & 1.72 \mathrm{E}+\odot 8 & 0.00 \mathrm{E}+\odot \odot \\ \text { Y-bar F } & . \odot & 41.9 & 41.9 \\ \text { Y-bar D } & .0 & 62.3 & 62.3 \\ \text { L-bar D } & . \odot & 55.3 & 55.3\end{array}$

Restricted $\mathrm{y}$-bar $\mathrm{D}$ between 18.7 and $115 \mathrm{keV} / \mathrm{micron}$ is 58.8 The average energy cannot be calculated

----DOSE AND DOSE EQUIVALENT DATA--.-

\begin{tabular}{|c|c|c|c|}
\hline Integral Dose, mrad & $\odot . \odot \odot E+\odot \odot$ & $5.85 \mathrm{E}+01$ & $5.85 E+01$ \\
\hline Standard Deviation & $\odot . \odot \odot E+\odot \odot$ & $6.82 \mathrm{E}-01$ & $6.82 \mathrm{E}-01$ \\
\hline Quality Factors & 1.0 & 11.8 & 11.8 \\
\hline Integral DE, mrem & $\odot . \odot \odot E+\odot \odot$ & $6.92 \mathrm{E}+02$ & $6.92 \mathrm{E}+02$ \\
\hline $\begin{array}{l}\text { Dose Rate, } \mathrm{mrad} / \mathrm{hr} \\
\text { DE Rate, } \mathrm{mrem} / \mathrm{hr}\end{array}$ & $\begin{array}{l}\odot . \odot \odot E+\odot \odot \\
\odot . \odot \odot E+\odot \odot\end{array}$ & $\begin{array}{l}1.30 \mathrm{E}+\odot \odot \\
1.53 \mathrm{E}+01\end{array}$ & $\begin{array}{l}1.30 \mathrm{E}+\odot \odot \\
1.53 \mathrm{E}+01\end{array}$ \\
\hline
\end{tabular}


INPUT FILE NAME: t22mt $12 . \mathrm{txt}$

FILE TITLE: TEPC 1122 in Ring Finger, glove. Pu Metal can. 9/16/99

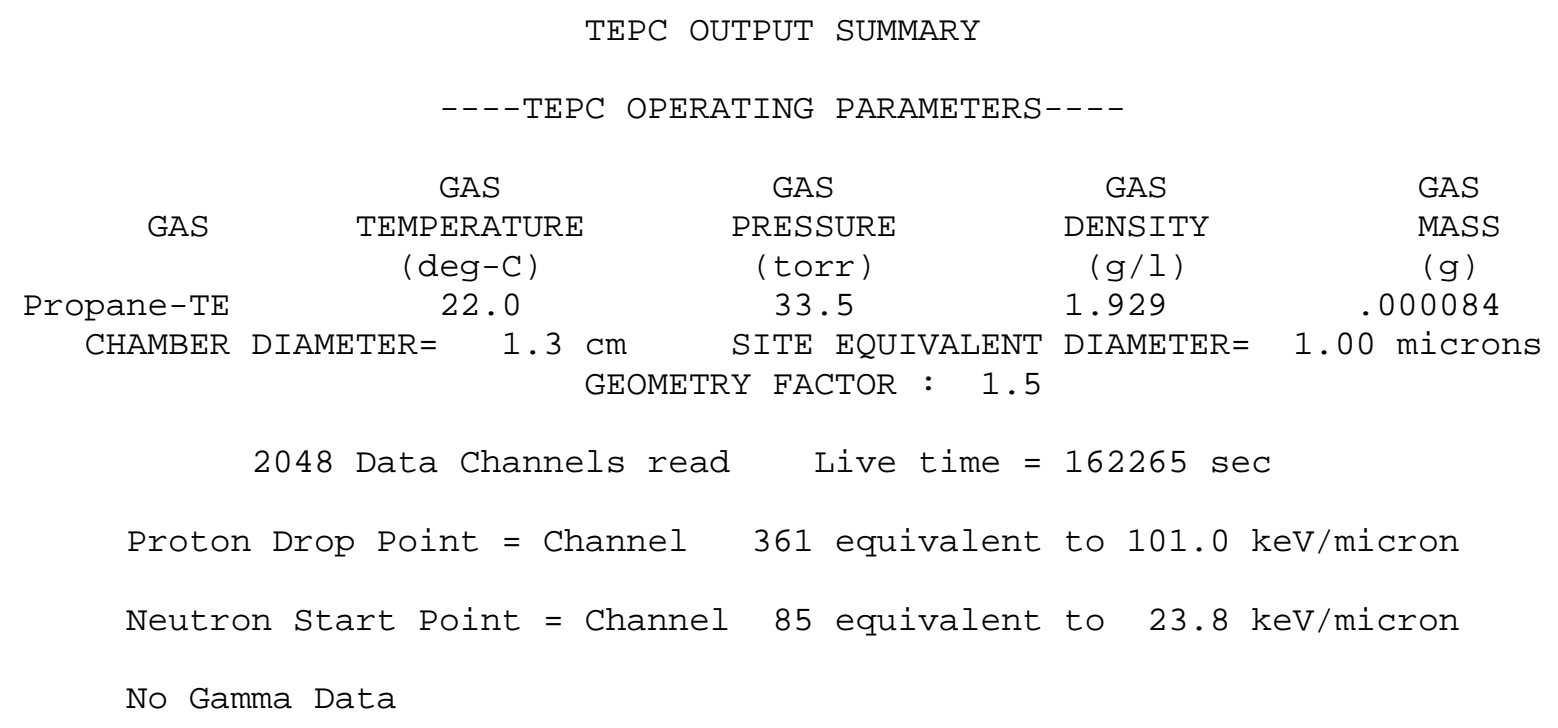

Integral Dose, mrad

Standard Deviation

Quality Factors

Integral DE, mrem

Dose Rate, $\mathrm{mrad} / \mathrm{hr}$

DE Rate, mrem/hr

\begin{abstract}
$\odot . \odot \odot E+\odot \odot$
\end{abstract}
$\odot .00 \mathrm{E}+\Theta \odot$

1.0

$\odot . \odot \odot E+\odot \odot$

$\odot . \odot \odot E+\odot \odot$

$\odot .00 \mathrm{E}+\odot \odot$

\section{5. $35 \mathrm{E}+01$}

6. $91 \mathrm{E}-01$

12.4

$6.62 \mathrm{E}+02$

1. $19 \mathrm{E}+00$

1. $47 \mathrm{E}+01$
5. $35 \mathrm{E}+01$

6. $91 \mathrm{E}-01$

12.4

$6.62 \mathrm{E}+02$

1. $19 \mathrm{E}+\odot \odot$

1. $47 \mathrm{E}+01$ 
Program TEPC_NG

Version: December, 1989

INPUT FILE NAME: t740x6 1.dat

FILE TITLE: TEPC 1074 in Index finger by 6\% 0xide can. 9/20-22/99

(subtracted off 671 alpha counts)

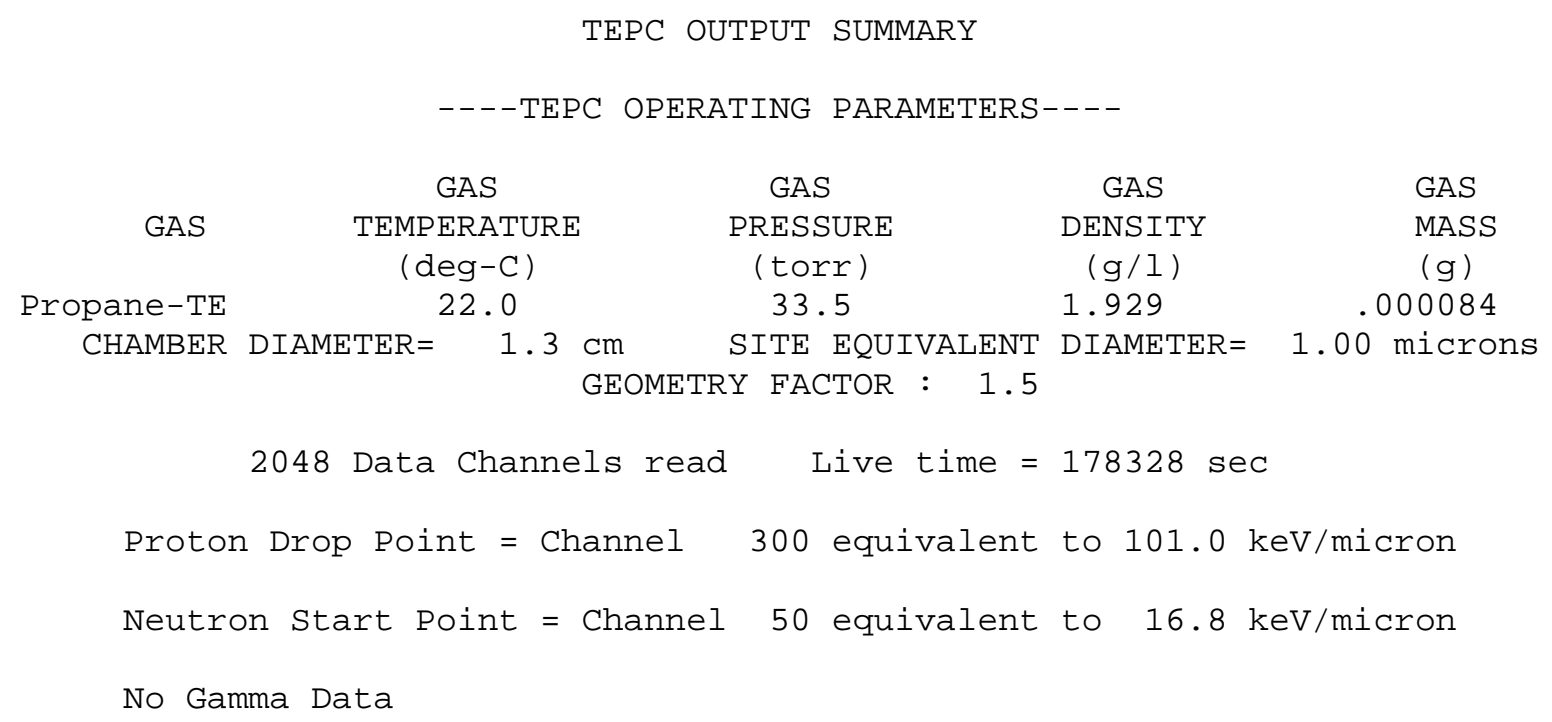

Integral Dose, mrad

Standard Deviation

Quality Factors

Integral DE, mrem

Dose Rate, $\mathrm{mrad} / \mathrm{hr}$

DE Rate, mrem/hr

\begin{abstract}
$\odot .00 E+\odot \odot$
\end{abstract}
$\odot . \odot \odot E+\odot \odot$

1.0

$\odot . \odot \odot E+\odot \odot$

$\odot .00 E+\odot \odot$

$\odot .00 \mathrm{E}+\odot \odot$

\section{$5.41 \mathrm{E}+01$}

$6.48 \mathrm{E}-01$

11.9

$6.47 \mathrm{E}+02$

1. $.9 \mathrm{E}+00$

1. $31 \mathrm{E}+01$
$5.41 \mathrm{E}+01$

$6.48 \mathrm{E}-01$

11.9

$6.47 \mathrm{E}+02$

1. $\odot 9 \mathrm{E}+\odot \odot$

1. $31 \mathrm{E}+01$ 
INPUT FILE NAME: t220x6.txt

FILE TITLE: TEPC 1122 in Ring finger by 6\% 0xide can, ZB. 9/20-22/99

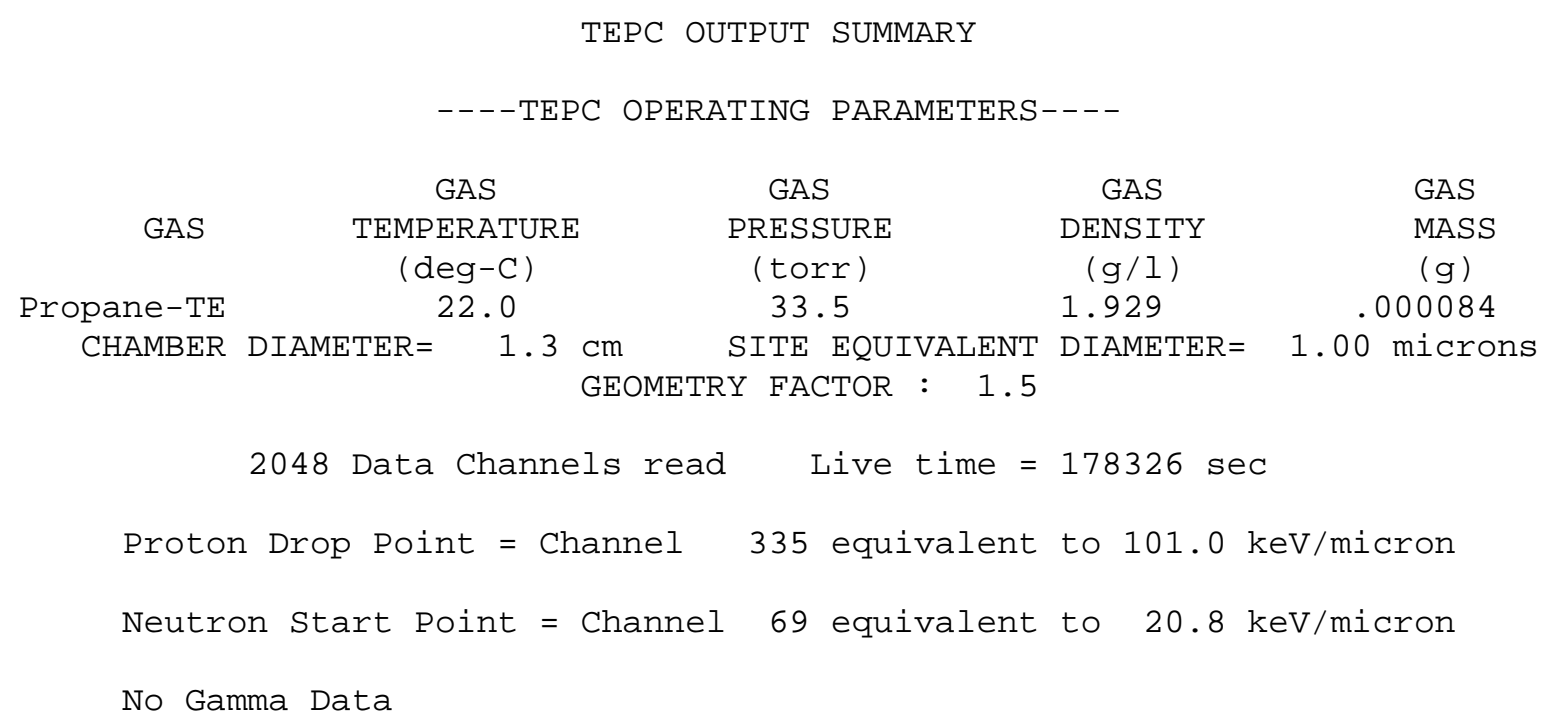

$\begin{array}{lccc} & \text { gamma } & \text { neutron } & \text { total } \\ \text { Counts/Ch } & 0.00 \mathrm{E}+\odot \odot & 5.51 \mathrm{E}+\odot 3 & 5.51 \mathrm{E}+03 \\ \text { Counts }{ }^{*} \mathrm{Ch} & 0.00 \mathrm{E}+\odot \odot & 7.79 \mathrm{E}+\odot 5 & 0.00 \mathrm{E}+\odot \odot \\ \text { Counts }{ }^{*} \text { Ch2 } & 0.00 \mathrm{E}+\odot \odot & 1.51 \mathrm{E}+08 & 0.00 \mathrm{E}+00 \\ \text { Y-bar F } & .0 & 42.6 & 42.6 \\ \text { Y-bar D } & .0 & 58.6 & 58.6 \\ \text { L-bar D } & .0 & 52.1 & 52.1\end{array}$

Restricted $y$-bar $D$ between 20.8 and $115 \mathrm{keV} / \mathrm{micron}$ is 61.4 The average energy cannot be calculated

----DOSE AND DOSE EQUIVALENT DATA----

Integral Dose, mrad

Standard Deviation

Quality Factors

Integral DE, mrem

Dose Rate, $\mathrm{mrad} / \mathrm{hr}$

DE Rate, mrem/hr

\begin{abstract}
๑. . $00 \mathrm{E}+0 \odot$
\end{abstract}
$\odot . ~ . ० E+\odot \odot$

1.0

$\odot . \odot \odot E+\odot \odot$

๑. $\odot \odot E+\odot \odot$

$\odot . ~ .0 E+\odot \odot$
4. $45 \mathrm{E}+01$

$6 . \odot \odot E-\odot 1$

11.8

5. $24 \mathrm{E}+02$

8. $99 \mathrm{E}-01$

1. $06 \mathrm{E}+01$
4. 45E+01

6 . $00 \mathrm{E}-01$

11.8

$5.24 \mathrm{E}+\odot 2$

8. $99 \mathrm{E}-01$

1. $06 \mathrm{E}+01$ 
INPUT FILE NAME: t70foil.txt

FILE TITLE: TEPC 1170 at 12" from 17\% 0xide can with foil. ZB. 9/22-24/99

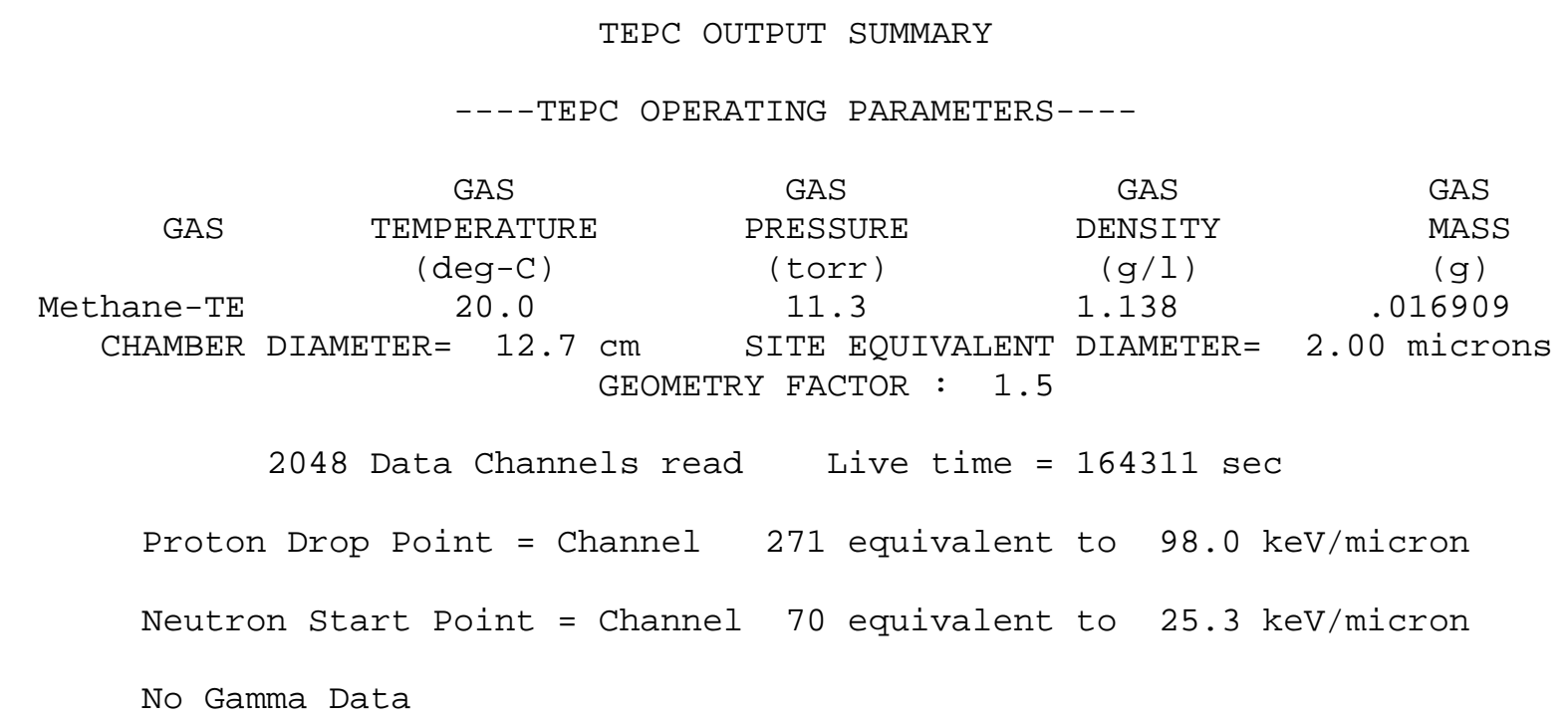

Integral Dose, mrad

Standard Deviation

Quality Factors

Integral DE, mrem

Dose Rate, $\mathrm{mrad} / \mathrm{hr}$

DE Rate, $\mathrm{mrem} / \mathrm{hr}$
$\odot . \odot \odot E+\odot \odot$
$1.50 \mathrm{E}+01$
1. $50 \mathrm{E}+01$
$\odot . \odot \odot E+\odot \odot$
3. 59E- 02
3. $59 \mathrm{E}-02$
1.0
12.0
12.0
$\odot . \odot \odot E+\odot \odot$
1. $79 \mathrm{E}+02$
1. $79 \mathrm{E}+02$
$\odot . \odot \odot E+\odot \odot$
3. $28 \mathrm{E}-01$
3. $28 \mathrm{E}-01$
$\odot .00 \mathrm{E}+\Theta \odot$
3. $93 \mathrm{E}+00$
3. $93 \mathrm{E}+0 \odot$ 
INPUT FILE NAME: t74foi 1.dat

FILE TITLE: TEPC 1074, Index finger, 17\% 0xide W/ foil. ZB 637. 9/22-24/99 (subtracted off 862 alpha counts)

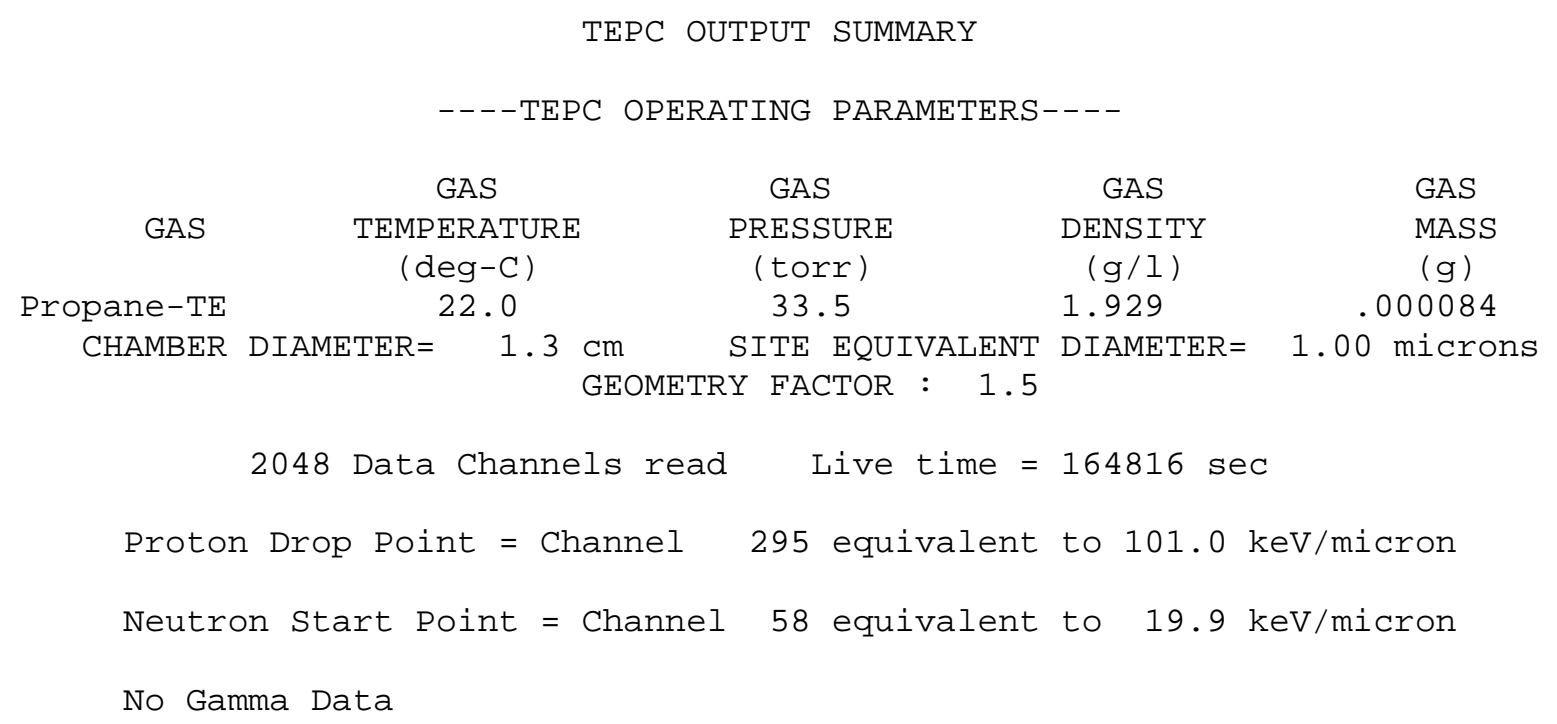

$\begin{array}{lccc} & \text { gamma } & \text { neutron } & \text { total } \\ \text { Counts } / \text { Ch } & 0.00 \mathrm{E}+\odot \odot & 4.00 \mathrm{E}+\odot 3 & 4.00 \mathrm{E}+\odot 3 \\ \text { Counts }{ }^{*} \text { Ch } & 0.0 \odot \mathrm{E}+\odot \odot & 5.10 \mathrm{E}+\odot 5 & 0.00 \mathrm{E}+\odot \odot \\ \text { Counts }{ }^{*} \text { Ch2 } & 0.00 \mathrm{E}+\odot \odot & 1.07 \mathrm{E}+\odot 8 & \odot .00 \mathrm{E}+\odot \odot \\ \text { Y-bar F } & . \odot & 43.7 & 43.7 \\ \text { Y-bar D } & . \odot & 72.0 & 72.0 \\ \text { L-bar D } & . \odot & 64.0 & 64.0\end{array}$

Restricted $\mathrm{y}$-bar $\mathrm{D}$ between 19.9 and $115 \mathrm{keV} / \mathrm{micron}$ is 57.2 Average Neutron Energy is $.8 \mathrm{MeV}$

----DOSE AND DOSE EQUIVALENT DATA--.-

\begin{tabular}{|c|c|c|c|}
\hline $\begin{array}{l}\text { Integral Dose, mrad } \\
\text { Standard Deviation }\end{array}$ & $\begin{array}{l}\odot . \odot \odot E+\odot \odot \\
\odot . \odot \odot E+\odot \odot\end{array}$ & $\begin{array}{l}3.31 \mathrm{E}+01 \\
5.24 \mathrm{E}-01\end{array}$ & $\begin{array}{l}3.31 \mathrm{E}+01 \\
5.24 \mathrm{E}-01\end{array}$ \\
\hline Quality Factors & 1.0 & 12.2 & 12.2 \\
\hline Integral DE, mrem & $\odot . \odot \odot E+\odot \odot$ & 4. $\odot 4 \mathrm{E}+\odot 2$ & $4.04 \mathrm{E}+02$ \\
\hline Dose Rate, $\mathrm{mrad} / \mathrm{hr}$ & 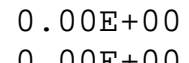 & $\begin{array}{l}7.24 \mathrm{E}-01 \\
8.82 \mathrm{~F}+0 \cap\end{array}$ & $\begin{array}{l}7.24 \mathrm{E}-01 \\
8.82 \mathrm{~F}+0 .\end{array}$ \\
\hline
\end{tabular}


INPUT FILE NAME: t22foil.txt

FILE TITLE: TEPC 1122 in Ring finger, near 17\% 0xide W/ Foil. ZB Rm 6

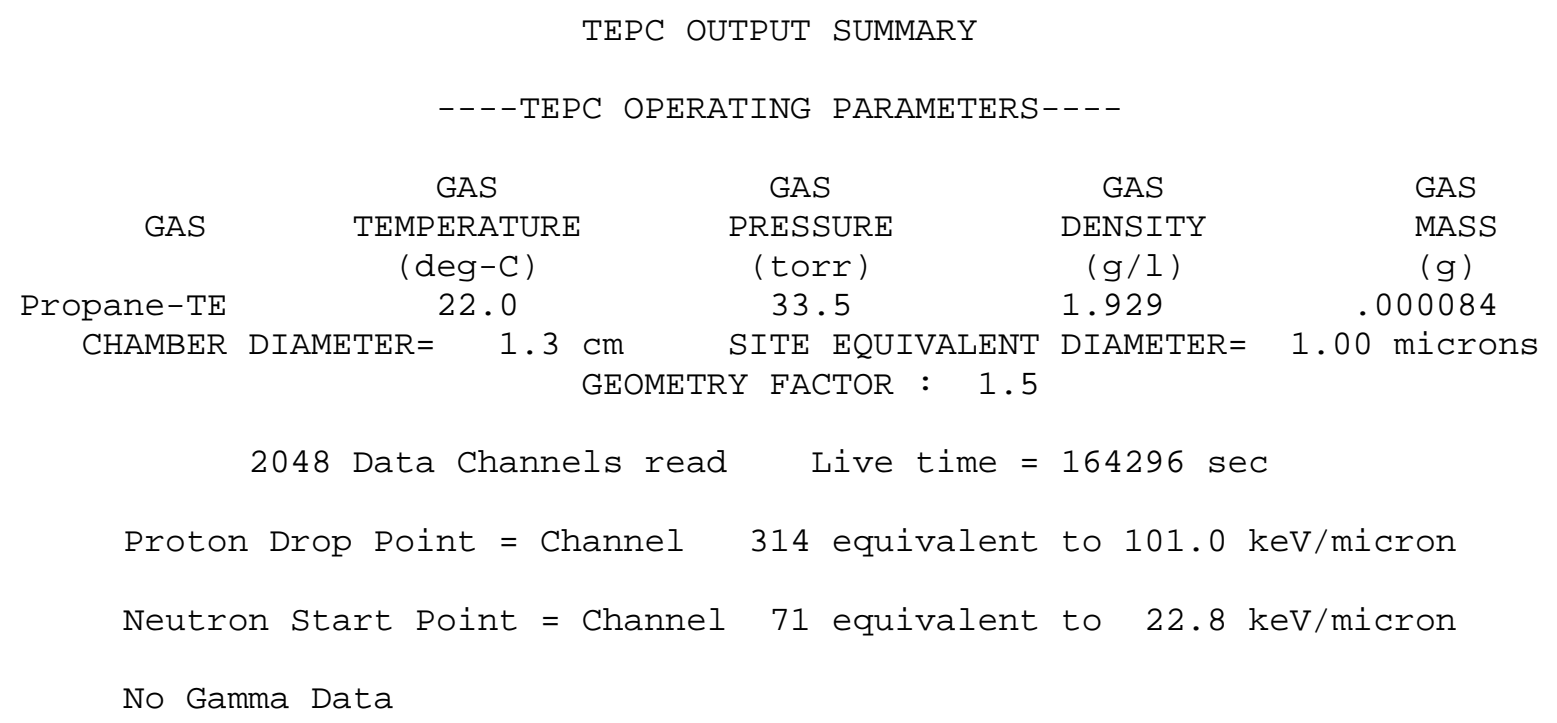

Integral Dose, mrad

Standard Deviation

Quality Factors

Integral DE, mrem

Dose Rate, $\mathrm{mrad} / \mathrm{hr}$

DE Rate, mrem/hr

\begin{abstract}
$\odot . \odot \odot E+\odot \odot$
\end{abstract}
$\odot .00 \mathrm{E}+\Theta \odot$

1.0

$\odot . \odot \odot E+\odot \odot$

$\odot . \odot \odot E+\odot \odot$

$\odot .00 \mathrm{E}+\odot \odot$
3. 35E+01

5. 36E- -01

12.2

4. $\odot 8 \mathrm{E}+02$

7. 34E- 01

8. $93 \mathrm{E}+00$
3. $35 \mathrm{E}+01$

5. 36E- 01

12.2

4. $\odot 8 \mathrm{E}+02$

7. 34E- 01

8. $93 \mathrm{E}+0 \odot$ 
INPUT FILE NAME: t70wpb.txt

Version: December, 1989

FILE TITLE: TEPC 1170 at 12" from 17\% 0xide W/ Pb shield. ZB 637. 9/24-27/99

TEPC OUTPUT SUMMARY

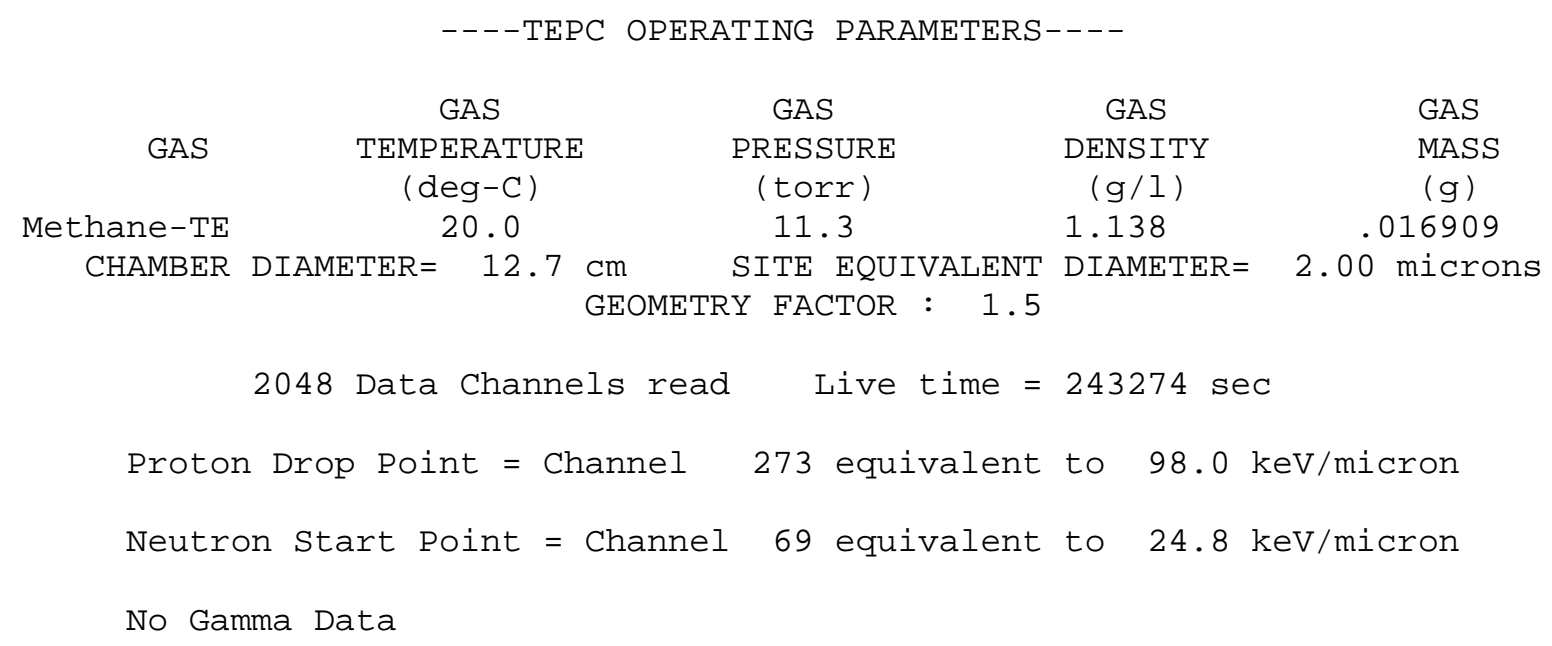

$\begin{array}{lccc} & \text { gamma } & \text { neutron } & \text { total } \\ \text { Counts } / \text { Ch } & \odot . \odot \odot \mathrm{E}+\odot \odot & 7.13 \mathrm{E}+\odot 4 & 7.13 \mathrm{E}+\odot 4 \\ \text { Counts }{ }^{*} \text { Ch } & \odot .0 \odot \mathrm{E}+\odot \odot & 8.92 \mathrm{E}+\odot 6 & 0.00 \mathrm{E}+\odot \odot \\ \text { Counts }{ }^{*} \text { Ch2 } & \odot .0 \odot \mathrm{E}+\odot \odot & 1.42 \mathrm{E}+\odot 9 & \odot . \odot \odot \mathrm{E}+\odot \odot \\ \text { Y-bar F } & . \odot & 44.9 & 44.9 \\ \text { Y-bar D } & . \odot & 56.9 & 56.9 \\ \text { L-bar D } & . \odot & 5 \odot .6 & 50.6\end{array}$

Restricted $\mathrm{y}$-bar $\mathrm{D}$ between 24.8 and $115 \mathrm{keV} / \mathrm{micron}$ is 65.2

The average energy cannot be calculated

----DOSE AND DOSE EQUIVALENT DATA----

Integral Dose, mrad

Standard Deviation

Quality Factors

Integral DE, mrem

Dose Rate, $\mathrm{mrad} / \mathrm{hr}$

DE Rate, $\mathrm{mrem} / \mathrm{hr}$ $\odot . \odot \odot E+\odot \odot$

$\odot . \odot \odot E+\odot \odot$

1.0

$\odot . \odot \odot E+\odot \odot$

$\odot . \odot \odot E+\odot \odot$

$\odot .00 \mathrm{E}+\odot \odot$
6. $\odot 8 \mathrm{E}+0 \odot$

2. $28 \mathrm{E}-02$

11.9

7. $23 \mathrm{E}+01$

8. $99 \mathrm{E}-02$

1. $07 \mathrm{E}+0 \odot$
6. $.8 \mathrm{E}+0 \odot$

2. $28 \mathrm{E}-02$

11.9

7. $23 \mathrm{E}+01$

8. 99E- 02

1. $07 \mathrm{E}+0 \odot$ 
INPUT FILE NAME: t74wpb 2. dat

FILE TITLE: TEPC 1074 in Index finger, 17\% 0xide can with Pb shield. 9/2427/99 (1017 alpha cts subtracted off)

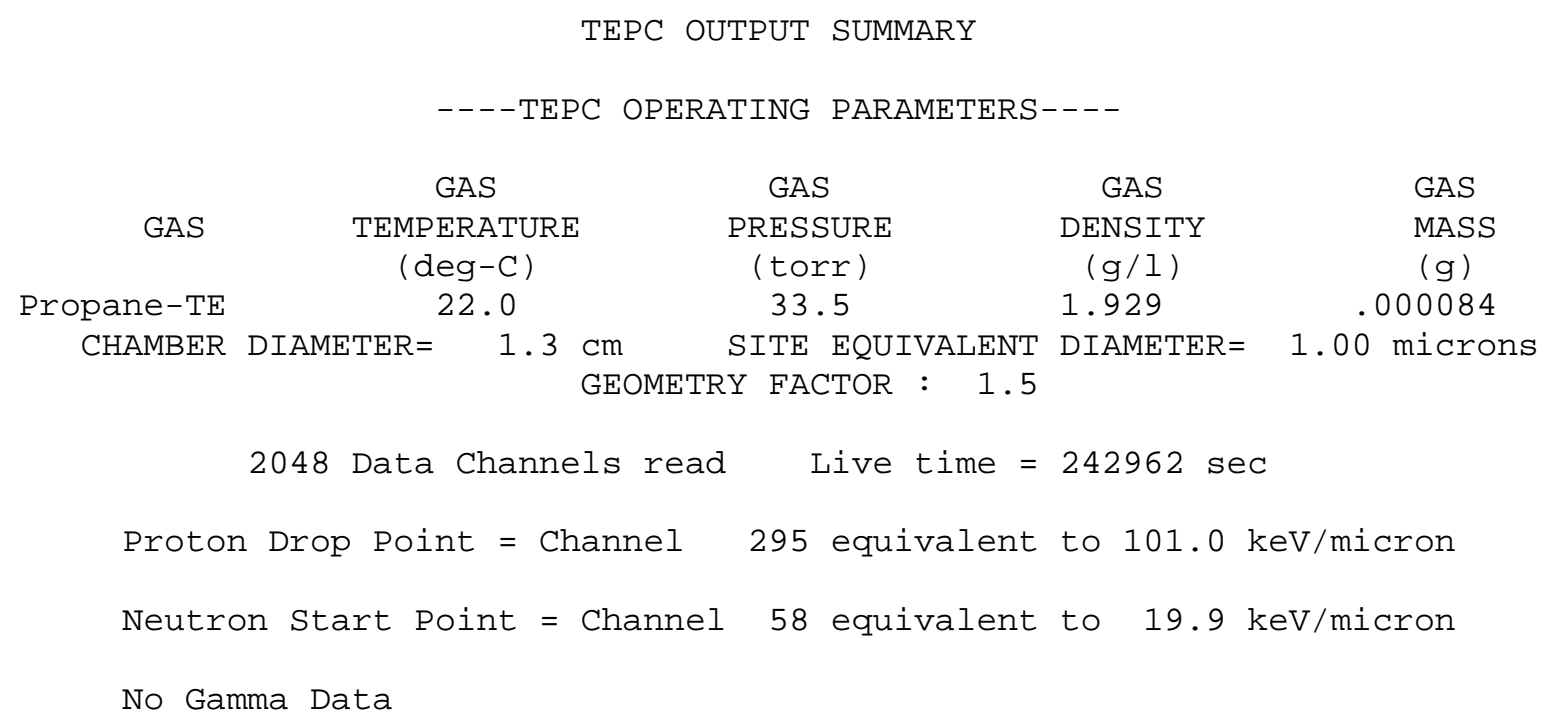

$\begin{array}{lccc} & \text { gamma } & \text { neutron } & \text { total } \\ \text { Counts } / \text { Ch } & 0.00 \mathrm{E}+\odot \odot & 1.74 \mathrm{E}+\odot 3 & 1.74 \mathrm{E}+\odot 3 \\ \text { Counts }{ }^{*} \text { Ch } & 0.00 \mathrm{E}+\odot \odot & 2.53 \mathrm{E}+\odot 5 & 0.00 \mathrm{E}+\odot \odot \\ \text { Counts }{ }^{*} \text { Ch2 } & 0.00 \mathrm{E}+\odot \odot & 6.16 \mathrm{E}+\odot 7 & 0.00 \mathrm{E}+\odot \odot \\ \text { Y-bar F } & . \odot & 50.0 & 50.0 \\ \text { Y-bar D } & . \odot & 83.3 & 83.3 \\ \text { L-bar D } & . \odot & 74.0 & 74.0\end{array}$

Restricted $\mathrm{y}$-bar $\mathrm{D}$ between 19.9 and $115 \mathrm{keV} / \mathrm{micron}$ is 60.7 The average energy cannot be calculated

----DOSE AND DOSE EQUIVALENT DATA--.-

\begin{tabular}{|c|c|c|c|}
\hline Integral Dose, mrad & $\odot . \odot \odot E+\odot \odot$ & $1.65 \mathrm{E}+01$ & 1. $65 \mathrm{E}+01$ \\
\hline Standard Deviation & $\odot . \odot \odot E+\odot \odot$ & $3.95 \mathrm{E}-01$ & $3.95 E-01$ \\
\hline Quality Factors & 1.0 & 13.3 & 13.3 \\
\hline Integral DE, mrem & $\odot . \odot \odot E+\odot \odot$ & $2.19 \mathrm{E}+02$ & $2.19 \mathrm{E}+02$ \\
\hline $\begin{array}{l}\text { Dose Rate, } \mathrm{mrad} / \mathrm{hr} \\
\text { DE Rate, } \mathrm{mrem} / \mathrm{hr}\end{array}$ & $\begin{array}{l}\odot . \odot \odot E+\odot \odot \\
\odot . \odot \odot E+\odot \odot\end{array}$ & $\begin{array}{l}2.44 \mathrm{E}-01 \\
3.25 \mathrm{E}+0 \odot\end{array}$ & $\begin{array}{l}2.44 \mathrm{E}-01 \\
3.25 \mathrm{E}+0 \odot\end{array}$ \\
\hline
\end{tabular}


Program TEPC_NG

Page 1

INPUT FILE NAME: t22wpb.txt

FILE TITLE:TEPC 1122 in Ring finger, 17\% 0xide with Pb Shield 9/24-27/99

TEPC OUTPUT SUMMARY

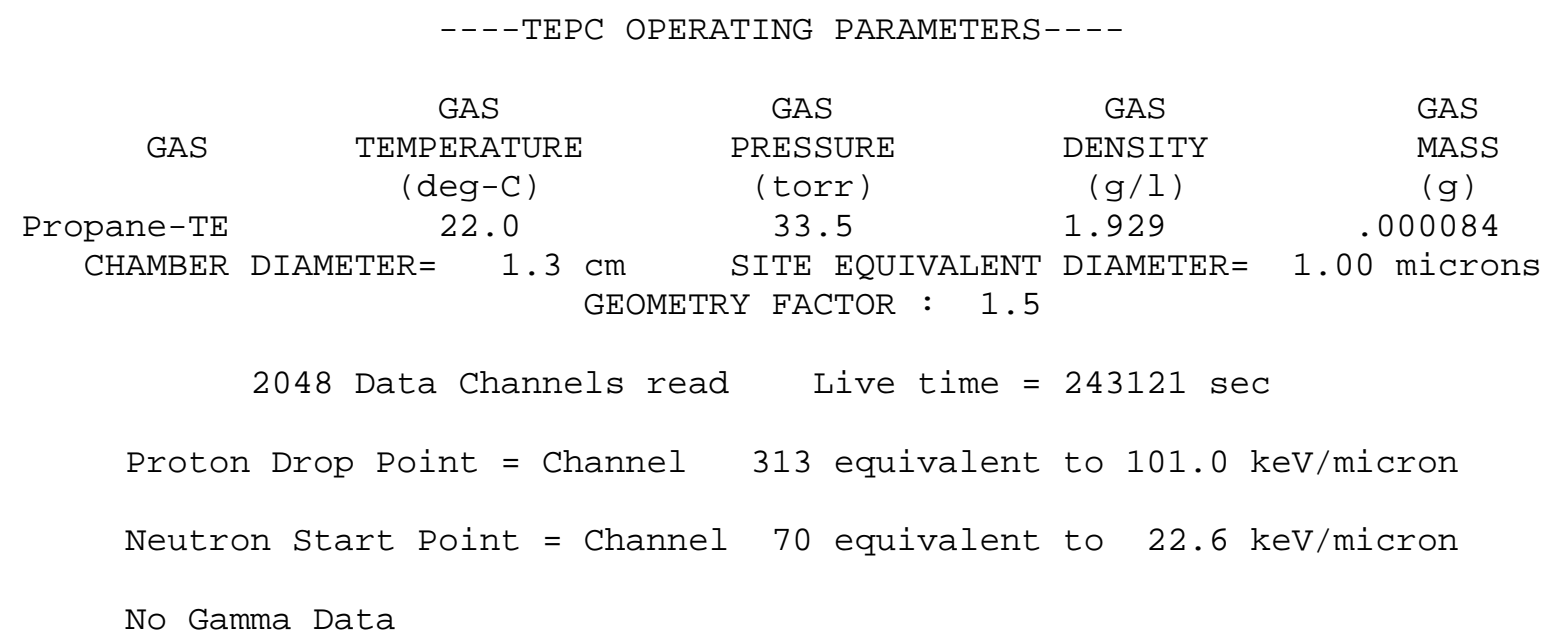

$\begin{array}{lccc} & \text { gamma } & \text { neutron } & \text { total } \\ \text { Counts/Ch } & 0.00 \mathrm{E}+\odot \odot & 1.62 \mathrm{E}+\odot 3 & 1.62 \mathrm{E}+03 \\ \text { Counts* Ch } & 0.00 \mathrm{E}+\odot \odot & 2.37 \mathrm{E}+05 & 0.00 \mathrm{E}+00 \\ \text { Counts }{ }^{*} \text { Ch2 } & 0.00 \mathrm{E}+\odot \odot & 4.65 \mathrm{E}+07 & 0.00 \mathrm{E}+00 \\ \text { Y-bar F } & .0 & 47.2 & 47.2 \\ \text { Y-bar D } & .0 & 63.3 & 63.3 \\ \text { L-bar D } & .0 & 56.2 & 56.2\end{array}$

Restricted $\mathrm{y}$-bar $\mathrm{D}$ between 22.6 and $115 \mathrm{keV} / \mathrm{micr}$ on is 68.2 The average energy cannot be calculated ----DOSE AND DOSE EQUIVALENT DATA----

$\begin{array}{lccr}\text { Integral Dose, mrad } & \odot . \odot \odot \mathrm{E}+\odot \odot & 1.45 \mathrm{E}+\odot 1 & 1.45 \mathrm{E}+\odot 1 \\ \text { Standard Deviation } & \odot . \odot \odot \mathrm{E}+\odot \odot & 3.61 \mathrm{E}-\odot 1 & 3.61 \mathrm{E}-01 \\ \text { Quality Factors } & 1 . \odot & 12.5 & 12.5 \\ \text { Integral DE, mrem } & \odot . \odot \odot \mathrm{E}+\odot \odot & 1.82 \mathrm{E}+\odot 2 & 1.82 \mathrm{E}+\odot 2 \\ & & & \\ \text { Dose Rate, mrad/hr } & \odot . \odot \odot E+\odot \odot & 2.15 \mathrm{E}-\odot 1 & 2.15 \mathrm{E}-01 \\ \text { DE Rate, mrem/hr } & \odot . \odot \odot \mathrm{E}+\odot \odot & 2.69 \mathrm{E}+\odot \odot & 2.69 \mathrm{E}+\odot \odot\end{array}$


APPENDIX F

\section{EXTREMITY DOSIMETER RESULTS}


EXTREMITY DOSIMETER RESULTS

\begin{tabular}{|c|c|c|c|c|c|c|c|}
\hline$\underline{\text { Source Can }}$ & $\begin{array}{l}\text { Glove } \\
\text { Finger }\end{array}$ & $\begin{array}{c}\text { Dosimeter } \\
\text { ID }\end{array}$ & $\begin{array}{c}\text { Exposure } \\
\text { Time } \\
\text { (hrs) } \\
\end{array}$ & $\begin{array}{c}\text { Integrated } \\
\text { Dose } \\
\text { (mrem) } \\
\end{array}$ & $\begin{array}{c}\text { Dose rate } \\
\mathrm{mrem} / \mathrm{h}\end{array}$ & $\begin{array}{l}\text { Std } \\
\text { Dev }\end{array}$ & Comments \\
\hline & Control & 34605 & & 2 & & & \\
\hline $20 \%$ Oxide & Index & 34598 & 51.2 & 5892 & 115 & & \\
\hline $20 \%$ Oxide & Index & 34644 & 51.2 & 7009 & 137 & & \\
\hline $20 \%$ Oxide & Index & 34696 & 51.2 & 5137 & 100 & & \\
\hline $20 \%$ Oxide & Index & 34731 & 51.2 & 6380 & 125 & & \\
\hline $20 \%$ Oxide & Index & 34778 & 51.2 & 5853 & 114 & & \\
\hline \multirow[t]{2}{*}{$20 \%$ Oxide } & Index & & & & 118 & 14 & Avg, std dev \\
\hline & Control & 34650 & & 3 & & & \\
\hline $20 \%$ Oxide & Middle & 34539 & 146.9 & 11535 & 79 & & left in glove finger for 2 cans \\
\hline $20 \%$ Oxide & Middle & 34568 & 51.2 & 6144 & 120 & & \\
\hline $20 \%$ Oxide & Middle & 34649 & 51.2 & 8160 & 159 & & \\
\hline $20 \%$ Oxide & Middle & 34671 & 51.2 & 7154 & 140 & & \\
\hline $20 \%$ Oxide & Middle & 34743 & 51.2 & 6435 & 126 & & \\
\hline \multirow[t]{2}{*}{$20 \%$ Oxide } & Middle & & & & 136 & 18 & 4-dosimeter average, std dev \\
\hline & Control & 34560 & & 10 & & & \\
\hline $20 \%$ Oxide & Ring & 34542 & 51.4 & 7281 & 142 & & \\
\hline $20 \%$ Oxide & Ring & 34602 & 51.4 & 7964 & 155 & & \\
\hline $20 \%$ Oxide & Ring & 34669 & 51.4 & 5958 & 116 & & \\
\hline $20 \%$ Oxide & Ring & 34748 & 51.4 & 5844 & 114 & & \\
\hline $20 \%$ Oxide & Ring & 34758 & 51.4 & 5899 & 115 & & \\
\hline \multirow[t]{2}{*}{$20 \%$ Oxide } & Ring & & & & 128 & 19 & Avg, std dev \\
\hline & Control & 34625 & & 4 & & & \\
\hline $20 \%$ Oxide & Little & 34628 & 51.1 & 7201 & 141 & & \\
\hline $20 \%$ Oxide & Little & 34631 & 51.1 & 6626 & 130 & & \\
\hline $20 \%$ Oxide & Little & 34656 & 51.1 & 6653 & 130 & & \\
\hline $20 \%$ Oxide & Little & 34683 & 51.1 & 6805 & 133 & & \\
\hline $20 \%$ Oxide & Little & 34704 & 51.1 & 6936 & 136 & & \\
\hline \multirow[t]{2}{*}{$20 \%$ Oxide } & Little & & & & 134 & 5 & Avg, std dev \\
\hline & Control & 34593 & & 0 & & & \\
\hline $12 \%$ Oxide & Index & 34536 & 95.4 & 2719 & 29 & & \\
\hline $12 \%$ Oxide & Index & 34577 & 95.4 & 3600 & 38 & & \\
\hline $12 \%$ Oxide & Index & 34662 & 95.4 & 4046 & 42 & & \\
\hline $12 \%$ Oxide & Index & 34663 & 95.4 & 3423 & 36 & & \\
\hline $12 \%$ Oxide & Index & 34760 & 95.4 & 3765 & 39 & & \\
\hline \multirow[t]{2}{*}{$12 \%$ Oxide } & Index & & & & 37 & 5 & Avg, std dev \\
\hline & Control & 34585 & & 7 & & & \\
\hline $12 \%$ Oxide & Middle & 34626 & 95.2 & 5281 & 55 & & \\
\hline $12 \%$ Oxide & Middle & 34678 & 95.2 & 4194 & 44 & & \\
\hline $12 \%$ Oxide & Middle & 34679 & 95.2 & 3816 & 40 & & \\
\hline $12 \%$ Oxide & Middle & 34707 & 95.2 & 4230 & 44 & & \\
\hline $12 \%$ Oxide & Middle & 34750 & 95.2 & 3507 & 37 & & \\
\hline $12 \%$ Oxide & Middle & & & & 44 & 7 & Avg, std dev \\
\hline
\end{tabular}




\begin{tabular}{|c|c|c|c|c|c|c|c|}
\hline Source Can & $\begin{array}{l}\text { Glove } \\
\text { Finger }\end{array}$ & $\begin{array}{l}\text { Dosimeter } \\
\text { ID }\end{array}$ & \begin{tabular}{|c|} 
Exposure \\
Time \\
(hrs)
\end{tabular} & $\begin{array}{l}\text { Integrated } \\
\text { Dose } \\
\text { (mrem) }\end{array}$ & $\begin{array}{c}\text { Dose rate } \\
\mathrm{mrem} / \mathrm{h}\end{array}$ & $\begin{array}{l}\text { Std } \\
\text { Dev }\end{array}$ & Comments \\
\hline & Control & 34595 & & 0 & & & \\
\hline $12 \%$ Oxide & Ring & 34537 & 95.3 & 4179 & 44 & & \\
\hline $12 \%$ Oxide & Ring & 34627 & 95.3 & 3715 & 39 & & \\
\hline $12 \%$ Oxide & Ring & 34665 & $\begin{array}{l}95.3 \\
\end{array}$ & 5008 & 53 & & \\
\hline $12 \%$ Oxide & Ring & 34681 & 95.3 & 4236 & 44 & & \\
\hline $12 \%$ Oxide & Ring & 34757 & 95.3 & 4343 & 46 & & \\
\hline \multirow[t]{2}{*}{$12 \%$ Oxide } & Ring & & & & 45 & 5 & Avg, std dev \\
\hline & Control & 34596 & & 10 & & & \\
\hline $12 \%$ Oxide & Little & 34619 & $\begin{array}{l}95.2 \\
\end{array}$ & 4467 & 47 & & \\
\hline $12 \%$ Oxide & Little & 34645 & $\begin{array}{l}95.2 \\
\end{array}$ & 6070 & 64 & & \\
\hline $12 \%$ Oxide & Little & 34648 & 95.2 & 3414 & 36 & & \\
\hline $12 \%$ Oxide & Little & 34668 & \begin{tabular}{l|l}
95.2 \\
\end{tabular} & 3301 & 35 & & \\
\hline $12 \%$ Oxide & Little & 34701 & $\begin{array}{l}95.2 \\
\end{array}$ & 3520 & 37 & & \\
\hline \multirow[t]{2}{*}{ 12\% Oxide } & Little & & & & 44 & 12 & Avg, std dev \\
\hline & Control & 34768 & & 2 & & & \\
\hline $12 \%$ Oxide & None & 34541 & 95.2 & 6688 & 70 & & \\
\hline $12 \%$ Oxide & None & 34551 & 95.2 & 6332 & 67 & & \\
\hline $12 \%$ Oxide & None & 34621 & $\begin{array}{l}95.2 \\
\end{array}$ & 8191 & 86 & & \\
\hline $12 \%$ Oxide & None & 34661 & 95.2 & 7756 & 81 & & \\
\hline $12 \%$ Oxide & None & 34700 & 95.2 & 6759 & 71 & & \\
\hline \multirow[t]{2}{*}{$12 \%$ Oxide } & None & & & & 75 & 8 & Avg, std dev \\
\hline & Control & 34741 & & 0 & & & \\
\hline Metal & Index & 34612 & 69.1 & 2162 & 31 & & Possible confusion between \\
\hline Metal & Index & 34653 & 69.1 & 1931 & 28 & & packets $10,11 \& 13$ \\
\hline Metal & Index & 34694 & 69.1 & 1965 & 28 & & (not completely sure which packet \\
\hline Metal & Index & 34713 & 69.1 & 2242 & 32 & & was on which finger) \\
\hline Metal & Index & 34776 & 69.1 & 2625 & 38 & & \\
\hline \multirow[t]{2}{*}{ Metal } & Index & & & & 32 & 4 & Avg, std dev \\
\hline & Control & 34710 & & 6 & & & \\
\hline Metal & Middle & 34558 & 69.0 & 2831 & 41 & & Possible confusion between \\
\hline Metal & Middle & 34616 & 69.0 & 2426 & 35 & & packets $10,11 \& 13$ \\
\hline Metal & Middle & 34622 & 69.0 & 2180 & 32 & & (not completely sure which packet \\
\hline Metal & Middle & 34667 & 69.0 & 2648 & 38 & & was on which finger) \\
\hline Metal & Middle & 34717 & 69.0 & 2088 & 30 & & \\
\hline \multirow[t]{2}{*}{ Metal } & Middle & & & & 35 & 5 & Avg, std dev \\
\hline & Control & 34685 & & 1 & & & \\
\hline Metal & Ring & 34591 & 69.2 & 2519 & 36 & & \\
\hline Metal & Ring & 34673 & 69.2 & 2054 & 30 & & \\
\hline Metal & Ring & 34716 & 69.2 & 2505 & 36 & & \\
\hline Metal & Ring & 34759 & 69.2 & 1912 & 28 & & \\
\hline Metal & Ring & 34765 & 69.2 & 2118 & 31 & & \\
\hline \multirow[t]{2}{*}{ Metal } & Ring & & & & 32 & 4 & Avg, std dev \\
\hline & Control & 34753 & & 0 & & & \\
\hline Metal & Little & 34615 & 69.1 & 2300 & 33 & & Possible confusion between \\
\hline
\end{tabular}




\begin{tabular}{|c|c|c|c|c|c|c|c|}
\hline Source Can & $\begin{array}{l}\text { Glove } \\
\text { Finger }\end{array}$ & $\begin{array}{l}\text { Dosimeter } \\
\text { ID }\end{array}$ & \begin{tabular}{|c|} 
Exposure \\
Time \\
(hrs)
\end{tabular} & $\begin{array}{c}\text { Integrated } \\
\text { Dose } \\
\text { (mrem) }\end{array}$ & $\begin{array}{l}\text { Dose rate } \\
\mathrm{mrem} / \mathrm{h}\end{array}$ & $\begin{array}{c}\text { Std } \\
\text { Dev }\end{array}$ & Comments \\
\hline Metal & $\overline{\text { Little }}$ & 34684 & 69.1 & 1901 & 28 & & packets $10,11 \& 13$ \\
\hline Metal & Little & 34719 & 69.1 & 2853 & 41 & & (not completely sure which packet \\
\hline Metal & Little & 34761 & 69.1 & 2797 & 40 & & was on which finger) \\
\hline Metal & Little & 34764 & 69.1 & 2810 & 41 & & \\
\hline \multirow[t]{2}{*}{ Metal } & Little & & & & 37 & 6 & Avg, std dev \\
\hline & Control & 34550 & & 3 & & & \\
\hline Metal & None & 34569 & 69.0 & 3490 & 51 & & \\
\hline Metal & None & 34620 & 69.0 & 3714 & 54 & & \\
\hline Metal & None & 34688 & 69.0 & 4196 & 61 & & \\
\hline Metal & None & 34749 & 69.0 & 3591 & 52 & & \\
\hline Metal & None & 34767 & 69.0 & 3552 & 51 & & \\
\hline \multirow[t]{2}{*}{ Metal } & None & & & & 54 & 4 & Avg, std dev \\
\hline & Control & 34538 & & 9 & & & \\
\hline Wkend Bkgd & Index & 34547 & 98.3 & 9 & 0.087 & & \\
\hline Wkend Bkgd & Index & 34557 & 98.3 & 8 & 0.083 & & \\
\hline Wkend Bkgd & Index & 34566 & 98.3 & 20 & 0.199 & & \\
\hline Wkend Bkgd & Index & 34640 & 98.3 & 14 & 0.140 & & \\
\hline Wkend Bkgd & Index & 34771 & 98.3 & 9 & 0.096 & & \\
\hline \multirow[t]{2}{*}{ Wkend Bkgd } & Index & & & & 0.121 & 0.049 & Avg, std dev \\
\hline & Control & 34763 & & 0 & & & \\
\hline Wkend Bkgd & Middle & 34647 & 98.3 & 0 & 0.001 & & \\
\hline Wkend Bkgd & Middle & 34703 & 98.3 & 7 & 0.073 & & \\
\hline Wkend Bkgd & Middle & 34705 & 98.3 & 24 & 0.239 & & \\
\hline Wkend Bkgd & Middle & 34728 & 98.3 & 12 & 0.120 & & \\
\hline Wkend Bkgd & Middle & 34738 & 98.3 & 2 & 0.023 & & \\
\hline \multirow[t]{2}{*}{ Wkend Bkgd } & Middle & & & & 0.091 & 0.095 & Avg, std dev \\
\hline & Control & 34586 & & 4 & & & \\
\hline Wkend Bkgd & Ring & 34543 & 98.3 & 1 & 0.008 & & \\
\hline Wkend Bkgd & Ring & 34581 & 98.3 & 3 & 0.028 & & \\
\hline Wkend Bkgd & Ring & 34639 & 98.3 & 36 & 0.367 & & \\
\hline Wkend Bkgd & Ring & 34682 & 98.3 & 0 & 0.002 & & \\
\hline Wkend Bkgd & Ring & 34782 & 98.3 & 10 & 0.107 & & \\
\hline \multirow[t]{2}{*}{ Wkend Bkgd } & Ring & & & & 0.102 & 0.154 & Avg, std dev \\
\hline & Control & 34601 & & 22 & & & \\
\hline Wkend Bkgd & Little & 34575 & 98.3 & 9 & 0.090 & & \\
\hline Wkend Bkgd & Little & 34583 & 98.3 & 13 & 0.134 & & \\
\hline Wkend Bkgd & Little & 34611 & 98.3 & 3 & 0.030 & & \\
\hline Wkend Bkgd & Little & 34618 & 98.3 & 5 & 0.051 & & \\
\hline Wkend Bkgd & Little & 34672 & 98.3 & 0 & 0.001 & & \\
\hline \multirow[t]{2}{*}{ Wkend Bkgd } & Little & & & & 0.061 & 0.052 & Avg, std dev \\
\hline & Control & 34570 & & 3 & & & \\
\hline Wkend Bkgd & None & 34540 & 98.3 & 0 & 0.001 & & \\
\hline Wkend Bkgd & None & 34556 & 98.3 & 9 & 0.093 & & \\
\hline Wkend Bkgd & None & 34564 & 98.3 & 15 & 0.155 & & \\
\hline
\end{tabular}




\begin{tabular}{|c|c|c|c|c|c|c|c|}
\hline Source Can & $\begin{array}{l}\text { Glove } \\
\text { Finger }\end{array}$ & $\begin{array}{l}\text { Dosimeter } \\
\text { ID }\end{array}$ & \begin{tabular}{|c|} 
Exposure \\
Time \\
(hrs)
\end{tabular} & $\begin{array}{l}\text { Integrated } \\
\text { Dose } \\
\text { (mrem) }\end{array}$ & $\begin{array}{c}\text { Dose rate } \\
\mathrm{mrem} / \mathrm{h}\end{array}$ & $\begin{array}{l}\text { Std } \\
\text { Dev }\end{array}$ & Comments \\
\hline Wkend Bkgd & None & 34608 & 98.3 & 14 & 0.138 & & \\
\hline Wkend Bkgd & None & 34698 & 98.3 & 4 & 0.042 & & \\
\hline \multirow[t]{3}{*}{ Wkend Bkgd } & None & & & & 0.086 & 0.064 & Avg, std dev \\
\hline & & & & & & & \\
\hline & Control & 34582 & & 6 & & & \\
\hline $6 \%$ Oxide & Index & 34563 & 49.7 & 1958 & 39 & & \\
\hline $6 \%$ Oxide & Index & 34607 & 49.7 & 1445 & 29 & & \\
\hline $6 \%$ Oxide & Index & 34637 & 49.7 & 1530 & 31 & & \\
\hline $6 \%$ Oxide & Index & 34657 & 499.7 & 1685 & 34 & & \\
\hline $6 \%$ Oxide & Index & 34670 & 49.7 & 1652 & 33 & & \\
\hline \multirow[t]{2}{*}{$6 \%$ Oxide } & Index & & & & 33 & 4 & Avg, std dev \\
\hline & Control & 34599 & & 2 & & & \\
\hline $6 \%$ Oxide & Middle & 34535 & 49.7 & 2175 & 44 & & \\
\hline $6 \%$ Oxide & Middle & 34548 & 499.7 & 1962 & 39 & & \\
\hline $6 \%$ Oxide & Middle & 34579 & 49.7 & 2072 & 42 & & \\
\hline $6 \%$ Oxide & Middle & 34580 & 49.7 & 2001 & 40 & & \\
\hline $6 \%$ Oxide & Middle & 34594 & 49.7 & 1916 & 39 & & \\
\hline \multirow[t]{2}{*}{$6 \%$ Oxide } & Middle & & & & 41 & 2 & Avg, std dev \\
\hline & Control & 34747 & & 3 & & & \\
\hline $6 \%$ Oxide & Ring & 34578 & 49.7 & 1456 & 29 & & \\
\hline $6 \%$ Oxide & Ring & 34641 & $\begin{array}{l}49.7 \\
\end{array}$ & 1646 & 33 & & \\
\hline $6 \%$ Oxide & Ring & 34643 & 49.7 & 1596 & 32 & & \\
\hline $6 \%$ Oxide & Ring & 34690 & 499.7 & 1780 & 36 & & \\
\hline $6 \%$ Oxide & Ring & 34715 & 49.7 & 1668 & 34 & & \\
\hline \multirow[t]{2}{*}{$6 \%$ Oxide } & Ring & & & & 33 & 2 & Avg, std dev \\
\hline & Control & 34740 & & 0 & & & \\
\hline $6 \%$ Oxide & Little & 34546 & 49.7 & 1978 & 40 & & \\
\hline $6 \%$ Oxide & Little & 34565 & 49.7 & 1686 & 34 & & \\
\hline $6 \%$ Oxide & Little & 34600 & 49.7 & 1402 & 28 & & \\
\hline $6 \%$ Oxide & Little & 34654 & 49.7 & 1768 & 36 & & \\
\hline $6 \%$ Oxide & Little & 34746 & 49.7 & 1735 & 35 & & \\
\hline \multirow[t]{2}{*}{$6 \%$ Oxide } & Little & & & & 35 & 4 & Avg, std dev \\
\hline & Control & 34686 & & 0 & & & \\
\hline $6 \%$ Oxide & None & 34590 & 49.6 & 272 & 5.5 & & Sometime during the $\mathrm{mmt}$ \\
\hline $6 \%$ Oxide & None & 34632 & 49.6 & 257 & 5.2 & & these dosimeters were \\
\hline $6 \%$ Oxide & None & 34642 & 49.6 & 297 & 6.0 & & moved behind the glove: \\
\hline $6 \%$ Oxide & None & 34714 & 49.6 & 296 & 6.0 & & perhaps 12-in from can CL. \\
\hline $6 \%$ Oxide & None & 34735 & 49.6 & 216 & 4.4 & & Don't know when \\
\hline \multirow[t]{2}{*}{$6 \%$ Oxide } & None & & & & 5.4 & 0.7 & Avg, std dev \\
\hline & Control & 34609 & & 0 & & & \\
\hline 17\% Ox w/ Foil & Index & 34676 & 45.8 & 1413 & 31 & & \\
\hline 17\% Ox w/ Foil & Index & 34691 & 45.8 & 1596 & 35 & & \\
\hline 17\% Ox w/ Foil & Index & 34712 & 45.8 & 1570 & 34 & & \\
\hline 17\% Ox w/ Foil & Index & 34727 & 45.8 & 1464 & 32 & & \\
\hline
\end{tabular}




\begin{tabular}{|c|c|c|c|c|c|c|c|}
\hline Source Can & $\begin{array}{l}\text { Glove } \\
\text { Finger }\end{array}$ & $\begin{array}{l}\text { Dosimeter } \\
\text { ID }\end{array}$ & \begin{tabular}{|c|} 
Exposure \\
Time \\
(hrs)
\end{tabular} & $\begin{array}{l}\text { Integrated } \\
\text { Dose } \\
\text { (mrem) }\end{array}$ & $\begin{array}{c}\text { Dose rate } \\
\mathrm{mrem} / \mathrm{h}\end{array}$ & $\begin{array}{l}\text { Std } \\
\text { Dev }\end{array}$ & Comments \\
\hline $17 \%$ Ox w/ Foil & Index & $3 \overline{\overline{780}}$ & 45.8 & 1605 & 35 & & \\
\hline \multirow[t]{2}{*}{ 17\% Ox w/ Foil } & Index & & & & 33 & 2 & Avg, std dev \\
\hline & Control & 34553 & & 0 & & & \\
\hline 17\% Ox w/ Foil & Middle & 34572 & 45.9 & 1956 & 43 & & \\
\hline 17\% Ox w/ Foil & Middle & 34658 & 45.9 & 2054 & 45 & & \\
\hline 17\% Ox w/ Foil & Middle & 34697 & 45.9 & 1038 & 23 & & \\
\hline 17\% Ox w/ Foil & Middle & 34755 & 45.9 & 1649 & 36 & & \\
\hline 17\% Ox w/ Foil & Middle & 34783 & 45.9 & 1626 & 35 & & \\
\hline \multirow[t]{2}{*}{ 17\% Ox w/ Foil } & Middle & & & & 36 & 9 & Avg, std dev \\
\hline & Control & 34766 & & 7 & & & \\
\hline 17\% Ox w/ Foil & Ring & 34571 & 45.9 & 1616 & 35 & & \\
\hline 17\% Ox w/ Foil & Ring & 34576 & $\begin{array}{l}45.9 \\
\end{array}$ & 1908 & 42 & & \\
\hline 17\% Ox w/ Foil & Ring & 34606 & 45.9 & 1794 & 39 & & \\
\hline 17\% Ox w/ Foil & Ring & 34633 & 45.9 & 1620 & 35 & & \\
\hline 17\% Ox w/ Foil & Ring & 34708 & 45.9 & 1688 & 37 & & \\
\hline \multirow[t]{2}{*}{ 17\% Ox w/ Foil } & Ring & & & & 38 & 3 & Avg, std dev \\
\hline & Control & 34655 & & 0 & & & \\
\hline 17\% Ox w/ Foil & Little & 34597 & 45.9 & 1905 & 42 & & \\
\hline 17\% Ox w/ Foil & Little & 34617 & 45.9 & 1321 & 29 & & \\
\hline 17\% Ox w/ Foil & Little & 34646 & 45.9 & 1661 & 36 & & \\
\hline 17\% Ox w/ Foil & Little & 34724 & $\begin{array}{l}45.9 \\
\end{array}$ & 1854 & 40 & & \\
\hline 17\% Ox w/ Foil & Little & 34732 & 45.9 & 1626 & 35 & & \\
\hline \multirow[t]{2}{*}{$17 \%$ Ox w/ Foil } & Little & & & & 36 & 5 & Avg, std dev \\
\hline & Control & 34574 & & 0 & & & \\
\hline 17\% Ox w/ Foil & None & 34545 & 45.8 & 2460 & 54 & & \\
\hline 17\% Ox w/ Foil & None & 34604 & 45.8 & 2322 & 51 & & \\
\hline 17\% Ox w/ Foil & None & 34709 & 45.8 & 2587 & 56 & & \\
\hline 17\% Ox w/ Foil & None & 34774 & 45.8 & 2509 & 55 & & \\
\hline 17\% Ox w/ Foil & None & 34781 & 45.8 & 2592 & 57 & & \\
\hline \multirow[t]{2}{*}{ 17\% Ox w/ Foil } & None & & & & 54 & 2 & Avg, std dev \\
\hline & Control & 34730 & & 0 & & & \\
\hline $17 \% \mathrm{Ox} \mathrm{w} / \mathrm{Pb}$ & Index & 34629 & 67.7 & 344 & 5.1 & & \\
\hline $17 \% \mathrm{Ox} \mathrm{w} / \mathrm{Pb}$ & Index & 34720 & 67.7 & 340 & 5.0 & & \\
\hline $17 \% \mathrm{Ox} \mathrm{w} / \mathrm{Pb}$ & Index & 34722 & \begin{tabular}{ll|}
67.7 \\
\end{tabular} & 357 & 5.3 & & \\
\hline $17 \% \mathrm{Ox} \mathrm{w} / \mathrm{Pb}$ & Index & 34729 & 67.7 & 281 & 4.2 & & \\
\hline $17 \% \mathrm{Ox} \mathrm{w} / \mathrm{Pb}$ & Index & 34777 & $\begin{array}{l}67.7 \\
\end{array}$ & 366 & 5.4 & & \\
\hline \multirow[t]{2}{*}{$17 \% \mathrm{Ox} \mathrm{w} / \mathrm{Pb}$} & Index & & & & 5.0 & 0.5 & Avg, std dev \\
\hline & Control & 34666 & & 8 & & & \\
\hline $17 \%$ Ox w/ $\mathrm{Pb}$ & Middle & 34680 & 67.7 & 456 & 6.7 & & \\
\hline $17 \% \mathrm{Ox} \mathrm{w} / \mathrm{Pb}$ & Middle & 34693 & $\begin{array}{l}67.7 \\
\end{array}$ & 430 & 6.4 & & \\
\hline $17 \% \mathrm{Ox} \mathrm{w} / \mathrm{Pb}$ & Middle & 34726 & 67.7 & 408 & 6.0 & & \\
\hline $17 \% \mathrm{Ox} \mathrm{w} / \mathrm{Pb}$ & Middle & 34736 & 67.7 & 455 & 6.7 & & \\
\hline $17 \% \mathrm{Ox} \mathrm{w} / \mathrm{Pb}$ & Middle & 34751 & 67.7 & 370 & 5.5 & & \\
\hline $17 \% \mathrm{Ox} \mathrm{w} / \mathrm{Pb}$ & Middle & & & & 6.3 & 0.5 & Avg, std dev \\
\hline
\end{tabular}




\begin{tabular}{|c|c|c|c|c|c|c|c|}
\hline Source Can & $\begin{array}{l}\text { Glove } \\
\text { Finger }\end{array}$ & $\begin{array}{l}\text { Dosimeter } \\
\text { ID }\end{array}$ & $\begin{array}{c}\text { Exposure } \\
\text { Time } \\
\text { (hrs) }\end{array}$ & $\begin{array}{c}\text { Integrated } \\
\text { Dose } \\
\text { (mrem) }\end{array}$ & $\begin{array}{l}\text { Dose rate } \\
\mathrm{mrem} / \mathrm{h}\end{array}$ & $\begin{array}{l}\text { Std } \\
\text { Dev }\end{array}$ & Comments \\
\hline & Control & & & 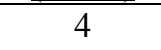 & & & \\
\hline $17 \% \mathrm{Ox} \mathrm{w} / \mathrm{Pb}$ & Ring & 34561 & 67.8 & 395 & 5.8 & & \\
\hline $17 \% \mathrm{Ox} \mathrm{w} / \mathrm{Pb}$ & Ring & 34660 & 67.8 & 431 & 6.4 & & \\
\hline $17 \% \mathrm{Ox} \mathrm{w} / \mathrm{Pb}$ & Ring & 34718 & 67.8 & 457 & 6.7 & & \\
\hline $17 \% \mathrm{Ox} \mathrm{w} / \mathrm{Pb}$ & Ring & 34733 & 67.8 & 399 & 5.9 & & \\
\hline $17 \% \mathrm{Ox} \mathrm{w} / \mathrm{Pb}$ & Ring & 34770 & 67.8 & 393 & 5.8 & & \\
\hline \multirow[t]{2}{*}{$17 \% \mathrm{Ox} \mathrm{w} / \mathrm{Pb}$} & Ring & & & & 6.1 & 0.4 & Avg, std dev \\
\hline & Control & 34613 & & 3 & & & \\
\hline $17 \% \mathrm{Ox} \mathrm{w} / \mathrm{Pb}$ & Little & 34554 & 67.7 & 370 & 5.5 & & \\
\hline $17 \% \mathrm{Ox} \mathrm{w} / \mathrm{Pb}$ & Little & 34674 & 67.7 & 403 & 5.9 & & \\
\hline $17 \% \mathrm{Ox} \mathrm{w} / \mathrm{Pb}$ & Little & 34721 & 67.7 & 424 & 6.3 & & \\
\hline $17 \% \mathrm{Ox} \mathrm{w} / \mathrm{Pb}$ & Little & 34737 & 67.7 & 382 & 5.6 & & \\
\hline $17 \% \mathrm{Ox} \mathrm{w} / \mathrm{Pb}$ & Little & 34772 & 67.7 & 387 & 5.7 & & \\
\hline \multirow[t]{2}{*}{$17 \% \mathrm{Ox} \mathrm{w} / \mathrm{Pb}$} & Little & & & & 5.8 & 0.3 & Avg, std dev \\
\hline & Control & & & 0 & & & \\
\hline $17 \% \mathrm{Ox} \mathrm{w} / \mathrm{Pb}$ & None & 34544 & 67.6 & 242 & 3.6 & & \\
\hline $17 \% \mathrm{Ox} \mathrm{w} / \mathrm{Pb}$ & None & 34687 & 67.6 & 267 & 3.9 & & \\
\hline $17 \% \mathrm{Ox} \mathrm{w} / \mathrm{Pb}$ & None & 34689 & 67.6 & 242 & 3.6 & & \\
\hline $17 \% \mathrm{Ox} \mathrm{w} / \mathrm{Pb}$ & None & 34711 & 67.6 & 232 & 3.4 & & \\
\hline $17 \% \mathrm{Ox} \mathrm{w} / \mathrm{Pb}$ & None & 34769 & 67.6 & 221 & 3.3 & & \\
\hline $17 \% \mathrm{Ox} \mathrm{w} / \mathrm{Pb}$ & None & & & & 3.6 & 0.3 & Avg, std dev \\
\hline
\end{tabular}


PNNL-13136

\section{DISTRIBUTION LIST - PFP NEUTRON MEASUREMENTS REPORT}

Fluor Daniel:

D.B. Ottley

L.K. Aldrich

T.J. Froelich

J.R. Cooper

R.W. Szempruch

R.G. Wilbanks

R.E. Gregory

DynCorps

R.J. Ford

DOE/RL:

W.M. Glines

J.J. Bevelacqua

PNNL:

R.I. Scherpelz

J.J. Fix

B.A. Rathbone

S.E. Huneycutt

A.W. Endres

D.E. Bihl

J.L. Kenoyer

M.E. Hevland

P.L. Tomeraasen

J.E. Tanner

D.L. Haggard

Distr.1 